THE POTENTIAL ENVIRONMENTAL BENEFITS OF REUSABLE AND RECYCLABLE MATERIALS STOCKS IN TORONTO'S SINGLE-DETACHED HOUSING

by

\author{
Deniz N Ergun \\ Bachelor of Science, University of Guelph, 2009 \\ A thesis \\ presented to Ryerson University \\ in partial fulfillment of the \\ requirements for the degree of \\ Master of Applied Science \\ in the Program of \\ Building Science
}

Toronto, Ontario, Canada, 2007

(C)(Deniz Ergun) 2014 


\section{Author's Declaration Page}

I hereby declare that I am the sole author of this thesis. This is a true copy of the thesis, including any required final revisions, as accepted by my examiners.

I authorize Ryerson University to lend this thesis to other institutions or individuals for the purpose of scholarly research.

I further authorize Ryerson University to reproduce this thesis by photocopying or by other means, in total or in part, at the request of other institutions or individuals for the purpose of scholarly research.

I understand that my thesis may be made electronically available to the public. 


\title{
THE POTENTIAL ENVIRONMENTAL BENEFITS OF REUSABLE AND RECYCLABLE MATERIALS STOCKS IN TORONTO'S SINGLE-DETACHED HOUSING
}

\author{
Master of Applied Science, 2014 \\ Deniz N Ergun \\ Building Science \\ Ryerson University
}

\begin{abstract}
This study examines the stocks of building materials in Toronto's in-use and annual obsolete single detached housing, to provide potential environmental benefit parameters for city scale material reuse and recycling. The material volumes of five archetypes, developed to represent typical Toronto housing, were measured and extrapolated to the city scale. Applying established criteria for reusability and recyclability, city scale reusable and recyclable stocks were determined for three environmental indicators: material volume headed to landfill, carbon dioxide emissions, and primary energy consumption. It was determined that $61-66 \%$ of the material volume in Toronto's in-use and annual obsolete housing could be reclaimed for reuse/recycling, and was mostly composed of masonry, concrete, and framing lumber from houses built from 1930-1960. Additionally, annual obsolete reusable materials represented an embodied carbon of 2,287-4,116 tonnes and energy of 52,883-95,189 GJ. By addressing common barriers to widespread uptake of reuse/recycling, Toronto could reap these determined potential environmental benefits.
\end{abstract}




\section{Acknowledgements}

I sincerely thank my supervisor, Dr. Mark Gorgolewski, for his guidance and insight, for supporting my interest in material reclamation, and for challenging me to push my ideas and research; all of which has made this thesis possible.

I also appreciate the useful feedback of my committee and thank them for their part in refining this thesis.

As well, this work would not have been possible without the support of my close friends and family. Particularly l'd like to highlight Nicholas So, Joseph Earle, and Peta-Gaye Ebanks, for enriching my learning experience and for sharing in the ups and downs, "ah-ha" moments, and well-needed laughs throughout the past two and half years.

l'd also like to highlight the help and support of Becky Conlon, Ana Yavari and my parents, Teri and Mehmet Ergun which has made completing this thesis just that much more enjoyable.

Finally, l'd like to highlight Brent Dienst, who came into my life while completing this thesis and has since offered his endless support and encouragement. It was truly critical in keeping me positive and moving forward. 


\section{Table of Contents}

AUTHOR'S DECLARATION PAGE ................................................................................................

ABSTRACT

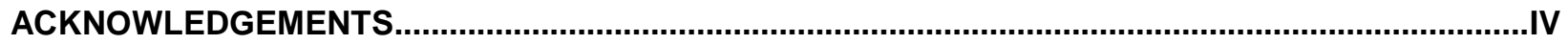

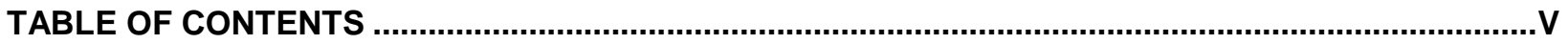

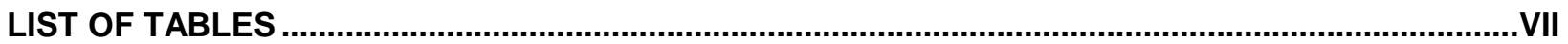

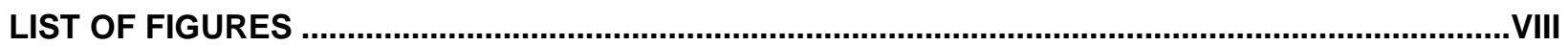

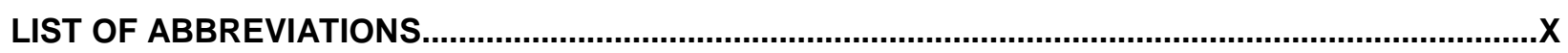

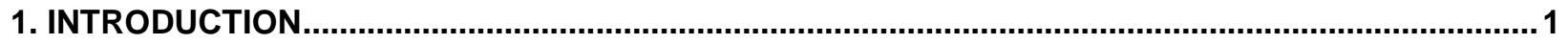

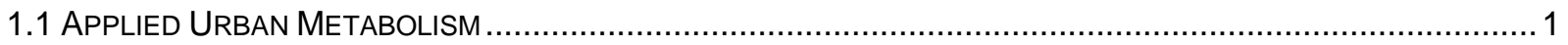

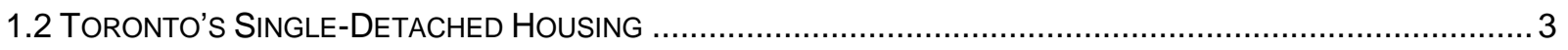

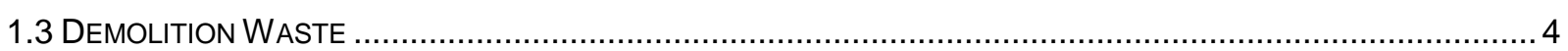

1.4 EMBODIED IMPACTS OF VIRGIN BUILDING MATERIALS............................................................

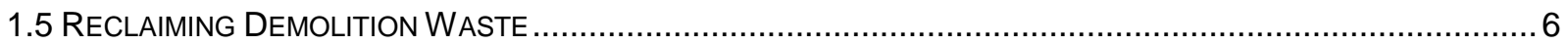

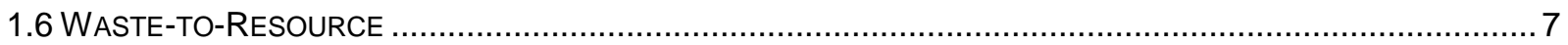

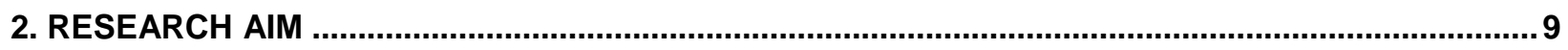

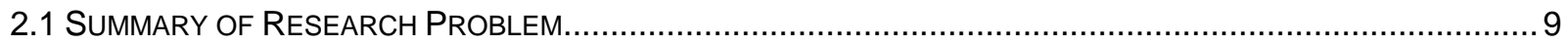

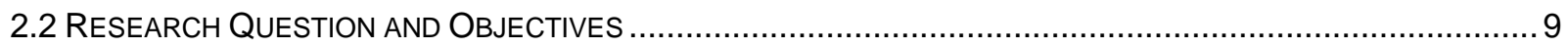

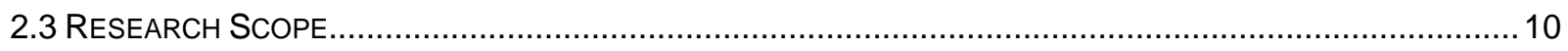

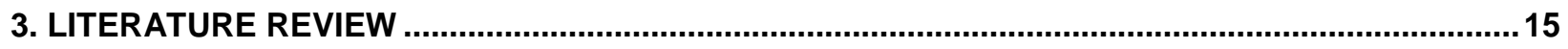

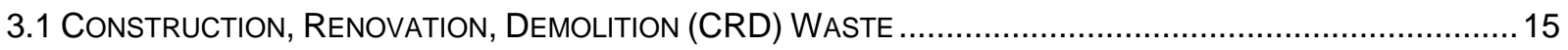

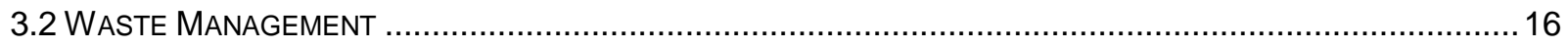

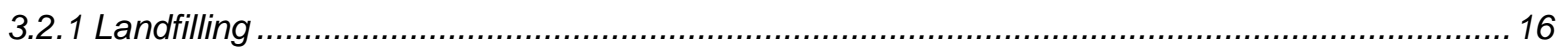

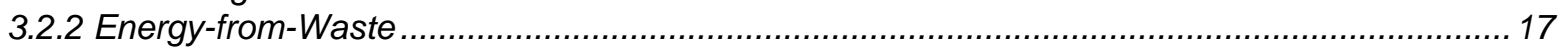

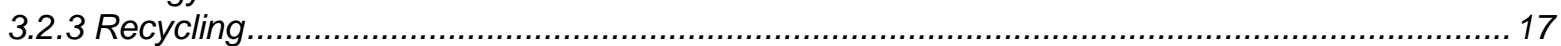

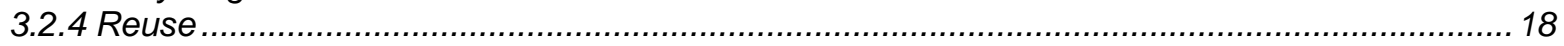

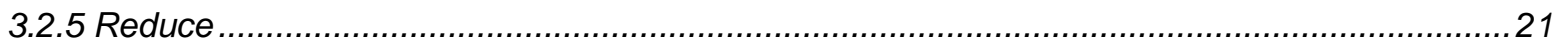

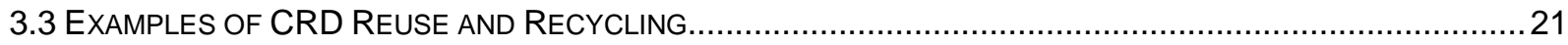

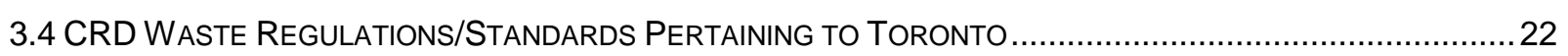

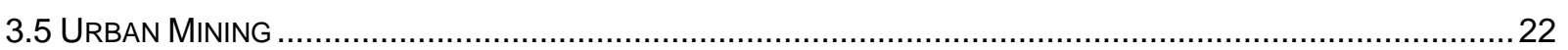

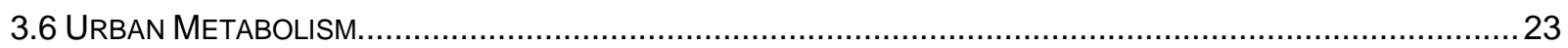

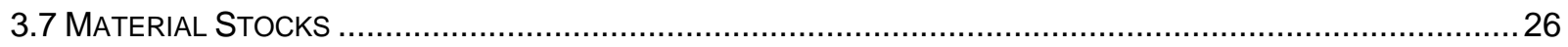

4. METHODOLOGY

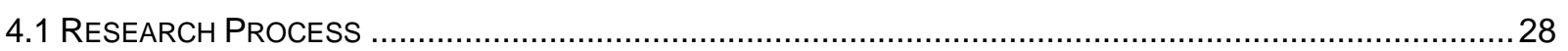

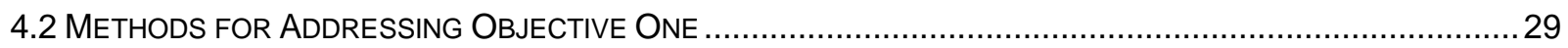

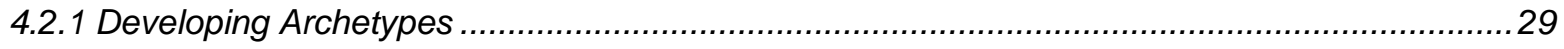




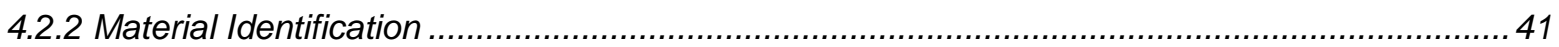

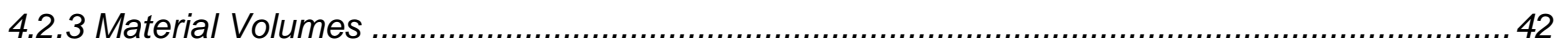

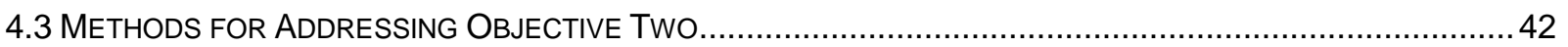

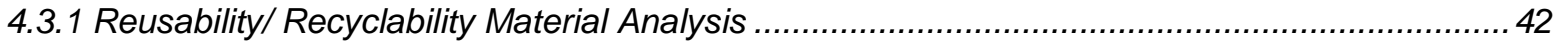

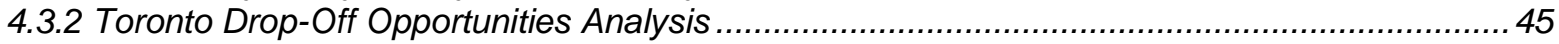

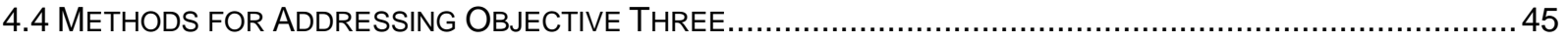

4.4.1 Determining Number of Archetype Houses ..................................................................... 46

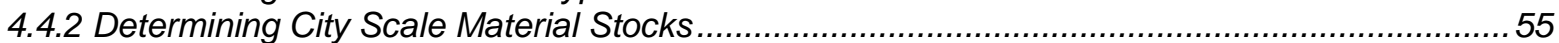

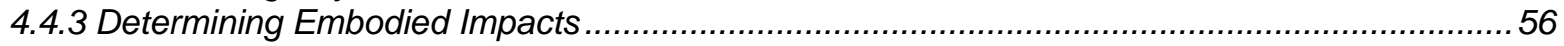

5. RESULTS AND DISCUSSION

5.1 OBJECTIVE ONE - MATERIAL INVENTORY OF ARCHETYPES ......................................................... 59

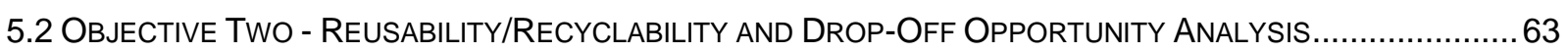

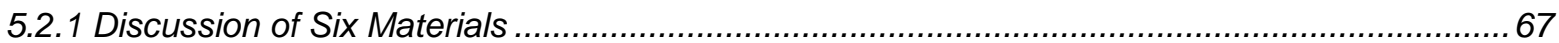

5.2.2 Material Reclamation by SDH Construction Date ........................................................... 92

5.3 OBJECTIVE THREE - IMPACTS OF RECLAIMING SUITABLE MATERIALS.............................................. 93

5.3.1 Composition of Archetypes in Toronto's SDH Stock ......................................................... 94

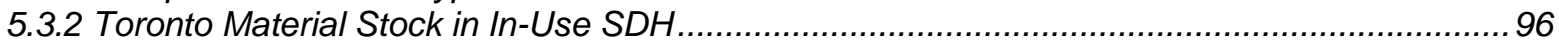

5.3.3 Archetype stock in annual obsolete SDH................................................................... 97

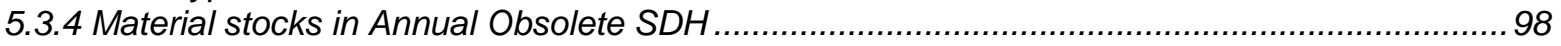

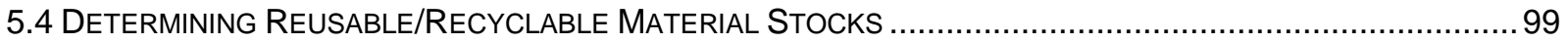

5.5 Embodied Primary EnERgy CONSUMPTION AND CO $\mathrm{CO}_{2}$ EMISSIONS ............................................... 109

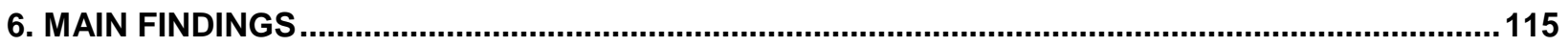

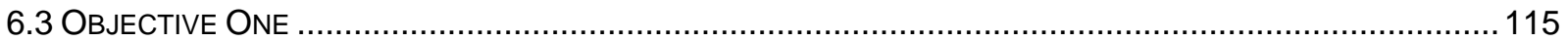

6.3.1 Changes in SDH Material Composition Over Time Impact Reusability/ and Recyclability of

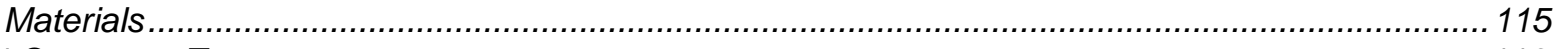

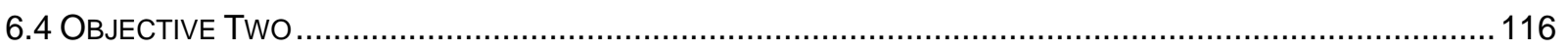

6.4.1 Deconstruction is an Important Tool for Reclaiming Materials ......................................... 116

6.4.2 Lack of Material Specific Codes or Standards ................................................................117

6.4.3 Lack of Infrastructure to Absorb Reclaimed Materials ..................................................... 118

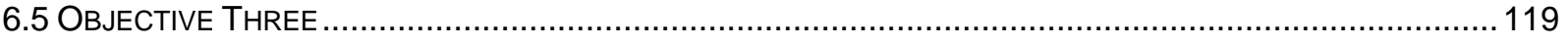

6.5.1 Potential to Reduce Toronto Metabolism of Building Materials ........................................... 119

6.5.2 Materials to Target Depend on Environmental Goals ..................................................... 120

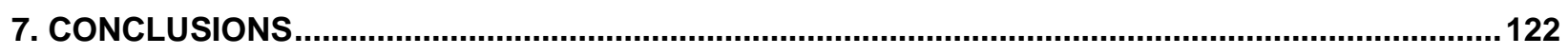

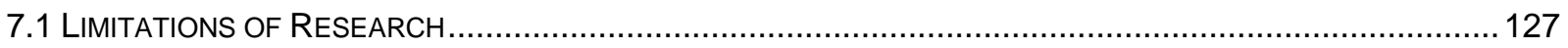

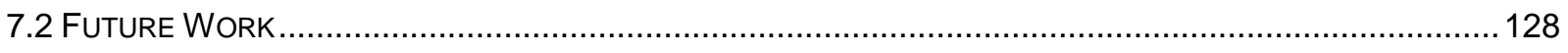

APPENDIX A - EXAMPLES OF CONSTRUCTION DRAWINGS ...................................................... 130

APPENDIX B - ASSUMPTIONS FOR DETERMINING MATERIAL VOLUMES ...................................134

APPENDIX C - ABSOLUTE VALUES FOR RESULTS

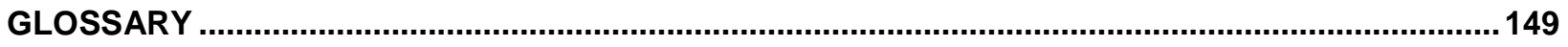

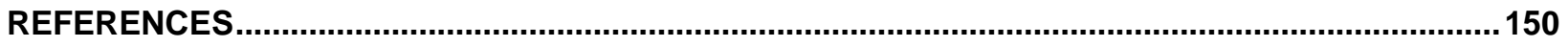




\section{List of Tables}

TABLE 1. DATA SOURCES FOR EMBOdied IMPACTS USED by ATHENA IMPACT ESTIMATOR (IE) FOR BUILDINGS... 56

TABLE 2. MATERIALS IDENTIFIED AS REUSABLE IN ARCHETYPE SDH AND CLOSEST EXTRA BASIC MATERIAL IN IE.58

TABLE 3. MATERIAL INTENSITY $\left(\mathrm{M}^{3} / \mathrm{M}^{2}\right)$ OF ARCHETYPE SDH. 62

TABLE 4: CRITERIA MOST LIMITING REUSE AND RECYCLING OF MATERIALS IDENTIFIED IN ARCHETYPE HOUSES AND

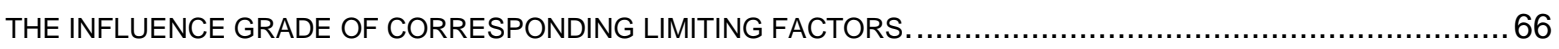

TABLE 5. REUSABILITY/RECYCLABILITY OF MATERIALS BASED ON ARCHETYPE.............................................93

TABLE 6. CLEARED DEMOLITION PERMITS BY ARCHETYPE FROM 2008 TO 2012 ..........................................97

TABLE 7. NUMBER OF INTERIOR AND EXTERIOR WOOD DOORS IDENTIFIED IN ARCHETYPES. ............................. 102

TABLE 8. MATERIAL COMPOSITION OF REUSABLE AND RECYCLABLE MATERIAL STOCKS, BY PERCENT OF MATERIAL STOCK VOLUME FOR MATERIALS COMPRISING MORE THAN 5\% TO STOCK VOLUME.................................. 105

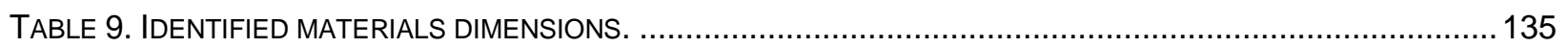

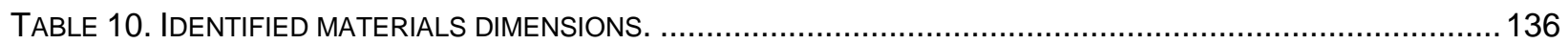

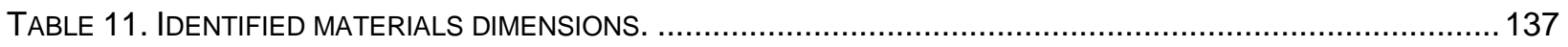

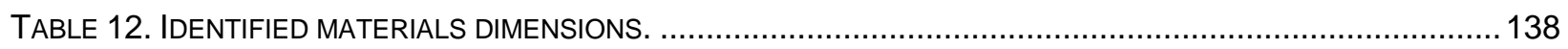

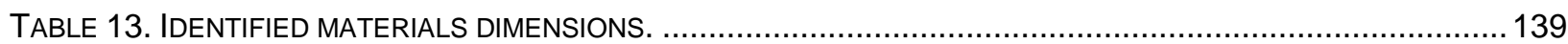

TABLE 14. VOLUMES $\left(\mathrm{M}^{3}\right)$ OF MATERIALS INVENTORIED IN THE FIVE ARCHETYPES....................................... 140

TABLE 15. VOLUMES (M $\left.{ }^{3}\right)$ OF MATERIALS IN TORONTO'S IN-USE SDH STOCK........................................... 141

TABLE 16. VOLUMES ( $M^{3}$ ) OF MATERIALS IN TORONTO'S ANNUAL OBSOLETE SDH STOCK............................ 142

TABLE 17. VOLUMES (M $\left.{ }^{3}\right)$ OF REUSABLE MATERIALS IN TORONTO'S IN-USE SDH STOCK................................143

TABLE 18. VOLUMES (M $\left.{ }^{3}\right)$ OF RECYCLABLE MATERIALS IN TORONTO'S IN-USE SDH STOCK. ........................... 144

TABLE 19. Volumes ( $\left.\mathrm{M}^{3}\right)$ OF REUSABLE MATERIALS IN TORONTO'S ANNUAL OBSOLETE SDH STOCK................ 145

TABLE 20. VOLUMES ( $\left.M^{3}\right)$ OF RECYCLABLE MATERIALS IN TORONTO'S ANNUAL OBSOLETE SDH STOCK............146

TABLE 21. $\mathrm{CO}_{2}$ FOSSIL EMISSIONS (MEGATONNE) EQUIVALENTS OF REUSABLE MATERIALS OF TORONTO'S IN-USE SDH STOCK.

TABle 22. Primary ENERgy Consumption (TERAJOULES) EQUIVALENTS OF REUSABLE MATERIALS OF

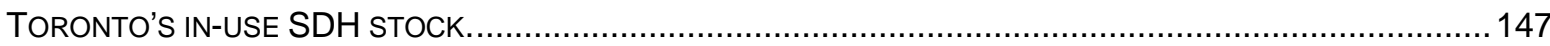

TABLE 23. $\mathrm{CO}_{2}$ FOSSIL EMISSIONS (TONNE) EQUIVALENTS OF REUSABLE MATERIALS OF TORONTO'S ANNUAL OBSOLETE SDH STOCK.

TABle 24. Primary EneRgy CONSUMPTION (GIGAJOULES) EQUIVALENTS OF REUSABLE MATERIALS OF TORONTO'S ANNUAL OBSOLETE SDH STOCK 


\section{List of Figures}

FIGURE 1. ILLUSTRATION COMPARING THE DIFFERENCE IN STOCK SIZES AT ANY GIVEN TIME FOR ENERGY, WATER, OR FOOD RESOURCES AND FOR CONSTRUCTION MATERIALS.

FIGURE 2. FLOOR AREA (M²) COVERED BY CLEARED DEMOLITION PERMITS FROM 2008 TO 2012 BY BUILDING TYPE

FIGURE 3. LEFT, BUILDING MATERIALS AFTER SDH DEMOLITION. RIGHT, HALF COMPLETED DEMOLITION OF SDH IN TORONTO..

FIGURE 4. COMPARISON OF MATERIAL FLOWS WHEN LANDFILLING, REUSING, AND RECYCLING RESOURCES 8

Figure 5. A map of the municipalities comprising the Greater Toronto Area: Toronto, halton, Peel,

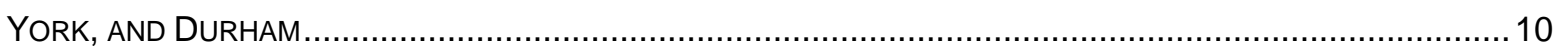

FIGURE 6. OUTLINE OF MATERIAL COMPONENTS THAT ARE INCLUDED IN THE SCOPE OF THE RESEARCH .........12

FIGURE 7. HIERARCHY OF ENVIRONMENTALLY DESIRABLE WASTE MANAGEMENT STRATEGIES........................... 16

FIGURE 8. ENVIRONMENTAL IMPACTS OF REUSING WOOD FROM GREENSPEC ANALYSIS, WHERE THE Y-AXIS

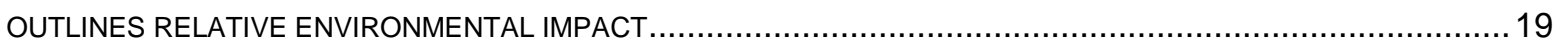

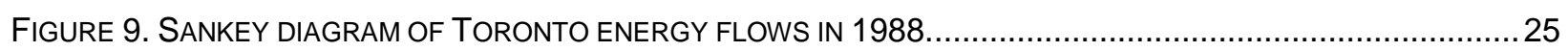

FIGURE 10. SUMMARY OF RESEARCH PROCESS BY OVERALL OBJECTIVE OUTPUTS AND STEPS TAKEN TO REACH

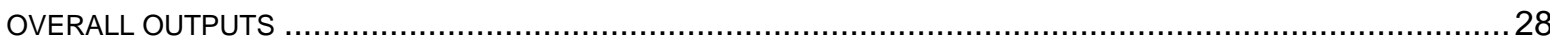

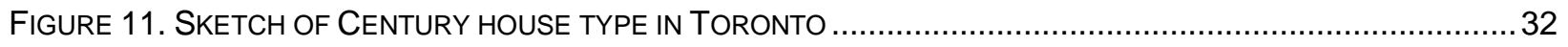

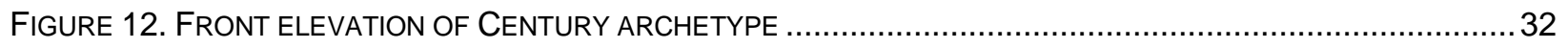

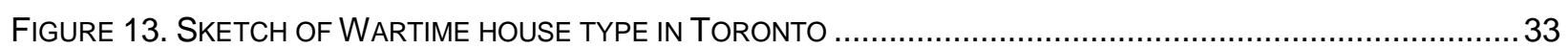

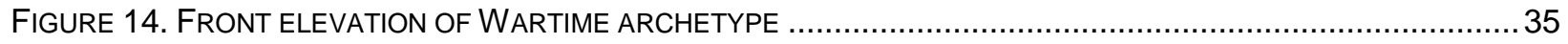

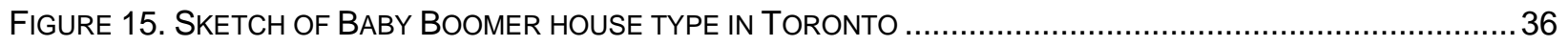

FIGURE 16. FRONT ELEVATION OF BABY BOOMER ARCHETYPE HOUSE AS SEEN ON CONSTRUCTION DRAWINGS .. 37

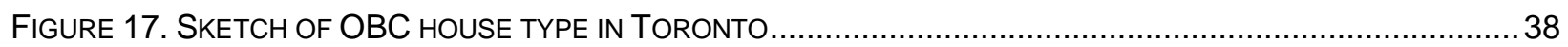

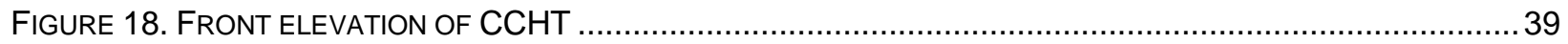

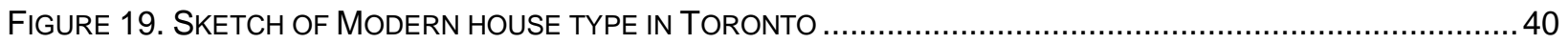

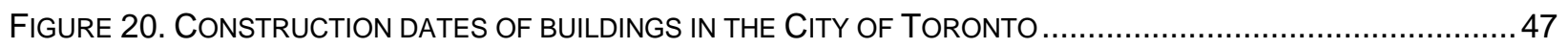

FIGURE 21. ZONING MAP SUPERIMPOSED ONTO CONSTRUCTION DATES MAP WHERE SHADED AREAS REPRESENT AREAS WITH SDH ZONING. IMAGE IS ALTERED TO HIGHLIGHT SHADING. ............................................50

FIGURE 22. CONSTRUCTION DATES MAP DIVIDED BY NEIGHBOURHOODSAND WARDS ....................................... 51

FIGURE 23. FINAL CONSTRUCTION DATES MAP WITH ZONING AND DIVISIONS ........................................... 52

Figure 24. PROPORTIONS OF CONSTRUCTION DATE GROUPS IN TORONTO'S 'RESIDENTIAL' ZONING. LEFT, RESULTS OF MAP DIVIDED BY NEIGHBOURHOOD. RIGHT, RESULTS OF MAP DIVIDED BY WARDS...................53

FIGURE 25. CONSTRUCTION DATES MAP WITH 2012 CLEARED DEMOLITION PERMIT LOCATIONS .........................54

FIGURE 26. VOLUMES OF SELECT MATERIALS IDENTIFIED IN EACH ARCHETYPE ............................................59 
FIGURE 27. VOLUME (M³) OF SOLID WOOD PRODUCTS IDENTIFIED IN THE ARCHETYPE HOUSES AND IN TORONTO'S IN-USE SDH STOCK .68

FIGURE 28. EXAMPLES OF BROKEN FL MEMBERS FROM MECHANICAL DEMOLITION OF TORONTO SDH 69

FIGURE 29. VOLUME $\left(M^{3}\right)$ OF CIP CONCRETE AND AGGREGATE IN ARCHETYPE HOUSES AND IN TORONTO'S IN-USE

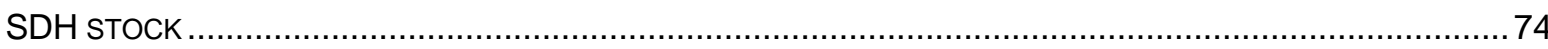

FIGURE 30. VOLUME OF MASONRY IN ARCHETYPE HOUSES AND IN TORONTO'S IN-USE SDH STOCK ...................77

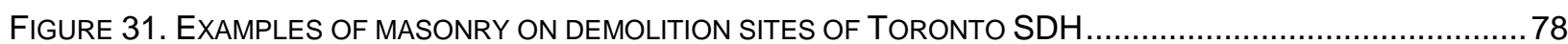

FIGURE 32. VOLUME OF GYPSUM PRODUCTS IN ARCHETYPE HOUSES AT THE ARCHETYPE HOUSES AND IN

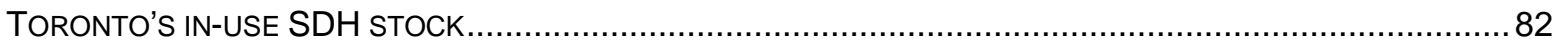

FIGURE 33. VOLUME OF STEEL IN ARCHETYPE HOUSES FOR THE FIVE ARCHETYPESAND IN TORONTO'S IN-USE SDH STOCK.

FIGURE 34. VOLUME OF ASPHALT SHINGLES DETERMINED FOR THE FIVE ARCHETYPESAND IN TORONTO'S IN-USE SDH STOCK. 89

FIGURE 35. MECHANICAL DEMOLITION OF SDH IN TORONTO, DEMONSTRATING A TYPICAL METHOD OF TEARING DOWN ASPHALT SHINGLES. .89

FIGURE 36. NUMBER OF SDH IN TORONTO AT THE END OF 2012, BY ARCHETYPE........................................94

FIGURE 37. 2006 PRIVATE DWELLINGS IN TORONTO BY CONSTRUCTION DATE. ........................................... 95

FIGURE 38. VOLUME OF SELECTED MATERIALS IN TORONTO'S IN-USE SDH STOCK. .......................................96

FIGURE 39. PROPORTION OF ARCHETYPE SDH STOCK DEMOLISHED FROM 2008 TO 2012 ............................99

FIGURE 40. VOLUMES OF SELECT MATERIALS IDENTIFIED IN TORONTO'S ANNUAL OBSOLETE SDH STOCK..........99

FiguRE 41. VolUMES OF SELECTED TOTAL, REUSABLE, AND RECYCLABLE MATERIALS IN THE FIVE ARCHETYPES, WHERE SOME MATERIALS WERE IDENTIFIED AS BOTH REUSABLE AND RECYCLABLE. ................................ 101

FIGURE 42. REUSABLE AND RECYCLABLE MATERIAL VOLUMES BY ARCHETYPE OF IN-USE SDH STOCK............103

FIGURE 43. REUSABLE AND RECYCLABLE MATERIAL VOLUMES BY ARCHETYPE OF ANNUAL OBSOLETE SDH STOCK

FiguRE 44. PERCENT OF TOTAL MATERIAL STOCK VOLUME THAT IS REUSABLE AT THE BUILDING SCALE, IN-USE SDH CITY SCALE, AND ANNUAL CITY SCALE. 107

FIGURE 45. PERCENT OF TOTAL MATERIAL STOCK VOLUME THAT IS RECYCLABLE AT THE BUILDING SCALE, IN-USE SDH CITY SCALE, AND ANNUAL CITY SCALE. 108

FIGURE 46. EMBODIED CO2 EMISSIONS (MEGATONNE) EQUIVALENTS OF SELECT REUSABLE MATERIALS OF TORONTO'S IN-USE SDH STOCK.

FIGURE 47. EMBODIED PRIMARY ENERGY CONSUMPTION (TERAJOULES) EQUIVALENTS OF SELECT REUSABLE MATERIALS OF TORONTO'S IN-USE SDH STOCK.

FIGURE 48. EMBODIED CO 2 EMISSIONS EQUIVALENTS OF REUSABLE MATERIALS OF TORONTO'S ANNUAL OBSOLETE SDH STOCK.

FIGURE 49. EMBODIED PRIMARY ENERGY CONSUMPTION EQUIVALENTS OF SELECT REUSABLE MATERIALS OF TORONTO'S ANNUAL OBSOLETE SDH STOCK. 
FIGURE 50. HOT SPOT AREAS IN TORONTO FOR DEVELOPING DROP-OFF FACILITIES.

FIGURE 51. 2012 TORONTO SDH BUILDING MATERIAL FLOW CONSIDERING ONLY DEMOLITION WASTE, NOT TO SCALE. 123

FIGURE 52. 2012 TORONTO SDH BUILDING MATERIAL FLOW WHEN THE MAXIMUM VOLUME OF REUSABLE AND RECYCLABLE MATERIALS ARE RECLAIMED; CONSIDERING ONLY DEMOLITION WASTE AND NOT TO SCALE.... 125

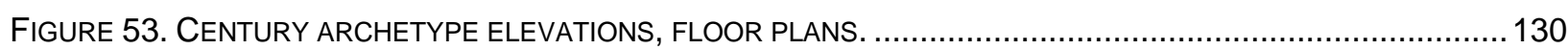

FIGURE 54. WARTIME ARCHETYPE ELEVATIONS, FIRST AND SECOND FLOOR PLANS, AND WALL SECTION...........131

FIGURE 55. BABY BOOMER ARCHETYPE FRONT AND REAR ELEVATIONS, FIRST AND SECOND FLOOR PLANS, AND WALL SECTION. 132

FIGURE 56. OBC AND MODERN ARCHETYPE FRONT AND REAR ELEVATIONS, FIRST AND SECOND FLOOR PLANS, AND WALL SECTION. 


\section{List of Abbreviations}

$\begin{array}{ll}\text { AS } & \text { Architectural salvage } \\ \text { CRD } & \text { Construction, renovation, and demolition } \\ \text { CSV } & \text { Comma-separated value } \\ \text { CIP } & \text { Cast-in-Place } \\ \text { FL } & \text { Framing lumber } \\ \text { KML } & \text { Keyhole markup location } \\ \text { LCA } & \text { Life cycle Assessment } \\ \text { MFA } & \text { Material Flow Analysis } \\ \text { SDH } & \text { Single-detached house(s/ing) } \\ \text { SRF } & \text { Specialist recycling facility } \\ \text { SY } & \text { Salvage yard } \\ \text { T\&G } & \text { Tongue and groove } \\ \text { TTS } & \text { Toronto transfer station } \\ \text { UBMO } & \text { Used building material organization }\end{array}$




\section{Introduction}

The dynamic nature of contemporary cities is heavily subsidized by the exploitation of hinterland and global natural resources. Cities function as a linear metabolism, ingesting raw and processed resources and, ultimately, discharging those resources, often in a polluting quantity or state, back into the peripheral environment (Cossu et al, 2012; Hendricks et al, 2000.). As cities continue to intensify, in terms of population and economic growth, it is apparent that the current paradigm is not sustainable and natural resources stocks will not sufficiently meet the demands of future urban generations (Worldwatch Institute, 2007).

In response to the challenge of reshaping how urban systems work, emerging literature looks to a biomimetic approach, finding inspiration from ecosystems, which are dynamic and rely on natural resources like cities but also manage to regenerate quality resources to sustain succeeding generations (Broto et al, 2012). Wolman first proposed the idea of thinking of cities as ecosystems in 1965 by pioneering research in urban metabolism. Where urban metabolism is, "the sum total of the technical and socio-economical processes that occur in cities, resulting in growth, production of energy, and elimination of waste" (Kennedy et al, 2007). In his research, Wolman (1965) developed a hypothetical city of one million inhabitants in the United States (U.S.A.) to model how energy, water, material, and food resources were consumed, stored, and discharged by the urban unit.

\subsection{Applied Urban Metabolism}

The urban metabolism concept has since been applied to real cities by utilizing material flow analysis (MFA), a method originating from the industrial ecology discipline that accounts for resource (energy, water, food, and materials) flows and stocks overtime (Baccini and Brunner, 2012; Brunner and Rechberger, 2004; Kennedy et al, 2011). Although not standardized, the basic MFA method includes inventorying resource inputs, outputs, and stocks, where total resource input is equal to the sum of the total stock and output in a designated time.

MFA literature at the urban scale tends to focus most on input and output flows rather than internal resource stocks (Baccini and Brunner, 2012; Bristow and Kennedy, 2013). When inventorying energy, water, and food resources it makes sense to focus on inputs and outputs because the resources are consumed and discarded in a relatively short period of time. 
On the other hand, illustrated in Figure 1, materials that are required to be durable and long lasting, such as those used in buildings, accumulate in the urban fabric and their stock grows overtime. So much so that a significant quantity of the total extracted natural resource stock used for producing materials resides in the current urban fabric (Brunner and Rechberger, 2004). Thus inventories of in-use urban resource stocks, especially building materials, are important in providing insight to the relationship between the city and its surrounding environment (Kennedy et al, 2007).

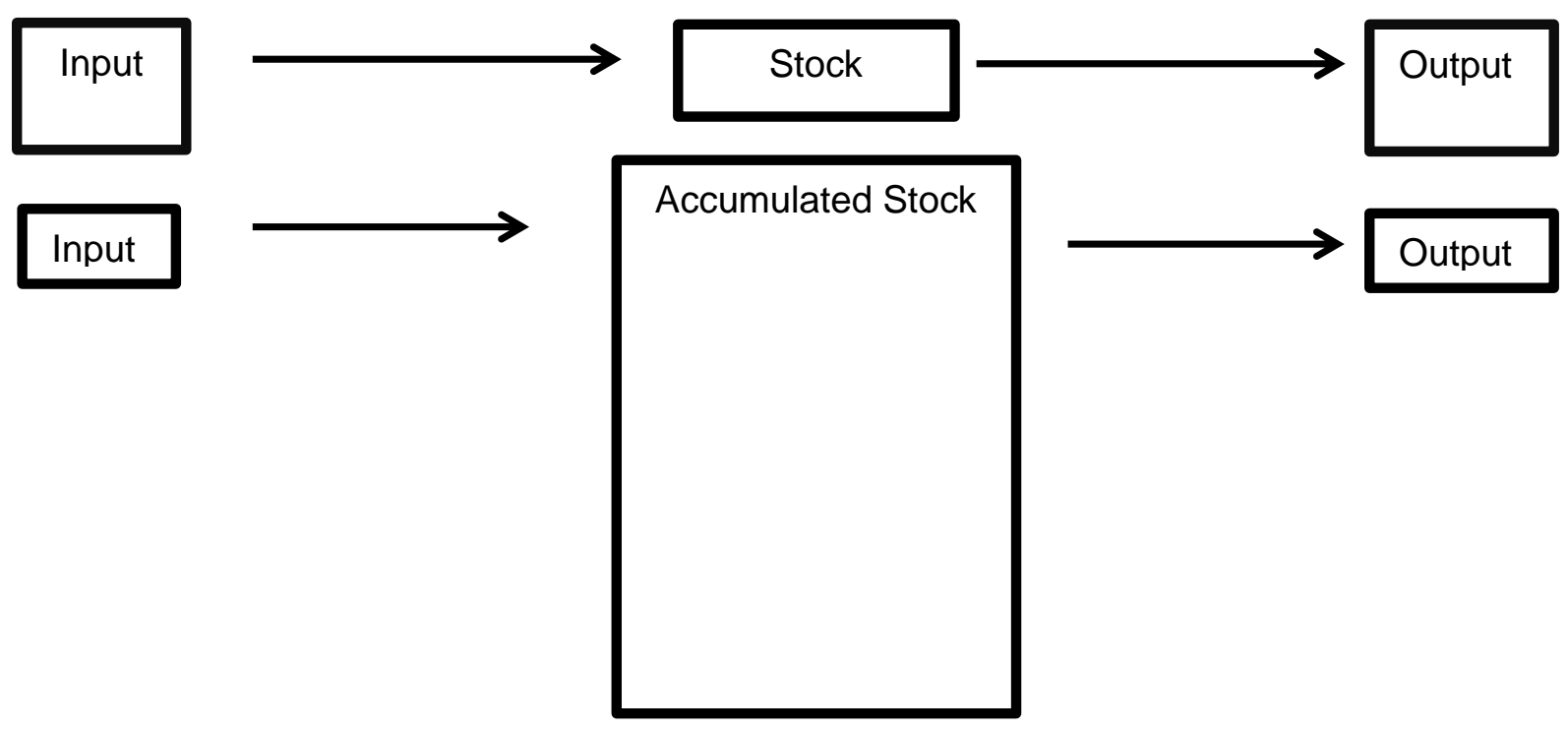

Figure 1. Illustration comparing the difference in stock sizes (not to scale) at any given time for energy, water, or food resources (top) and for construction materials (bottom).

The City of Toronto, in the province of Ontario, Canada has contributed significantly to urban metabolism literature (e.g. Sahely et al, 2003, Kennedy and Hoornweg, 2012, Bristow and Kennedy, 2013). There have been four MFAs concerning Toronto, examining energy, water, food and building material inputs and outputs and energy stocks (Sahely et al, 2003; Codoban, and Kennedy, 2008; Bristow and Kennedy, 2013). Furthermore, Toronto has been the source of prominent conceptual literature on urban metabolism and its future applications to sustainable design (e.g. Kennedy and Hoornweg, 2012; Kennedy et al, 2007).

Literature on metabolic activities in Toronto identifies a clear need for reliable descriptive analysis of building material stocks (Bristow and Kennedy, 2013; Codoban, and Kennedy, 2008; Sahely et al, 2003). Sahely (2003) provided a rough outline of cast-in-place (CIP) concrete and 
residential framing lumber $(F L)$ inputs and outputs by correlating average material volumes used in standard construction at the beginning of the $21^{\text {st }}$ Century with data on residential construction starts from 1987 to 1999 . However as the study examined a geographical area including neighbouring municipalities as well as the City of Toronto, the data did not account for Toronto's rich history and distinct housing mosaic shaped by a diversity of building materials and methods common to different eras (Sahely et al, 2003).

\subsection{Toronto's Single-Detached Housing}

Of the building types that comprise the building stock in Toronto, single-detached houses (SDH) stand out because they are highly prone to redevelopment (City of Toronto Open Data, 2013). $\mathrm{SDH}$ are addressed in numerous ways by the literature, including single-detached houses, detached houses, and single-family dwellings. Statistics Canada (2012b) defines a SDH as, "a single dwelling not attached to any other dwelling or structure (except its own garage or shed). A single-detached house has open space on all sides, and has no dwellings either above it or below it."

Redevelopment of SDH in Toronto is a multifaceted issue that largely stems from the city's increasing land value because of its geographical limitations to outward growth and sprawl. For example, the average SDH in 2012 cost almost twice as much as it did in 2002, $\$ 1,089,748$ versus $\$ 551,918$ respectively (CMHC, 2013; CMHC 2002). In many cases, those who can afford to purchase $\mathrm{SDH}$ are purchasing property for its land rather than its building and can also afford to rebuild a custom SDH. From 2008 to 2012 an average of 727 SDH were demolished annually for redevelopment, representing $86 \%$ of total demolition permits cleared by the City of Toronto from 2008 to 2012. As well, the floor area covered by SDH cleared demolition permits represents a significant proportion of the total floor area covered by demolition permits in Toronto as shown in Figure 2 (City of Toronto Open Data, 2013). 


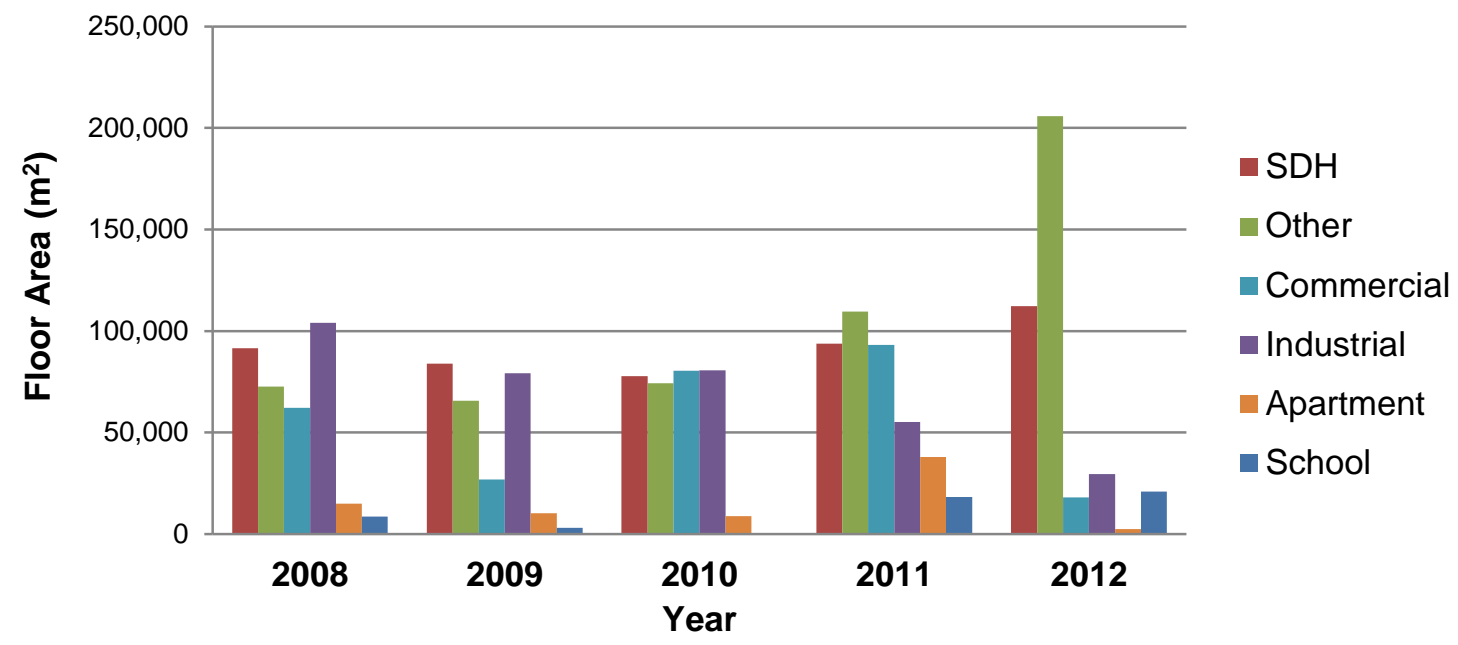

${ }^{*}$ An outlier is removed from industrial buildings in 2011, which covered $1,002,673 \mathrm{~m}^{2}$.

Figure 2. Floor area $\left(\mathrm{m}^{2}\right)$ covered by cleared demolition permits from 2008 to 2012 by building type (City of Toronto Open Data, 2013).

\subsection{Demolition Waste}

Demolition waste is significant and is used to describe the waste generate from a disassembled obsolete building. Demolition of Toronto's buildings generated roughly 38-64 thousand tonnes of landfilled debris in 2012, based on CRD waste per construction industry employee data from NRCan (2006) and City of Toronto data on residents employed by the construction industry (City of Toronto, 2013a). Of all construction, renovation, and demolition (CRD) activities required for a building, most waste is generated in a building's demolition. For example, demolition waste can be 20 to 30 times greater than construction waste and provincial data indicates that at least $80 \%$ (when measured in mass) ends up in landfill, putting immense pressure on hard-to-find void landfill space (NRCan, 2006).

\subsection{Embodied Impacts of Virgin Building Materials}

By sequestering materials in landfills, the urban fabric requires a constant input of virgin building materials. The environmental burdens associated with manufacturing virgin building materials are extensive as the construction industry consumes about half of the non-renewable resources extracted from the environment (Hawken et al, 1999). As well, decades of intensive resource exploitation has resulted in a resource stock that is likely unable to meet demands of future consumers and are generally increasingly more difficult to extract (ISWA, 2011; Worldwatch Institute, 2007). 
Immense amounts of resources are required to extract, manufacture, and transport high quality building materials to market. These processes also result in emissions to land, water, and air that diminish the quality of the living ecosystem. The direct and indirect environmental impacts of extracting, manufacturing/processing, and transporting resources for building materials are described as embodied impacts. Often, these impacts are outlined by reporting carbon dioxide $\left(\mathrm{CO}_{2}\right)$ emissions to indicate the impact of greenhouse gases on climate change and as primary energy consumption to indicate the impact of consuming non-renewable energy sources.

Likewise, the City of Toronto has goals to significantly reduce both $\mathrm{CO}_{2}$ emissions and primary energy consumption through its Climate Change Action Plan and its energy conservation and demand plan scheduled to be completed in July 2014 (City of Toronto, 2011). For example, In 2007 Toronto established goals to reduce $\mathrm{CO}_{2}$ emissions by $80 \%$ of the 22 gigatonnes emitted in 1990 by 2050; where residential buildings produced $25 \%$ (although it is not clear if this figure considers embodied impacts) and landfill management produced $4 \%$ of the total $\mathrm{CO}_{2}$ emitted in 2004 (City of Toronto, 2007).

Typically in colder climates like Canada embodied impacts of SDH are low in comparison to the energy required to operate the building (Winistorfer et al, 2005). However, literature demonstrates that approaches, such as increasing thermal resistance through insulation, to significantly reduce SDH operating energy result in a higher proportion of a building's lifetime impacts occurring at the embodied stage (Balson and Lowres, 2012; Verbeeck and Hens, 2007). Thormark (2006) explains that as much as $40-60 \%$ of the total energy use can be accounted for by embodied energy in some SDH with extremely low operating energy.

Further emphasizing the importance of embodied impacts is emerging literature demonstrating that typical assessments comparing embodied versus operational impacts omit the influence of the cumulative carbon affect (De Selincourt, 2012). Carbon accumulates in the atmosphere because, as described by The International Panel on Climate Change (IPCC), the carbon cycle has reached saturation (Rhys, 2011); excessive carbon emissions are no longer being recycled into nutrients for land- or water- based organisms. Instead carbon is collecting in the atmosphere (De Selincourt, 2012; Rhys, 2011). Therefore the date in which carbon is released into the atmosphere affects the greenhouse gas impact it has on climate (Rhys, 2011). For example 1 tonne of carbon emitted today will have ten years more impact by the end of the century than 1 tonne emitted in ten years. 


\subsection{Reclaiming Demolition Waste}

It is suspected that about $75 \%$ of the demolition waste, by weight, headed to landfill has residual value that can be utilized by reclaiming and reintroducing materials it into the urban fabric through reuse or recycling; where reclaiming refers to taking materials out of waste stream to use as resource (Yeheyis et al, 2012). Studies to quantify embodied impacts of materials indicate that impacts are significantly reduced when materials are reclaimed and reused rather than recycled. Reuse is a waste management strategy that uses reclaimed materials or objects in their original or mostly original form. Thus, most of the initial energy inputted into producing material carries through to its subsequent lives (Olson, 2011).

Reuse encompasses three levels of preparation for secondary use. The first is direct reuse, where materials are used as close as possible to their original state and for their original purpose requiring almost no preparation (ISWA, 2011). The second is renewed reuse, where materials are slightly altered by cleaning, repairing, refurbishing, or mild remanufacturing to serve a new function (Guy and Nicholas, 2011). Finally, the third is rethought reuse, where reclaimed materials are fused with new materials to create a secondary product with a new function (Guy and Nicholas, 2011).

Recycling is generally considered less desirable, from an environmental perspective, than reuse because it can involve high levels of remanufacturing/reprocessing to prepare materials for secondary use (Kay and Essex, n.d.). In some cases recycling processes can have comparable or greater environmental impacts compared to virgin materials production, sometimes but not limited to the additional transportation required. The recycling process generally involves cleaning and breaking down or melting of reclaimed materials to extract desirable elements from those materials. The elements are processed/manufactured, which typically involve integration with other (often virgin) elements to produce a secondary, but also new, product (PWGSC, 2000).

In some cases materials can be recycled into secondary products with similar functions or forms, such as recycling reclaimed structural steel with virgin ore to produce secondary structural steel (Gorgolewski et al, 2006). However, often materials are downcycled into secondary products with lower quality or functionality or are downcycled in such a way that 
recyclable elements cannot be extracted again, resulting in eventual landfilling of the products (Mcdonough and Braungart, 2002).

The reusability/recyclability of building materials is greatly dependent on factors such as how the material is installed in the building and its useful life, as well as available technology, policy, and knowledge on its secondary uses. However reusability is also dependent on how materials are removed from a building (Yeheyis et al, 2011). While materials intended for recycling benefit from specialized removal from a building, materials intended for reuse depend on careful and intentional removal through a process known as deconstruction.

Deconstruction differs significantly from the traditional mechanical demolition which is the most common manner in which SDH are disassembled in Toronto and is demonstrated in Figure 3. Deconstruction involves selectively disassembling building materials in a manner to preserve their integrity (Falk and Guy, 2007). Typically deconstruction involves manually taking apart a structure piece-by-piece, with intentions to preserve the material's state and form and, as such, is highly dependent on precision, care, adaptability and judgement (Falk and Guy, 2007).
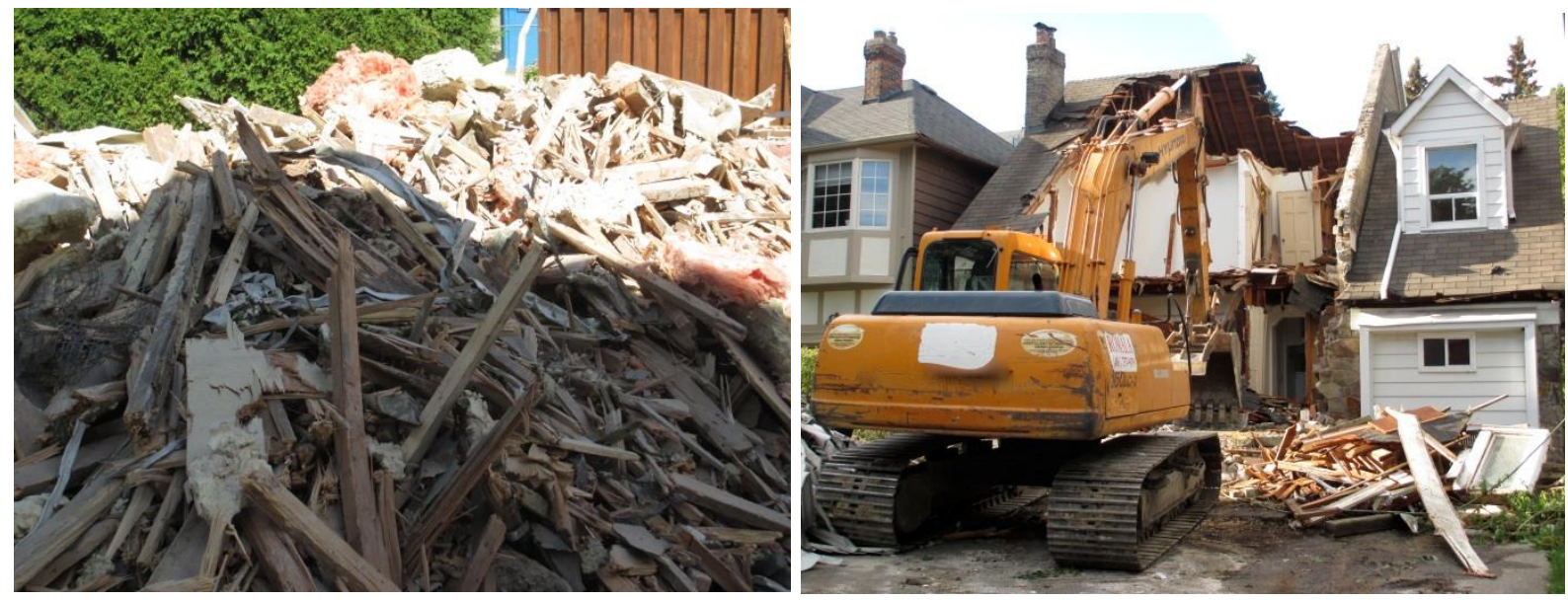

Figure 3. Left, building materials after SDH demolition. Right, half completed demolition of SDH in Toronto (pictures taken with permission of on-site demolition crew).

\subsection{Waste-to-Resource}

Case studies have demonstrated that there are significant social-economic and environmental benefits to reclaiming suitable materials (Addis, 2006; Falk and Guy, 2007; RCO, 2006). In the urban context, reclaiming materials from obsolete buildings fall under the umbrella of the 'urban 
mining' concept, which looks at obsolete materials as resources for future development rather than waste (Cossu et al, 2012; Krook and Baas, 2013).

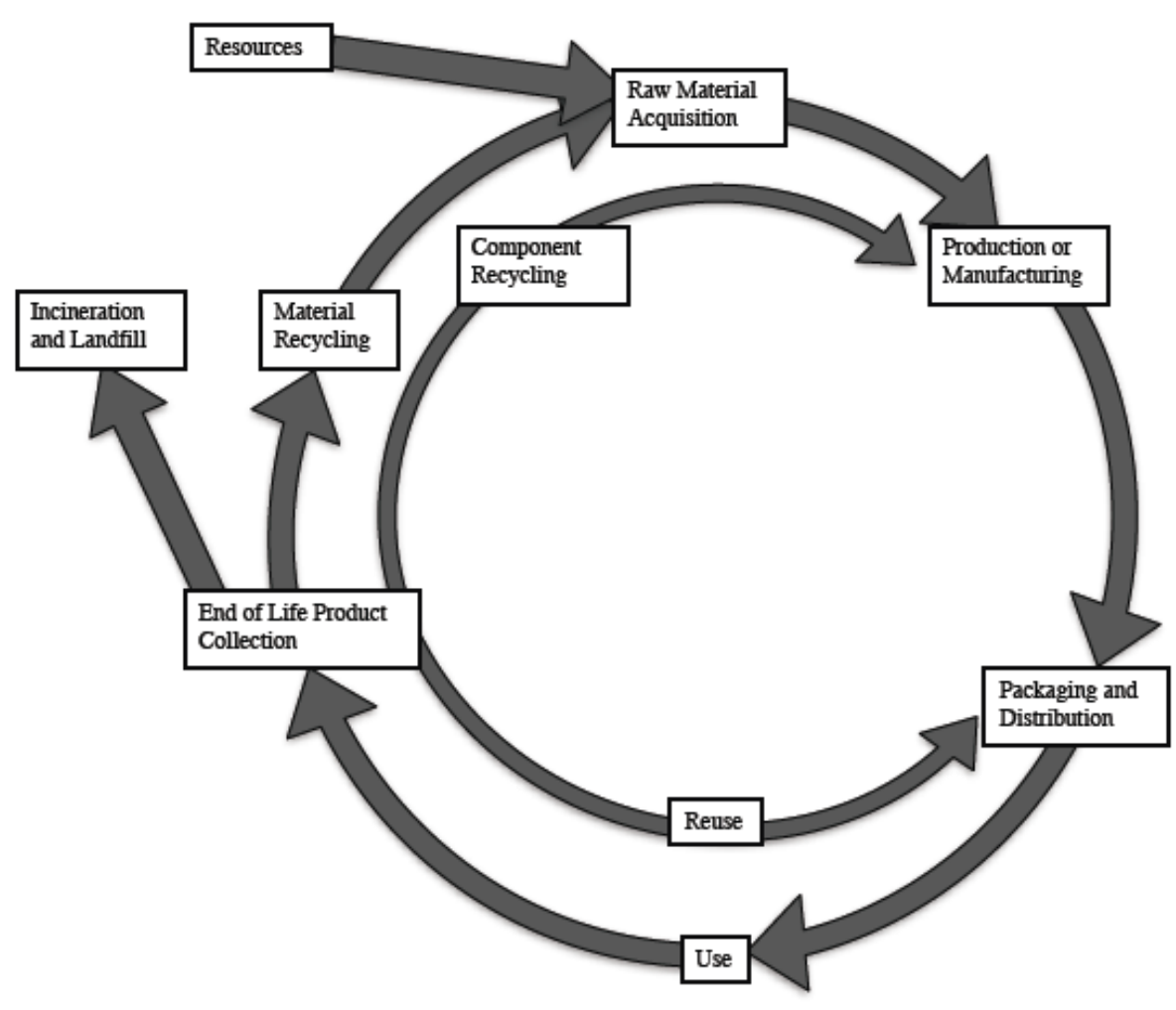

Figure 4. Comparison of material flows when landfilling, reusing, and recycling resources (Olson, 2011).

Urban mining begins to close the loop, reshaping the linear metabolism into a cyclical, regenerative model (Brunner, 2011; Cossu et al, 2012). However to develop policy and infrastructure needed to facilitate urban mining it is important to develop descriptions of material stocks much like the data offered by urban metabolism research (Brunner, 2011; Krook and Baas, 2013). Odum (1997) explains that to understand the value of reclaiming building materials, analysis is best done at the city scale because it is large enough to develop closed loop material pathways. Yet, while literature demonstrates examples of reclaimable material inventories for specific building projects (e.g. US EPA, 2008; Falk and Guy, 2007), there is little literature available estimating large scale building material stocks that highlight reclaimable materials and none at the city scale (Davila, 2013; Falk, 1999; FCSHWM, 2000; Sianchuk, 2012). 


\section{Research Aim}

\subsection{Summary of Research Problem}

Under the current paradigm, redevelopment of Toronto's single-detached housing comes at the expense of increasing environmental pressures on already stressed hinterland and global resources through the embodied impacts associated with the production of virgin building materials and for void landfill space to sequester demolition waste. At the same time, the City of Toronto has goals to significantly improve its environmental sustainability by, among other approaches, significantly reducing its $\mathrm{CO}_{2}$ emissions and primary energy consumption (City of Toronto, 2007; 2011).

One alternative to the current paradigm is to create more cyclical material flows by reclaiming suitable materials from obsolete SDH and reintroducing them back into Toronto's urban fabric through reuse and recycling. Development of proactive policy and infrastructure to facilitate reclamation in Toronto, also called urban mining, can benefit from information on material stocks in Toronto's SDH (Brunner, 2011; Krook and Baas, 2013). However, lack of governmental data on building material consumption and wastage has hindered any sufficient description on material stocks in previous research concerning Toronto's resource metabolism (Sahely et al, 2003).

\subsection{Research Question and Objectives}

To inform policy on the potential of utilizing material stocks of reclaimable building materials from Toronto's urban fabric, the following research questions are asked:

What is the estimated inventory of materials that can be reclaimed for reuse and recycling in Toronto's stock of typical in-use and annual obsolete single-detached housing?

What are the associated embodied carbon and energy impacts and/or implications to the volume demolition waste headed to landfill of reusing and recycling suitable materials?

Three objectives in the research must be met to sufficiently answer the above questions:

1. Identify and quantify materials in the envelope and interior partitions of typical houses in Toronto's single-detached housing stock. 
2. Identify the reusability and recyclability of identified materials and opportunities/infrastructure currently available in the City of Toronto to absorb those materials.

3. Determine the embodied carbon and energy impacts and/or implications to the volume of demolition waste headed to landfill of reusable and recyclable materials at the city scale.

\subsection{Research Scope}

This thesis seeks to inventory the materials that are reclaimable for reuse/recycling from in-use and obsolete typical SDH within the boundaries of the City of Toronto. Specifically, the thesis sets to identify and quantify the embodied impacts and/or implications to void landfill space of reusable and recyclable materials. The research was bounded by geography, waste management strategies, typical SDH styles, material applications in $\mathrm{SDH}$, and environmental implication indicators, which are discussed below.

\subsubsection{Geography}

The scope of the research included the City of Toronto. Settlement in Toronto dates back to the late 1700's and the city is now Canada's largest by population. Toronto's current boundary was formed in 1998 through the amalgamation of six formerly separate municipalities: Toronto, Etobicoke, East York, York, North York, and Scarborough (Tomalty, 1997).

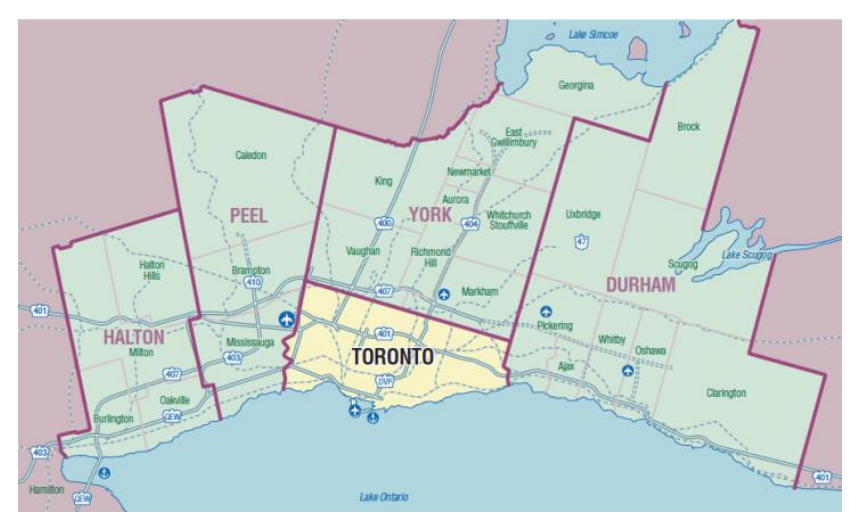

Figure 5. A map of the municipalities comprising the Greater Toronto Area: Toronto, Halton, Peel, York, and Durham (City of Toronto, 2013d). 
Toronto is also part of a larger geographic region, called the Greater Toronto Area (GTA). Figure 5 shows that the GTA includes the municipalities of Toronto, Halton, Peel, York and Durham (City of Toronto, 2013d). However, only the City of Toronto was included in the scope of this thesis. First, large scale housing development in Toronto predates the surrounding regions. More examples of older houses can be found in Toronto (reviewed by Blaszak, 2010). Second, Toronto has a higher density and thus properties tend to be smaller than in the surrounding suburban developments (CMHC, 1985). Third, there is limited space for urban sprawl in Toronto and thus less space for new housing developments (Province of Ontario, 2013). For instance, from 2001 to 2012 Toronto SDH construction represented an average of only $8 \%$ of the total SDH construction starts in the GTA (CMHC, 2013).

\subsubsection{Waste Management Strategies}

As the research views the materials available in obsolete buildings as resource rather than waste, the scope considered only reuse and recycling waste management strategies. The scope does not include other waste management strategies as waste reduction and energyfrom-waste. Instead, this thesis defines a reclaimed material as one that can be used (in part or as a whole) to make physical secondary products that may be useful in future redevelopment of Toronto's built infrastructure.

\subsubsection{Material Application}

The scope of the research included inventorying materials that make up the envelope, interior partitions, flooring and interior finishing elements of SDH. Figure 6 illustrates the assemblies considered in the scope.

The scope did not include any materials associated with building operations including mechanical, electrical, or plumbing services. The scope also did not include materials from building elements not typically found in the exterior elevation or floor plan construction drawings, such as ceiling finishes, or materials from building elements that tend to be highly variable or stylized from house to house, including staircases, hardware, adhesives, permanent and movable furniture, balconies, porches, and trim. As well, because of limitation to time and because these components were thought to be comprise a small volume of the total materials, window frames and details such as jambs and sashes, as well as structural bridging, and flashing and were not included. Lintels were only included when outlined on floor plans and 
were over envelope fenestrations. As well, bi-fold, folding, or sliding interior doors were not included. Finally, the interior components of chimneys were not included.

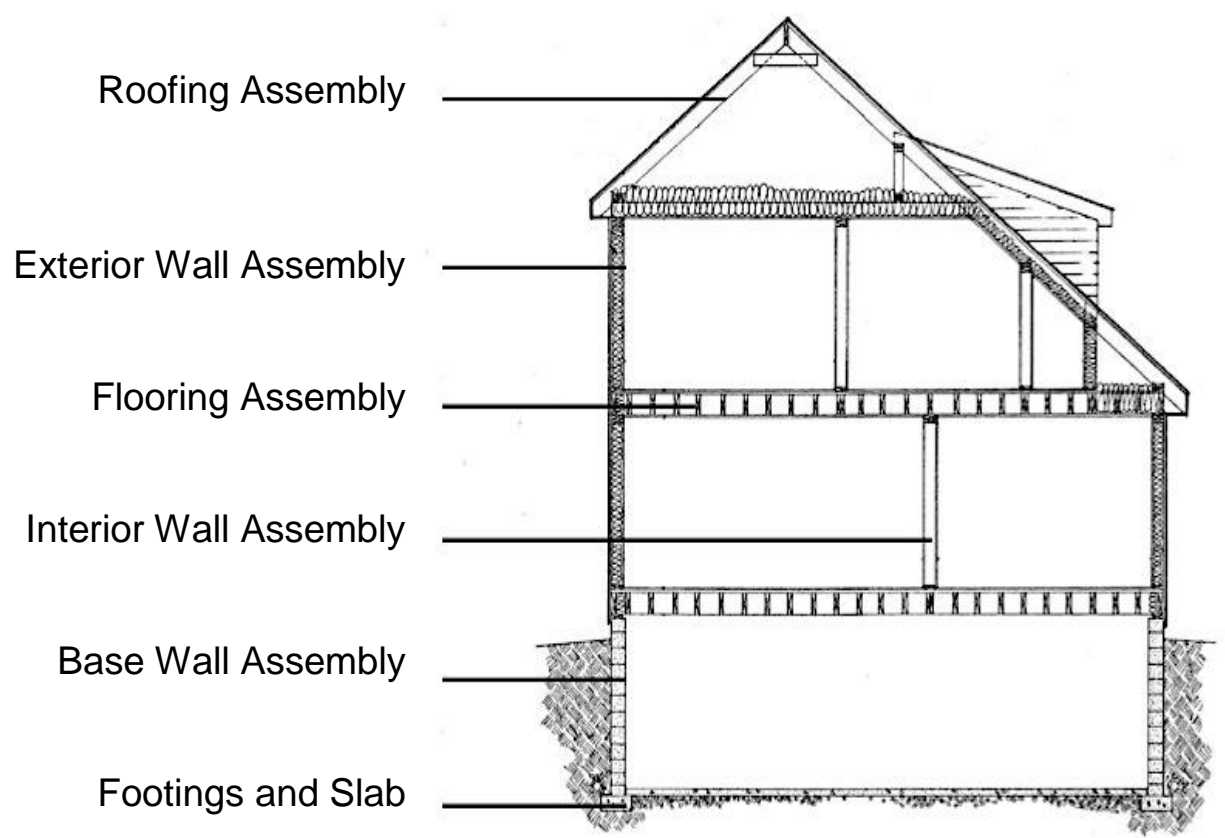

Figure 6. Outline of material components that are included in the scope of the research (Interioridir, n.d.).

\subsubsection{Construction Practices}

SDH with typical designs and materials were considered in the scope of the research. The vast majority of Toronto housing can be divided into typical unit types from the time period of construction and can be used to accurately represent the housing stock with sufficient accuracy for the purpose of this research. Typical until types can be usually found en-mass, in developments, and with similar physical characteristics to their neighbours. In contrast, the study does not include highly stylized, one-off house types.

One-off housing was excluded from the scope for three reasons. First, the time and resources available for the thesis limited the number of different house types that could be analyzed. By focusing the available time and resources on typical house styles, more of the Toronto's SDH stock was represented than focusing on one-off styles. Second, although one-off house styles can be found in the city, they make up a small proportion of the total housing stock (Tomalty, 1997). Third, archetypal representations can only be effectively developed from housing with underlying similarities (Cutler, Breiman 1994). 


\subsubsection{Environmental Indictors}

The scope of the research included quantification of three environmental indicators. The first was material volumes $\left(\mathrm{m}^{3}\right)$ of total, reusable, and recyclable materials. In comparison, many Canadian reports concerning CRD waste generation express material quantities in mass (NRCan, 2006). Quantifications of waste in mass are likely prevalent in the literature because measuring weight, a function of mass, is part of disposal facilities operations (NRCan, 2006). Such operations measure the weight of disposal bins to determine tipping or other relevant fees (NRCan, 2006). However the environmental issues related to decreasing void landfill space are better described by metrics of volume. As well, measuring material volume is more relevant to new construction, where material specifications typically outline materials by volume dimensions and not by weight.

For materials that can be reused two additional indicators were examined: primary energy consumption and greenhouse gases through carbon dioxide emissions $\left(\mathrm{CO}_{2}\right)$. Because material reuse requires minimal manufacturing at most, there are examples of literature explaining its environmental impact in terms of the embodied impacts of virgin materials saved from its use. Thus in the research, materials suitable for reuse were outlined in terms of embodied impacts (e.g. Davilia, 2013; Kay and Essex, n.d.). Specially, embodied primary energy consumption and greenhouse gases through carbon dioxide emissions $\left(\mathrm{CO}_{2}\right)$ are general reported and internationally recognized as significant indicators for global environment concerns such as peak oil and climate change(Kay and Essex, n.d.).

Embodied primary energy consumption and $\mathrm{CO}_{2}$ emissions were not identified for materials suitable for recycling. In comparison to reuse, recycling is associated with significantly more inputs of energy, raw resources and outputs of emissions to land, water, and air. Because of this, predicting the embodied energy or emissions saved through recycling is far more complex and depends on many factors. This is arguably also true for reused materials. But without sufficient data on the energy and emission caused by direct, renewed, or rethought reuse, literature typically uses equivalent embodied impacts of virgin materials to get a general understanding and following suit allows this research to provide comparable results (Kay and Essex, n.d.).

Likewise, there is information on energy input and emissions of various recycling/downcycling processes. However to consider all the possible secondary recycled products for the identified 
materials would require time and resources not available in this thesis. For example, Gao (2001) outlined that solid wood products can be recycled/downcycled into five other construction materials: glued laminated wood, wafer board, particleboard, middle density board, and hardboard. Nevertheless, the research question can be sufficiently addressed without the inclusion of such indicators for recyclable materials. 


\section{Literature Review}

\subsection{Construction, Renovation, Demolition (CRD) Waste}

Waste from the construction industry is most often, but not exclusively, defined as CRD waste. Key literature on Canadian CRD waste references inconsistent statistics. Depending on the source, literature suggests that CRD waste accounts for $21 \%, 30 \%$ or $35 \%$ by mass and $25 \%$ by volume of Canada's total non-hazardous solid waste (CH2M, 2000; CCA, 2001; RCO, 2006; Yeheyis et al, 2012).

Two studies have gathered the primary source data on national CRD waste generation that is interpreted by key literature. The first study, from Environment Canada and NRCan in 1992 , reported that $C R D$ waste accounted for 6.5 million tonnes of the non-hazardous solid waste stream (Environment Canada and NRCan, 1993). The second study, a biennial survey of the waste management industry, from Statistics Canada, reported that CRD waste accounted for 3.8 million tonnes of the non-hazardous solid waste stream in 2002 (Statistics Canada, 2004). While data from both studies are widely referenced, their differences are significant and can be accounted for by inconsistent definitions of CRD waste; the Environment Canada and NRCan (1993) study included roadway infrastructure in its definition of CRD and Statistics Canada (2004) did not.

Either way, it is evident that both primary source studies are outdated. More recent literature have employed waste generation models to update the 1992 or 2002 statistics with relevant demographic and construction industry data (RCO, 2006; NRCan, 2006). However, because waste generation models tend to produce statistics that are more speculative than absolute, national CRD waste disposal is best represented as a range of 2.8 - 4.7 million tonnes annually or 2.9 - 4.9 tonnes per an employee in the construction industry, not including road construction (NRCan, 2006). Nevertheless, it is expected that CRD waste statistics are high variable, based on season, local economy, and municipal infrastructure (RCO, 2006).

Most data on CRD waste in Canada is presented at a national scale, although there is limited data at provincial and urban scales as well. NRCan (2006) utilized primary source data to model CRD wastes for Canadian provinces and territories, determining that the Province of Ontario disposed of just over 1 million tonnes of CRD waste in 2002. In 2000, the province of Alberta gathered primary source data by surveying over 50 disposal sites to determine CRD waste 
composition (CH2M, 2000). The City of Calgary in Alberta conducted two follow up studies in 2006 and 2010 and also determined CRD waste amounts and composition to better improve reclamation of suitable materials (WDCDSC, 2011). Although the results of Calgary's studies are not available to the public, they suggest that the City of Calgary recognizes that management of CRD waste needs to be improved (WDCDSC, 2011).

\subsection{Waste Management}

The waste hierarchy, shown in Figure 7, is a globally accepted ranking scheme used by the European Waste Framework Directive to guide waste management strategies based on each strategy's environmental impact. Not surprisingly, landfilling falls at the bottom of the list and is ubiquitously considered the least effective or last resort strategy to manage waste.

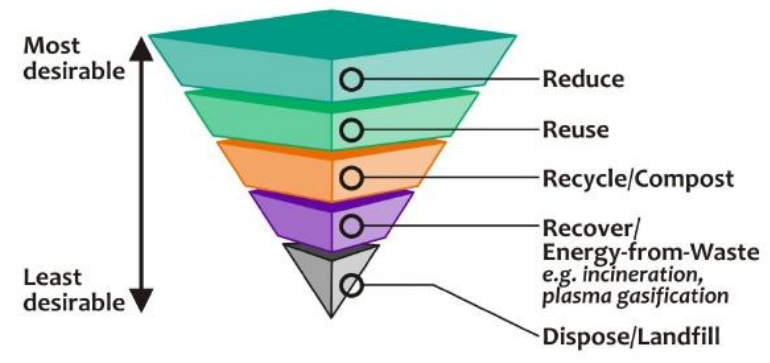

Figure 7. Hierarchy of environmentally desirable waste management strategies (City of Ottawa, 2012).

\subsubsection{Landfilling}

Nationally, about $84 \%$ of CRD waste by weight is disposed at landfills (NRCan, 2006). Survey's conducted by Environment Canada and NRCan (1993) and CH2M (2000) have demonstrated that CRD waste is typically composed of wood, bricks, concrete, drywall, roofing, and metal materials. It is estimated that about $75 \%$ of the material that ends up in landfill has some residual value, which could be utilized through reuse and recycling (Yeheyis et al, 2012).

In Toronto, non-hazardous SDH demolition waste is primarily sent to Green Land landfill, located over $200 \mathrm{~km}$ outside the city (City of Toronto, 2013g). Toronto has been notoriously riddled with difficulties in securing long-term space to landfill its immense amounts of waste, about 500 thousand tonnes generated in 2013 (City of Toronto, 2013h; Yeheyis et al, 2012). After a controversial stint of sending waste across the border to Michigan, Toronto acquired Green Lane, a non-hazardous solid waste landfill in St. Thomas, Ontario in 2011 (City of 
Toronto, 2013h). However, Green Lane is a relatively short-term solution for Toronto and is expected to reach capacity by 2029 (City of Toronto, 2013h).

Kim and Missios (2007) determined that large-scale landfills (greater than 100 hectares) in the GTA have a significantly greater hindrance on residential development than small-scale landfills. More so, landfills are problematic for a number of reasons related to human and ecosystem health and resource depletion. Some of the most concerning environmental impacts of landfills relate to groundwater and air contamination from emissions of toxic liquid leachate and methane $\left(\mathrm{CH}_{4}\right)$ and carbon dioxide $\left(\mathrm{CO}_{2}\right)$ greenhouse gases (PWGSC, 2000).

\subsubsection{Energy-from-Waste}

Energy-from-waste is not examined in this thesis. The topic has a robust library of literature, as it is the main method of waste management in many cities around the world.

\subsubsection{Recycling}

Recycling falls in the middle of the waste hierarchy, below reuse and above energy-from-waste as shown in Figure 7. NRCan (2006) reported that about $20 \%$ or 554 thousand tonnes of CRD waste was reclaimed for recycling in 2006, using waste recovery data that was primarily from the U.S.A. A more recent industry survey from Statistics Canada indicated that in 2010 national CRD waste diversion was actually higher, at 653 thousand tonnes, not accounting for materials diverted at the building site (Statistics Canada, 2010). However Statistics Canada (2010) also reported that in Ontario, just over 154 thousand tonnes of CRD waste was diverted at disposal facilities in 2010, about $26 \%$ less than in 2008.

The inputs (energy, raw resources) and outputs (material, pollutants to air and water) required in remanufacturing/reprocessing, packaging, and distributing recycled materials are not always less than those associated with the production of virgin materials (Mcdonough and Braungart, 2002). For example, Goa et al (2001) determined that in Japan recycled drywall required 2.96 $\mathrm{MJ} / \mathrm{kg}$ more energy in its production than virgin drywall.

Conversely, Carpenter et al (2012) used life cycle assessment (LCA), which considers all lifetime environmental and human health impacts of a process, to determine that end-of-life management strategies that considered $83 \%$ recycling for suitable CRD wastes in the state of New Hampshire, U.S.A. produced less air and water emissions than if the wastes were 
landfilled. As well, Goa et al (2001) demonstrated that overall, substituting $58 \%$ of virgin building materials with recycled materials in a wood framed SDH in Japan had a total embodied energy savings of $9.7 \%$ or $28.3 \mathrm{GJ}$. Of the materials considered in the study, utilizing recycled exterior finishing materials, specifically aluminum components, had the biggest impact on reducing overall embodied energy of the studied SDH (Goa et al, 2001).

Promotion and education to the public most commonly highlights recycling as an ideal waste management strategy to reclaim material (NRCan, 2006; Kay and Essex, n.d.). This is further apparent in the literature as examples demonstrate the term recycling coupled with reuse or the terms used interchangeably implying that they are one in the same (Brunner, 2011; Yeheyis et al, 2011). Kay and Essex (n.d.) outlined that enthusiasm for recycling can be attributed to two main factors. First is the preference for demolition over deconstruction. Second is a lack of avenues to inform the public of the superior benefits of other waste management strategies (Kay and Essex, n.d.). For example, the Ontario Government's three R's (reduce-reuse-recycle) campaign suggests that reducing, reusing, and recycling waste have equal positive impacts to the environment, while the waste hierarchy clearly ranks the strategies demonstrating each has significantly different impacts (Environment Canada, 2003; Yeheyis et al, 2011).

\subsubsection{Reuse}

Reuse is the second to top tier of the waste hierarchy and is generally considered an environmentally benign waste management strategy.

There has been little technical work to provide more than anecdotal advocacy of the environmental benefits of reuse. Using LCA, O'Brien (2006) determined that the transportation distance of deconstruction employees and to reuse drop-off facilities had significant influence on total environmental and human health impacts of deconstruction and reuse. For military barracks in Florida, full or partial (about $44 \%$, by time) deconstruction was environmentally favourable to demolition when reclaimed materials, mostly wood, were reused within a $32 \mathrm{~km}$ radius of the obsolete building site (O'Brien, 2006).

Lifecycle assessment has been also utilized to quantify embodied impacts of reusing specific building materials. The Building Research Establishment (BRE) compared the environmental impacts of reusing steel and FL (timber studwork in Figure 8) to manufacturing virgin wood and steel in the United Kingdom (GreenSpec, 2012). Figure 8 demonstrates that reused wood studs 
had a significantly less potent impact as according to the environmental indicators considered in their research (GreenSpec, 2012).
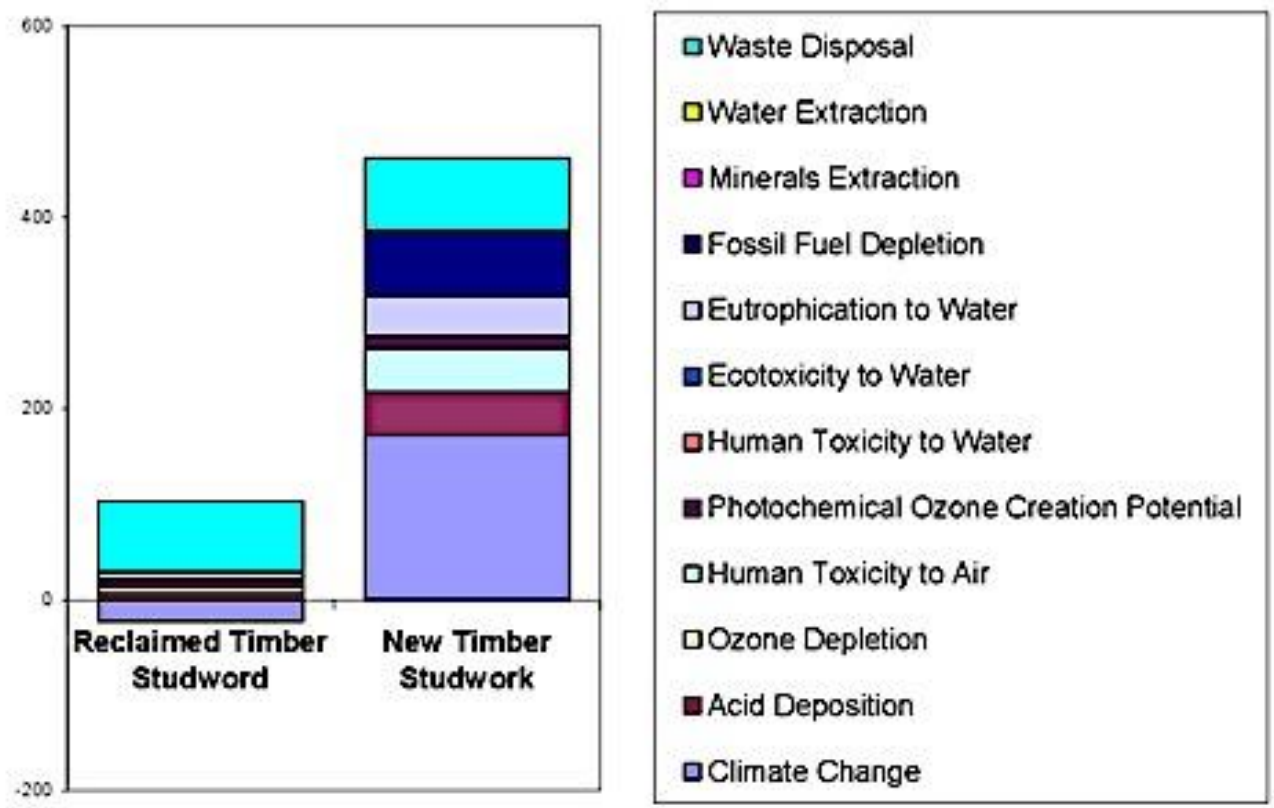

Figure 8. Environmental impacts of reusing wood from GreenSpec analysis, where the y-axis outlines relative environmental impact (GreenSpec, 2012).

A more relevant LCA was recently conducted by the United States Forest Service Research and Development research program in the U.S.A. The results were congruent with the results from the BRE study in that reusing wood products showed significantly less environmental impacts than producing and landfilling virgin wood products (Bergman et al, 2013; GreenSpec, 2012). Specifically Bergman et al (2013) determined that embodied primary energy (fossil fuel and biomass) consumption was 15 and 9 times less in reused FL and hardwood flooring, respectively, than in their virgin counterparts. Likewise, embodied $\mathrm{CO}_{2}$ emissions were about four times less in both reused products than in their virgin counterparts.

However, since such examples of LCA concerning material reuse are limited, literature attempting to quantitatively demonstrate the embodied impacts of reuse often presents data on the embodied impact saved by not producing virgin materials and do take into account additional impacts involved in material reuse. For example, Kay and Essex (n.d.) and Davila (2013) both used data from the University of Bath's Inventory of Carbon and Energy (ICE) on embodied impacts of virgin material production to determine $\mathrm{CO}_{2}$ and primary energy 
consumption equivalents of reusing building materials. Kay and Essex (n.d.) reported that in 2007 the reclamation and reuse of brick, steel, and lumber saved 188, 13, 159 thousand tons of $\mathrm{CO}_{2 \text { equivalent }}$ greenhouse gases in the United Kingdom. Davila (2013) determined that reusing 38x89mm studs from one SDH in Youngstown, U.S.A. was equivalent to $4.54 \mathrm{MJ} / \mathrm{m}^{3}$ of energy savings. Finally, Goa et al (2001) determined that reusing lumber in Japan resulted in an energy saving of $2.76 \mathrm{GJ} /$ ton based on the assumption that material reuse required no additional manufacturing energy.

Still literature concerning building material reuse is primarily limited to position papers, calling for more policy development, or instructional guidelines, discussing which materials can be reclaimed for reuse (e.g. Addis, 2006; Falk and Guy, 2007; Kernan 2002). From such literature it is clear that technical, historical, and cultural characteristics influence the reusability of a product or a material. Generally, as described by Addis (2006), reusability comes down to a material meeting all of the five criteria listed below:

1. Materials that can be recovered through demolition or deconstruction, can be transported, and can be stored.

2. Materials that are reliable. Reliability refers to the durability of a product and it's ability perform its intended function for the required lifetime. Reliability will be highly dependent on the secondary application for the material (Anityasari and Karbernick, 2008).

3. Materials that are inherently in demand by the construction market, or valued for their rareness. Material reuse generally is best suited for materials/products with slow changes in technology over time (Anityasari and Karbernick, 2008).

4. Available in quantities that consumers require.

5. Sufficiently restorable or refurbishable.

\subsubsection{Deconstruction}

Deconstruction requires more labour than demolition and case studies from The Reuse People, an American used building material organization (UBMO) demonstrates that it also can take 5 to 10 times longer based on the size and style of the SDH (personal communication, Ted Rieff). In fact, O'Brien (2006) determined that manual deconstruction reduced the speed of wood-framed building disassembly by an average of $2.27 \mathrm{~kg} / \mathrm{hour}$ in comparison to mechanical demolition. 
However as the deconstruction industry grows, more instructional literature is surfacing to optimize costs of deconstruction (Falk and Guy, 2007; Guy and Gibeau, 2003). For example, a number of sources suggest that costs can be optimized by mapping out reclaimable materials and incorporating elements of mechanical demolition for non-suitable materials (e.g. Falk, 1999; Falk and Guy, 2007; O'Brien, 2006). Nevertheless, case studies consolidated by Australia's Department of Environment, Climate Change and Water (2010) show that costs for deconstruction are dependent on building typology, materials, and surrounding infrastructure and in America it is usually twice as expensive for SDH (person communication, Ted Rieff). Because of relatively high labour costs in Canada, deconstruction is perceived to be an expensive, and therefore unattractive, alternative to quick and inexpensive demolition (Saotome, 2007).

\subsubsection{Reduce}

Reduce is not examined in this thesis. However the topic has a robust library of literature, as it is the most environmentally preferential waste management strategy of the hierarchy.

\subsection{Examples of CRD Reuse and Recycling}

Examples from European cities demonstrate that regulatory frameworks are powerful in increasing reclamation rates of CRD waste. Six European countries have met the European Waste Framework Directive and have demonstrated over 70\% reclamation (RCO, 2006; European Commision, 2011; Saotome, 2007). In particular, Estonia, Denmark, and the Netherlands reclaim $92 \%, 94 \%$, and $98 \%$ by weight of CRD wastes for reuse or recycling (European Commision, 2011).

The European Waste Framework Directive is the main policy driving the reduction of landfilling CRD waste in Europe. But both Denmark and the Netherlands achieved and continue to achieve high reclamation rates through their own initiatives driven by limited landfill space and increased difficulty importing raw material resources for construction (Hendricks and Jenssen, 2001; Malia, 2013). More so, both countries were relentless in enforcing initiatives to meet their goals and, thus, achieve them years before anticipated (Malia, 2013). Such initiatives include heavy taxation on non-recyclable materials, banning certain materials from landfills, making recycled products attractive to consumers, and imposing mandates for onsite material separation (MHSPE, 2001). 
Canadian specific examples illustrate that reclamation of CRD waste through reuse and recycling can be cost effective and significantly less detrimental to the environment than landfilling (Gorgolewski et al, 2006; RCO, 2006; NRCan, 2006). Using waste management action plans, 15 buildings demonstrating material or whole building reuse and material recycling in the GTA were able to save 2.5 million dollars and just over 1 million $\mathrm{kg}$ of $\mathrm{CO}_{\text {2equilvalent }}$ greenhouse gases (RCO, 2006). However, $\mathrm{CO}_{2 \text { equilvalent }}$ greenhouse gases savings determined from the case studies represented only equivalent emissions to virgin material production and did not consider the addition impacts of reuse (RCO, 2006). Although none of the case studies are of $\mathrm{SDH}$, they emphasize that the accumulated impacts of reuse and recycling can be significant.

\subsection{CRD Waste Regulations/Standards Pertaining to Toronto}

There is minimal regulation that addresses CRD waste relevant to Toronto. In an attempt to increase reclamation of CRD waste from landfill, the Province of Ontario developed the 3R's Regulations (102/94 and 103/94) in 1994 under the Environmental Protection Act. The goal of these regulations were to reduce waste going to landfill by $50 \%$ in buildings with a floor area of $186 \mathrm{~m}^{2}$ or greater by the year 2000 (Environment Canada, 2003). Specifically regulation 103/94 specifies that brick and concrete, drywall (unpainted), steel, and wood (untreated) from

demolished building must be recycled. However, both regulations were highly criticized for being poorly enforced by the government (Saotome, 2007). In 2000 it became apparent that the regulations were not effective and waste reduction goals set out by the province were not met (Saotome, 2007).

There are currently two guides produced by the Canadian Standards Association that deal with building deconstruction and adaptive reuse that are applicable to Toronto. These standards were written with guidance from steering committees comprised of various construction industry professionals, academics, and parties representing various materials associations within Canada. They are 'The Guideline For Design For Disassembly And Adaptability Of Buildings' published in 2006 and 'Deconstruction of Buildings and Their Related Parts' published in 2012.

\subsection{Urban Mining}

The importance of reclaiming materials from the built environment has also become more prominent in academic literature regarding urban mining. In a meta-analysis of current research in urban mining, Krook and Baas (2013) explained that it has varying definitions and 
applications. Although it is clear that the majority of literature focuses on mining metal materials from obsolete urban reservoirs (Cossu et al, 2012).

Even so, the urban mining concept has been somewhat integrated with CRD waste (Davila, 2013). In this case, obsolete buildings act as a sort of structured waste deposit within the city (Krook and Baas, 2013). Most literature on urban mining focuses on reclaiming materials for recycling or is not Canadian specific (Brunner, 2011). Nevertheless, Davila (2013) successfully applied the concept to building material reuse in an urban context.

Brunner (2011) explains that to effectively design the infrastructure to facilitate urban mining, it is necessary to understand, first, the location of materials, and second, in what form, state, and assembly they are used in. By measuring and mapping out construction drawings from historic house pattern catalogues, Davila (2013) was able to successful determine the reusable materials in a neighbourhood of Youngstown, Ohio. Although no complimentary research has been conducted at the city scale, it is apparent that research to quantify material stocks and flows is critical in transitioning the concept of urban mining into a practical tool for increasing urban resource efficiency.

\subsection{Urban Metabolism}

Cities are an important unit for research as they are home to just over $50 \%$ of the world's population (UNDE and SAPD, 2013). The underlying ideology of urban metabolism is that when cities mimic how ecosystems acquire, consume, and cycle resources they are more environmentally and socio-economically sustainable (Broto et al, 2012). Since its inception in 1965 by Wolman, more than 70 studies of urban metabolism have been conducted for cities all over the world. A review by Kennedy et al (2011) of 20 comprehensive urban metabolism studies (including the City of Toronto) indicated that contemporary cities have become increasingly material intensive in the past few decades (Kennedy et al, 2007).

Construction materials are considered an important measurable in urban metabolism research because they are essential to the physical fabric of a city (Kennedy and Hoornweg, 2012). Of the four urban metabolism metrics, the intensity of annual construction material flows tends to fall in-between other resources (lower than water, higher than food) (Brunner, 2007). However, there is sufficient international data to demonstrate that raw resources for construction materials are becoming more difficult to access and distant to urban centres, increasing the detrimental 
embodied impacts associated with urban material consumption (ISWA, 2011; Kennedy et al, 2007).

At the same time, building material flows are difficult to accurately quantify because of inconsistent data (Kennedy et al, 2007). Two of the most successful studies of building material flows include metabolic studies of Hong Kong and Vienna (Warren-Rhodes and Koenig, 2001; Hendricks et al, 2000). In both cases periodical data related to construction material input was available from government sources (Warren-Rhodes and Koenig, 2001; Hendricks et al, 2000). As well, these studies focus on the flows into and out of the system but do not look in detail at the stock of materials in the system at any time. In the case for Hong Kong, between 1971 and 1997 cement and wood inputs grew by over $250 \%$ and $100 \%$ respectively, while the population only grew by $78 \%$.

In the context of Toronto, one MFA study examined energy flow for the city in 1988 and the results are shown in Figure 9 in a Sankey diagram (ICLEI, 1997). In conjunction with energy flows, a second relevant study conducted by Bristow and Kennedy (2013) attempted to quantify energy stocks in Toronto. As well, Codoban and Kennedy (2008) examined water, food, electricity and natural gas flows in four City of Toronto neighbourhoods. These three studies did not include analysis of building materials.

One MFA study considering the City of Toronto, by Sahely et al (2003), did include building material flows, but did not attempt to quantify stocks. As well, Sahely et al (2003) determined metabolic activity for the Greater Toronto Area. Thus, the construction data used was vague and included only material inputs and outputs (Sahely et al, 2003). The study only considered lumber and concrete, using statistics on historical housing starts in conjunction with American data of average FL used in more recent residential construction (Sahely et al, 2003).

Nevertheless, these Toronto urban metabolism studies were critical in demonstrating the positive impacts of recycling, as household waste outputs decreased overtime because of the blue bin (household recycling) program initiated in 1994 (Sahely et al, 2003). Generally urban metabolism studies demonstrate that alternative waste management practices promote cyclical material flows and therefore reduce flow intensities (and increase resource efficiency), while landfilling promotes linear metabolic flow and facilitates the necessity for greater raw resource inputs (Kennedy et al, 2011). 
METROPOLITAN TORONTO

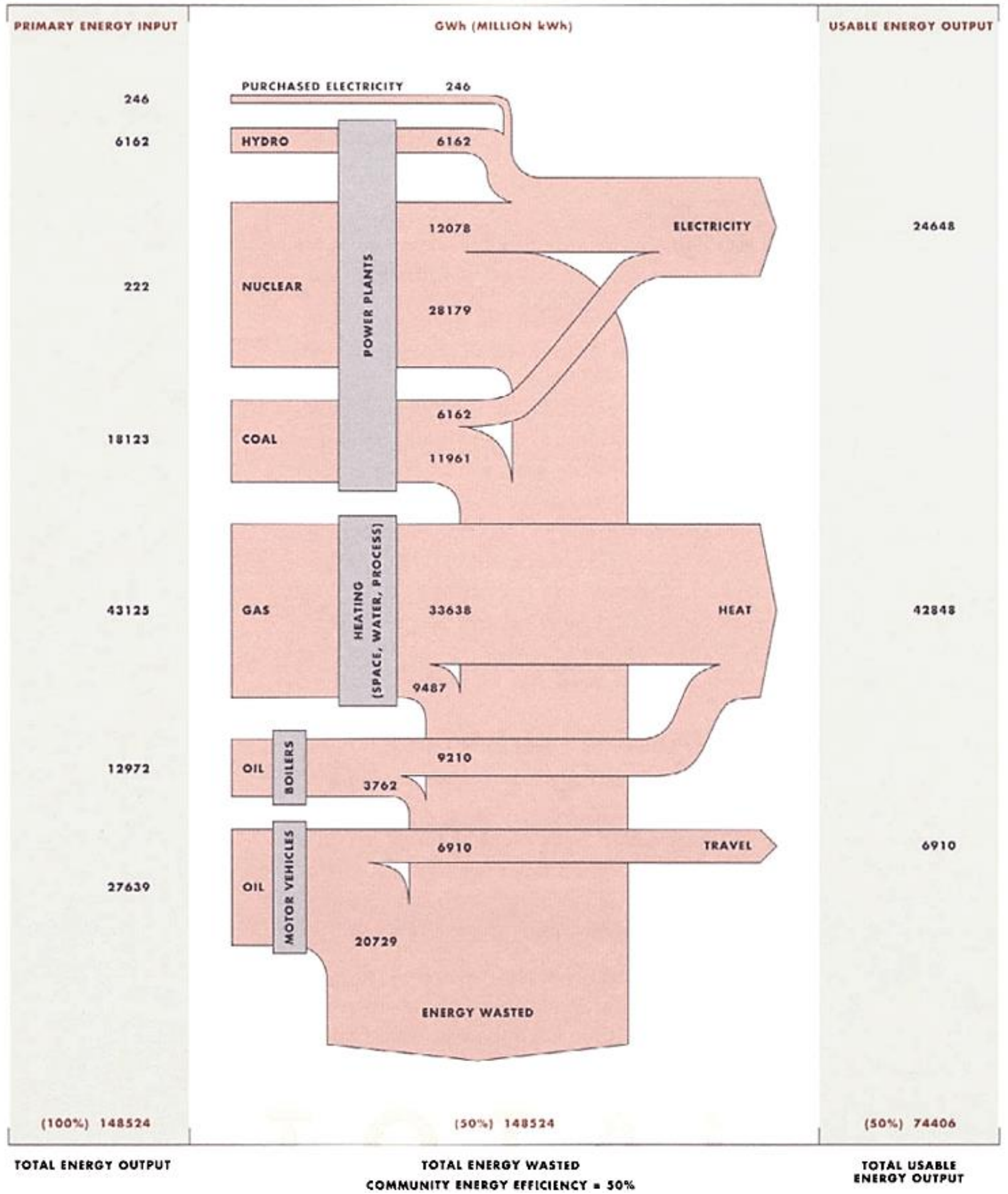

Figure 9. Sankey diagram of Toronto energy flows in 1988 (ICLEI, 1997). 
It is apparent from the literature that the concepts of urban mining, urban metabolism, and waste management are interrelated. Each subject approaches the issue of obsolete material stocks in the built environment (e.g. Davilia, 2013; Kennedy et al, 2007; RCO, 2006). Waste management and urban metabolism research tends to best define the issue, demonstrating that by sequestering large amounts of materials in landfills an unsustainable linear metabolism is propagated, creating stress of void landfill space and embodied impacts associated with virgin material production (Cossu et al, 2012). While waste management literature approaches the issue mostly at provincial and national scales in Canada, urban metabolism attempts to localize the issue to the city scale (Odum, 1997).

As well, urban metabolism research takes it a step further by quantifying in-use material stocks and facilitates proactive policy development to actualize urban mining (Brunner, 2011; Hendricks et al, 2000; Kennedy et al, 2011). At the same time, the waste hierarchy justifies urban mining from an environmental perspective and outlines that reuse, more so than recycling, is a sustainable management approach to creating closed loop urban material pathways.

\subsection{Material Stocks}

Literature related to waste management also has used material inventories to highlight the built environment as a source of future materials, therefore reducing the embodied impacts associated with virgin material production (Falk, 1999). However no North American literature examines material stocks at the urban scale. Instead, there are plenty of examples of building scale material stock inventories (e.g. Cavalline and Weggel, 2013; Falk and Guy, 2007). For instance, during the deconstruction process of a building or small group of buildings, it is very common to inventory materials suitable for reuse. Professionals survey building materials to determine which materials should be reclaimed through deconstruction (Falk and Guy, 2007; Guy and Nicholas, 2011). In these cases, materials are typically evaluated based on the judgement of the surveyor with the ultimate goal of balancing the additional costs of deconstruction with resale or tax exemption of the reclaimed materials (US EPA, 2008).

Only one example of a large-scale in-use building material stock inventory could be found in a North American context. Falk (1999) used lumber production and SDH construction and demolition data to estimate that 2.2 million $\mathrm{m}^{3}$ of wood is available from obsolete SDH annually in the U.S.A. However his estimate is based on very general data and does not outline the types 
and forms that lumber products would be available (Falk, 1999). Although it does provide some context for material recovery at a larger scale, more detailed information about material form and use would provide important information for reuse and recycling policy development (Falk, 1999; Brunner, 2011). 


\section{Methodology}

\subsection{Research Process}

Figure 10 outlines an overview of the process utilized to address the research objectives as well as the main outputs of the objectives. The research objectives were approached with a multistep methodology, where outputs of each step (demonstrated as the nodes in Figure 10) contribute to the inputs of the following research step. A more detailed description of the methods used to address each objective is presented in the following chapter.

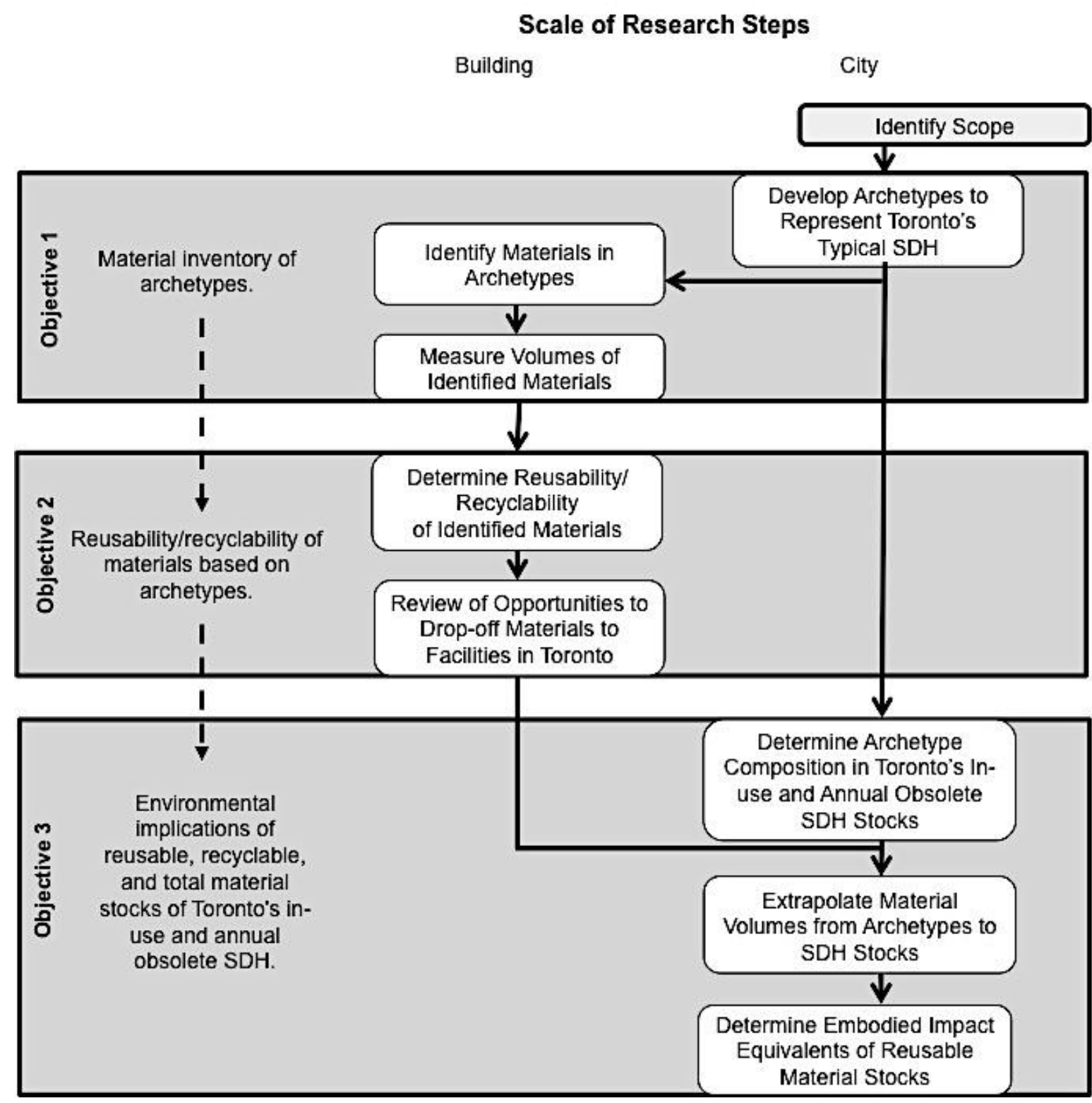

Figure 10. Summary of research process by overall objective outputs (left) and steps taken to reach overall outputs (right, as nodes). 
An archetypal analysis approach was utilized to filter out SDH construction styles that best represent Toronto's SDH stock. Figure 10 demonstrates that utilizing archetypes reduced the scale of the study to individual buildings. At the building scale, materials were effectively identified, quantified, and analyzed for reusability/recyclability. From there, appropriate housing data from the City of Toronto was used to extrapolate material results back to the city scale. From there environmental indicators of embodied impacts and void landfill space were determined for the appropriate city scale stocks.

\subsection{Methods for Addressing Objective One}

To address the first objective and identify and quantify materials in buildings that represent Toronto's typical SDH stock, it was first necessary to discern the typical characteristics of the stock. With the time and resources available, the most effective method to do this was to develop several archetype houses to represent the greater SDH stock.

Archetype development is an appropriate research method to address the objectives of this thesis because they facilitate analyses of heterogeneous data sets that are difficult to measure, such as Toronto's SDH stock (Culter and Breinman, 1994). Generally, archetypes are developed by identifying underlying common, or defining, traits within the data set and using those traits to create a representative figure (Culter and Breinman, 1994). Each archetype reflects all individuals of the data set, or subset, as equally as possible and therefore can be analyzed to draw conclusions on the larger, mixed data set (Culter and Breinman, 1994). This research approach is utilized by various disciplines, including similar studies on urban housing (Culter and Breinman, 1994). For example, Blaszak (2010) developed archetypes of Toronto's heterogeneous SDH stock to analyze operational energy loss and develop recommendations for effective retrofitting.

\subsubsection{Developing Archetypes}

Comprehensive data of SDH construction in the City of Toronto does not exist. Instead, a review of Toronto's SDH stock unveiled patterns and trends in construction throughout history. Blaszak (2010) used a similar method to develop archetypes for SDH in the boundaries of the City of Toronto before its amalgamation in 1998. Blaszak's (2010) research presents an extensive history of Toronto's housing, which was utilized as the starting point for developing archetypes in this thesis. 
To adapt the archetypes developed by Blaszak (2010), an extensive literature review of relevant housing history was conducted and supplemented with some limited on-site observation of SDH demolition in Toronto. Overall, the literature suggested that the design of and materials used in SDH housing were often correlated to external factors such as political ideals, socio-economic conditions, resource availability, building codes, and demographics of the time they were built (e.g. CMHC, 1985; Rubin, 1979; Tomalty, 1997).

Key literature included publications from the Canadian Mortgage and Housing Corporation (CMHC) (eg. CHMC, 2000; CMHC, 2006). CMHC began as a crown corporation and is now Canada's largest and most reputable agency of housing mortgages and statistics. As well, $\mathrm{CMHC}$ publishes extensive literature on housing (from homeowner guides to construction trends).

Based mostly on the literature review, five distinctive house types were found to represent the vast majority of Toronto's current typical SDH stock and were the basis for each archetype: Century, Wartime, Baby Boomer, Ontario Building Code (OBC), and Modern. For each archetype, elevations and floor plan drawings were found, from which material could be identified and their volume's measured.

There is an implicit margin of error in using archetype drawings to identify and measure materials. In reality, variations occur for many reasons including liberties taken by contractors or last-minute adjustments to designs that aren't outlined in drawings. As well, changes or upgrades in the building over its life are not represented in drawings. However, for the purposes of identifying and quantifying materials in the envelope and interior partitions of a building, drawings were extremely useful. First drawings provided insight into the interior layers of building envelopes that could not be accessed in SDH without causing serious damage. Second construction drawings could be easily adapted to take into account trends identified in the literature and on-site observations of SDH demolitions.

Alternatively, obtaining data directly from houses was considered. For this method, materials would have been identified and quantified on-site of a house either during a major renovation or demolition. However, it was not feasible to get access to SDH that fit the archetypes and take the necessary time to safely and accurately obtain data. Instead, some limited observation of SDH demolition was carried out to supplement the literature and drawings. 
Where there were gaps or missing pertinent details in the drawings, additional literature was consulted and the results were added to the missing components of the drawings. As well, material specifications, geometry, and dimensions of the drawings were all compared to the information of typical construction practices. Comparing the details of the drawing to the literature was critical in verifying the accuracy of each drawing as a correct representation of each archetype.

The drawings were selected on availability and likeness to the house type descriptions. Useful drawings were to scale and included floor plans and/or elevations and, in some cases, envelope assemblies. Examples of the construction drawings for each archetype are available in Appendix A. The example drawings in Appendix A include exterior elevations, above ground floor plans, and a wall section for most of the archetypes and are described as either original construction or adapted drawings based on the descriptions below.

\subsubsection{Century Archetype (Pre 1930)}

The first archetype is based on literature indicating that SDH construction methods were relatively consistent before 1930 in Toronto (City of Toronto, 2013b). After the city's first great fire in 1849, regulations were put into place to decrease the use of wood in construction (City of Toronto, 2013b). At the same time, clay and shale were abundant and regionally available resources (CMHC, 2002). Thus, the majority of remaining SDH from this time have double wythe, load bearing, clay brick exteriors (CMHC, 2002). Throughout this thesis bricks that are made with clay or shale are referred to as clay bricks.

However wood was still abundantly used in semi-structural applications such as in the interior partitions, flooring, roofing, sheathing, lath, and to a lesser extent as cladding. At the time, FL used for wall studs, rafters, and joists were typically cut $51 \mathrm{~mm}$ wide (FPL, 1964). There were no overarching regulating standards for wood dimensions and FL dimensions varied slightly from region to region (FPL, 1964). As well wood was mostly surfaced by hand, making the thicknesses of sheathing and flooring thicker than in all the other archetypes (personal communication, American Lumber Standards Committee). 


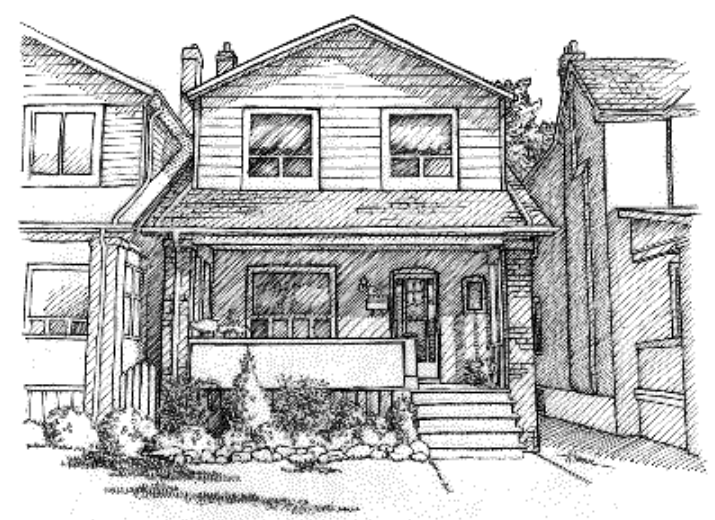

Figure 11. Sketch of Century house type in Toronto (CMaple Tree Publishing, 2013).

In analogous literature, houses from this time period are identified as century houses, as a significant proportion of them are more than 100 years old. Century houses are considered the first example of a widespread housing style in North America (CMHC, 2003). Today, these houses sit on narrow, deep urban lots and are rectangular two story buildings (with an underground crawl space) with short ends facing the street, as seen in Figure 11 (CMHC, 2003). Because of their age, most of these houses have had minor to major renovation, including renovated attics (CMHC, 2003). However, although styling and finishing elements can differ significantly between the houses, the core elements generally remain congruent (CMHC, 2003).

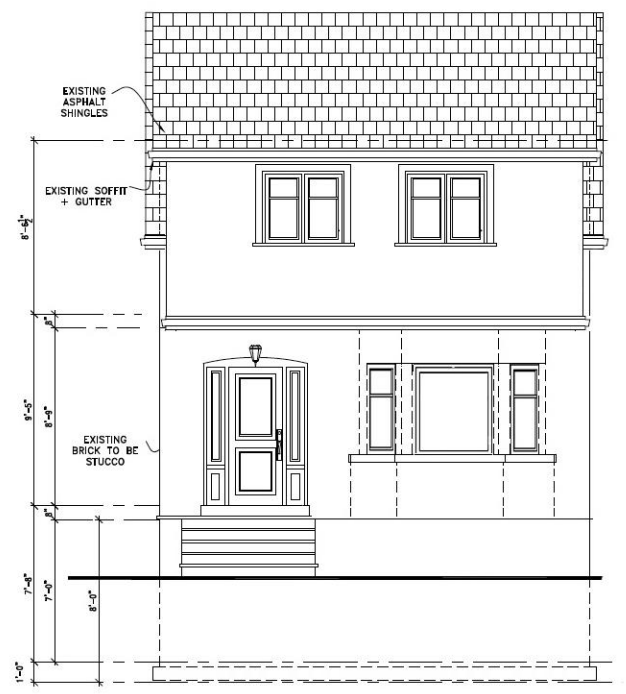

Figure 12. Front elevation of Century archetype (personal communication, homeowners). 
The archetype Century house was based off of construction drawings of a Toronto house built in the 1920 s with a usable floor area of $116 \mathrm{~m}^{2}$. The house was chosen because it matched the physical characteristics identified for the Century house type (two story, load bearing brick exterior, crawl space, etc.) and the homeowners had access to elevation and floor plan drawings, which were originally created for a renovation to the original house.

The drawings in Appendix A, Figure 53 demonstrate the original components of the house as identified by the construction drawings as well as adapted floor plans. Although floor plan drawings were available in the construction drawings, they were slightly adapted to align with the interior layouts shown in the CMHC (2003) publication 'Renovating Distinctive Homes: The Century House'.

\subsubsection{Wartime Archetype (1931-1960)}

After the Second World War, Toronto saw an influx of similarly designed houses that are the basis for the second archetype. To address massive housing shortages for industry workers, housing developments were propagated en-mass throughout the 1940 s and ' 50 s by the Canadian crown corporation, Wartime Housing Limited (CMHC, 2006).

In 1947 Wartime Housing Limited ended and became the CMHC who continued to design these small, efficient SDH (CMHC, 2006). CMHC published more than 15 pattern books that contained small SDH designs from Canadian architects (Teodorescu, 2012). The houses in these books were popular to both homeowners and developers and commonly built throughout the '40s, '50s, and early '60s (CMHC, 2000). Since these houses were first inspired by the impacts of the Second World War on industry, they are called Wartime in this thesis.

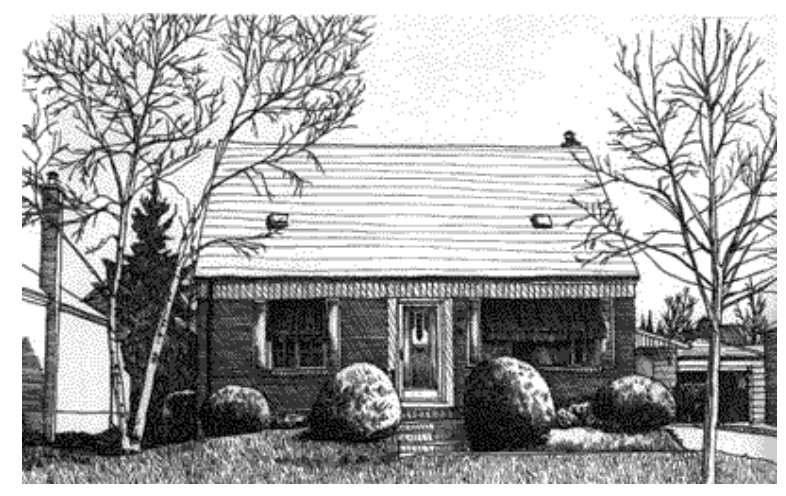

Figure 13. Sketch of Wartime house type in Toronto (@Maple Tree Publishing, 2013). 
The houses reflected the government's egalitarian principals and were designed to be cost effective and time efficient to build (Teodorescu, 2012). Figure 13 shows that distinguishing features include their small size and minimal use of resources. Ultimately, these house were successful because they had simple adaptable interior layouts to fit changing needs over the decades (CMHC, 2000). They were built near industry, on the periphery of the city, where land was abundant and each house was situated on a spacious lot. This era of SDH construction is often referred to as the beginning of suburban development in Toronto.

Because of the increased demand for wood products during this time, recommendations throughout the U.S.A. were established to reduce the size of FL and sheathing (FPL, 1965). As well, the intricate relationship between the Canadian and U.S.A lumber industries forced Canada to follow suit with the same standardized wood dimensions, which were reduced by an average of $9.5 \mathrm{~mm}$ from the previous era (FPL, 1965).

Even so, concrete and clay bricks and cinder blocks were popularly used for structural components. Like the previous era, double wythe bricks were used primarily as above grade load bearing elements. However the inner layer, and in some cases the outer layer as well, was replaced with cheaper to produce concrete bricks. Cinder blocks, which are also concrete, were used as basement walls.

The archetype Wartime house was based on construction drawings of a one and half $\left(1 \frac{1}{2}\right)$ storey house with a usable floor area of $102 \mathrm{~m}^{2}$, designed by Toronto-based architect Henri Fliess in 1954 for CMHC. Of the house designs that prevailed from the wartime and post-war decades, 11/2 storey houses published in $\mathrm{CMHC}$ catalogues were the most popular (CMHC, 2000). Between the years of 1945 and 1960, 100 thousand $11 / 2$ storey houses were built in Ontario, a good portion in fast growing urban areas such as Toronto (CMHC, 2000). 
Henri Fliess is a well-known Toronto architect who designed 15 house types for CMHC for the Toronto's Don Mills community (Teodorescu, 2012). In that area of the city, about 300 to 500 of Fliess' houses were built between 1940 and 1960 (LeBlanc 2006). Fliess' drawings used in this thesis was obtained directly from the $\mathrm{CMHC}$ and included exterior elevations, floor plans, and wall sections (Appendix A, Figure 54).

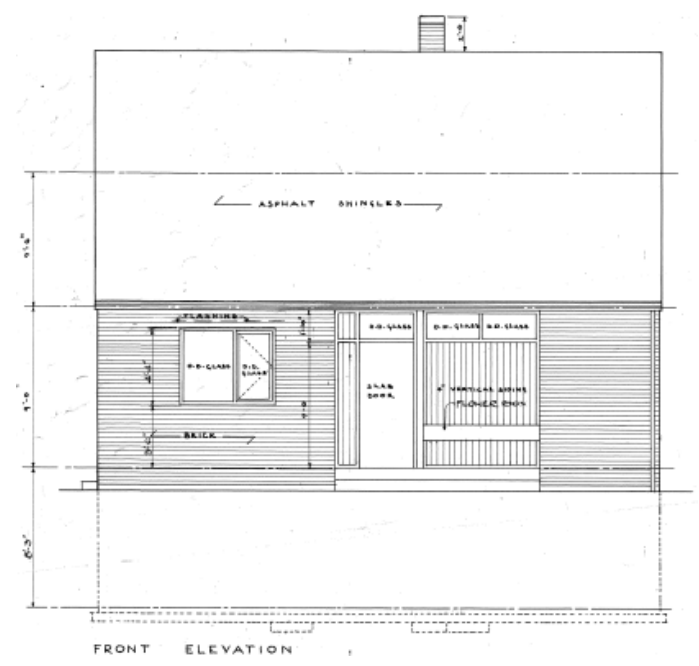

Figure 14. Front elevation of Wartime archetype (personal communication, $\mathrm{CMHC}$ ).

\subsubsection{Baby Boomer Archetype (1961-1975)}

The third archetype was based on SDH with large footprints built in the 1960s and early '70s, shown in Figure 15. The 1960's had unprecedented growth of residential construction; baby boomers were reaching the age of buying their own family houses (CMHC, 1985). Canadian families were more affluent than the preceding decades and desired larger houses (CMHC, 1985). At the same time, rapid population growth in Toronto incited increased density and property sizes began to shrink (CMHC, 1985; CUCS, 1979). 


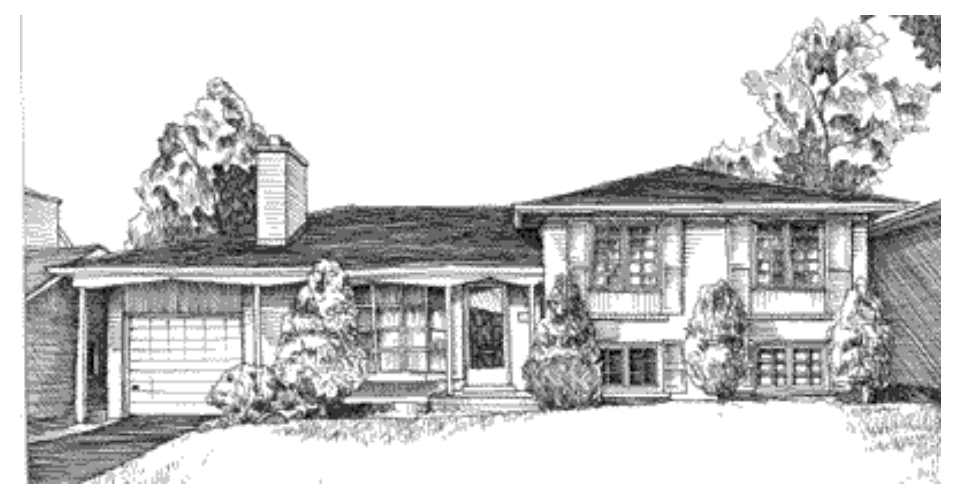

Figure 15. Sketch of Baby Boomer house type in Toronto (@Maple Tree Publishing, 2013).

These houses often had simple rectangular plans with the large side of the house facing the street and were usually located in suburban areas of the city (CMHC, 2002). Inside, floor plans were open including, a common area for dining, cooking, and living (CMHC, 2002). Usable floor area grew from 1960 to 1975 , starting at $111 \mathrm{~m}^{2}$ and reaching $153 \mathrm{~m}^{2}$ by the mid 70 s (CMHC, 2002; US Census Bureau, 2012).

Like the previous era, most of the structural components relied of double wythe concrete and clay bricks as load bearing elements. At the same time, CIP concrete began to replace cinder blocks as the structural component of the basement walls. Other significant changes from the previous era include the emergence of engineered wood products for sheathing and subflooring, the gradual introduction of double pane windows, and carpet as a floor finishing (CMHC, 2002; CMHC, 2006). As well, unlike the previous eras, which used lime (until the 1900's) or gypsum plaster on lath, drywall became the preferred interior-finishing product for walls throughout the 60's (CMHC, 2002). 


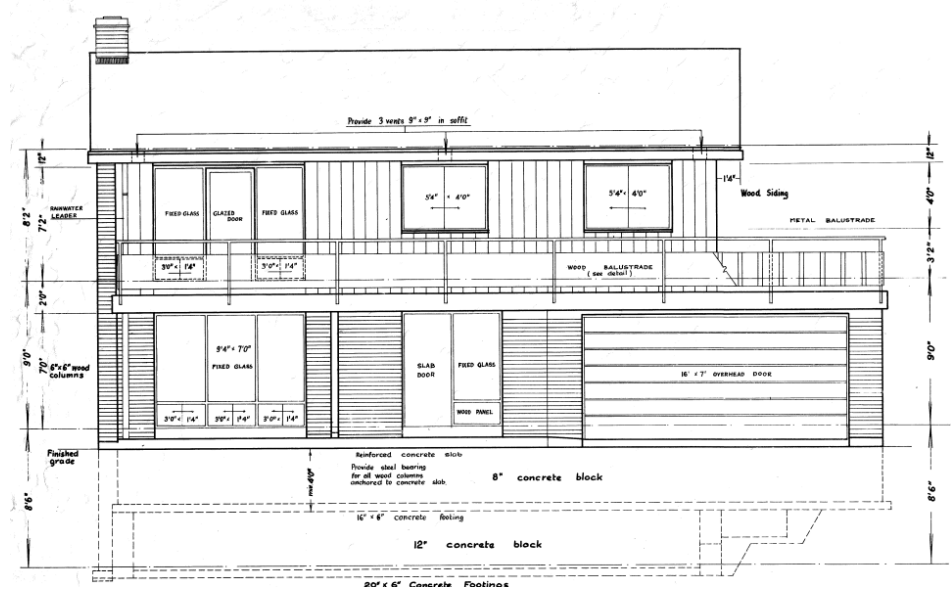

Figure 16. Front elevation of Baby Boomer archetype house as seen on construction drawings (personal communication, $\mathrm{CMHC}$ ).

The Baby Boomer archetype was based on $\mathrm{CMHC}$ construction drawings of a house by architect Ralph Goldman with a usable floor area of $128 \mathrm{~m}^{2}$ from 1964. The chosen construction drawings were of a two-story house with a rectangular footprint and examples of them can be seen in Appendix A, Figure 55. The drawings were obtained directly from the CMHC and include elevations, floor plans, and multiple wall sections. Unlike the drawings used for the Wartime archetype, also provided by CMHC, it is not clear where Goldman's design was built in Canada. Nevertheless, the size, shape, and material specifications aligned with the literature and on-site observations and so, the drawings were determined to be appropriate to use for material identification and volume measurements.

At the same time, two key modifications were made to the $\mathrm{CMHC}$ construction drawings based on the literature. First, the basement was modified to be not finished. Including a finished basement would have made the total usable floor area much larger than average for the time and therefore, the basement was considered as to have no wall and flooring finishes. Second, since balconies were not included in the scope of the study, one sliding door on the second floor was removed and replaced with a window that matched others on the same wall in the drawings. 


\subsubsection{Ontario Building Code (OBC) Archetype (1976-2000)}

The fourth archetype was based on the influence of the establishment of the Ontario Building Code (OBC) in 1975 on housing styles. The OBC acted, and still acts, as a compressive guideline for house builders (CMHC, 2006). The early stages of the code focused most on providing rules to ensure homeowner health and safety (CMHC, 2006). At the same time, the energy crisis in the 1970's began to peak interest in reducing operating energy demands by increasing the thermal resistance of envelope assemblies (CMHC, 2006).

Another key change demonstrated through this era was the common use of platform wood framing for the majority of above grade load bearing elements. In 1970 the American Lumber Standards Committee established standards to further reduce lumber dimensions by $3.2 \mathrm{~mm}$ (personal communication, American Lumber Standards Committee). Although standardized reductions vary slightly based on lumber dimensions.

The population in Toronto decreased throughout the late 1980s and early ' 90 s as residents emigrated to the growing suburban communities surrounding the city (Tomalty, 1997). Reflecting this phenomenon, housing construction at this time in Toronto occurred on the periphery closest to the neighbouring suburban areas (City of Toronto, 2003). As well, house styles reflected the track housing being built en-mass in neighbouring suburbs. House sizes continued to grow, mimicking the prospering economy of the 1980s and lot sizes became increasingly, and disproportionately, smaller (CMHC, 1985).

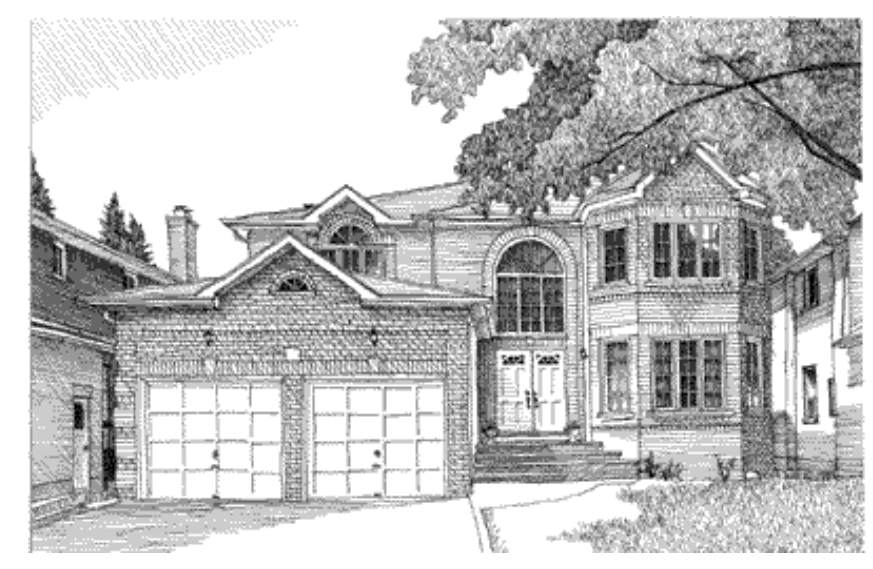

Figure 17. Sketch of OBC house type in Toronto (@Maple Tree Publishing, 2013). 
Houses were large, two storey, and included space for car parking, as seen in Figure 17. As well, these homes embraced composite, engineered, and manufactured products such as carpeting, manufactured trusses, and plywood (CMHC, 2002). CMHC (2002) explains, "by the end of the " 70 s the standard Canadian frame house had made the transition from the site-built crafted product to site-assembled, engineered product."

The archetype OBC house was based on construction drawings of the CCHT research houses with a usable floor area of $173 \mathrm{~m}^{2}$ built in 1998 (Figure 18) (Government of Canada, 2013). The two identical research houses were built to represent mass track housing in Southern Ontario and were built in partnership from the CMHC, NRCan, and NRC (Government of Canada, 2013). Thus, although the houses were built in Ottawa, they were designed to represent the average construction practices of areas including the City of Toronto (Government of Canada, 2013). As well, the geometry of the houses were congruent with observations and Toronto relevant literature of $\mathrm{OBC}$ house types. The drawings were obtained by Ryerson University from NRCan and $\mathrm{CMHC}$. The drawings were very comprehensive with to-scale floor plans, exterior elevations, and wall sections, as shown by the examples in Appendix A, Figure 56.

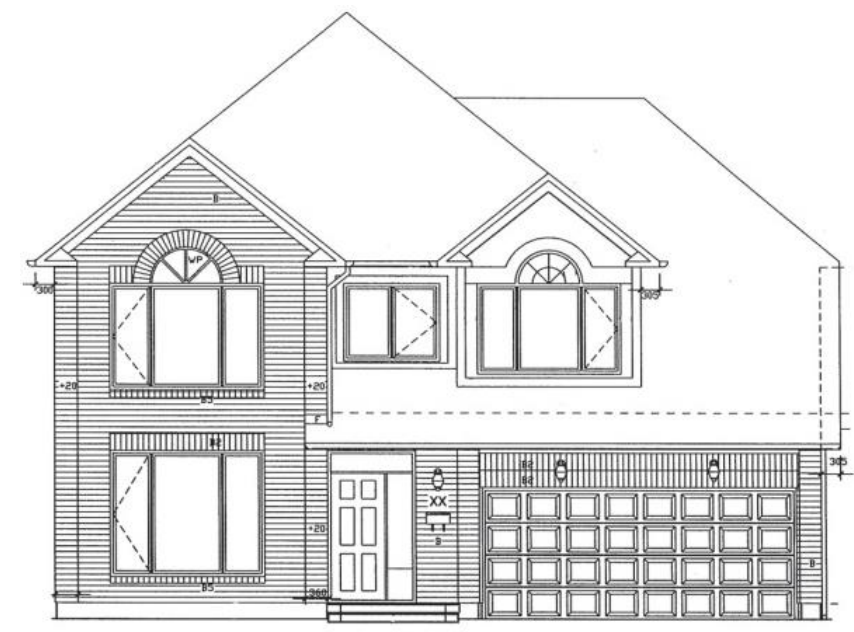

Figure 18. Front elevation of CCHT (NRCan and CHMC, 1998).

To make the drawings more relevant to the $\mathrm{OBC}$ time period, several adaptations were made to materials to make them more congruent with the 1990 OBC, when the average SDH useable floor area was $193 \mathrm{~m}^{2}$ (with an unfinished basement) (US Census Bureau, 2012). Under section 9 , the 1990 OBC outlines minimum allowable material dimensions and qualities for housing 
construction. Thus these values were assumed to be the material dimensions and qualities in the OBC house.

Other key adaptations to the drawings included changes to non-load bearing studs, load bearing studs, and basement finishes. While the drawings specified metal studs for non-load bearing elements, it was assumed that $38 \times 89 \mathrm{~mm}$ wood studs were used, because it is likely that wisespread use of metal studs is more common to housing styles in the 21 st Century. Changes were also made to the dimensions of the load bearing wood studs, which in the drawings suggest they are $38 \times 140 \mathrm{~mm}$ but were modified to be $38 \times 89 \mathrm{~mm}$. Finally, it was assumed that the basement was unfinished to ensure that the usable floor area was more closely aligned with typical usable floor areas of the time.

\subsubsection{Modern House Archetype (2001-2012)}

The last identified house type reflects growing concerns for environment and energy conservation in the $21^{\text {st }}$ century. This archetype also meets $\mathrm{OBC}$ requirements but with more emphasis on reducing operational energy consumption (Province of Ontario, 2012). Although awareness of environmental and energy conservation was emerging throughout the 1990s as well, that decade was not included in the Modern archetype (CMHC, 2006). Mainly, it was more advantageous to base the Modern archetype on the most recent construction practices to present some insight into the direction of future housing.

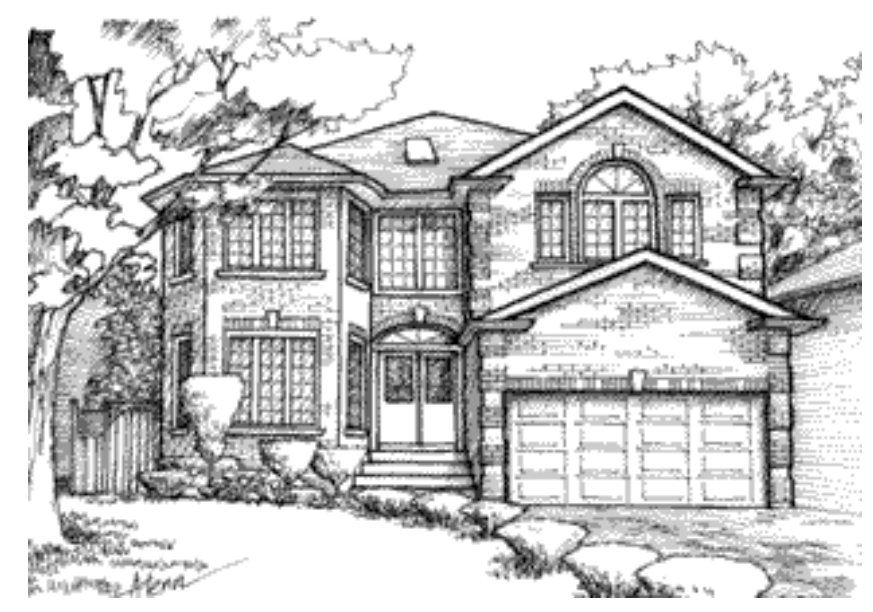

Figure 19. Sketch of Modern house type in Toronto (@Maple Tree Publishing, 2013). 
As well, the literature suggested that codes and standards in the $21^{\text {st }}$ century more aggressively enforced reducing energy consumption than in the '90s (CMHC, 2006). The Modern archetype is much like the houses of the OBC house in look, Figure 19. Of the material components considered in this research, the primary differentiating feature of the Modern archetype is that the envelope is designed to increase thermal resistance. For example, the Modern archetype sets highest-to-date insulation R-values and lowest-to-date window U-values standards. But similar to the previous decades, the houses tend to be large, with two stories and space for parking.

The Modern archetype was also based on construction drawings of the $\mathrm{CCHT}$ research houses built in 1998 (Figure 18). As houses constructed in the $21^{\text {st }}$ century were found to generally include a finished basement, the $\mathrm{CCHT}$ drawings were used more exactly with a usable floor area was $262 \mathrm{~m}^{2}$. Likewise the average usable floor area of SDH built in 2012 based on City of Toronto building permits was much higher, about $300 \mathrm{~m}^{2}$ (City of Toronto Open Data, 2013). However the 2012 average may be inflated because it considers permits for non-typical SDH construction, such as a SDH with a useable floor area of $1340 \mathrm{~m}^{2}$.

Although, the build date of the $\mathrm{CCHT}$ houses was two years prior to the time period considered for the Modern archetype, the CCHT houses were built to meet the envelope standards of R2000 in 1998. As such, the envelope requirements of R2000 in 1998 are more closely in line with the requirements of the 2006 OBC than OBC versions throughout the 1990s (Province of Ontario, 2012). Thus, the thermal resistance of windows, doors, and insulation of the CCHT houses are more likely congruent with houses built in the $21^{\text {st }}$ Century. The drawings therefore did not need any additional modifications.

\subsubsection{Material Identification}

Materials were identified based on the specifications in construction drawings, commonalities found in the literature review, and observations from limited SDH demolitions in Toronto. Over 15 additional construction drawings and material specifications that fit the general look and dimensions of the archetypes were consulted as well. Additional drawings were obtained from various sources including the Toronto Archives, $\mathrm{CMHC}$, homeowners, and architecture magazines such as Ontario Homes and Living and Canadian Homes and Gardens. 


\subsubsection{Material Volumes}

Digitized PDF copies of original and adapted construction drawings were imported and measured with Bluebeam $\AA$ Revu $\AA$ software. Bluebeam $\AA$ Revu $\AA$ is an advanced PDF editor and mark-up software, used by some industry to measure building material volumes for LCA. The software allowed for measurement of material dimensions or areas with a calibrated ruler tool. The drawings were first measured in their original units, as houses built before 1970 used imperial units. The final material volumes were calculated for each house and converted to metric units $\left(\mathrm{m}^{3}\right)$.

The results of the material volumes greatly depended on the accuracy of the measurement tools in Bluebeam ${ }^{\circledR}$ Revu ${ }^{\circledR}$ software. When calibrating the measurement tool, two points that had measurements on the drawings were selected and the measurements were inputted into the software. In the case for the Century house, the digitized drawings had points that the software could snap to, making measurement results likely the most consistent for that archetype.

In some cases, specific information on material dimensions could not be sourced from construction drawings. As such, literature was consulted to discern common dimensions. For instance, the thickness of subflooring was not outlined in the construction drawings, whereas the surface area was measured on floor plans. Literature demonstrated that subflooring had relatively standard thicknesses (according to the era in which it was installed) and the appropriate thicknesses were utilized for determining material volumes. Dimensions and assumptions for the respective archetypes are outlined in Appendix B.

\subsection{Methods for Addressing Objective Two}

Once an inventory of materials in the archetype houses was established, each material was evaluated to determine whether it could be reclaimed for reuse and/or recycling. The reusability/recyclability of a material was first examined in a general context based on its common characteristics when used in SDH construction. Then opportunities to drop-off materials to reuse/recycling facilities in the GTA were also determined.

\subsubsection{Reusability/ Recyclability Material Analysis}

To explore the suitability of each material for reuse/recycling, materials were evaluated with criteria adapted from Addis (2006). The importance of the criteria, listed below, in determining 
reusability/recyclability of a material is supported by complementary research (e.g. Cooper and Allwood, 2012; Gorgolewski et al). Although the criteria were originally developed by Addis (2006) to determine the reusability of materials, their themes were found to be relevant to recycling. Thus the criteria were slightly adapted to include recycling and are:

1. Materials that can be recovered from a building in a useful condition.

2. Materials with a remaining useful life.

3. Secondary products have demand in the market.

4. Secondary products are available in quantities that consumers require.

5. Technology is available to restore, refurbish, or recycle materials.

Over 60 sources of literature were consulted to generate the results of the material analysis. The literature included academic research, industry association reports, deconstruction reference guides, and relevant standards. The focus of the review was of literature relevant to the City of Toronto or Province of Ontario. However, because there were significant gaps in regionally relevant literature, sources from the international community were also consulted and used to draw comparisons between best/innovative practices and current practices in Toronto.

\subsubsection{Criteria 1 - Recoverability}

To address the first criteria, the issues involved with material disassembly from the archetypes that directly influence reusability and/or recyclability were outlined. Materials considered recoverable for reuse were those that could be disassembled whole, intact, or with reparable damage. For example, discussing the issues of mechanical hardware versus chemical adhesives and how they impact the damage to the material when recovered from adjacent materials.

\subsubsection{Criteria 2 - Durability}

To address the second criteria, the useful life of the identified materials was compared against the average life of a SDH based on literature on standard lifetimes. Materials considered durable, were those that the literature indicated typically have a useful life that could be utilized in a secondary building. Like the previous criteria, durability is more relevant to determining reusability rather than recyclability. 


\subsubsection{Criteria 3 - Demand}

To address the third criteria, common secondary products from reclaimed materials were outlined based on the literature's indication of current levels of understanding and technological capabilities. Emphasis in the analysis was placed on determining secondary products or uses for materials most closely related to the material's initial use. From there, emphasis was put on secondary products related to the construction of SDH, then the broader construction industry, and finally, the least emphasis was put on secondary products not related to construction.

It is outside this thesis' scope to provide a detailed cost analysis for reuse/recycling of each material. Even so, costs are undeniably influential in the discussion of the demand for secondary products. Thus, in very few cases, some light reference to product costs are outlined in the discussions of demand for secondary products but should be taken with the understanding that more thorough research is necessary to the accurately understand the influence of costs.

As standards and codes can greatly influence the market demand for secondary products, they were also included in the analysis. First, standards can provide industry guidelines on management and use of reclaimed materials. Second, codes and standards can encourage or discourage the uptake of reused/recycled products in secondary applications. Conversely, the lack of codes or standards may be equally influential in hindering the use of secondary products.

\subsubsection{Criteria 4-Quantity}

The forth criteria was not addressed in the material analysis. This criterion was partially addressed by inventory and developing city scale material stocks, which provides insight into current and future supple of reclaimed materials. Material quantity is a significant factor in reusability/recyclability because the current building design process relies heavily of consistency and predictability (Gorgolewski, 2008). Typically the inconsistent supply of reclaimed materials can be a significant barrier in making secondary products logistically and financially attractive to builders (Gorgolewski, 2008). However, it was outside the scope of this thesis to address the quantity of materials that consumers require. At the same time consumer demands have an interdependent relationship with material supply (which is determined), where increasing supply can promote demand or vice versa. 


\subsubsection{Criteria 5 - Preparation for Secondary Use}

To address the fifth criteria, the processes involved in refurbishing, remanufacturing, or recycling reclaimed materials were explored. Depending on the intended secondary purpose of the reclaimed material, the time, labour, or equipment involved in transforming or cleaning the product may be significant in determining its reusability/recyclability. For example, removing nails from $F L$ is a labour intensive and timely task that can be costly and ultimately a disincentive to prepare FL for reuse.

As well, materials may be contaminated by substances that are hazardous to human health or that impact quality of secondary products. Therefore it is important to address the available procedures to decontaminate materials. As some contaminants cannot be remediated or are banned, the materials in which they reside are likely not reusable/recyclable.

\subsubsection{Toronto Drop-Off Opportunities Analysis}

To complement the material analysis, an evaluation of the reuse/recycle infrastructure currently available in the City of Toronto and the surrounding GTA was conducted. Specifically, the opportunities for professionals or homeowners to drop-off reclaimed materials to reuse/recycling facilities were determined. However, the results of the analysis were not considered in developing city scale reusable and recyclable material stocks.

To establish an understanding of drop off opportunities, a thorough search of businesses and facilities within the GTA was conducted using online search engines and business directories. The materials accepted at respective facilities were determined by either searching their website or contacting them directly for more information. Only facilities that would accept demolition debris from SDHs were considered as drop-off opportunities in the analysis.

\subsection{Methods for Addressing Objective Three}

To achieve the third objective and determine the embodied impacts and/or implications to void landfill space of reclaiming materials at the city scale, first an estimate of the number of in-use and annual obsolete SDH archetypes, based on age, in the City of Toronto at the end of 2012 was established. From there, the volume of material in each archetype was extrapolated to the city scale. 


\subsubsection{Determining Number of Archetype Houses}

Limited data exists on the age of SDH in the City of Toronto. As well, none of the available data offers accounts of construction dates for the current in-use SDH stock. As such, a multi-stage visual analysis of various relevant maps was conducted in conjunction to utilizing the limited statistical data available.

A key resource in achieving this objective was the City of Toronto's construction dates map, Figure 20. The map was created in 2003 by the City of Toronto's Survey and Mapping Services to geographically express data of building construction dates collected by tax assessment surveys (personal communication, City of Toronto). As the raw data from tax assessment surveys was not made available by the City of Toronto, the construction dates map provided the next best insight into SDH construction date.

Construction dates demonstrated in Figure 20 were catagorized into time periods by the City of Toronto to reflect trends in Toronto's construction industry overtime (personal communication, City of Toronto). For example, patterns of growth from the downtown core and post-war suburban development shaped the boundaries of several of the construction date categories (personal communication, City of Toronto). The date categories in Figure 20 include pre 1901 (yellow), 1901-1915 (orange), 1916-1930 (red), 1931-1945 (purple), 1946-1960 (blue), 19611975 (light green) and 1976-2003 (dark green). A small percentage of the tax assessment data was not adequately plotted and was marked on the map as Building Construction Date Not Available or Greenspace (white) (personal communication, City of Toronto).

The time periods illustrated in the construction dates map aligned well with the time periods established for the archetype SDH. Yellow, orange, and red time periods correspond with the Century archetype (pre-1930); purple and blue, correspond with the Wartime archetype (19311960), light green correspond with the Baby Boomer archetype (1961-1975), and dark green correspond mostly to the OBC archetype (1976-2000). The last archetype, the Modern archetype (2001-2012) is not illustrated on the construction dates map. 


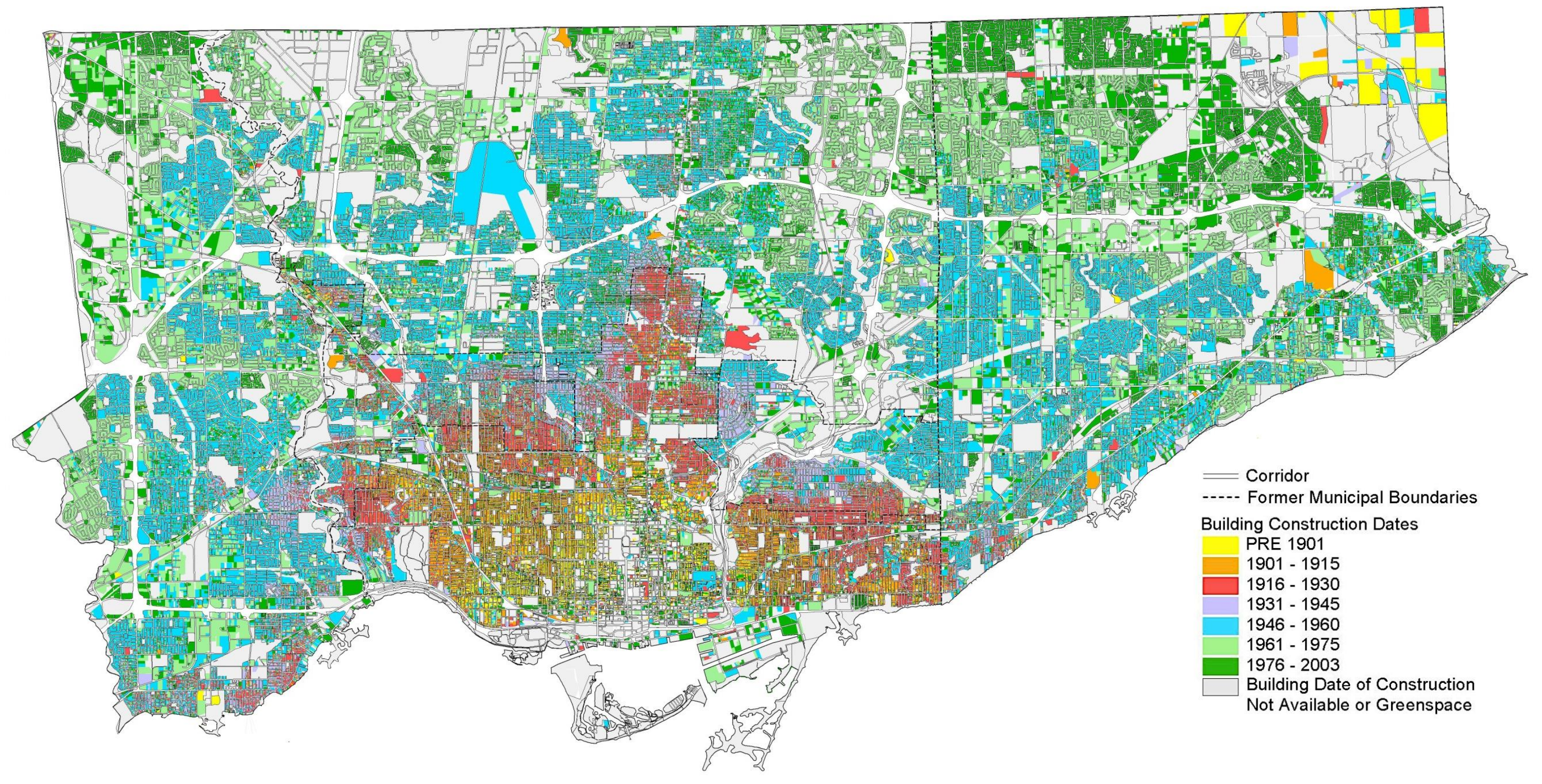

Figure 20. Construction dates of buildings in the City of Toronto (City of Toronto, 2003). 
Alternative sources of construction date data were considered but proved to be insufficient include housing construction start data from $\mathrm{CMHC}$ and 2006 statistical data from the City of Toronto neighbourhood profile project. Although these data sources offered some insight into construction dates, both had significant gaps in their information and were not suitable for estimating the amount of SDH fitting the archetypes in Toronto at the end of 2012. In the first case, housing construction start data could be only obtained for the GTA and could not be supplemented with data to indicate which of the constructed SDH remain. In the second case, construction date data from the city was inclusive of all residential building types, providing no detail of SDH construction.

Although the construction dates map also had limitations as a data source for achieving the third objective, the limitations could be overcome with supplementary data. One such limitation was that the map did not provide linkages between building type and construction date. Another limitation was that the map was published too early to be useful for determining the number of SDH that fit the Modern archetype. Specifically, the map was published in 2003 and did not account for the majority of SDH built from 2001 to the end of 2012.

The first limitation was overcome by using residential zoning maps to indicate areas authorized to construct SDH. The second limitation was overcome by utilizing SDH construction start data from CMHC's Housing Now Toronto reports (December 2001-December 2012). This data could be used because it was reasonable to assume that of SDH built from 2001 to 2012 have not since been demolished and are currently still in-use in Toronto.

Housing Now Toronto is a monthly publication of CMHC for the City of Toronto. The reported data is based on a variety of sources, believed to be accurate by the CMHC who is well established in Canadian housing and construction industry. As well, the accuracy of the data is supported by the Government of Canada, which publishes archived copies of the report on the Statistics Canada, CANSIM database.

CMHC Housing Now Toronto reports data as far back 2001. Thus the available data correlated well with the time period considered for the Modern archetype. Only monthly editions are available, so end-of-year data from December issues of each year was extracted and tabulated to determine the number of in-use SDH fitting the Modern archetype. 


\subsubsection{Determining Proportions of Archetype SDH}

To determine the number of the remaining SDH archetypes, Toronto land use zoning maps were sourced to supplement information from the construction dates map. Zoning maps were obtained from the City of Toronto and are based on Bylaw No. 569-2013.

The zoning maps demonstrate the areas that are permitted to have SDH buildings but, in some areas, include other residential buildings types as well. For example, in the downtown core area, the City of Toronto only distinguishes zoning as 'residential', which includes SDH, semidetached housing, row housing, and apartments. However, the area of residential zoning is relatively small and concentrated to the center (core) of the city. Historical data indicates that SDH in Toronto's core tend to fit the Century archetype and was corroborated with the analysis of residential zoning superimposed on the construction dates map (Blaszak, 2010).

Outside the downtown core area, the zoning maps show areas with SDH and semi-detached housing zoning together. The grouping of SDH and semi-detached houses was not considered as a significant limitation because 2011 Statistics Canada Census data indicated that there are almost four times as many SDH as semi-detached homes in Toronto (275,010 versus 72,405 respectively). Thus the area represented in the zoning map is dominated by SDH (City of Toronto, 2013f).

The zoning map was superimposed onto the constructions dates map. Using Adobe Photoshop CS6, a high-resolution image of construction dates with shading to indicate SDH zoning was produced as shown in Figure 21.

For visual analysis of the zoning/dates map, the map was divided into smaller subsections, as seen in Figure 22. The divisions were numbered and so could be analyzed as an individual unit, allowing for greater accuracy and detail for record keeping. The zoning/dates map was divided in two different ways (by Toronto's 140 neighbourhoods and 44 wards) and analyzed twice to ensure accuracy, Figure 22. 


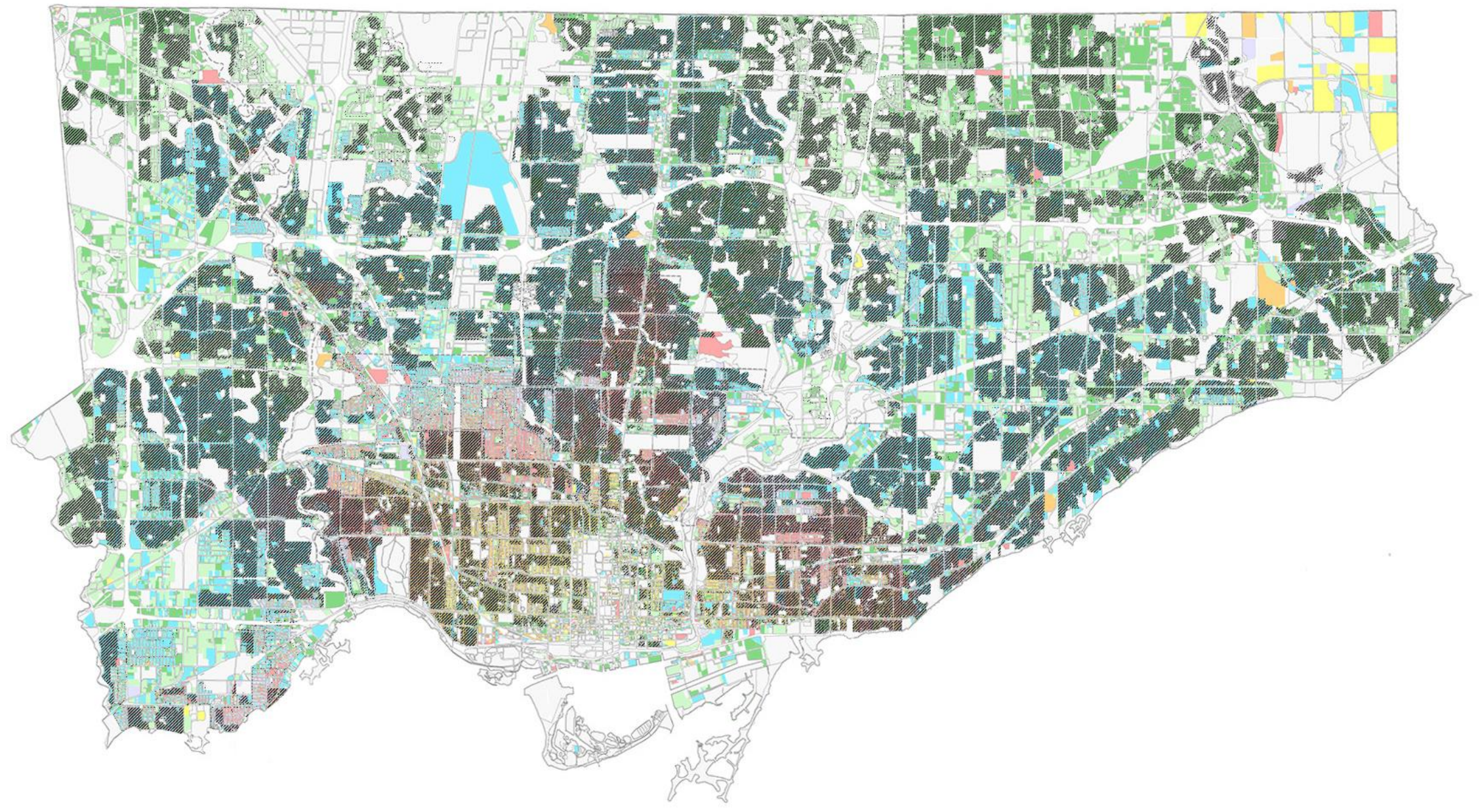

Figure 21. Zoning map superimposed onto construction dates map where shaded areas represent areas with SDH zoning. Image is altered to highlight shading (City of Toronto, 2003; 2013f). 

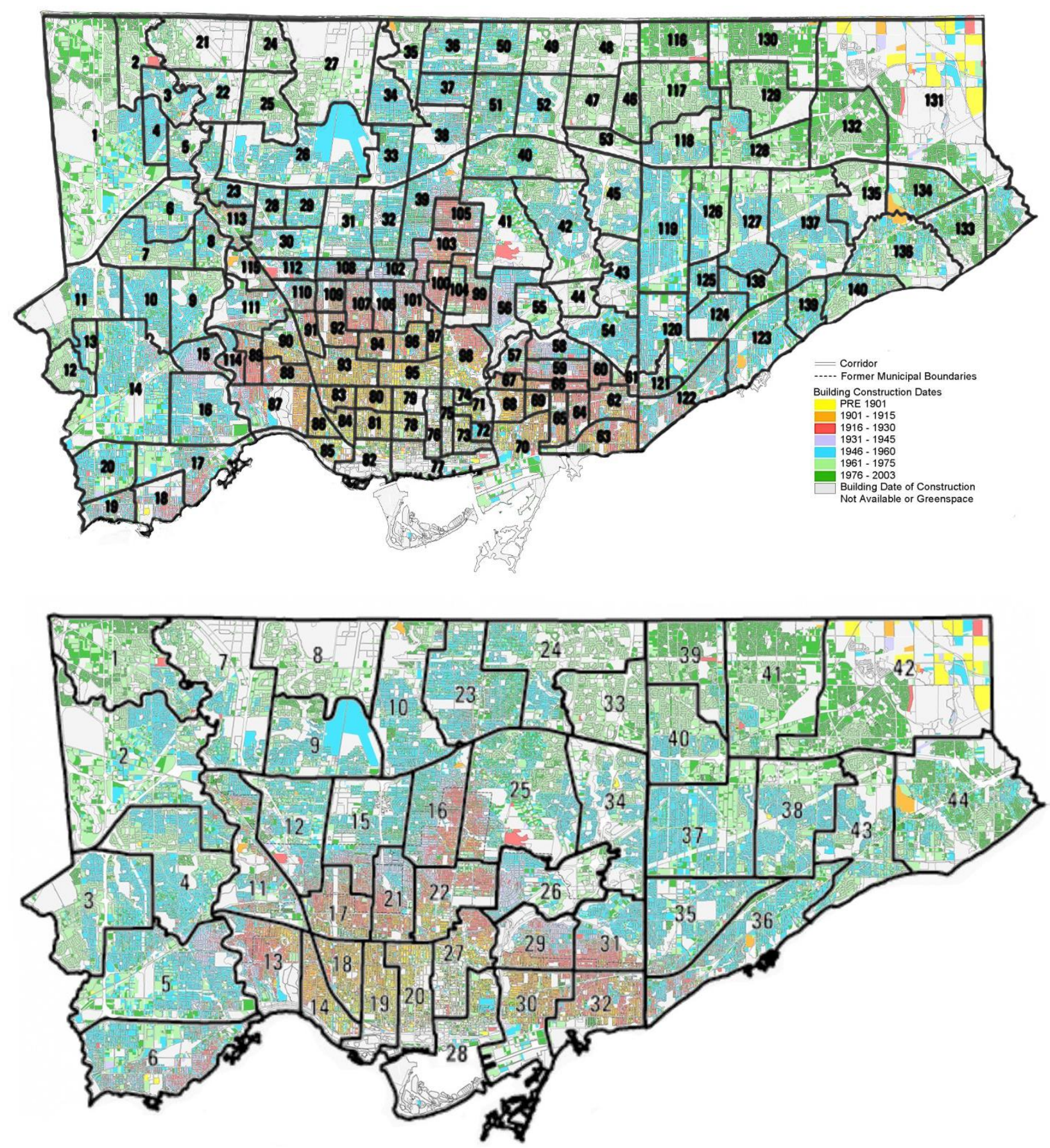

Figure 22. Construction dates map divided by neighbourhoods (top) and wards (bottom). Images are altered to highlight divisions (City of Toronto, 2003; 2013c; 2013e).

The resulting maps were visually inspected to determine proportions of colours that fell in the shaded areas of each division, Figure 23. Colour proportions were recorded out of $100 \%$. For 
example, if the shaded area of a division covered two colours equally, half yellow and half blue, it was recorded that the section was $50 \%$ yellow and $50 \%$ blue. In the cases where shaded areas fell on white or grey areas of the map, the respective proportion was recorded as 'unidentified'. These areas corresponded to spaces where accurate data from tax assessment rolls could not be mapped out by the City of Toronto.

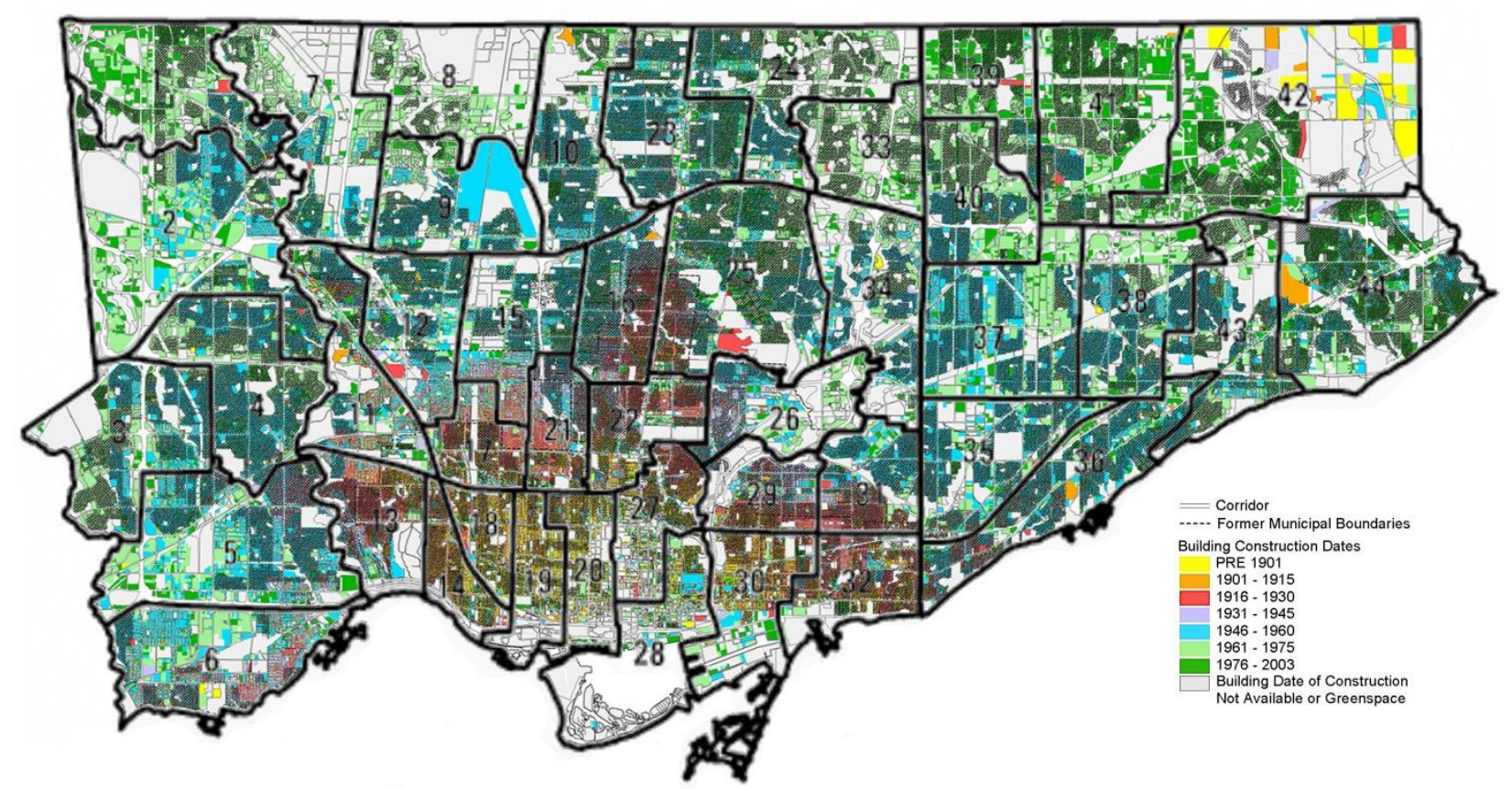

Figure 23. Final construction dates map with zoning and divisions (City of Toronto, 2003; 2013e; 2013f).

Based on the 2011 Statistics Canada Census results, the amount of SDH in each ward and neighbourhood is published by City of Toronto (City of Toronto, 2013c; City of Toronto, 2013e respectively). With this statistical data and the results of the visual analysis, an estimate of the number of $\mathrm{SDH}$ constructed in each time period was generated for the city. From there, the amount of SDH corresponding to each archetype was determined. For example, if a ward/neighbourhood was known to have $50 \mathrm{SDH}$ and was recorded to be $50 \%$ yellow and $50 \%$ blue, the results were that 25 houses matched the Century archetype and 25 houses matched the Wartime archetype. The results for each division were tallied to establish an overall estimate of the composition of the five archetypes in Toronto's in-use SDH stock. 
Figure 24 demonstrates the results of the visual analysis when the zoning and construction dates map was divided by neighbourhoods and wards. It is clear from Figure 24 that visual analysis of the map divided by neighbourhood and by ward yielded very similar results. Overall, $0.86 \%$ of zoning areas were recorded as 'unidentified'.

Even so, when the map was divided by ward it was easier and likely more accurate to visually analyze. Therefore the number of each archetype in Toronto's in-use SDH stock was determined from the results of the visual analysis of the map divided by ward.
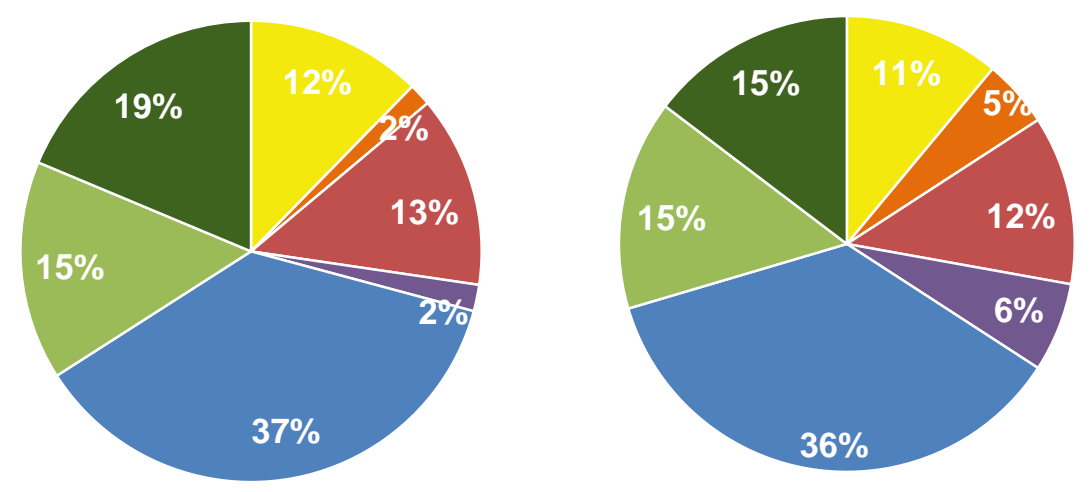

Pre 1901

- 1901-1915

- 1916-1930

- 1931-1945

- 1946-1960

-1961-1975

-1976-2003

${ }^{*}$ Colours in Figure 24 are meant to match those in construction dates map legend.

Figure 24. Proportions of construction date groups in Toronto's 'residential' zoning. Left, results of map divided by neighbourhoods. Right, results of map divided by wards.

Without data on the number of typical versus one-off house types, it was assumed that all of Toronto's SDH stock fit into the archetypes. Although this assumption is not indicative of the actual housing mosaic in Toronto, it was necessary to enable the analysis to be carried out and was not believed to greatly impact the results to answer the research questions since the archetypes were chosen to carefully reflect typical house characteristics of each period..

Based on the 2011 Census data and the CMHC Housing Now Toronto SDH construction starts, there was an overlap of SDH counts from 2001 to 2011. Therefore the initial results based on the construction dates map were adjusted by dividing the total amount of SDH construction starts from 2001 to 2011 and subtracting it equally from the totals for Century, Wartime, Baby Boomer, and $\mathrm{OBC}$ archetypes to ensure that results were not exaggerated. 


\subsubsection{Determining Annual Obsolete SDH}

To determine the number of annual obsolete SDH in Toronto, data on demolition permits was obtained from the City of Toronto's online catalogue of datasets as comma-separated value (CSV) files. Each catalogue included information on permit date and type, building type, and address. From these catalogues, cleared demolition permits of SDH from 2008 to 2012 were used.

To determine the age of demolished SDH from 2008 to 2012, the addresses of cleared demolition permits were mapped onto the construction dates map using Google Earth, with the assumption that SDH built after 2001 have not yet been demolished. To do this, addresses of the demolition permits were converted from CSV files into a keyhole markup location (KML) files, readable by Google Earth, with the online program BatchGeo (http://batchgeo.com/). To ensure that addresses were accurately mapped out on Google Earth, 10 addresses were chosen at random and also mapped on Google Maps. The locations of the 10 addresses were compared and verified that the permits were accurately mapped out using Google Earth.

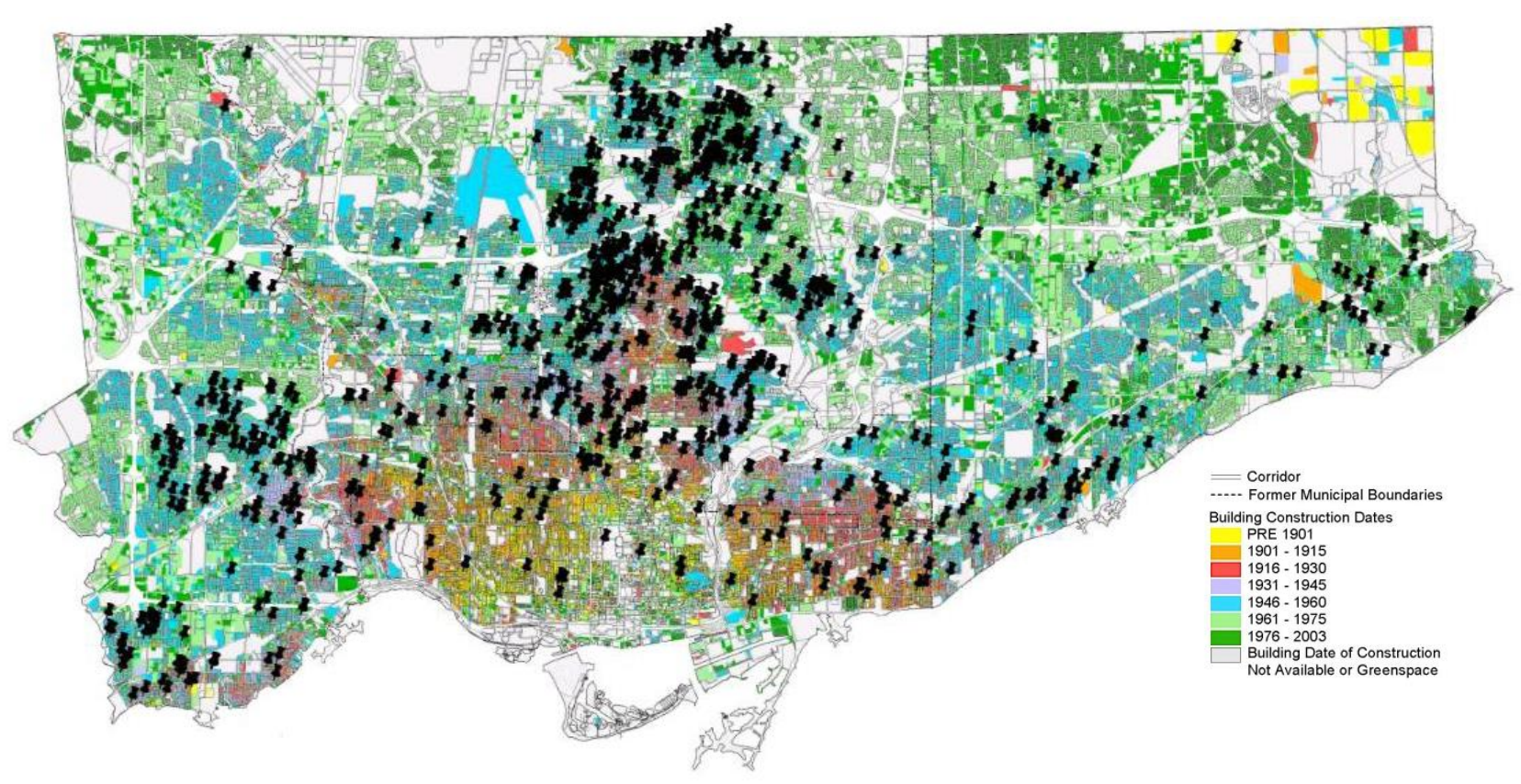

Figure 25. Construction dates map with 2012 cleared demolition permit locations (City of Toronto, 2003). 
To date the SDH from cleared demolition permits, Toronto's construction dates map was added as a layer to match city boundaries outlined in Google Earth.

Figure 25 demonstrates an example of the resultant map with demolition permit data for 2012 . The colour, corresponding to construction date group, that each point landed on was recorded and then the point was deleted to prevent duplicate results. Demolition permits were correlated with archetypes based on the construction time period each colour represented on the map. In cases where the points landed on white or grey areas of the map, the construction date of the demolished SDH was recorded as 'unidentified'.

The demolition data only takes into consideration cleared demolition permits, and may be slightly lower than actual SDH demolition from 2008 to 2012. Because it could not be confirmed that the SDH in open permits had been demolished, they were not included. The City of Toronto categorizes demolition permits based on the year that they are cleared. It would not be fair to assume that demolition of SDH in all permits occurred in the year that the permit was cleared because often the permit closes when reconstruction is complete. However, the data did not offer additional information of when SDH had been demolition and thus, this thesis assumes that all SDH permits are cleared in the same year as demolition.

The results of the archetypes demolished in 2012, according to 2012 cleared demolition permit data were also applied to generate the total stock of in-use SDH in Toronto at the end of 2012. That is because the Census data only provided information on the Century, Wartime, Baby Boomer, and OBC archetypes up to 2011. Although CMHC data could be used to determine the total number of SDH construction starts in 2012, demolition in 2012 also had to be considered.

\subsubsection{Determining City Scale Material Stocks}

By determining the composition of SDH archetypes in Toronto's in-use stock and annual obsolete stock, it was possible to extrapolate material volume results to the city scale. The materials volumes identified in each archetype SDH were multiplied by the amount that archetype was determined to exist in the respective city scale stocks. For example, if $1 \mathrm{~m}^{3}$ of wood was found in the Century archetype and it was determined that 100 houses fitting the Century archetype were in in-use or annual obsolete SDH stocks in Toronto, then it was determined that there was $100 \mathrm{~m}^{3}$ wood at the city scale. 
Stocks of reusable/recyclable materials were determined based on the results of the materials analysis. Material's identified with suitability for reuse and/or recycling from Addis's (2006) adapted criteria were extrapolated to city scale in-use and annual obsolete SDH stocks.

\subsubsection{Determining Embodied Impacts}

Embodied primary energy consumption and $\mathrm{CO}_{2}$ emissions were determined for materials identified as reusable in in-use and annual obsolete SDH stocks. Primary data for embodied impacts used from Athena Impact Estimator for Buildings (IE) 4.2, a building specific LCA software developed by the Athena Sustainable Materials Institute (ASMI). IE uses data based on ASMI datasets, conducted directly by the Institute, and data from the U.S. Life Cycle Inventory Database. All datasets used in IE are from ISO compliant primary research studies. ASMI datasets have the added benefit of being conducted in a Canadian context and, in some cases, are studies specific to Central Canada, Ontario, or Toronto. The data sources for the modelled materials are outlined in Table 1.

Table 1. Data sources for embodied impacts used by Athena Impact Estimator (IE) for Buildings.

\begin{tabular}{|c|c|}
\hline Extra Basic Material & Data Source used by IE \\
\hline Ontario Standard Brick & $\begin{array}{l}\text { Canadian clay brick data developed in } 1998, \text { updated } \\
\text { in } 2009 \text {. }\end{array}$ \\
\hline Concrete 30 Mpa Average fly Ash & Canadian regional cement data updated from original \\
\hline Concrete Block & 1993 data (concrete designs remain unchanged). \\
\hline $\begin{array}{l}\text { Large Dimension Softwood Lumber, Kiln Dried } \\
\text { Small Dimension Softwood Lumber, Kiln Dried }\end{array}$ & $\begin{array}{l}\text { Canadian regional data updated in } 2009 \text { Corrim data } \\
\text { for US reflects PNW and SE production } 2004 \text {. }\end{array}$ \\
\hline Wide Flange Sections & All product profiles reviewed and adjusted to reflect \\
\hline Hollow Structural Steel & fuel use by type and mix of EAF and integrated steel \\
\hline Galvanized Steel Studs & $\begin{array}{l}\text { production technologies per product in both Canada } \\
\text { and the US. }\end{array}$ \\
\hline Galvanized Sheet & Canadian regional data originally developed in 2000 . \\
\hline $\begin{array}{l}\text { Wood tongue and groove (T\&G) panels } \\
\text { Wood Siding Beveled }\end{array}$ & $\begin{array}{l}\text { Canadian regional data originally developed in } 2000 . \\
\text { Cedar siding data updated in } 2009 .\end{array}$ \\
\hline Concrete Brick & $\begin{array}{l}\text { Canadian concrete brick data developed in 1998, } \\
\text { updated in } 2005 .\end{array}$ \\
\hline Natural Stone & Developed in 2009 from a secondary data source. \\
\hline OSB Board & $\begin{array}{l}\text { Canadian regional data originally developed in } 1993 \\
\text { updated in } 2006 \text {. Resource harvesting profile, updated } \\
\text { in } 2009 \text {. }\end{array}$ \\
\hline Aluminum & No Information Available \\
\hline Standard Glazing & $\begin{array}{l}\text { Frame and Glazing data and quantity take offs, } \\
\text { updated in } 2013 .\end{array}$ \\
\hline
\end{tabular}


Embodied $\mathrm{CO}_{2}$ fossil emissions and primary energy consumption data from IE consider cradleto-Toronto impacts of producing virgin materials and not additional impacts associated with reuse, including transportation (to drop-off facilities or secondary building site) or activities involved in renewed or rethought reuse. As well, the results exclude the impacts of equipment used in deconstruction or transportation of the deconstruction crew, which can be significant (O'Brien, 2006). Rather, the results outline the emissions and energy consumption from resource extraction, resource transportation, manufacturing, and transportation to Toronto of virgin building materials that the reclaimed material stocks may replace if reused.

The following inputs were used to define the building model in IE:

$\begin{array}{ll}\text { Project Location: } & \text { Toronto } \\ \text { Building Type: } & \text { Single Family Residential } \\ \text { Building Life Expectancy: } & 20 \text { Years }\end{array}$

A low building life expectancy was chosen to ensure that the embodied impacts accounted for one application of the material and not replacements needed throughout the average building's lifetime. For example, in a building with a life expectancy of 60 years, as much as three replacements of asphalt shingles can be applied because of the product's life expectancy is only 20 to 30 years.

The volumes of materials in in-use and annual obsolete stocks identified as reusable were inputted into the building model as extra basic materials and modelled separately. In the rare case where IE did not have the exact material, the closest IE material was chosen. A full list of the IE materials used to model the identified reusable materials is outlined in Table 2. In some cases material metrics had to be changed to compliment the metrics used by IE and are outlined in Table 2. Metrics for respective materials were inputted into the model to the closest whole number.

For each model, report tables were generated by IE 'By Life Cycle Stages'. Data for embodied impacts was taken from 'Total' in the Manufacturing category (which includes resource extraction, resource transportation, and manufacturing activities) and 'Transportation' in the Construction category (which includes transportation from manufacturing site to Toronto). Data for $\mathrm{CO}_{2}$ emissions were taken from the reported total carbon dioxide, fossil fuels in $\mathrm{kg}$. Data for primary energy consumption was taken from the reported total primary energy consumption $\mathrm{MJ}$, 
including hydro, coal, diesel, heavy fuel oil, liquefied petroleum gas, natural gas, and nuclear consumption based on typical energy profiles in Ontario.

Table 2. Materials identified as reusable in archetype SDH and closest extra basic material in IE.

\begin{tabular}{|c|c|c|c|c|}
\hline $\begin{array}{l}\text { Identified } \\
\text { Reusable Material }\end{array}$ & $\begin{array}{l}\text { Closest Extra Basic } \\
\text { Material }\end{array}$ & $\begin{array}{l}\text { Metric } \\
\text { in IE }\end{array}$ & $\begin{array}{c}\text { Embedded } \\
\text { Assumptions in IE }\end{array}$ & $\begin{array}{c}\text { External } \\
\text { Assumptions }\end{array}$ \\
\hline Clay Brick & Modular (metric) Brick & $\mathrm{m}^{2}$ & $\begin{array}{l}\text { 89mm thick, } \\
\text { extruded brick }\end{array}$ & \\
\hline CIP Concrete & $\begin{array}{l}\text { Concrete } 30 \text { Mpa Average } \\
\text { fly Ash }\end{array}$ & $\mathrm{m}^{3}$ & & \\
\hline $\begin{array}{l}\text { Rafters, Joists, } \\
\text { Beams, Doors }\end{array}$ & $\begin{array}{l}\text { Large Dimension } \\
\text { Softwood Lumber, Kiln } \\
\text { Dried }\end{array}$ & $\mathrm{m}^{3}$ & & \\
\hline Studs, Strapping & $\begin{array}{l}\text { Small Dimension } \\
\text { Softwood Lumber, Kiln } \\
\text { Dried }\end{array}$ & $\mathrm{m}^{3}$ & & \\
\hline WF Beams & Wide Flange Sections & tonne & & 7.85 tonne $/ \mathrm{m}^{3}$ \\
\hline Steel Columns & Hollow Structural Steel & tonne & & 7.85 tonne $/ \mathrm{m}^{3}$ \\
\hline Steel Studs & Galvanized Steel Studs & tonne & & 7.85 tonne $/ \mathrm{m}^{3}$ \\
\hline Lintels & Galvanized Sheet & tonne & & 7.85 tonne $/ \mathrm{m}^{3}$ \\
\hline Hardwood Flooring & Pine Wood T\&G Panels & $\mathrm{m}^{2}$ & & $12.7 \mathrm{~mm}$ thick \\
\hline Wood Cladding & $\begin{array}{l}\text { Cedar Wood Beveled } \\
\text { Siding }\end{array}$ & $\mathrm{m}^{2}$ & & $18 \mathrm{~mm}$ thick \\
\hline Cinder Block & Concrete Block & Block & $\begin{array}{l}406 \times 203 \times 203 \\
\text { hollow block }\end{array}$ & \\
\hline Concrete Brick & Concrete Brick & $\mathrm{m}^{2}$ & & $101.6 \mathrm{~mm}$ thick \\
\hline $\begin{array}{l}\text { Rubblestone, } \\
\text { Aggregate } \\
\text { Oriented Strand }\end{array}$ & Ballast (Aggregate) & $\mathrm{m}^{2}$ & $30 \mathrm{~mm}$ thick & \\
\hline $\begin{array}{l}\text { Board } \\
\text { (OSB) }\end{array}$ & OSB Board & $\mathrm{m}^{2}$ & $9 \mathrm{~mm}$ thick & \\
\hline Aluminum siding & Aluminum & tonne & & 2.699 tonnes $/ \mathrm{m}^{3}$ \\
\hline Window Glass & Standard Glazing & $m^{2}$ & & $6.53 \mathrm{~mm}$ \\
\hline
\end{tabular}




\section{Results and Discussion}

The following chapter outlines the results and discussion of important finding as they apply to each research objective.

\subsection{Objective One - Material Inventory of Archetypes}

The results and discussion of the material inventory (material identification and volume measurements) of the five archetype construction drawings representing typical unit types in Toronto's SDH stock are presented below. The assumptions and dimensions used to determine material volumes are outlined in Appendix B. Figure 26 presents the identified materials with a measured volume greater than $2.0 \mathrm{~m}^{3}$. The select materials presented in Figure 26 are presented in figures throughout the Results and Discussion chapter. However, a full list of the identified materials and their absolute volumes are outlined in Appendix C, Table 14.

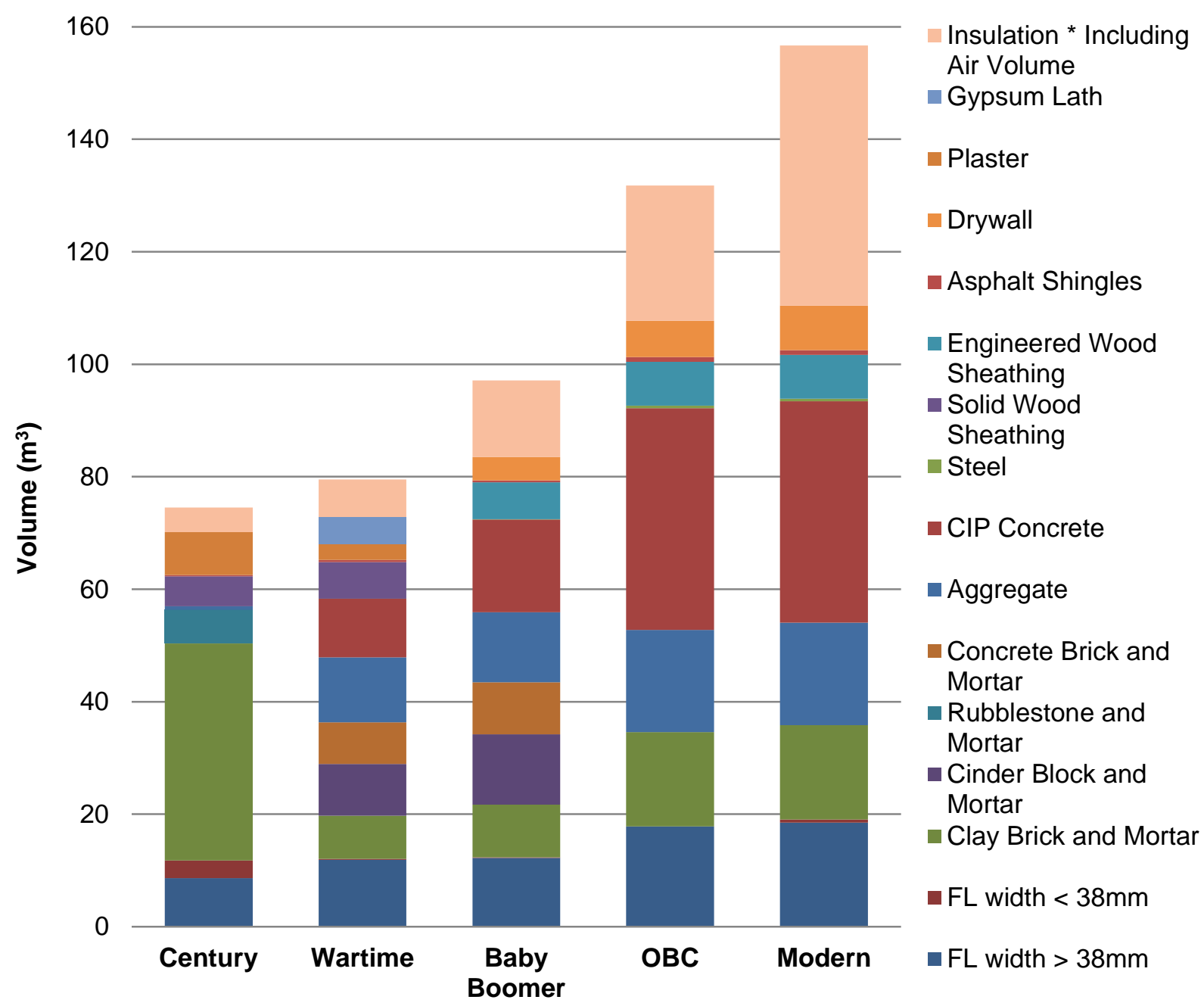

Figure 26. Volumes of select materials identified in each archetype. 
Figure 26 demonstrates that the highest material volume measured in the Century archetype was clay bricks and mortar (50\% of total volume), in the Wartime archetype was framing lumber (FL) (16\% of total volume), in the Baby Boomer archetype was cast in place (CIP) concrete ( $16 \%$ of total volume), in the OBC archetype was also CIP concrete (29\% of total volume), and in the Modern archetype was insulation including air volume (29\% of total volume).

Figure 26 suggests that the materials with the highest volumes in each archetype tended to be those identified in the exterior envelope of the buildings (for example, CIP concrete and clay bricks). However, Figure 26 also suggests that there was significance in inventorying both interior wall partitions as well. For example, FL comprised a significant proportion of the total material volume in the Wartime, Baby Boomer, $\mathrm{OBC}$, and Modern archetypes and was identified in the interior partitions (primarily as studs and floor joists) as well as the exterior envelope. Additionally, plaster comprised a significant proportion of the total material volume in the Century archetype and was identified only in interior partitions.

It is clear from Figure 26 that the material composition of the Century archetype stands out from the remaining four archetypes. For example, the fewest materials (14 different materials) were identified in the Century archetype. As well, the Century archetype had the highest volume of clay bricks in comparison to the remaining archetypes, comprising $35 \%$ of the total material volume measured in the archetype. It was clear from the Century house construction drawings and the literature that SDH constructed before 1930 had simple wall assemblies, reflecting a less mechanized and globalized building industry at the time (CMHC, 2003). The literature also supports the high volume of clay bricks determined in the Century archetype as it outlines that at the time the raw resources to manufacture clay bricks were abundantly available in Toronto and that clay bricks were specified in building to address fire safety concerns.

Nevertheless, the total volume of solid wood products (FL, sheathing, and wood paneling) found in the Century archetype is lower than the results determined by Davilia (2013). Although Davilia (2013) applied a similar methodology to determine material volumes by measuring drawings in house catalogues, he inventoried $30 \mathrm{~m}^{3}$ of solid wood products in a SDH built in the same period as the Century archetype. In comparison, this thesis determined that the Century archetype had about $21 \mathrm{~m}^{3}$ of solid wood products. However, the difference in volumes may be accounted for because Davilia (2013) considered a SDH that utilized wood framed platform construction and therefore wood was the main structural material for his archetype. For example, Davilia (2013) 
determined $\mathrm{FL}$ volume to be about $20 \mathrm{~m}^{3}$, which is more closely aligned with $\mathrm{FL}$ volumes measured in the $\mathrm{OBC}$ and Modern archetypes that also utilize wood framed construction.

At the same time, FL volumes in the $\mathrm{OBC}$ and Modern archetypes are low in comparison to existing literature. Both Sahely et al (2003) and Falk (1999) assumed that the average SDH built in the $\mathrm{OBC}$ archetype era had about $30 \mathrm{~m}^{3}$ of $\mathrm{FL}$ based on data from the National Association of Home Builders (NAHB). $30 \mathrm{~m}^{3}$ is widely referenced as the volume of $F L$ in the average America $\mathrm{SDH}$. The reference originates from results of annual Builder Practice Surveys, not available to the public, now carried out by the Home Innovation Research Labs (personal communication, NAHB). Data from the 2001 Builder Practices Survey indicates that the average American SDH with a usable floor area of $211 \mathrm{~m}^{2}$ had about $33 \mathrm{~m}^{3}$ of $\mathrm{FL}$ (personal communication, NAHB). However, it is unclear if these surveys include $F L$ that is purchased but wasted during construction. Either way, case studies of SDH deconstruction throughout the U.S.A. demonstrate SDH with comparable FL volumes (personal communication, Ted Reiff).

Figure 26 demonstrates that FL volumes in the $\mathrm{OBC}$ and Modern archetypes were determined to be significantly less than $32 \mathrm{~m}^{3}$ ( 17.8 and $18.5 \mathrm{~m}^{3}$ for the respective archetypes). Even when FL volumes determined in this thesis are calibrated to the floor area of the average American $\mathrm{SDH}$, the results are significantly low $\left(22 \mathrm{~m}^{3}\right.$ in the $\mathrm{OBC}$ archetype and $15 \mathrm{~m}^{3}$ in the Modern archetype). However extrapolating the results to the floor area of the average American SDH does not take into account differences in surface area to volume ratios or that a larger floor area may require additional interior partitions. This may be especially significant if the average American SDH in 2001 had a finished basement with interior partitions, requiring additional FL, whereas the Modern archetype (with a larger usable floor area than the America statistic) had a finished basement with no interior partitions.

The FL volumes determined for the OBC and Modern in this thesis are likely modest and may reflect assumptions about stud distance, the number of studs at corners, and the number of studs around windows and doors (outlined in the Appendix B). As well, these conservative results may reflect that this thesis did not consider FL elements such as bracing and webbing (except in engineered roof trusses).

Nevertheless, FL volumes from archetype-to-archetype correlate well with the descriptions of their construction styles, outlined in the Methodology. For example, FL volume was found to be 
lowest in the Century archetype and highest in the OBC and Modern archetypes; and the Wartime and Baby Boomer archetypes, which utilized both wood frame construction and loadbearing masonry, had FL volumes in the middle.

Generally, the volumes of the identified materials align well with their descriptions outlined in the Methodology. Table 3 shows that total material volume increased as the archetype construction era became more recent. As well, except for the Wartime archetype, usable floor area of the archetype SDH increased as construction era became more recent. This trend aligns well with literature discussing the economic and cultural influences in common SDH construction practices overtime (CMHC, 2006). Simple linear regression suggests a positive correlation between total material volumes and increasing usable floor areas in the archetypes houses $\left(r^{2}=\right.$ 0.93). Although with five data points, no definite conclusions can be made.

Table 3. Material intensity $\left(\mathrm{m}^{3} / \mathrm{m}^{2}\right)$ of archetype SDH.

\begin{tabular}{lccccc}
\hline & Century & Wartime & Baby Boomer & OBC & Modern \\
\cline { 2 - 5 } & 116 & 102 & 128 & 173 & 262 \\
Usable Floor Area $\left(\mathrm{m}^{2}\right)$ & 77.7 & 83.9 & 100.9 & 136.2 & 161.1 \\
$\begin{array}{l}\text { Total Material Volume }\left(\mathrm{m}^{3}\right) \\
\begin{array}{l}\text { Material Intensity } \\
\text { (Total Material Volume/Usable }\end{array}\end{array}$ & 0.67 & 0.82 & 0.78 & 0.79 & 0.61 \\
\begin{tabular}{l} 
Floor Area, $\left.\mathrm{m}^{3} / \mathrm{m}^{2}\right)$ \\
\hline
\end{tabular} & & & & & \\
\hline
\end{tabular}

At the same time, although the Wartime archetype had a smaller usable floor area than the Century archetype, it had a higher total material volume. However, this discrepancy may be accounted for because the Wartime archetype had a concrete foundation slab whereas the Century archetype utilized rammed earth (which was not considered in this study) and some limited aggregate for its basement floor. As well, as shown in Table 3, the Wartime archetype had the highest material intensity of all five archetypes; indicating that its design used a significant volume of material for its small floor area. This result is surprising as literature suggests that SDH built the in the Wartime archetype era were typically material efficient. At the same time, the floor plans of these SDH in the early 1950's tended to have less open space and have more interior partitions. The differences in material intensities between the archetypes may also be somewhat explained by differing volume to surface area ratios, where the ratio of the area of exterior building envelopes to total building volume lowers as the total volume of the building increases. 


\subsection{Objective Two - Reusability/Recyclability and Drop-Off Opportunity Analysis}

The results and discussion of the reusability/recyclability and drop-off opportunity analysis are presented below. Table 4 demonstrates the results of the reusability and recyclability analysis for the materials identified in the archetype SDH and opportunities to drop-off suitable materials to reuse and recycling facilities in Toronto.

It was clear from the literature review that none of the identified materials could completely meet all of the considered criteria. One or more of the adapted criteria limited the material's reusability/ recyclability in some way. Table 4 demonstrates the factors that the literature indicated were the most influential in limiting the reusability/recyclability of materials based on the five evaluation criteria adapted by Addis (2006), which include:

$\begin{array}{cl}\text { Criteria Number } & \text { Limitations to Reuse/Recyclability } \\ 1 & \text { Recoverability } \\ 2 & \text { Durability } \\ 3 & \text { Demand - Secondary Products (SP) } \\ 3 & \text { Demand - Regulations } \\ 4 & \text { Quantity (considered in other sections) } \\ 5 & \text { Preparation for Secondary Use - Processing } \\ 5 & \text { Preparation for Secondary Use - Contamination }\end{array}$

It was evident that the impact of the most limiting criteria varied considerably from material-tomaterial. For some materials it was found that the most influential criteria completely prevent its reusability or recyclability. For example criteria 2 , durability, completely prevent asphalt shingle reuse. For other materials it was found that the most influential criteria only hinder or present obstacles to material reusability or recyclability that the literature indicated could be overcome with current knowledge and technology. For example, criteria 3 and 5 present challenges that hinder FL reuse but, overall, the material is considered reusable.

To summarize the impact or weight of the most limiting criteria onto the respective identified materials, each criterion was given a letter grade of $A, B, C$, or $D$ based on consensus from existing literature. The grades indicate the following: 
A: Criteria completely prevent reusability/recyclability.

B: Criteria present significant limitations to reusability/recyclability. No large-scale practice but some limited examples of small-scale recycling for specific products or individual homeowners reusing material.

C: Criteria typically hinder reusability/recyclability. Although a significant volume may be lost, literature demonstrates examples of large-scale reuse/recycling under some circumstances. D: Criteria present minor limitations to reusability/recyclability. Although minor material volume may be lost, literature demonstrates that materials can be reused/recycling.

Grades to describe the influence of limiting criteria were allocated on a relative basis. There is no absolute differential factor or degree between limiting criteria. Instead, the grades are meant to provide a general summary of the literature, which is mostly qualitative. However, to provide some definition, materials were only considered reusable/recyclable if their limiting criteria were given a $\mathrm{C}$ or $\mathrm{D}$ grade. In the cases where sufficient literature could not be found to draw conclusions or there was found to be no significant limiting criteria, the limiting criteria is marked as 'Not Applicable (NA)' in Table 4.

Table 4 also demonstrates the results of the opportunities analysis, showing regional facilities available to accept the respective reclaimable materials from contractors or homeowners. Five categories of drop off opportunities were found and include:

- Toronto Transfer Stations (TTS)

- Salvages Yards (SY)

- Specialist Recycling Facilities (SRF)

- Used Building Material Organizations (UBMO)

- Architectural Salvage Organization (AS)

To recycle suitable materials in Toronto, materials can be dropped off at TTS, SY, or directly to SRF. Transfer stations are municipally run temporary holding centers for waste materials. Typically waste is dropped off to a transfer station where it is redirected to an appropriate path (to be recycled, treated as hazardous waste, or sent to landfill). On the other hand, salvage yards are independently run businesses that collect smaller amounts of reclaimed material and sell larger batches to recyclers. Finally, reclaimed materials can be dropped directly at a SRF. SRF recycle one or a few types of materials on-site and generally accept materials from the 
public as long as they meet specified requirements (usually related to the amount of material being dropped off. Thus, SY and TTS tend to more useful to small-scale contractors or homeowners who have smaller batches of material to drop-off.

To reuse suitable materials in Toronto, materials can be dropped off at UBMO, ASS, and in some cases, SY. The best example of a UBMO is the Habitat for Humanity Restore, a non-profit organization that reclaims suitable materials from buildings and resells to consumers. UBMO and SY may collect materials directly from building, but will also accept reclaimed materials from the public. As well, UBMO and SY will often store and resell material directly back to the public. Materials such as structural elements like FL to kitchen cupboards can be found at warehouse stores from these types of businesses. ASS act almost exactly in that same way as UBMO and SY, but differ in that they specialize in architectural artefacts, typically antique pieces that exhibit craftsmanship or other rare characteristics. Generally, ASS in Toronto tend to be smaller, and sell reclaimed materials for more than UBMO.

The results in Table 4 do not take in account very important financial factors. However in reality, although there is sufficient knowledge and technology to reuse or recycle suitable material, costs can provide significant limitation to both reuse and recycling. For example, it may be less costly for homeowners to landfill demolition materials than paying for deconstruction. That is, the direct (through resale) or indirect (through donation tax-benefits) paybacks may not compensate the additional costs of deconstruction and reuse. In the case for recycling, cases in the U.S.A. demonstrate that the initial investment into recycling technology may not be compensated by demand for recycled secondary products. Although, as construction standards continue to embrace reclaimed materials, demand for secondary materials is likely to grow.

The results of the materials analysis demonstrate that the limiting factor to recyclability for almost all recyclable materials was contamination from other building debris. In fact, the literature review suggests that contamination is key to limiting industry from embracing building debris for recycling. This issue highlights that demolition is also a significant limiting factor in reclaiming materials for recycling, as it was already understood to completely hinder material reuse. Therefore the results in this thesis support that deconstruction is an important tool to increasing reclamation of reusable and recyclable materials. 
Table 4: Criteria most limiting reuse and recycling of materials identified in archetype houses and the influence grade of corresponding limiting factors.

\section{Reusability}

$\begin{array}{ccc}\text { Criteria } & \text { Most Limiting } \\ \text { Grade } & \text { Criteria } & \begin{array}{c}\text { Drop- } \\ \text { Off GTA }\end{array}\end{array}$

FL width

$>39 \mathrm{~mm}$

FL, width

$<39 \mathrm{~mm}$

Clay Bricks

Cinder Blocks

Concrete

Bricks

Rubblestone

Aggregate

CIP Concrete

Steel

Solid Wood

Sheathing

Engineered

Wood

Sheathing

Aluminum

Vinyl

Asphalt

Shingles

Wood Panels

Glass In

Windows

Solid Wood

Doors

Drywall

Plaster,

Gypsum Lath

Linoleum

Ceramic Tiles

Carpet

Solid Wood

Flooring

Roofing Felt

Breathing

Paper

Waterproofing

Parging

Polyethylene

Vapour Barrier

Insulation

\begin{tabular}{clc}
\hline D & $\begin{array}{l}\text { (3) Regulations } \\
\text { (5) Processing }\end{array}$ & $\begin{array}{c}\text { UBMO } \\
\text { AS }\end{array}$ \\
\hline C & $\begin{array}{l}\text { (3) SP } \\
\text { (3) Processing }\end{array}$ & $\begin{array}{c}\text { UBMO } \\
\text { AS }\end{array}$ \\
\hline C & $\begin{array}{l}\text { (1) Recoverability } \\
\text { (3) Regulations }\end{array}$ & UBMO \\
\hline C & $\begin{array}{l}\text { (1) Recoverability } \\
\text { (3) Regulations }\end{array}$ & UBMO \\
\hline C & $\begin{array}{l}\text { (1) Recoverability } \\
\text { (3) Regulations }\end{array}$ & UBMO \\
\hline D & \multicolumn{1}{c}{ NA } \\
\hline N & \multicolumn{1}{c}{ NA } \\
\hline A & (1) Recoverability \\
\hline$C$ & (3) SP & SY \\
\hline$C$ & (2) Durability & \\
\hline
\end{tabular}

C (5) Contamination

\begin{tabular}{clc}
\hline C & (3) SP & SY \\
\hline A & $\begin{array}{l}\text { (1) Recoverability } \\
\text { (2) Durability }\end{array}$ \\
\hline A & (2) Durability & \\
\hline C & (2) Durability & \\
\hline C & (2) Regulations & UBMO \\
& AS \\
\hline D & (3) SP & UBMO \\
B & (1) Recoverability & AS \\
\hline A
\end{tabular}

A (1) Recoverability

C (1) Recoverability UBMO

B (1) Recoverability

B (5) Contamination

C (2) Durability

A (1) Recoverability

A (1) Recoverability

A (1) Recoverability

A (1) Recoverability

A (1) Recoverability

B

(5) Contamination
Recyclability

\begin{tabular}{|c|c|}
\hline $\begin{array}{c}\text { Criteria } \\
\text { Grade }\end{array}$ & $\begin{array}{c}\text { Most Limiting } \\
\text { Criteria }\end{array}$ \\
\hline
\end{tabular}

\begin{tabular}{ccc}
\hline D & (5) Contamination & TTS \\
\hline D & (5) Contamination & TTS \\
\hline D & (5) Contamination & SRF \\
\hline D & (5) Contamination & SRF \\
\hline D & (5) Contamination & SRF \\
\hline A & (3) SP & \\
\hline A & (3) SP & SRF \\
\hline D & (5) Contamination & SY \\
\hline D & \multicolumn{1}{c}{ NA } \\
\hline C & (5) Contamination & \\
\hline C & (5) Contamination & TTS \\
\hline D & \multicolumn{2}{c}{ NA } \\
\hline
\end{tabular}

A (5) Processing

D (5) Contamination TTS

D (5) Contamination

D (5) Contamination

D (5) Contamination TTS

(5) Contamination TTS

A (5) Contamination

A (3) SP

B (5) Contamination

D $\quad$ NA $\quad$ SRF

D (5) Contamination

C (5) Contamination

A (5) Contamination

A (5) Contamination

A (2) SP

A (5) Contamination

B (3) SP

(5) Contamination 
The results in Table 4 also demonstrate that there is limited infrastructure to drop-off reclaimed materials in the GTA. For example, less than 5 small-scale businesses and not-for-profits used building materials organizations were identified in Toronto. As well about 10 architectural salvage shops were identified, but would likely only be keen to absorb minimal volumes of antique material from SDH fitting the Century archetype.

Recycling facilities to drop-off reclaimed materials were also limited. Facilities to drop-off reclaimed materials such as CIP concrete and gypsum are especially important as the literature of the six focus materials indicated that urban SDH property sizes were too small for material recycling to occur on-site. For five of the materials identified as recyclable based on the adapted criteria, no drop-off opportunities were found in the GTA. Furthermore, six of the materials identified as recyclable based on the adapted criteria were found to be accepted at TTS for recycling, which does not guarantee that the material is actually recycled.

\subsubsection{Discussion of Six Materials}

In total twenty materials and component categories are presented in Table 4. Of these, six materials were chosen to discuss in more detail based on the following three considerations. First is that solid wood products, CIP concrete, and masonry made up half the materials identified in the five archetypes (about half of the total material volume in the five archetypes). Second is that concrete, wood, and metal (such as steel) comprise the largest portions of the CRD waste stream in Canada and are important to address in more detail to touch on the broader discussion on diverting demolition waste from landfill (NRCan, 2006).

Third, and finally, is that the Environmental Protection Act recognizes wood, drywall, brick, concrete, and steel as wastes once removed from a demolition site. No other material found in Table 4 is included in the designation of demolition waste by the EPA. Only when these materials are transported to another site for resale as a construction material are they not considered waste. As these materials are highlighted in regulation, it is important to outline relevant literature and understanding of their reusability. 
Thus the follow six materials were chosen for detailed analysis:

\section{Solid Wood Products CIP Concrete \\ Masonry \\ Gypsum \\ Asphalt Shingles \\ Steel}

\subsubsection{Solid Wood Products}

Solid wood products were identified in all the five archetypes. Figure 27 demonstrates the differences in volumes of the material inventoried in the five archetypes and the total material stock in Toronto's in-use SDH. A further discussion of material stocks in Toronto in-use SDH are presented in the Results and Discussion of the follow section, Objective Three - Impacts of Reclaiming Suitable Materials.

Here solid wood products describe two main groups of materials. The first is framing lumber $(\mathrm{FL})$, which was further divided by width. FL with a width equal or greater to $38 \mathrm{~mm}$ represents studs, floor and roof joists, beams, columns, and roof rafters. FL with a width less than $38 \mathrm{~mm}$ typically represents strapping and wooden lath. The second is wood panels used for exterior cladding or as tongue and groove (T\&G) wall, roof, of subfloor sheathing.
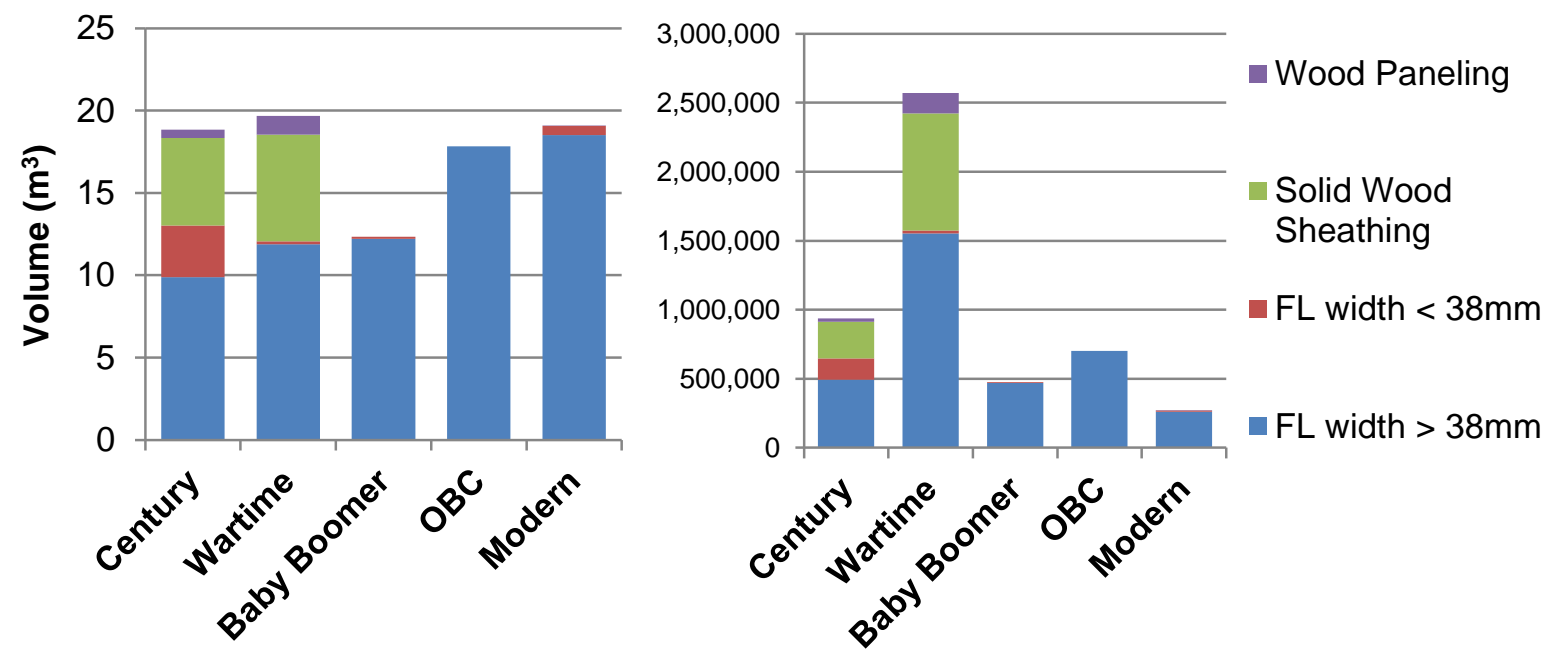

Figure 27. Volume $\left(\mathrm{m}^{3}\right)$ of solid wood products identified in the archetype houses (left) and in Toronto's in-use SDH stock (right). 


\subsection{Recoverability}

Through deconstruction, solid wood can be reclaimed for reuse by separating material at or close to connection points. Each connection of the reclaimed FL or wood panels is removed separately. Case studies from the United States and Australia demonstrate recovery rates of $50-90 \%$ of $\mathrm{FL}$ in deconstructed buildings (DOE, 2010). While literature specific to the recovery rates of wood cladding could not be found, Falk and Guy (2007) suggest 85-90\% recovery (floor area) for wood flooring products.

Deconstruction is pivotal to reclaiming wood for reuse because it minimizes damage that impacts the mechanical and physical properties of the FL or wood panels. Likewise, solid wood products recovered from demolished buildings are only suitable for recycling, as they will likely be severely damaged.
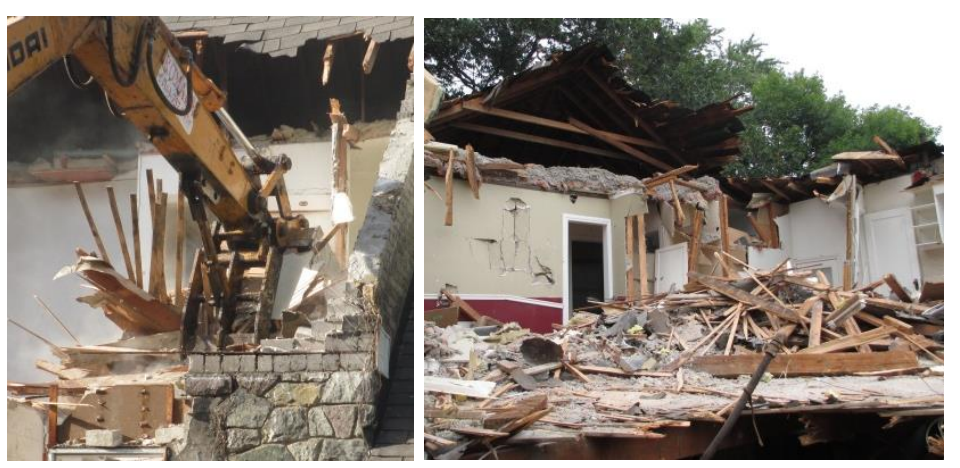

Figure 28. Examples of broken FL members from mechanical demolition of Toronto SDH (pictures taken with permission of demolition crew).

Connections are important in the discussion of the recoverability of solid wood products. The common use of chemical adhesives after 1960 (Baby Boomer, OBC, and Modern Archetypes) in SDH construction adds barriers to deconstruction. Elements with chemical adhesives are virtually impossible to detach at connections without significant damage, so material volume is lost. Thus, the presence of adhesives in SDH may indicate that deconstruction will require more labour, skill, and equipment to reclaim less volume of suitable materials for reuse.

Examples from the literature have conflicting opinions on the recoverability of T\&G sheathing from Century and Wartime archetypes. Although they can be recovered because they are attached by nails, denailing is considered a labour intensive and time consumer task that may not be worthwhile (Falk and Guy, 2007). This is especially true for sheathing as it is often made 
of lower quality wood and roof sheathing can be laden with an accumulation of holes from reroofing (Falk and Guy, 2007).

\subsubsection{Durability}

Wood is generally considered a durable material if maintained in an appropriate environment. Exposure to moisture, temperature, weathering agents, biological growth, and chemical reactants can elicit damage that reduces the life span and mechanical or physical quality of reclaimed solid wood products (Falk et al, 1999; Falk and Green, 1999). For example, Janowiak et al (2005) discovered that a higher volume of wood panels reclaimed from exterior cladding exhibited detrimental damage when recovered from the south face of a building. In contrast, 70year-old FL demonstrated no significant loss in mechanical or load bearing capacities over time when recovered from a well-protected and maintained building envelope (Falk et al, 2008). In fact, mechanical stiffness of older reclaimed solid wood products tends to be higher than its virgin counterparts because the wood has more time to dehydrate, if kept in a dry environment (Falk et al, 2008).

Furthermore, solid wood products typically found in the Century (and in limited cases Wartime archetypes) would likely be more durable than wood harvested more recently (Addis, 2006; Falk and Guy, 2007). Wood harvested from old growth trees tend to be found in larger cuts, with tighter growth rings, and have lower moisture content which make it more durable (Falk 1999, Falk and Guy, 2007). Comparatively, more recently harvested trees likely come from less mature trees as the remaining old growth forest stock is under environmental protection.

\subsubsection{3 a Demand, Secondary Products}

If salvaged appropriately, solid wood products are generally considered reusable for a variety of secondary applications (Falk and Guy, 2007). Consumers typically evaluate the quality of solid wood products based on size, cut, species, aesthetical quality (ex. grains), and/or structural quality (ex. number of knots). Generally, wood found in older buildings is perceived to be superior to wood sold today, sometimes reflecting in higher prices than virgin wood (Falk, 1999; Falk and Guy, 2007). Older buildings such as the Century archetype and to some degree the Wartime archetype showcase wood products from old-growth forests, which have since been depleted, and tend to be hardwood, have tighter grains, fewer defects, and be in larger cuts (Falk, 1999; Falk and Guy, 2007). For example, FL in the Century archetype was cut to 
dimensions at least 20\% larger than FL in the OBC and Modern archetypes (FPL, 1964). The superior mechanical and aesthetic qualities of the FL from old-growth forests are in high demand and limited supply, creating a favourable market and uptake for their reuse.

However solid wood products from any era can be reused into non-structural construction products such as furniture, interior or exterior wood paneling, non-load bearing FL, and flooring. There is also opportunity to reuse reclaimed FL in structural applications of new construction (ex. Davis, 2012; Falk et al, 1999; Falk et al, 2003). For example, a not-for-profit organization in the United States, Emergent Structures, reclaimed 770 studs from estates and reused them to make roof trusses in affordable housing projects (Emergent Structures, 2010).

Research to investigate the appropriateness of reclaimed lumber in structural applications is still limited and mostly concentrated to a research and development (R\&D) program from the United States Department of Agriculture, Forest Services (ex. Falk and Green, 1999; Falk et al, 2003; Falk et al, 2008) and to testing wood reclaimed from deconstructed military buildings (Davis, 2012). The Forest Products Association of Canada promotes the use of reclaimed lumber but, beyond anecdotal support, no Canadian specific research is available for structural applications of reclaimed FL.

USDA literature demonstrates that physical damage in the form of splits, rot, or holes caused during the initial construction, use, and deconstruction most influence FL reusability in structural application and construction (Falk et al, 1999; Janowiak et al, 2007). Without extensive damage, lumber has the mechanical and physical qualities to be reused in structural applications (Falk et al, 1999). Davis (2012) further explains that it is most appropriate for FL to take loads in the same way as their original construction (compression members reused as columns and bending members reused as beams).

At the same time, a significant proportion of $F L$ in construction is non-structural or semistructural. For example, $12 \%$ of the volume of $38 \times 89 \mathrm{~mm}$ studs in the OBC archetype was used in non-load bearing applications. As such, FL would not need to meet the mechanical and physical performance qualities expected if it were used in structural applications.

Solid wood products that are not valuable for reuse applications and are not considered hazardous, can still be reclaimed for recycling. Wood can be recycled (usually downcycled) into 
a variety of products. Some main examples include wood being chipped or shredded into animal bedding, landscape mulch, and fuel stock (Dovetail Partners, 2013). As well, engineered wood products such as subflooring and sheathing contain recycled wood. Although there is no literature to support that engineered products contain recycled wood from demolition debris, there also is no evidence to suggest that reclaimed wood cannot be incorporated.

\subsubsection{3b Demand - Regulations}

The OBC 2012 acknowledges the use of reclaimed FL in SDH construction in a compliance alternative regarding grading standards for FL by end use for residential buildings. The Province of Ontario (2012) states:

Sound used lumber may be acceptable for reuse without a grade stamp provided that: (a) visual examination shows no excessive weakening by holes, notches, nail splits or other damage, (b) where the grade or species is unknown, the minimum grade shall apply for span table use, and (c) lumber has not been subjected to termite infestation.

The reference suggests that reclaimed ungraded FL can be reused provided it meets the three criteria listed above. Allowing for ungraded $\mathrm{FL}$ is important in promoting reuse, as there are no standardized assessment methods established to determining grade of reclaimed wood products. Current visual grading practices for virgin FL are not transferable to reclaimed SLF (Falk et al, 2008; Davis, 2012). Defects associated with low-grade scores may not actually impact the structural properties when reclaimed FL is tested appropriately (Falk et al, 2008; Davis, 2012).

There are no regulatory measures or policies regarding reclaiming wood with lead paint. Lead paint is likely to be found on wooden cladding materials before 1976 . There are no regulations permitting or banning the resale of wood with lead paint, and it is therefore treated as a hazardous waste and disposed of accordingly without any consideration for reuse (Napier et al, 2005). Disposal may be premature as there is evidence to suggest that, with proper methods, lead paint can be safely removed from valuable reclaimed wood for reuse/recycling (Janowiak et al, 2005). 


\subsection{Preparation for Secondary Use - Processing}

Nails, bolts, and other hardware are a prime source of nuisance for preparing wood for reuse (Falk and Guy, 2007). The process of removing hardware from wood can be time consuming, physically demanding, and costly. For example it took a whole day of work for 80 volunteers to de-nail the 770 pieces of FL reused for roof trusses for the Emergent Structures project (Emergent Structures, 2010). Although paid professional are likely to be more time efficient at removing nails, the current industry is not equipped for a high intake of reclaimed wood (Dovetail Partners, 2013). The lack of skilled professionals results in low processing efficiency and usually higher costs (Dovetail Partners, 2013).

While trimming often removes significant damage and can increase grade, the length of the secondary product is reduced which can impact how it can be reused. Data demonstrates that anywhere between $305 \mathrm{~mm}$ to $900 \mathrm{~mm}$ or at least $22 \%$ of the total length needs to be trimmed to alleviate the effect of damage (Falk et al, 1999; Davis, 2012). Falk and Guy (2007) suggest that a $25 \%$ loss in volume should be expected when estimating the amount of reclaimed lumber that can be reused. However, virgin $38 \times 89 \mathrm{~mm}$ lumber is typically sold at lengths of $2350 \mathrm{~mm}$ and while shorter pieces can be incorporated into framing, Falk and Guy (2007) suggest that reclaimed FL shorter than $910 \mathrm{~mm}$ has limited application in construction.

\subsection{Preparation for Secondary Use - Contamination}

Lead was a base for paint for a number of years and was applied readily on solid wood panels such as exterior cladding that, in some cases, is now considered in demand. Wood with lead paint can be milled to remove the paint layer and reclaim the remaining valuable wood (Janowiak et al, 2005). However there is not enough research or regulation at present to draw conclusions or guide practices regarding reclaiming wood with lead paint (Napier et al, 2005).

Any wood in contact with building paper or roofing underlayment is likely to be contaminated (Falk and Guy, 2007). Since wall and roof sheathing tends to be on the exterior half of envelope systems, the sun's heat bakes a bituminous residue onto the wood panels over time that cannot be removed, limiting reuse (Falk and Guy, 2007). 


\subsubsection{CIP Concrete}

Figure 29 demonstrates that cast in place (CIP) concrete and aggregate was identified in all the archetypes except the Century house, which had $0.6 \mathrm{~m}^{3}$ of only aggregate, Figure 29.

Nevertheless, the following discussion focuses of the reclamation option for CIP concrete. Only the OBC and Modern archetypes had CIP concrete basement walls, whereas the remaining three archetypes utilized clay and cinder bricks. CIP concrete was used for the basement slabs and footings in the Wartime, Baby Boomer, $\mathrm{OBC}$, and Modern archetypes, ranging from 75 to $101.6 \mathrm{~mm}$ deep.
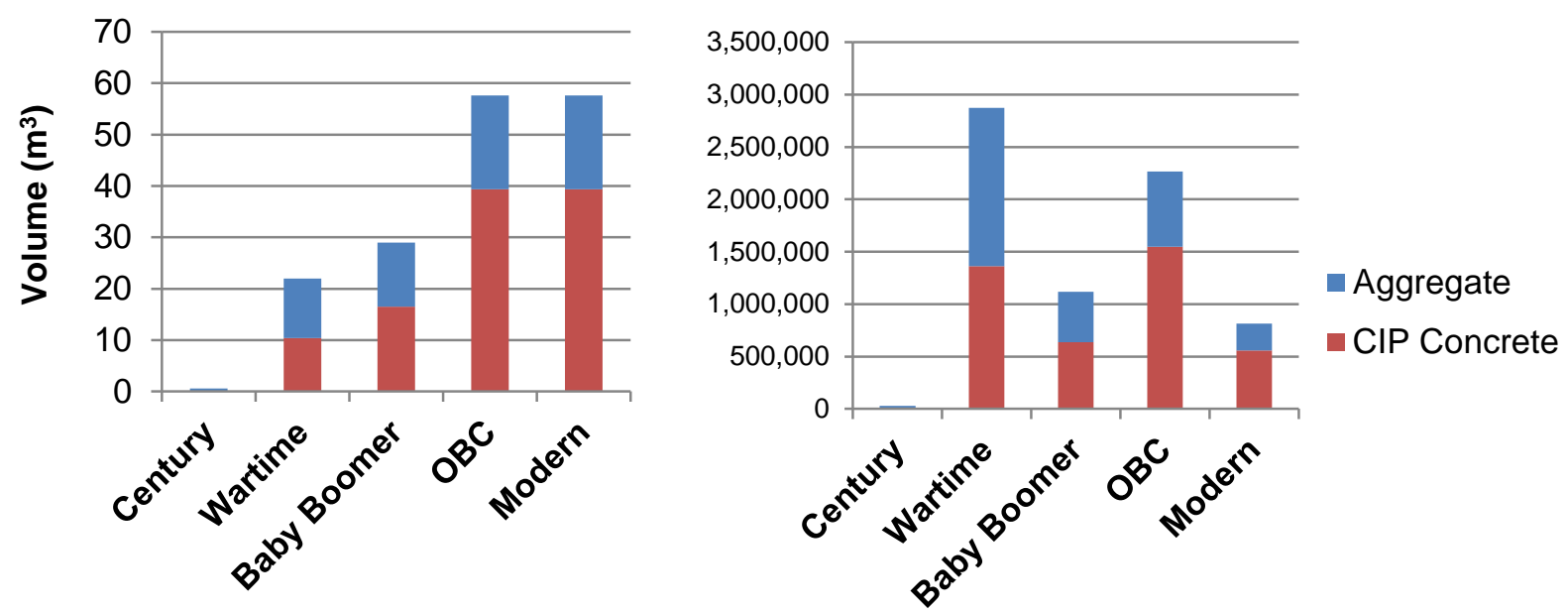

Figure 29. Volume $\left(\mathrm{m}^{3}\right)$ of CIP concrete and aggregate in archetype houses (left) and in Toronto's in-use SDH stock (right).

\subsection{Recoverability}

The only practical way to remove CIP concrete from obsolete SDH is to break it down to smaller pieces. Because it cannot be reclaimed intact, reuse is not an option. In limited cases, whole foundations have been reused through restoration on the original site for new construction. This is likely only possible for foundations built more recently because of changing requirements for foundation performance.

Crushed stone on the other hand, is less difficult to reclaim because it is already broken up and easy to remove from site. Although there are issues of contaminations from soil and other extraneous building materials, and so crushed stone has to be effectively cleaned and sorted to be suitable for reuse. 


\subsection{Durability}

Concrete is an engineered material that is typically designed to withstand environmental stressors over long periods of time. Concrete applied below grade is faced with prolonged exposure to water which leaves it susceptible to deterioration if not properly protected. Likewise, CIP concrete can develop cracks from initial construction moisture. Damage such as cracking to below-grade concrete is important to recycling when concrete has to be cracked anyway to be removed, but is an important issue if the concrete is going to be reused as a foundation (US Army Corps of Engineers, 2004).

\subsubsection{3a Demand - Secondary Products}

Concrete can be downcycled as concrete aggregate (RCA). The City of Toronto's uses RCA in about $95 \%$ of sewer, water main or road construction projects that require backfill or sub-base (Hein, 2011). In Toronto, RCA is economically attractive because it is readily available and requires less transportation than raw aggregates from quarries (U.S. Army Corps of Engineers, 2004). However most RCA is sourced from roadways and no substantial market for reclaimed concrete from small obsolete buildings current exists in the city (Hein, 2011; MNR, 2009).

One prominent example of RCA sourced from building demolition in Toronto is during the renovation of the Toronto Pearson Airport. When the former Terminal One was being demolished, 200,000 tonnes of concrete was reclaimed, cleaned, and crushed on-site to make RCA for road base. Non-traditional methods were used to strip off concrete in sections from the terminal to keep the reclaimed concrete as separate as possible from other materials. (RCO, 2006)

RCA can be also used in Portland cement concrete mixtures. Literature from Southern Ontario demonstrates that concrete mixtures can be designed to address the unique physical and mechanical properties of RCA, but research focuses on designing mixtures with suitable strength and durability for road applications (Bulter et al, 2011; Smith, 2009). After two years of use, roads paved with $30 \%$ RCA concrete performed comparable with concrete with no RCA (Smith, 2009).

Colorado, US provides an example of RCA that highlights its use in structural applications. No such example could be found in Canada. In Colorado, 560 tonnes of reclaimed concrete from 
airport runways was recycled as RCA and incorporated into concrete that made up the foundation and tilt-up panels of a near-by industrial complex. In addition to RCA, the concrete engineered by ReCrete Materials Inc. also contained reclaimed flyash, demonstrating that RCA could contribute to other alternative methods of structural concrete production. (CMRA, 2013)

\subsubsection{3b Demand - Regulations}

RCA is accepted by the Ontario Provincial Standards for Roads and Public Works Standard (OPSS) 1010 Material Specification for Aggregates. According to OPSS 1010, RCA can be used in granular A, B, and M aggregates to be used as backfill, granular base and sub-base for pavement, stabilizer for soft subgrades, and under fill for concrete on grade slabs (Province of Ontario, 2012). RCA can make up $100 \%$ of the composition of aggregate material where it is permitted but may only contain $1 \%$ by mass or less extraneous building material, such as brick, gypsum, and wood (Province of Ontario, 2012).

Mirroring the lack of case studies, RCA and RCA concrete are not recognized within the OBC and there are no other Canadian standards that address the inclusion of RCA into construction materials (Province of Ontario, 2012).

\subsubsection{5a Preparation for Secondary Use - Processing}

The process of creating RCA is similar to making aggregate from raw resources. Thus the necessary equipment and facilities are readily available. Essentially, recycling concrete requires concrete to be crushed to desirable sizes using crushers and sieves and to be cleaned of possible contaminates (Bulter et al, 2011; Smith, 2009; U.S. Army Corps of Engineers. 2004).

In the case for urban SDH, concrete would likely need to be collected and prepared for downcycling (crushed) at an external site. Toronto's SDH properties tend to be too small to allow for on-site crushing. In Southern Ontario, concrete from SDH would need to be collected onsite and brought to a Toronto transfer stations or transported directly to a nearby quarry sites that is equipped to crush and clean reclaimed concrete and prepare it as RCA. 


\subsubsection{5b Preparation for Secondary Use - Contamination}

Demolition activities tend to create batches of heterogeneous materials, causing additional challenges to isolating materials. Reclaimed concrete from demolition tends to be contaminated with extraneous building materials (U.S. Army Corps of Engineers. 2004). If not separated, the resulting RCA has undesirable physical and mechanical properties and limited to no secondary applications in construction (Butler et al, 2011).

\subsubsection{Masonry}

In this section masonry describes clay bricks, concrete brick, and cinder blocks. However the following discussion focuses most on the reclamation issues of clay bricks. Clay bricks and mortar were identified in all the archetypes and are the focus of this discussion. Clay bricks accounted for $49 \%$ of the total material volume in the Century archetype as they were used for in triple wythe for the basement walls and in double wythe for the above ground walls and acted as the primary load bearing element of the house, Figure 30.
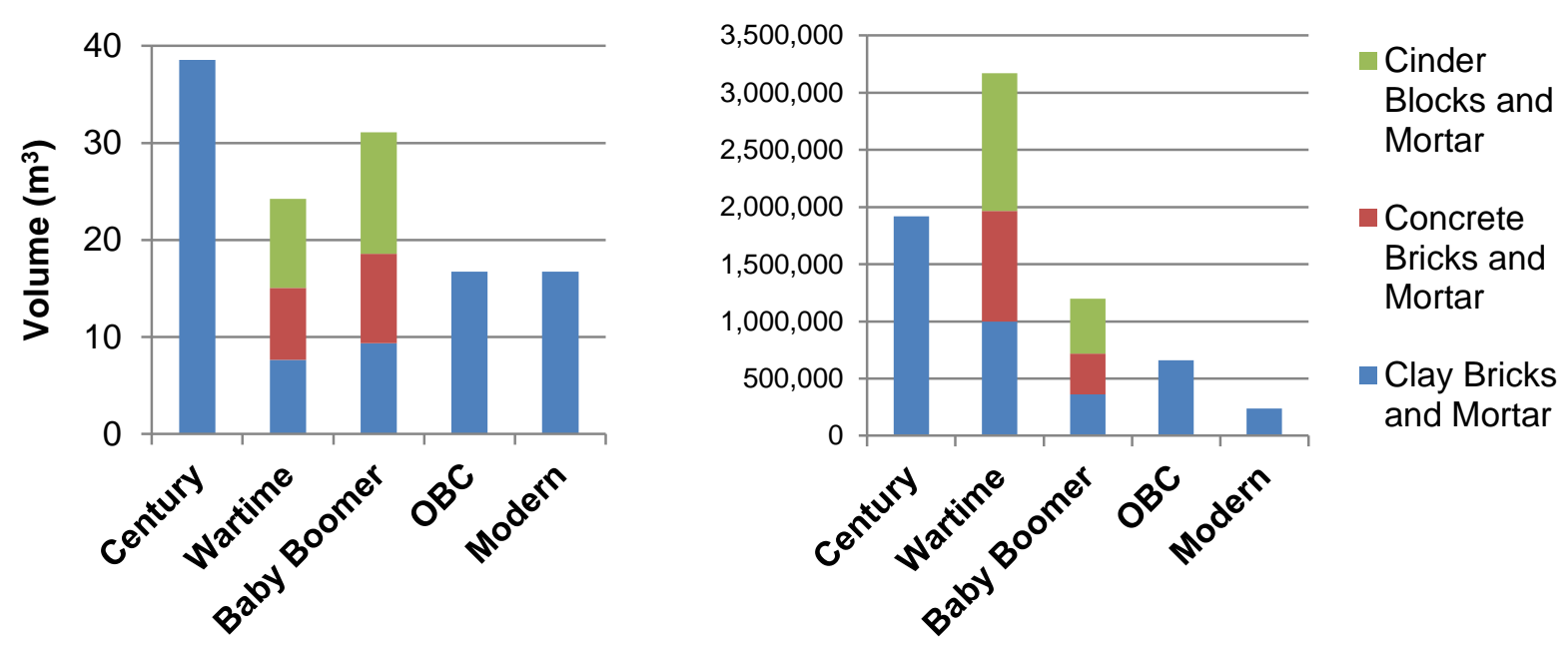

Figure 30. Volume of masonry in archetype houses (left) and in Toronto's in-use SDH stock (right).

Concrete masonry was used in the conjunction with clay bricks in the Wartime and Baby Boomer archetypes. As well, concrete was used in cinder blocks for basement walls and as bricks in the inner layer of the load bearing double wythe brick walls on the first floor of the houses. Likewise the $\mathrm{OBC}$ and Modern archetypes utilized clay brick as their primary cladding material. 


\subsection{Recoverability}

Masonry is installed into buildings with chemical bonds, in the form of mortar. In the case of brick, the strength of mortar determines the success of recovery. One mortar type commonly used in the early part of the twentieth century is lime based which allows masonry to be easily separated, whereas the mortar types commonly used since the late 1950's are cement based and have a much stronger chemical bond that makes separation significantly more difficult and timely. Thus masonry attached with cement mortar is generally not considered recoverable for reuse whereas masonry with lime based mortar can be recovered and cleaned for reuse (Falk and Guy, 2007; Norby et al, 2009).

Based on the dates of transition from common use of lime based mortar to cement based mortar, it is likely that only masonry from the Century and Wartime archetypes could be reclaimed through deconstruction for reuse. Masonry from the remaining archetypes would be difficult to impossible to remove without significant damage or material loss through deconstruction because of mortar strength. This may be especially true since these archetypes tend to use cored bricks that have less strength and are more likely to be damaged through recovery. The recovered masonry would likely be fragmented and better suited for recycling. Fragmented brick for recycling does not require the special care involved in deconstruction and so material could be recovered through demolition as seen in Figure 31, which is faster and perceived as a less expensive process.

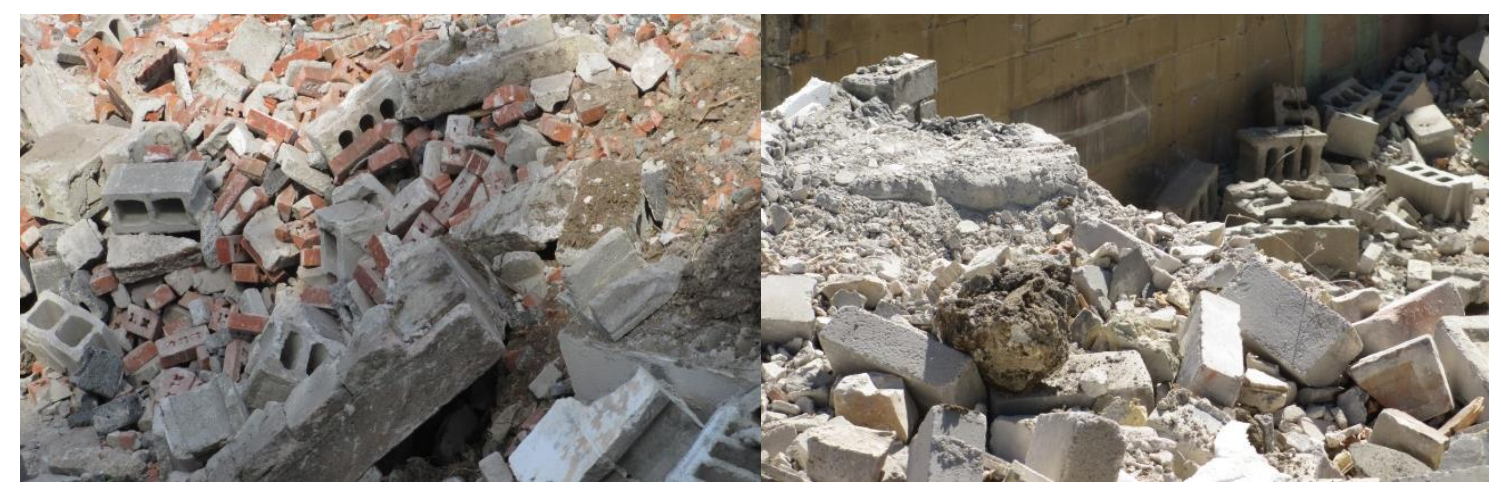

Figure 31. Examples of masonry on demolition sites of Toronto SDH (pictures taken with permission of on-site demolition crew).

Houses of double wythe load bearing clay brick walls like the Century archetype that utilize lime mortar are the most ideal and cost effective to deconstruct for clay brick recovery (Norby et al, 
2009). The simplicity of the load bearing wall assembly, in that it is primarily made up of only clay brick and mortar, minimizes the time and space required to sort and store separate materials (Norby et al, 2009). Especially since small urban lots, like those found in the City of Toronto, have issues of space.

\subsection{Durability}

The remaining masonry in Toronto's housing has proven to be naturally durable against environmental elements. As well, there is consensus among the literature that masonry is a durable material (Falk and Guy, 2007; Norby et al, 2009). For example, Cavalline, and Weggel (2013) determined clay brick reclaimed from a school building had mechanical and thermal conductivity properties that fell within ranges of virgin clay brick.

\subsubsection{3a Demand - Secondary Products}

With some exception to firing times and temperature, there has not been a significant change in clay brick manufacturing technology (Norby et al, 2009). Reclaimed clay bricks are often made with similar methods as their virgin counterparts (Norby et al, 2009). Reclaimed clay bricks, especially non-extruded clay bricks, are in demand because of their durability in terms of performance, but also because of their aesthetic qualities (Falk and Guy, 2007). Weathering provides a natural aged look that cannot be duplicated in virgin products and is considered beautiful, rare, or unique.

The remaining clay brick may be still reclaimed to be downcycled into aggregate, to be either used as crushed clay brick or, limitedly, in concrete mixtures. There has been minimal research in clay brick downcycling in a North American context (Bektas et al, 2009; Cavalline and Weggel, 2013; Khalad and DeVenny, 2004). Furthermore, most of this research has focused on downcycling post-industrial or excess unused clay brick (Khalad and DeVenny, 2004). In Toronto, downcycled unused masonry from construction waste sources as lake-fill at Leslie Spit, a public park site (Friends of the Spit, 2013).

The bias against clay brick sourced from demolition is primary due to the inclusion of mortar, where reclaimed batches typically consist of $70 \%$ brick and $30 \%$ mortar by volume (Cavalline and Weggel, 2013). When downcycled, the resulting product is called recycled brick masonry aggregate (RBMA) and has unique physical and mechanical properties that impact its 
effectiveness as a raw aggregate substitute in concrete (Cavalline and Weggel, 2013; Yang et al, 2011).

Nevertheless, the properties of RBMA do not make it impossible to utilize. For example, Cavalline, and Weggel (2013) engineered RBMA concrete that met standards for structural and pavement performance in the United States. As well the international community shows examples of engineered RBMA concrete with comparable properties to traditional concrete as reviewed by Khalad and DeVenny (2004). However research in this field is still young, especially in comparison to the progress made in engineering concrete with RCA (Chen et al, 2003; Khalad and DeVenny, 2004).

\subsubsection{3b Demand - Regulations}

Although there is evidence to support that RBMA can be successfully incorporated into paving materials, RBMA is not recognized in OPSS 1010 Material Specification for Aggregates.

On the other hand OBC 2012 does address the use of reclaimed masonry for reuse. The Province of Ontario (2012) states outline that as long as the masonry complies with Section 9.20 and is, "...free of old mortar, soot or other surface coating..." and meets performance standards of virgin masonry it can be used in new construction. If brick does not meet these standards, than The Compliance Alternatives for Residential Occupancies, Section 9 of the OBC insinuates that reclaimed masonry would not be acceptable as the primary exterior cladding material for new residential construction. Specically, the Province of Ontario (2012) states, "Used masonry may be reused for patching and filling openings to match adjacent work. Used interior brick may not be used for exterior applications."

\subsubsection{5.a Preparation for Secondary Use - Processing}

The process of recovering clay bricks can be time consuming and costly (Falk and Guy, 2007). Each brick unit needs to be recovered and cleaned of mortar before being stacked and transported. In Toronto professional services are available to clean clay bricks from pollutants like carbon and some paints with high-pressure hydrochloric acid or hot steam and water sprays. Because preparation for reuse is mostly done on the demolition site and is time consuming, costs associated with bringing skilled professional labour to the building site can get high (Norby et al, 2009; Cavalline, and Weggel, 2013). 
RBMA needs minimal preparation, as reclaimed batches need to be crushed, sorted, and washed (Cavalline, and Weggel, 2013; Chen et al, 2003). Khalaf and Devenny (2004) review that in order to achieve optimal aggregate sizes for concrete mixtures (roughly $20 \mathrm{~mm}$ ), reclaimed clay brick and mortar must be crush twice. Although on-site crushers can be used, crushing at centralized locations is ideal for demolition debris as it allows for additional cleaning technologies to remove extraneous building materials from RBMA (Khalad and DeVenny, 2004). Although no specific sources of clay brick crushing facilities could be found in the Toronto Area.

\subsubsection{5.b Preparation for Secondary Use - Contamination}

Contamination does not appear to be an important issue for clay brick reuse, although there is very little literature on the topic. Because clay bricks do not require any surface treatments, they are usually free of hazardous contaminates (except dirt from years of exposure to particulates like carbon) when reclaimed for reuse (Norby et al, 2009). On the other hand, RBMA is likely to be contaminated with extraneous building materials when it is reclaimed from demolished buildings (Cavalline, and Weggel, 2013).

\subsubsection{Gypsum}

Gypsum, in some form, is used in all of the archetypes as the primary interior finish for walls. The Century and Wartime archetypes used a wet application gypsum plaster on lath, Figure 32. Although lime plaster was predominately used before the 1900s. Figure 32 also demonstrates that transitioning from wooden lath around the 1930s to a gypsum lath allowed the thickness, and therefore total volume, of plaster to be reduced. Gypsum lath is much like drywall in that it is panels of gypsum material sandwiched between two pieces of adsorbent paper, but is twice as thick. Drywall Gypsum lath was sometimes backed with aluminum foil that acted as a rudimentary vapour barrier and, on the other side, had a dimpled surface that was plastered with gypsum.

Drywall, which is $12.7 \mathrm{~mm}$ thick is typically sold in $1219 \times 2438 \mathrm{~mm}$ panels and is comprised of a gypsum core sandwiched between two pieces of paper, accounting for $95 \%$ and $5 \%$ of the total weight respectively. Drywall was identified in Baby Boomer, OBC, and Modern archetype, Figure 32 and is the focus of the following discussion. 

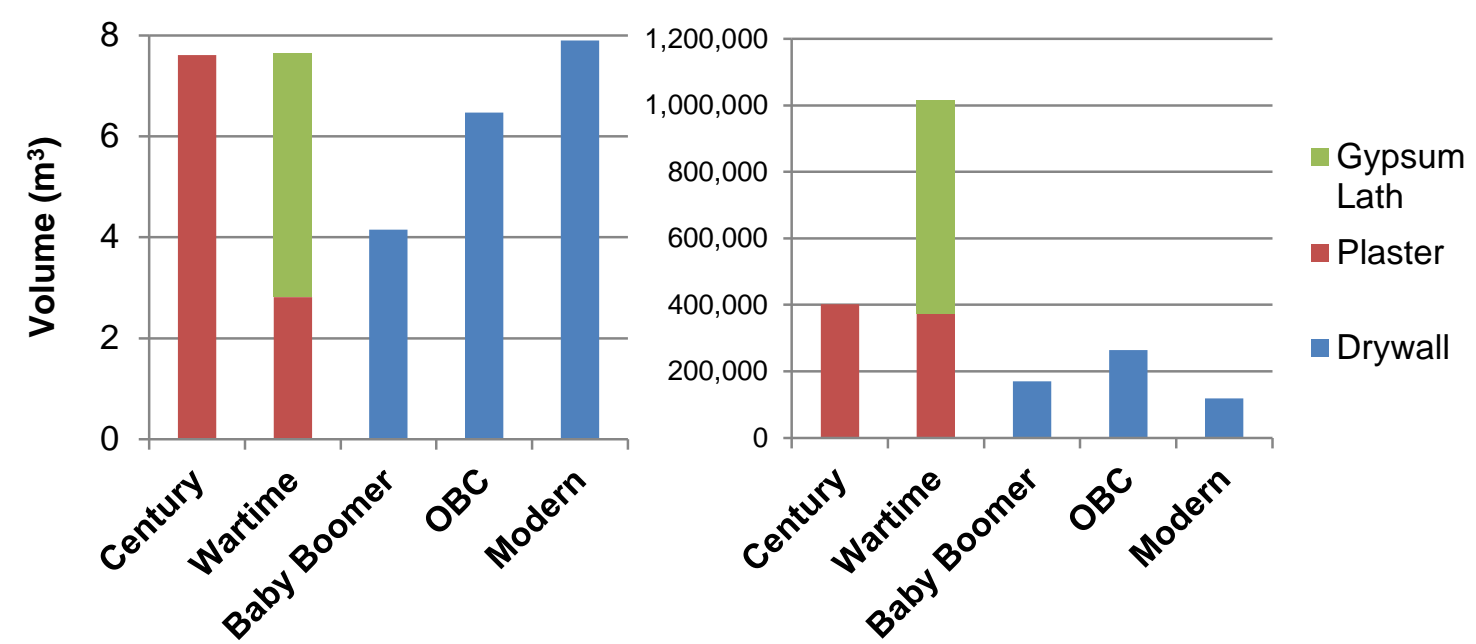

Figure 32. Volume of gypsum products in archetype houses at the archetype houses (right) and in Toronto's in-use SDH stock (left).

\subsection{Recoverability}

Gypsum in plaster is impossible to recover in a form suitable for reuse. Because plaster is applied wet, it bonds chemically to lath. The only effective method of remove gypsum is to chip it away from the underlying lath, leaving the material in a fragmented condition not suitable for reuse.

The brittle nature of the gypsum layer in drywall makes it difficult also to reclaim in a reusable condition (Falk and Guy, 2007). As well the damage caused by screwing drywall into wooden studs makes it impossible to recover whole undamaged panels of drywall. Instead, it is more practical to reclaim smaller sections of drywall for reuse, in a limited way, for applications that require patch-up work (Falk and Guy, 2007).

Gypsum can be recycled (Addis, 2006; Falk and Guy, 2007). The interior finishes are ideally removed separately from the remaining materials, separated and kept away from other building materials. Typically, demolition does not allow for this as once the whole building is levelled it is impossible to ensure no other debris has contaminated the gypsum debris. 


\subsection{Durability}

Gypsum is considered a durable material when installed. Durability is only compromised if drywall is extensively exposed to moisture and/or degrading biological agents, such as mould or mildew. However in dry, protected environments, drywall can be useful for up to 70 years and there are examples of plaster walls remaining over 100 years, although these typically need repair at some point (NAHB and BoA, 2007). The issue is that gypsum becomes significantly less durable once it is removed from the building assembly, as it is easily damaged through deconstruction, transportation, storage, and reconstruction.

\subsubsection{3a Demand - Secondary Products}

Drywall contains valuable paper and gypsum material that can be recycled or downcycled into secondary products. There is a large and diverse market for downcycled paper products (Saotome, 2007). Recycled gypsum can also be downcycled as animal bedding or as soil and compost amendment for agriculture or waste management (WHMD, 2007). As well, gypsum can be recycled into construction related products such as new drywall, and stucco, or downcycled as an additive for cement and concrete products (Saotome, 2007; WHMD, 2007). In Ontario, drywall recycler New West Gypsum, states that drywall in Ontario with recycled content incorporates about $22 \%$ recycled gypsum (likely by weight) (New West Gypsum Recycling Inc., 2013). However it is important to note that New West Gypsum currently only accepts postindustrial or unused construction waste drywall (New West Gypsum Recycling Inc., 2013).

The bias against recycling drywall from building demolition is that the materials is perceived as having more risk of being contaminated with other building materials (Saotome, 2007; Chandara et al, 2009). Since non-used, post-industrial, and construction waste gypsum is readily available and requires less cleaning than used gypsum, there isn't a high demand for the product. As such, case studies that discuss recycling or downcycling of drywall focus on post-industrial or construction waste gypsum (Saotome, 2007), although there is no literature to suggest that clean demolition waste could not be incorporated into recycling practices as well.

There are also no apparent initiatives in Toronto or Ontario that use recycled gypsum as an additive in cement mortar mixtures. Although some international research has demonstrated recycled gypsum can offer cost benefits while meeting mechanical standards (BRE and WRAP, 2008; Chandara et al, 2009; Onishi et al, 2012). In fact, Onishi et al (2012) determined that 
reclaimed demolition gypsum integrated into cement mortar could be used foundation work for construction of new SDH in Japan. Furthermore, recycled gypsum may be economically favourable because of increasing costs of raw gypsum. For example BRE and WRAP (2008) determined that recycled gypsum was half the cost of raw gypsum in the United Kingdom, resulting in an overall $24 \%$ lower cost in concrete production.

\subsubsection{3b Demand - Regulations}

There are no regulations for the specific use of reclaimed gypsum. The OBC 2012 does not address reclaimed gypsum. Generally, drywall has to conform to CAN/CSA and ASTM performance standards, but neither of these specifically support or discourage the use of recycled gypsum (Province of Ontario, 2012). Thus, responsibility is left to the manufacturer to ensure that drywall with recycled content meets the corresponding performance standards. For instance, New West Gypsum tests the quality of drywall products with recycled gypsum, showing that up to $33 \%$ by weight can be incorporated while meeting performance standards (New West Gypsum Recycling Inc., 2013).

There are also no regulations that specifically address recycling drywall with lead paint. Management of lead is covered under the EPA regulation and it is considered a hazardous waste. No North American research or case studies could be sourced to demonstrate that gypsum could be safely extracted from drywall by removing contaminated paper. Rather, the lack of literature suggests, that whole specimens of drywall are treated as hazardous waste and discarded appropriately. Likewise, gypsum from plaster, lath, or drywall can be remediated from small amounts of lead contamination by downcycling it as a soil amendment.

\subsubsection{5a Preparation for Secondary Use - Processing Demands}

The process of gypsum recycling is relatively simple as it is highly mechanically optimized (Saotome, 2007; BRE and WRAP, 2008). Before drywall batches can be processed at recycling facilities, they are screened for extraneous material debris (New West Gypsum Recycling Inc., 2013). Once effectively cleaned of other materials, drywall is separated into it gypsum and paper components (New West Gypsum Recycling Inc., 2013). The resulting materials are shredded and incorporated into their respective new products (New West Gypsum Recycling Inc., 2013). Gypsum-paper separation and shredding can also be done directly on large 
construction sites and downcycled onsite as soil amendment, eliminating transportation costs (WHMD, 2007).

\subsubsection{5b Preparation for Secondary Use - Contamination}

Recycling gypsum and paper from demolition is limited by possible contamination of extraneous building materials (Saotome, 2007; Onishi et al, 2012). Ensuring that drywall is clean is critical to meeting performance standards for drywall, cement, and concrete products but requires more time and labour (BRE and WRAP, 2008). Along with possible contamination from materials, reclaimed drywall can also be contaminated by paint containing lead. In this case, it is likely that general practice is to discard the material as hazardous waste.

\subsubsection{Steel}

Steel was found in four of the five archetypes,

Figure 33. In the Wartime and Baby Boomer archetype steel was found in angle lintels above openings, but each house also had one wide flange beam. In the OBC and Modern archetypes however, steel was predominate in 10 Wide Flange beams with two steel plates and in 24 columns. Furthermore, Figure 33 demonstrates that the modern archetype has the highest volume of steel as it also utilized steel in its non-load bearing partitions as studs and plates.
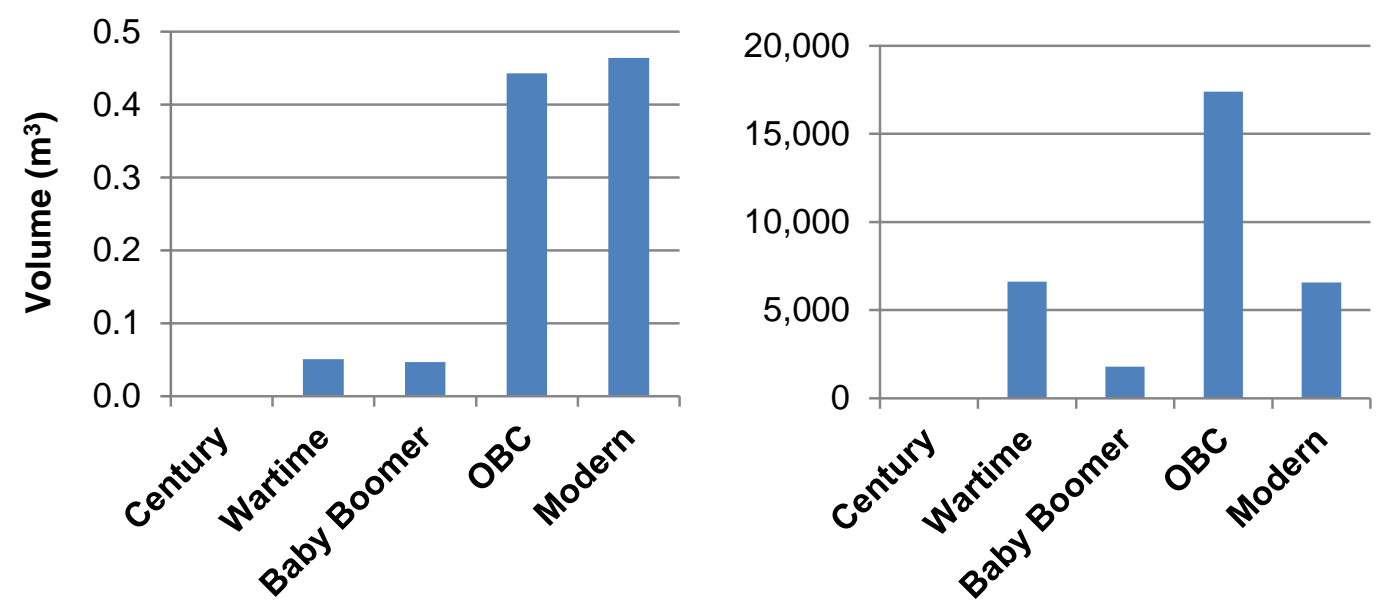

Figure 33. Volume of steel in archetype houses for the five archetypes (left) and in Toronto's inuse SDH stock (right). 


\subsection{Recoverability}

Structural steel elements in the archetypes rely mostly on mechanical but also on welded connections. For mechanical connections it is possible to recover steel is a state that is suitable for reuse. However, difficulty arises in how the steel is treated through and after it is recovered. For instance, steel used at lintels and as studs tend to be relatively thin, less than $10 \mathrm{~mm}$ and is vulnerable to damage. This is especially true in demolition where steel elements are knocked down mechanically before they are recovered from the remaining debris. Steel beams and columns may be less vulnerable to damage than lintels and studs, but special care would be needed to ensure limited damage, especially at the ends.

Steel is relatively easy to isolate from other demolition debris because of its magnetic properties. Thus steel can be recovered for recycling. In a review of steel recovery in Canada, Gorgolewski et al (2006) determined only about $1 \%$ (by mass) of steel was landfilled because it could not be recovered from demolition debris. Likewise, steel is one of the most recycled materials in the world.

\subsection{Durability}

Steel is generally considered a durable material. Corrosion from rust can occur when steel is exposed to water and oxygen. Once rust has formed, it creates a positive feedback loop that further encourages corrosion by holding pollutants and moisture onto the steel's surface. However this is less of an issue for steel in buildings, which corrosion is not usually a significant issue.

The durability of steel products, in terms of mechanical and physical properties, rely heavily on the amount of care taken in it recovery from the building. Where damage can greatly impact the ability of products to be reused in structural applications without significant loss in volume from trimming ends.

\subsubsection{3a Demand - Secondary Products}

Steel retains its material properties, which makes it suitable for reuse. Cooper and Allwood (2013) used industry interviews and literature to estimate that $50-75 \%$ of mass of structural steel 
and cold-rolled sections had potential for reuse, accounting for losses in mass due to damaged ends and through processing to make steel ready for reuse.

In Ontario, research in steel reuse is headed by Ryerson University but focuses mostly on nonresidential buildings. Gorgolewski et al (2006) determined there is not a significant demand for reclaimed steel in non-residential buildings, even though it is typically found at lower costs than virgin steel. However in the case of low-rise residential buildings lower costs are more often taken advantage of. According to the archetypes measured in this thesis, SDH use relatively small volumes of steel in comparison to other materials identified in the construction drawings like concrete, brick, and FL. Therefore, unlike other building types, SDH can utilize irregular and small pieces of steel for structural applications.

Another limitation to steel reuse is the high monetary value of scrap steel for recycling (Gorgolewski et al, 2006, Falk and Guy, 2007). Coupled with the cost saving of demolition in comparison to deconstruction, reclaiming steel for reuse can be perceived as economically less attractive than recycling (Gorgolewski et al, 2006, Falk and Guy, 2007). However, this also depends on the steel market (Gorgolewski et al, 2006).

Generally, recycling in the metal sector is not a new initiative and has historically been undertaken for steel products, in a large part because it has been economically advantageous to use reclaimed steel rather than virgin iron ore (Steel Recycling Institute, 2011). Steel is $100 \%$ recyclable and, theoretically, can be recycled indefinitely without losses to quality. Therefore, steel can be recycled back into steel, including steel products for the construction industry.

\subsubsection{3b Demand - Regulations}

There is a general lack of code and standards concerning use of reclaimed steel for reuse. Particularly the OBC generally references the use of steel that meets certain mechanical performance or grade standards (Province of Ontario, 2012). However, the OBC 2012 permits the use of structural steel elements, such as column, based on dimensions and not by grade. For example, Province of Ontario (2012) outlines in section 9.17.3 that, "steel pipe columns shall have an outside diameter of not less than $73 \mathrm{~mm}$ and a wall thickness of not less than 4.76 $\mathrm{mm}$ ". 
When dropped off at a SY, steel can be graded before it is resold to the public. One method to determining the mechanical properties of reclaimed steel is to use coupon testing to determine performance (Gorgolewski et al, 2006). However, mechanical properties can also be assumed using default properties from relevant CSA standards. Another method is to assume structural capabilities by referencing historical data based on basic understanding of when the material was manufactured and its physical dimensions (Gorgolewski et al, 2006). However, using this method sometimes requires assuming the lowest performance grade based on manufacture date, which can limit the application for the reused steel (Cooper and Allwood, 2013). Although, this limitation may be less significant in residential buildings.

\subsubsection{5a Preparation for Secondary Use - Processing}

Contractors from demolition projects in Canada favour directly selling reclaimed steel for reuse (Gorgolewski et al, 2006). On-site sales are advantageous because the contractors are not left with the responsibility of locating and transporting steel to a secondary site (drop-off facility).

Steel recycling is a highly mechanized process involving cleaning, sorting, and sometime cutting or shredding (Gorgolewski et al, 2006). Reclaimed steel is transported directly or indirectly (through brokers) back to steel manufacturers for recycling (Gorgolewski et al, 2006). In North America, the majority of steel manufacturing utilizes electric arc furnace (versus basic oxygen furnace) technology, which can be fed up to $90 \%$ reclaimed steel. Typically recycled steel in North America has 55\% post-consumer and 35\% pre-consumer reclaimed steel (Steel Recycling Institute, 2011).

\subsubsection{5b Preparation for Secondary Use - Contamination}

Because steel can be easily removed from extraneous materials because of its magnetic qualities, contamination is not a critical issue for reuse or recycling.

\subsubsection{Asphalt Shingles}

Asphalt shingles were found in all five archetype SDH, Figure 34. The volume of asphalt shingles correlates directly with the area of roof, which is evidently largest in the OBC and Modern archetypes. Although clay, wood, and rock are sometimes used as roofing materials on $\mathrm{SDH}$, asphalt shingles are by far the most popular roofing material. 

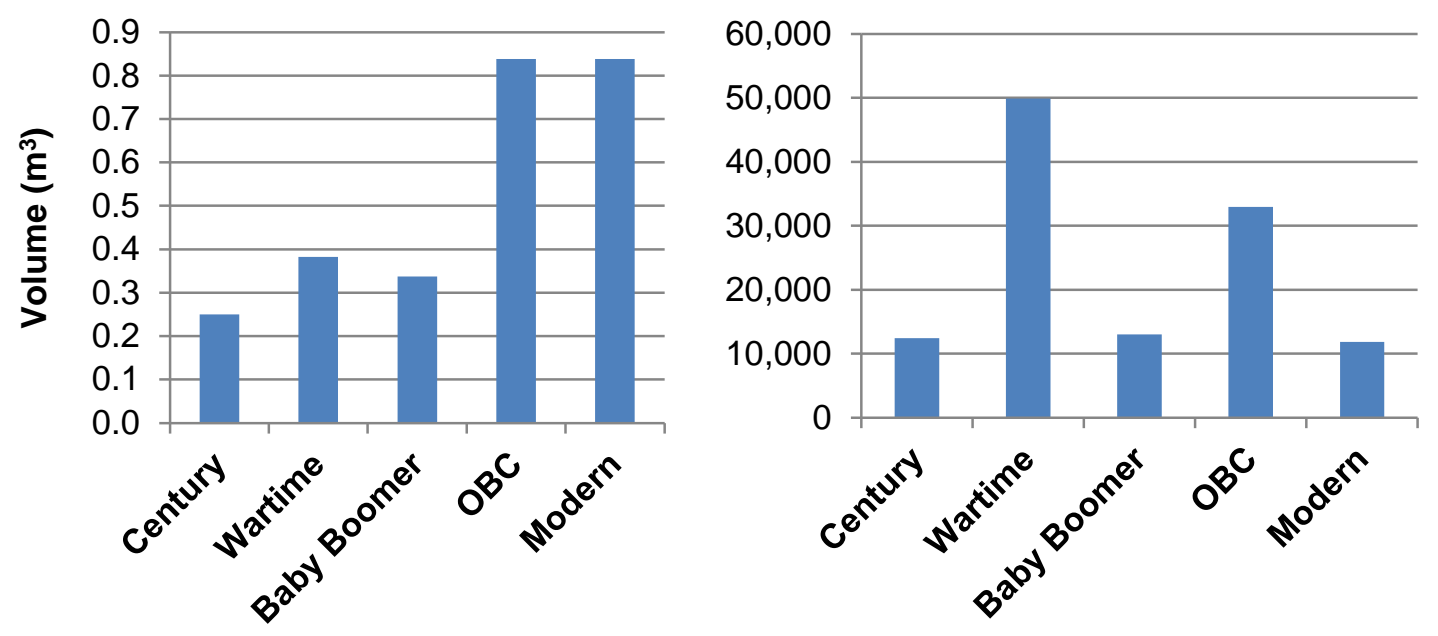

Figure 34. Volume of asphalt shingles determined for the five archetypes (left) and in Toronto's in-use SDH stock (right).

\subsection{Recoverability}

In typical demolition, asphalt shingles are torn down with other roofing materials, Figure 35. However, shingles can be relatively easily removed by hand, separately from other building materials. A common method used to recover shingles from sheathing is to use a tool called a shingle fork, which can get between a shingle and underlayment or underlayment and sheathing. This removal method does not allow shingles to be reclaimed in whole pieces but because shingles do not have long lifespans and cannot be reuse, they do not need to be recovered with special care.

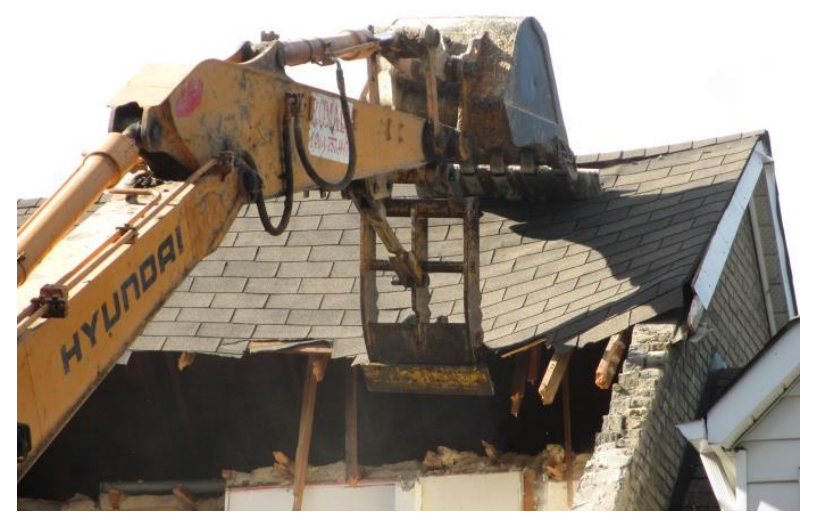

Figure 35. Mechanical demolition of SDH in Toronto, demonstrating a typical method of tearing down asphalt shingles. 


\subsection{Durability}

Roofing shingles typically have a life span of the 20-30 years (NAHB and BoA, 2007). Therefore, shingles do not make a good candidate for reuse and can only be reclaimed for recycling.

\subsubsection{3a Demand - Secondary Products}

The cellulosic fibre, trap rock, limestone, and asphalt cement components of asphalt (both organic and fibreglass) shingles can be extracted and downcycled into other products. The largest market for reclaimed asphalt shingles (RAS) is the road construction industry.

Virgin asphalt cement RAS can be substituted to some degree by RAS in hot-mix asphalt (HMA) for road paving (MNR, 2009). As well, RAS can be used in cold patch pavement for potholes and aggregate for rural road cover. There is well-established literature concerning reclaiming post-industrial shingle scrap for HMA products (MNR, 2009). Mostly, the popularity of RAS is greatly driven by its comparatively lower costs to raw virgin asphalt cement minerals. Primarily, the steadily rising price of raw asphalt binder is pushing the uptake of RAS.

There is limited literature concerning the use of RAS in HMA specific to Canada. While research is concentrated to the University of Waterloo, it shows that properly engineered HMA with 6\% or less by mass RAS content can meet Ontario standards for binder and surface pavements (Islam, 2011; Yang et al, 2013). To investigate the performance of RAS, Yang et al (2007) worked with a local paving manufacturer to use HMA with a $2 \%-3 \%$ RAS content by mass on two roads in the Greater Toronto Area. This research intended to investigate the durability of the products under the pressures of road traffic and environmental elements (Yang et al, 2013). No updated literature could be found to verify outcome of this research.

\subsubsection{3b Demand - Regulations}

Ontario has adopted provisional standards established with the Association of American State Highway and Transportation Officials (AASHTO) regarding the use of post-industrial and postconsumer shingles in HMA. The standards are the only North American guidelines for grading RAS aggregates and binders, for determining sizing requirements for RAS, and establishing 
limits to regulate the amount of extraneous materials that can be in RAS batches without impact the quality of HMA.

Asbestos was acutely used in the manufacturing of shingles up until the 1970's. Even though most of the shingles with asbestos have past their useful life and have been likely replaces, asbestos contamination still an important issue to address (CMRA, 2007). Disposal of asbestos shingles is covered under the EPA, Regulation 347 'Managing Asbestos Waste'. However, neither of these regulations is specific to asphalt recycling and may be inappropriately conservative and discourage shingle recycling. As such, CMRA (2007) suggested that future regulations should better balance safety with incentive to recycle shingles.

\subsubsection{5a Preparation for Secondary Use - Processing}

RAS batches must be thoroughly separated from extraneous building materials, especially when reclaimed from building demolition. There is no standard equipment or technique to clean RAS, but the process may be extensive based on the level of contamination and the properties of the extraneous building materials (MNR, 2009). Once cleaned, the shingles are shredded and screened to ensure that only pieces $13 \mathrm{~mm}$ or smaller get incorporated into HMA (MNR, 2009).

\subsubsection{5b Preparation for Secondary Use - Contamination}

Contamination threatens the integrity of the final HMA product (Islam, 2011). Likewise, RAS batches more likely to arrive at recycling facilities contaminated with other building debris, such as insulation and wood, as a result of the demolition process (Islam, 2011). Although RAS can be cleaned, some facilities that aren't equipped to adequately separate unwanted elements are therefore more inclined discard batches and draw from abundant non-contaminated sources (MNR, 2009).

Asbestos was included in some asphalt shingles from the early 1900 s to the 1970 s. Asbestos is considered a carcinogen and is dangerous when its fibers are inhaled. CMRA (2007) determined that the probability of encountering a shingle with asbestos is small, but significant. About 300 shingles out of 27,000 sampled from a variety of shingle recycling facilities were found to have some asbestos (CMRA, 2007). In the cases where shingles are contaminated, whole batches are typically discarded as hazardous waste (CMRA, 2007). 


\subsubsection{Material Reclamation by SDH Construction Date}

Table 5 outlines a summary of the results of the reusability/recyclability analysis, not drop-off opportunities in Toronto, when considering SDH construction date. In the cases where materials from all the archetypes that they were identified in are reusable or recyclable, the materials are given a designation of 'All'. In the cases where materials are only reusable or recyclable from specific archetypes, although identified in others, the materials are designated by the archetype name.

Table 5 demonstrates that material reusability was found to be more dependent on SDH construction date than recyclability. For example, seven materials that are considered reusable (as they their most limiting criteria was graded with a C or D) are so only if reclaimed from specific archetypes. At the same time the results in Table 5 do not demonstrate how consumer demands are influenced by the age of reusable material. For instance, it was found that solid wood products found in the Century and Wartime archetypes are more in demand than solid wood products found in the remaining archetypes, as wood is likely from old-growth forests that has desirable, but hard to find, mechanical and physical qualities. So while it is true to say that solid wood products from all the archetypes can be reused, in reality it is likely that there would be greater demand for wood found in the Century and Wartime archetypes. 
Table 5. Reusability/recyclability of materials based on archetype.

\begin{tabular}{|c|c|c|}
\hline Material & Reusable & $\begin{array}{c}\text { Recyclable/ } \\
\text { Downcyclable }\end{array}$ \\
\hline FL, width $>39 \mathrm{~mm}$ & All & All \\
\hline FL, width $<39 \mathrm{~mm}$ & All & All \\
\hline Clay Bricks & $\begin{array}{l}\text { Century } \\
\text { Wartime }\end{array}$ & All \\
\hline Cinder Blocks & Wartime & All \\
\hline Rubblestone & All & - \\
\hline Concrete Bricks & Wartime & All \\
\hline Aggregate & All & - \\
\hline Cast in Place Concrete & - & All \\
\hline Steel & All & All \\
\hline Solid Wood Sheathing & - & All \\
\hline Engineered Wood Sheathing & Modern & All \\
\hline Aluminum & All & All \\
\hline Vinyl & - & - \\
\hline Asphalt Shingles & - & All \\
\hline Wood Paneling & All & All \\
\hline Glass In Windows & Modern & All \\
\hline Solid Wood Doors & All & All \\
\hline Drywall & - & All \\
\hline Plaster and gypsum lath & - & - \\
\hline Linoleum & $\begin{array}{l}\text { OBC } \\
\text { Modern }\end{array}$ & - \\
\hline Ceramic Tiles & - & - \\
\hline Carpet & - & - \\
\hline Solid Wood Flooring & All & All \\
\hline Roofing Felt & - & - \\
\hline Breathing Paper & - & - \\
\hline Basement Water Control & - & - \\
\hline Parging & - & - \\
\hline Polyethylene Vapour Barrier & - & - \\
\hline Insulation & - & - \\
\hline
\end{tabular}

\subsection{Objective Three - Impacts of Reclaiming Suitable Materials}

Based on the outputs addressing objectives one and two, the results and discussion of Toronto's SDH total material stocks, reusable and recyclable material stocks, and embodied carbon emissions and primary energy consumption are presented below. 


\subsubsection{Composition of Archetypes in Toronto's SDH Stock}

Figure 36 demonstrates the results of the visual analysis of the Toronto construction dates map superimposed with residential zoning and divided by Toronto wards when calibrated to reflect the total stock of SDH at the end of 2012, based on construction starts data from CMHC Housing Now Toronto 2012 and the City of Toronto 2012 SDH cleared demolition permits.

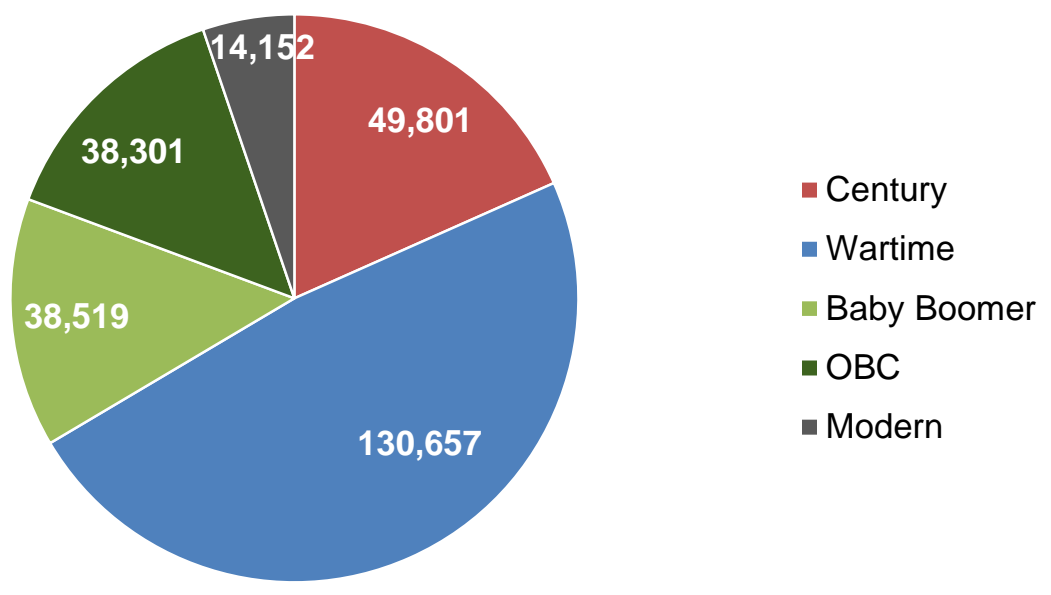

Figure 36. Number of SDH in Toronto at the end of 2012, by archetype.

The results indicated that the majority (48\%) of the SDH in Toronto fit the Wartime archetype, which aligns well with historical literature that indicates houses were built en-mass during that time period. In descending order the remaining archetypes comprised 19\% (Century), 14\% (Baby Boomer), 14\% (OBC), and 5\% (Modern) of Toronto in-use SDH stock. The construction dates of $1.4 \%$ of the stock could not be identified, representing 3765 SDH.

The methods used in this thesis to determine Toronto's in-use SDH stock resulted in a comparable total SDH stock to statistics from the 2011 Census (275,196 versus 275,010 SDH in 2011 respectively). The difference represents $0.07 \%$ of SDH in the 2011 Census SDH data, suggesting confidence in the results of this thesis.

Conducting the visual analysis of the constructions dates and residential zoning map twice also provided confidence in the results. One piece of comparable literature could be sourced from the City of Toronto ward profiles using data from the 2006 Census (City of Toronto, 2013e). The 2006 ward profiles considers all private dwellings in the City of Toronto, including singledetached $(27.3 \%$ of total dwellings), semi-detached ( $7.1 \%$ of total dwellings), row ( $5.6 \%$ of total 
dwellings), detached duplex (4.5\% of total dwellings), apartment more than five stories (38.8\% of total dwellings), apartment less than five stories (16.6\% of total dwellings), and other attached houses $(0.1 \%$ of total dwellings) (City of Toronto, 2013e). Accordingly the proportions of Toronto's 2006 private dwelling stock by construction date are shown in Figure 37.

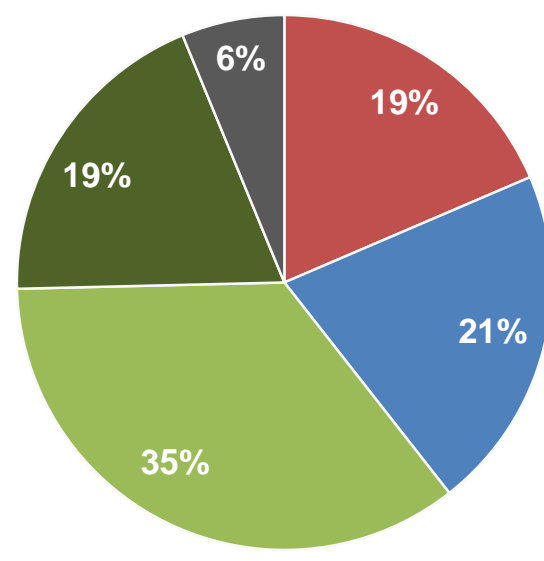

- Before 1946

-1946-1960

$\square 1961-1980$

- 1981-2000

- 2001-2006

Figure 37. 2006 private dwellings in Toronto by construction date (City of Toronto, 2012e).

The time periods developed by the City of Toronto (2013e) somewhat align with those used in this thesis, Figure 37. One significant difference between the two is that in this thesis the time period considered as Wartime was extended to before 1945. The decision to include SDH built from 1930 to 1945 as Wartime reflects observations of the demolition of six SDH in various locations in Toronto which had building materials and styles more closely aligned with those established for the Wartime archetype.

Another significant difference between this thesis and data from the 2006 Census is the proportions of dwellings constructed in the Wartime and Baby Boomer archetypes eras. The difference likely reflects that the City of Toronto (2013e) data includes apartments, which were not included in this thesis. From historical data on apartment construction in Toronto, it is possible to estimate that about 210,000 dwellings were constructed in apartment buildings (greater than five stories) between 1961 to 1980, more than any other time period considered in the 2006 ward profiles (Dennis, 1989). 


\subsubsection{Toronto Material Stock in In-Use SDH}

Absolute volumes of the all identified materials in the archetypes extrapolated to the scale of all in-use SDH in Toronto are outlined in Appendix C, Table 15. The total material stock for in-use $\mathrm{SDH}$ was determined to be $26,487,673 \mathrm{~m}^{3}$. Figure 38 demonstrates the volume of selected materials in the stock as they pertain to the different archetypes.

Figure 38 demonstrates that the largest proportion of material volume identified the in-use SDH stock was in SDH fitting the Wartime archetype. Figure 38 also demonstrates that clay bricks and mortar, CIP, FL, insulation (including air volume), and aggregate were found to be the five most abundant materials in Toronto's in-use SDH stock: representing 16\%, 16\%, 14\%, 12\%, and $11 \%$ of the total volume in the stock respectively.

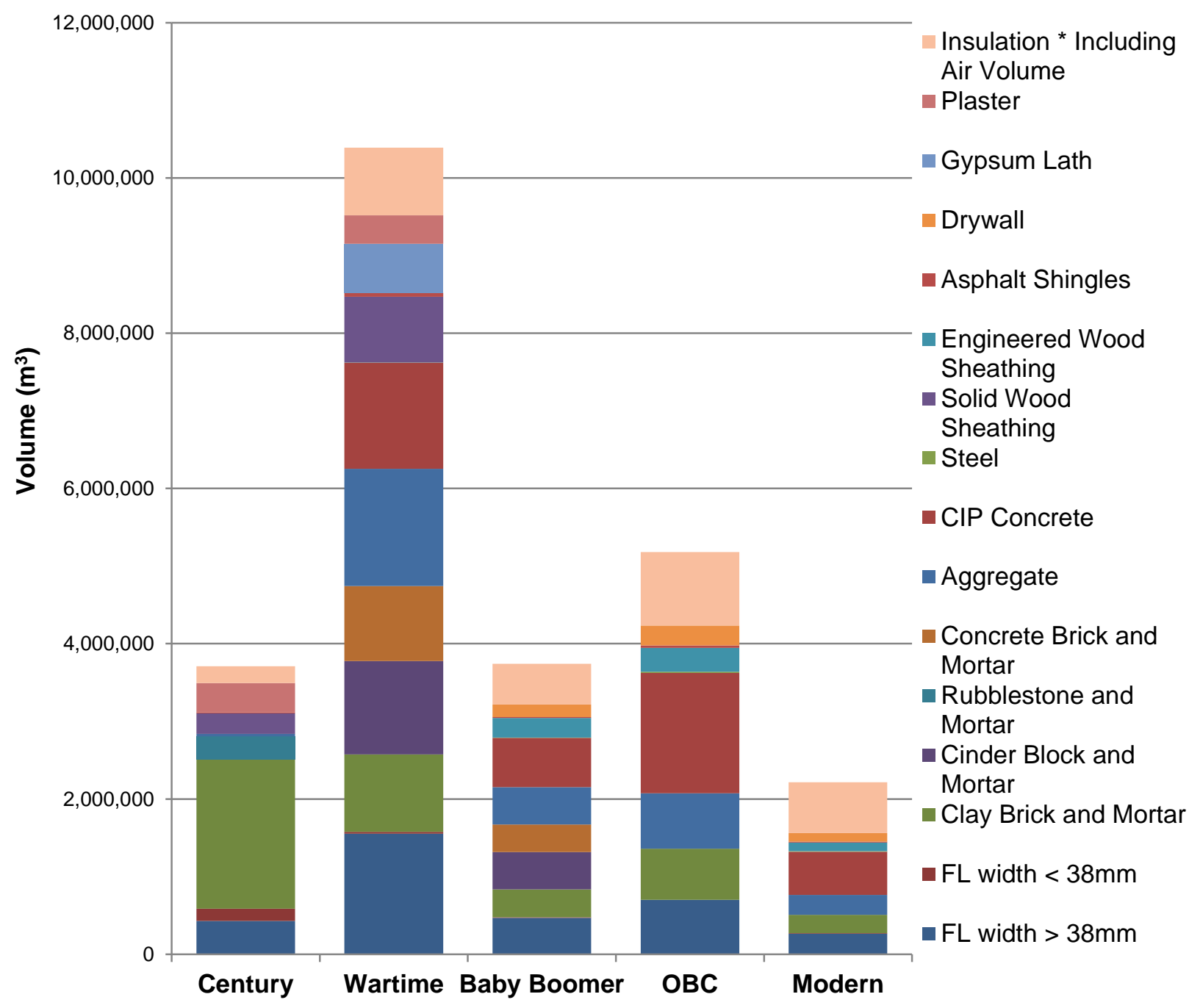

Figure 38. Volume of selected materials in Toronto's in-use SDH stock. 


\subsubsection{Archetype stock in annual obsolete SDH}

Based on visual analysis of SDH demolition permits mapped out on the Toronto construction dates map, Table 6 demonstrates the results of cleared demolition permits for SDH from 2008 2012 by archetype. Where the average number of total demolition permits from 2008 to 2012, shown in Table 6, represents Toronto's annual obsolete SDH stock.

Table 6. Cleared demolition permits by archetype from 2008 to 2012.

\begin{tabular}{lcccccc}
\hline Year & Century & Wartime & Baby Boomer & OBC & Unidentified & Total \\
\hline 2008 & 96 & 396 & 92 & 120 & 25 & 729 \\
2009 & 91 & 357 & 92 & 93 & 37 & 670 \\
2010 & 95 & 310 & 69 & 88 & 18 & 580 \\
2011 & 111 & 410 & 98 & 108 & 23 & 750 \\
2012 & 153 & 491 & 114 & 111 & 35 & 904 \\
\cline { 2 - 7 } Average & 109 & 393 & 93 & 104 & 28 & 727 \\
\hline
\end{tabular}

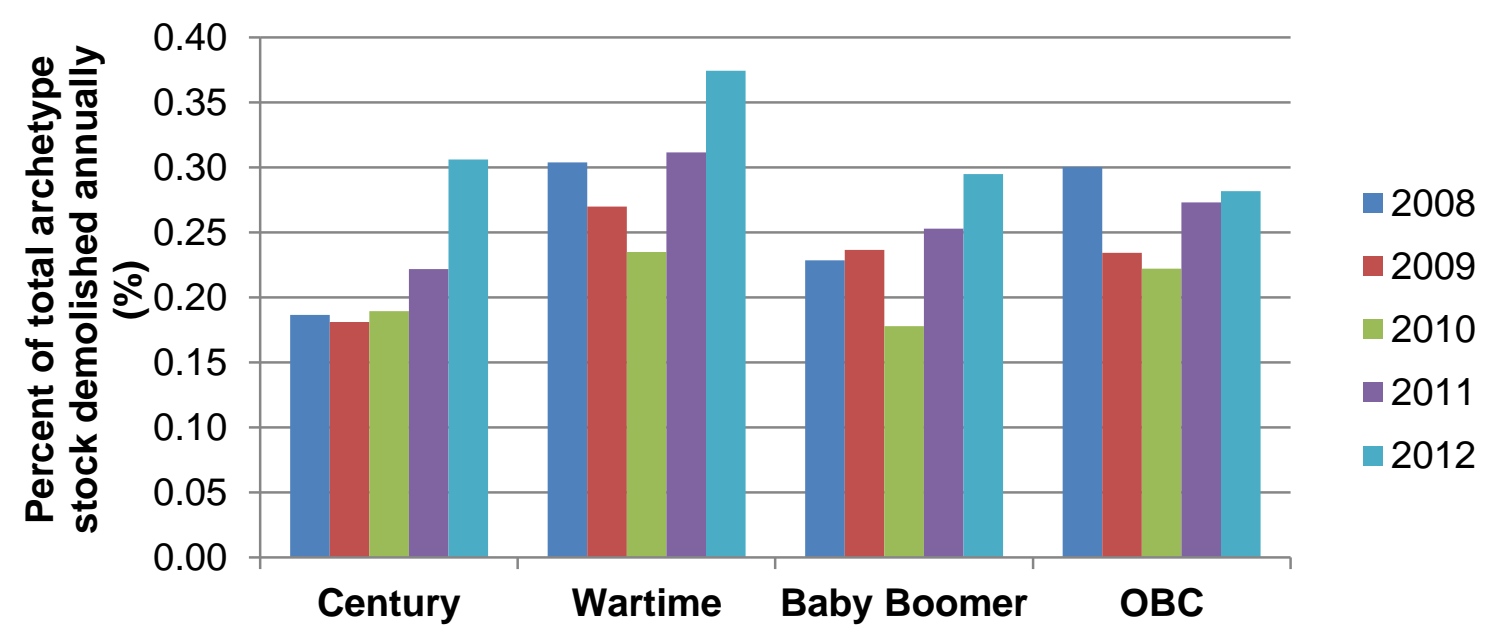

Figure 39. Proportion of archetype SDH stock demolished from 2008 to 2012.

Accounting for changes in SDH composition from 2008 to 2012, the proportions of each archetype demolished annually from its total stock in Toronto are demonstrated in Figure 5. Figure 5 reinforces the importance of examining older as well as more recently SDH archetypes when determining to materials stocks in annual obsolete SDH. Although it is clear that on average SDH fitting the Wartime archetype were found to represent the highest amount of demolition permits annually in Toronto, they were also found to be the most abundant archetype in Toronto's SDH in-use stock. Likewise, the proportion of each archetype demolished annually was found to be almost equal: on average $0.22 \%, 0.30 \%, 0.24 \%$, and $0.26 \%$ for Century, 
Wartime, Baby Boomer, and OBC archetypes respectively. Thus it can be determined that an average .26\% of Toronto's SDH stock is demolished annually and at that rate, it would take 379 years for the all the materials in 2012's SDH stock to be become available for reclamation in obsolete buildings. However, because of the high number of renovations in Toronto's stock, a significant volume of material is likely to become available before then (City of Toronto Open Data, 2013).

\subsubsection{Material stocks in Annual Obsolete SDH}

Based on the results of dating Toronto cleared demolition permits, Figure 40 demonstrates the extrapolated volumes of select material in the average annual obsolete SDH stock. The total material stock in the annual obsolete SDH stock was determined to be $65,296 \mathrm{~m}^{3}$. Absolute volumes of the identified material in the stock are presented in Appendix C, Table 16.

Figure 40 shows that the highest volume of materials in the annual obsolete stock was found in SDH fitting the Wartime archetype (51\%), which is to be expected because of the high number of average cleared demolition permits corresponding to SDH built in Wartime archetype time period. The remaining archetypes represented 13\% (Century), 15\% (Baby Boomer), and 21\% (OBC) of the total material stock. Figure 40 also shows that clay bricks and mortar, CIP concrete, FL, insulation including air volume, and aggregate comprised the five highest volumes of the stock: representing $15 \%, 15 \%, 15 \%, 12 \%$, and $10 \%$ of the volume in the stock respectively. 


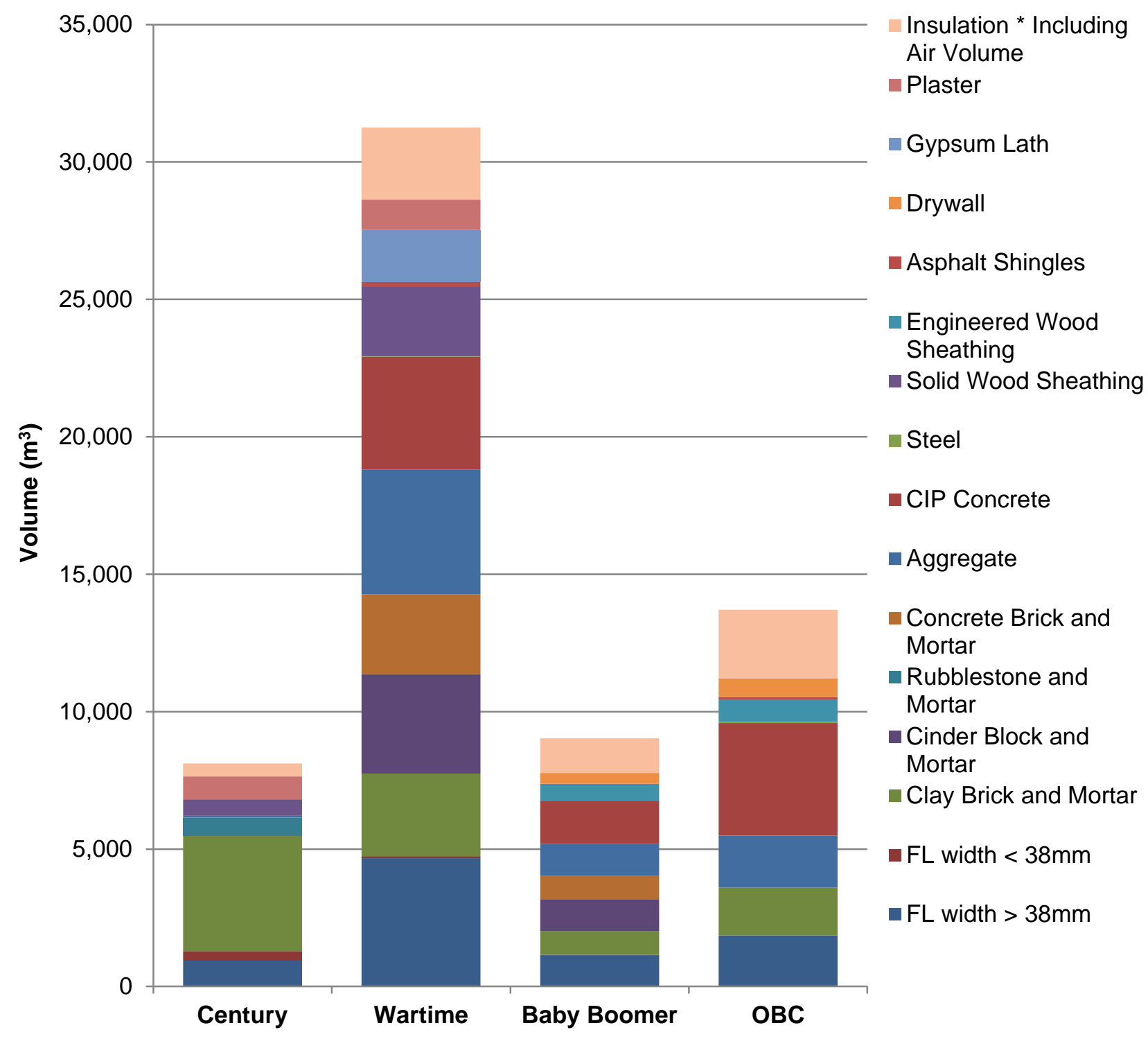

Figure 40. Volumes of select materials identified in Toronto's annual obsolete SDH stock.

\subsection{Determining Reusable/Recyclable Material Stocks}

Based on the results of the material reusability/recyclability analysis by archetype outlined in Table 5, the total stock of selected reusable and recyclable materials in the individual archetypes, in-use SDH, and annual obsolete SDH are demonstrated in Figure 41, Figure 42, and Figure 43 respectively. Absolute volumes of the all identified material in the stocks are outlined in Appendix C, Table 17 - Table 20. 
Figure 41 shows that the volume of recyclable materials was found to increase as the SDH archetypes construction dates became more recent. Simple linear regression demonstrates that the amount of recyclable materials may be positively correlated to total material volume in each archetype $\left(r^{2}=0.78\right)$. Although with only five data points, no definite conclusions can be made. Because the Century and Wartime archetypes had similar volumes of recyclable materials, higher volumes of recyclable materials found in more recently constructed archetypes are also likely due to the popularization of drywall and engineered wood products throughout the 1960's.

Figure 41 also shows that the Century and Wartime archetypes had the highest volume of reusable materials. Higher reusable material volumes in the Century and Wartime archetypes may be attributed to the popularization of cement based mortar after 1960 as concrete brick, cinder block, and clay bricks made up $23 \%$ of the total volume of reusable materials found in the five archetypes. It is also apparent in Figure 41 that the volume of reusable materials was found to be higher in the OBC and Modern archetypes than in the Baby Boomer archetype. The Baby Boomer archetype had the lowest reusable material volume, which is likely because it also had a lower total volume of materials than the more recently constructed archetypes but also used cement based mortar.

Additionally, in the case for the Modern archetype, additional materials such as windows, linoleum flooring, and engineered wood sheathing were considered reusable. First, windows in the Modern archetype were determined to be the only, of all the considered archetypes, that could possible meet performance standards of the 2012 OBC, currently requiring windows to have maximum $\mathrm{U}$-value of $2 \mathrm{~W} / \mathrm{m}^{2 *} \mathrm{k}$ (Province of Ontario, 2012). Even so, the technology of the windows in the Modern archetype may not be sufficient to meet current standards and will likely not meet ever-increasing standards in the future. Second, linoleum flooring is considered reusable, but due to the popular use of asbestos in adhesive products until the 1980's older flooring is likely to be contaminated and was not considered reusable in this thesis. Third, engineered wood sheathing is generally only considered reusable when installed for short periods of time because then there is less chance of damage or contamination from its use in the building (usually caused by heat and moisture) (Falk and Guy, 2007). At the same time, with the popular use of wood glue and other adhesives, recovery may be a significant issue in removing large and undamaged volumes of sheathing for reuse. 


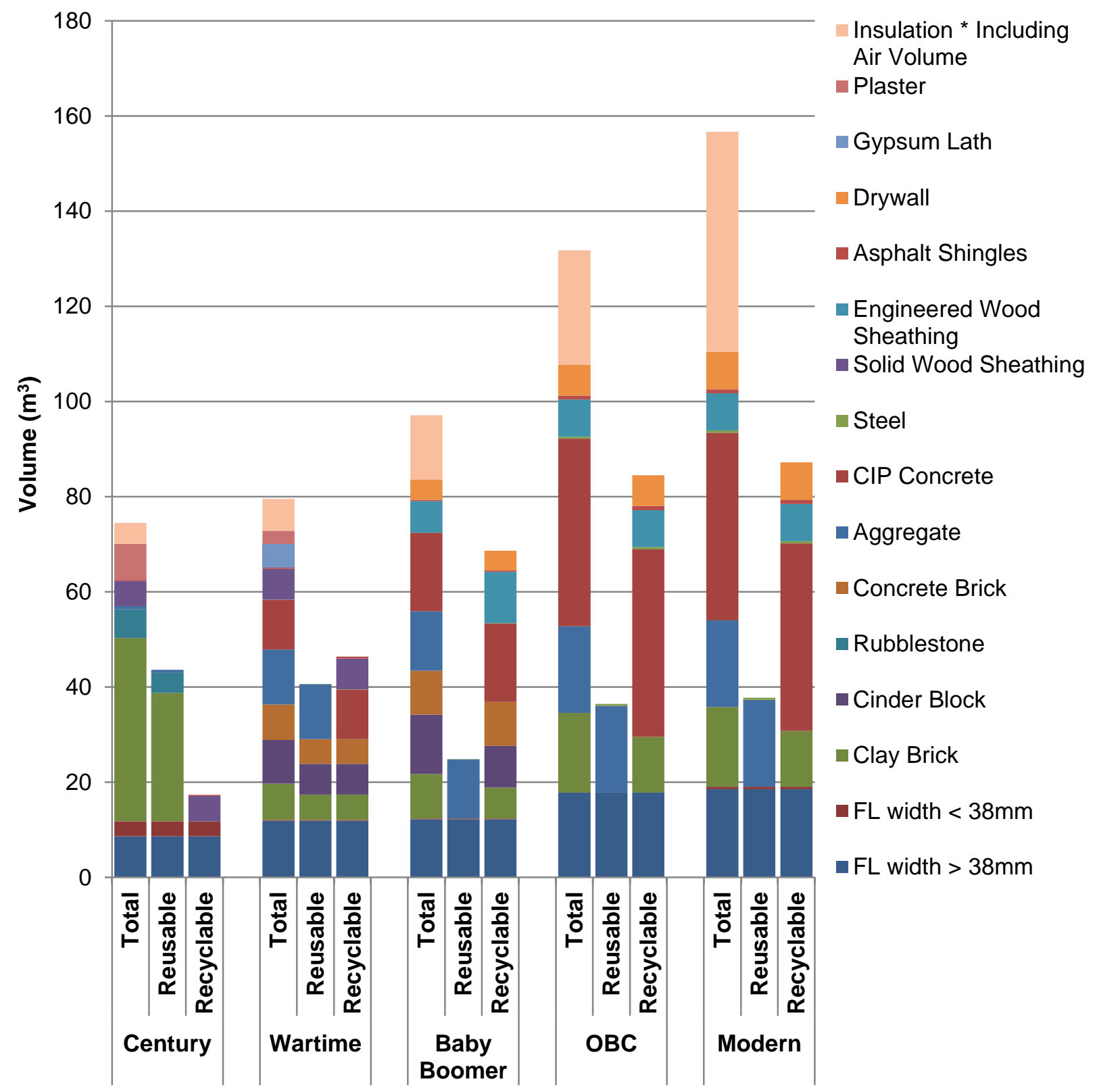

Figure 41. Volumes of selected total, reusable, and recyclable materials in the five archetypes, where some materials were identified as both reusable and recyclable.

At the same time, the Modern archetype also had the largest volume of insulation. Overall, the material inventories demonstrate that there are higher volumes of insulation in SDH constructed more recently, likely because of increasing awareness of the thermal resistance benefits offered by insulation. Other than mineral wool, batt insulation is generally not considered recyclable (Falk and Guy, 2007). However, mineral wool insulation is not as commonly used in construction as fibreglass insulation, which is not recyclable (Falk and Guy, 2007). Alternatively, 
batt or board insulation can be reused in some cases (Addis, 2006). However, as insulation loses thermal resistivity overtime, a higher volume of it would likely be required to achieve Rvalues required by the OBC 2012. This may become a problem when wall thickness cannot be increased. As such, most literature indicates that insulation reuse is limited to small-scale, do-ityourself projects for cottages, sheds, or other secondary buildings.

Wood in doors is presented in volume in table of Appendix C. However, it is important to consider that undamaged doors would likely be reused as is and therefore it is also useful to consider the number of interior and exterior doors in the each archetype outlined in Table 7. Table 7 demonstrates that the Wartime archetype had significantly more interior doors than the remaining archetypes, which can be accounted for because only wood doors were considered in this thesis. In the Wartime archetype, all closet doors were wood doors, while in the Baby Boomer, OBC, and Modern archetypes closet doors were typically sliding, non-wood doors and were not considered in this thesis.

Table 7. Number of interior and exterior wood doors identified in archetypes.

\begin{tabular}{lccccc}
\hline Door Type & Century & Wartime & Baby Boomer & OBC & Modern \\
\hline Exterior & 2 & 3 & 3 & 1 & 1 \\
Interior & 11 & 16 & 7 & 10 & 10 \\
\hline
\end{tabular}




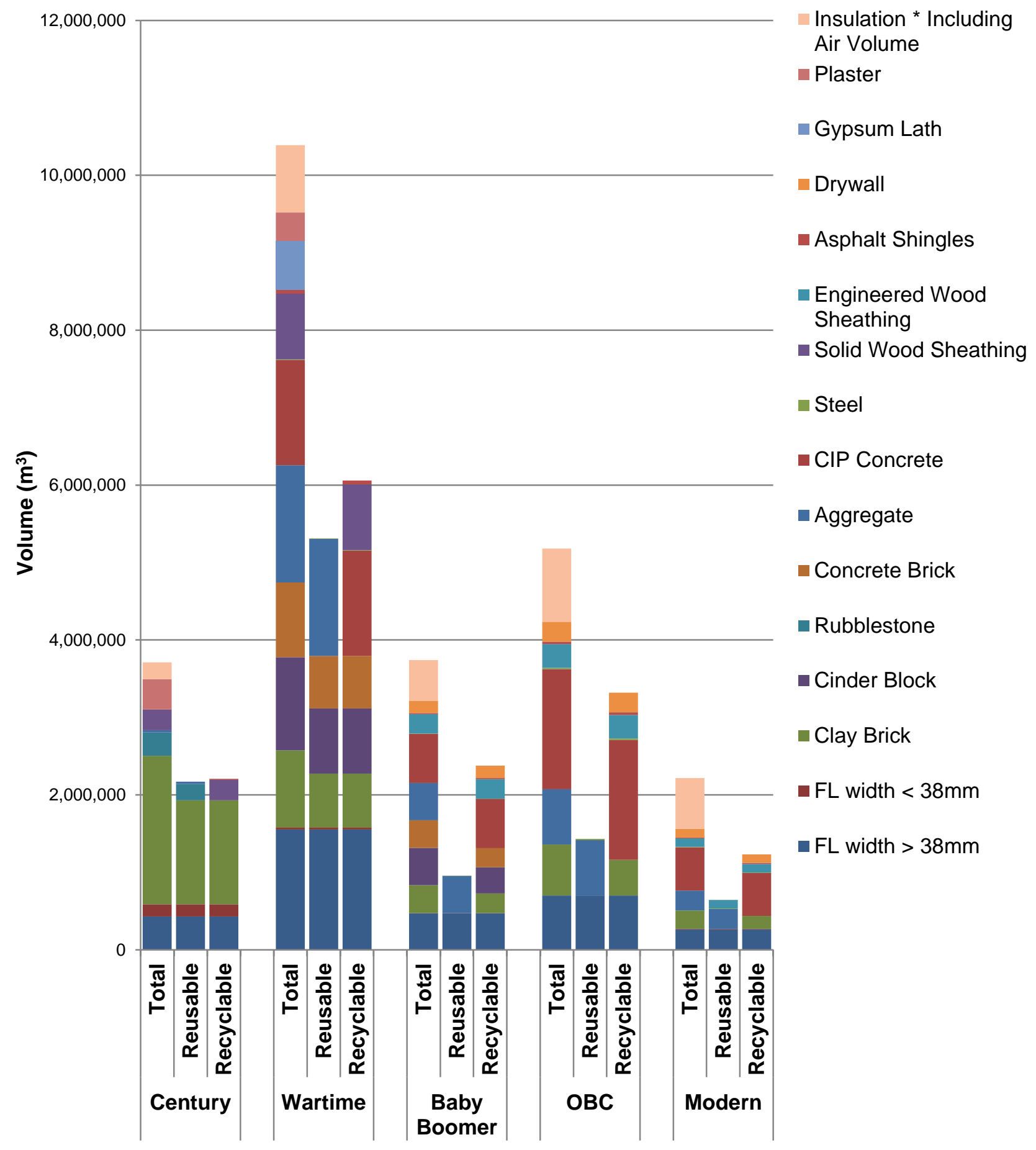

Figure 42. Reusable and recyclable material volumes by archetype of in-use SDH stock. 


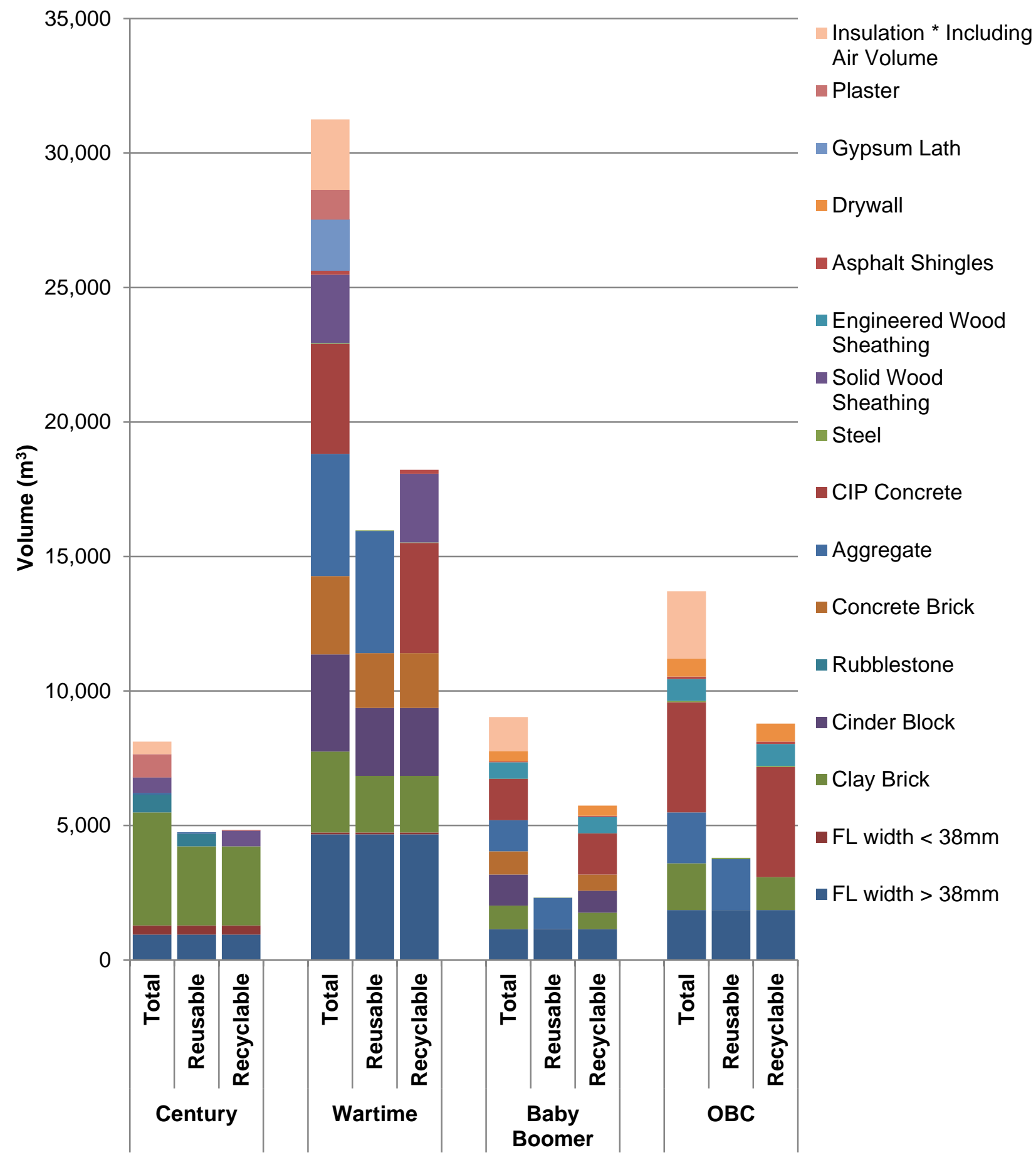

Figure 43. Reusable and recyclable material volumes by archetype of annual obsolete SDH stock. 
Without considering material loss due to damage or contamination, $73 \%$ of the volume of Toronto's in-use and annual obsolete SDH could be reclaimed for reuse or recycling. These results are comparable to existing Canadian literature estimating that $75 \%$ of demolition waste can be reclaimed. In Toronto SDH, the stocks of reusable and recyclable materials are equal to about $48,390 \mathrm{~m}^{3}$ of material being available annually in obsolete $\mathrm{SDH}$. As of 2012 , accumulated in-use Toronto SDH had material stock of reusable and recyclable materials of $19,380,284 \mathrm{~m}^{3}$.

Figure 42 and Figure 43 demonstrate that the Wartime archetype was found to be influential in determining the overall composition of Toronto's in-use and annual obsolete SDH reusable and recyclable material stocks. For example, Table 8 outlines that the composition of the reusable and recyclable materials in in-use and annual obsolete SDH stocks were almost identical and were also the materials identified to have large volumes in the Wartime archetype.

Table 8. Material composition of reusable and recyclable material stocks, by percent of material stock volume for materials comprising more than $5 \%$ to stock volume.

\begin{tabular}{|c|c|c|c|c|c|}
\hline \multicolumn{3}{|c|}{ Reusable } & \multicolumn{3}{|c|}{ Recyclable } \\
\hline Material & In-use & $\begin{array}{c}\text { Annual } \\
\text { Obsolete }\end{array}$ & Material & In-use & $\begin{array}{c}\text { Annual } \\
\text { Obsolete }\end{array}$ \\
\hline $\mathrm{FL}$ & $33 \%$ & $31 \%$ & CIP & $26 \%$ & $24 \%$ \\
\hline Aggregate & $27 \%$ & $27 \%$ & $\mathrm{FL}$ & $22 \%$ & $23 \%$ \\
\hline Clay Bricks & $18 \%$ & $16 \%$ & Clay Bricks & $18 \%$ & $17 \%$ \\
\hline Cinder Blocks & $8 \%$ & $12 \%$ & Cinder Blocks & $7 \%$ & $8 \%$ \\
\hline Concrete Bricks & $6 \%$ & $10 \%$ & Solid Wood Sheathing & $7 \%$ & $8 \%$ \\
\hline & & & Concrete Bricks & $6 \%$ & $7 \%$ \\
\hline
\end{tabular}

Figure 41, Figure 42, and Figure 43 demonstrate the reusable and recyclable material stocks assuming that all suitable materials can be recovered from SDH without considerable damage or contamination. In reality, it is likely that at least some volume of suitable materials would be impacted by damage caused from the material's initial construction, use in the original building, or deconstruction. As well, it is likely that at least some volume would be impacted by contamination of hazardous materials or undesired adjacent materials that cannot be cleaned off, even in materials that the literature indicated were not usually impacted by contamination.

The material analysis indicated that there is not sufficient data on recovery rates for all the materials identified in the archetype houses. When estimating reclaimable solid wood flooring, Falk and Guy (2007) explain damage should be assumed to be as low as $10 \%$. When 
estimating FL inventories in SDH for America, Falk (1999) estimated that $25 \%$ by volume would be lost from damage. Likewise Calvier (2013) determined that as much as $50 \%$ of steel by weight cannot be reused because of damage. Furthermore, FCSHWM (2000) state that case studies of deconstructed buildings tend to demonstrate average recovery rates of $80 \%$ by volume with a minimum of $50 \%$ and maximum of $90 \%$.

The gap in literature concerning material recovery rates highlights disconnect between the deconstruction industry (as it is the most prominent source for building material reclamation in North America) and quantitative literature. Based on the limited literature available, three scenarios of material loss due to damage or contamination were created to estimate a more realistic stock of materials that could be reclaimed for reuse and recycling: 1) 10\% loss in material volume, 2) $25 \%$ loss in material volume, and 3) $50 \%$ loss in material volume.

It should be noted that although these scenarios do not directly take into account the varying demands for reclaimed materials, they do consider the varying conditions of $\mathrm{SDH}$, as some buildings and their materials have more damage and contamination than others. As well, even though these scenarios were developed from literature pertaining to material reuse they were also applied to determining recyclable materials stocks.

Even so, material recyclability is less impacted by damage such as physical deformation in the form of splits, dents, etc. than reusability. Thus even the most conservative material loss scenario of $10 \%$ loss in material volume may be high (Gorgolewski et al, 2006). At the same time, it would be ambitious to assume that $100 \%$ of suitable reclaimed material could be recycled. Thus, even though it may be high, a 10\% loss in material volume was assumed in estimating overall recyclable stocks.

Figure 44 and Figure 45 demonstrate the results of the total percent of reusable and recyclable materials, respectively, for the individual archetypes, in-use SDH stock and obsolete SDH stocks considering the three material loss scenarios. 


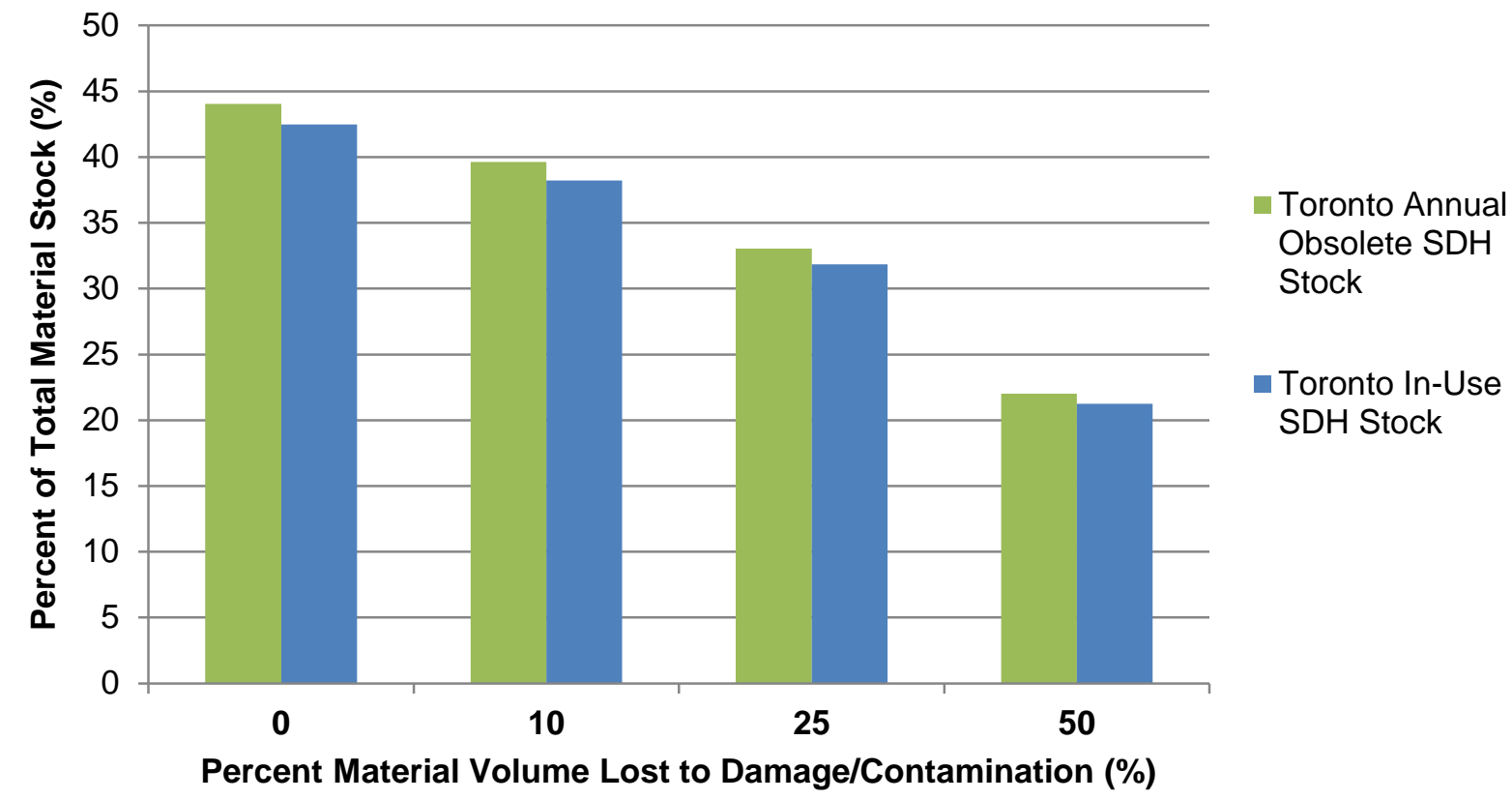

Figure 44. Percent of total material stock volume that is reusable at the building scale, in-use SDH city scale, and annual city scale.

Figure 44 demonstrates that $22 \%$ - $40 \%$ of Toronto's annual obsolete SDH material stock was found to be reusable when considering 10\% - 50\% material volume loss. In total, 14,378 $25,881 \mathrm{~m}^{3}$ of material was determined to be reusable in annual obsolete SDH. Likewise, Figure 44 demonstrates that $20 \%-38 \%$ of Toronto's in-use SDH stock was found to be reusable when considering 10\% - 50\% material volume loss, slightly lower than in annual obsolete SDH. This represents a volume of reusable material in the in-use SDH stock of 5,625,421 - 10,125,758 $\mathrm{m}^{3}$ of material.

The slight difference between the reusable materials proportions demonstrated in Figure 44 may be accounted for by the slight differences in archetype composition in the stocks.

Particularly, the Wartime archetype was found to have higher volumes of reusable materials in comparison to the more recently constructed archetypes and so its presence in the stocks was very influential in determining the total proportions of reusable materials. For example, reusable materials in the SDH fitting the Wartime archetype comprised $51 \%$ of the total reusable material volumes determined for in-use SDH and 60\% and annual obsolete SDH stocks in Toronto respectively (since a large proportion of current annual demolitions are of this archetype. 


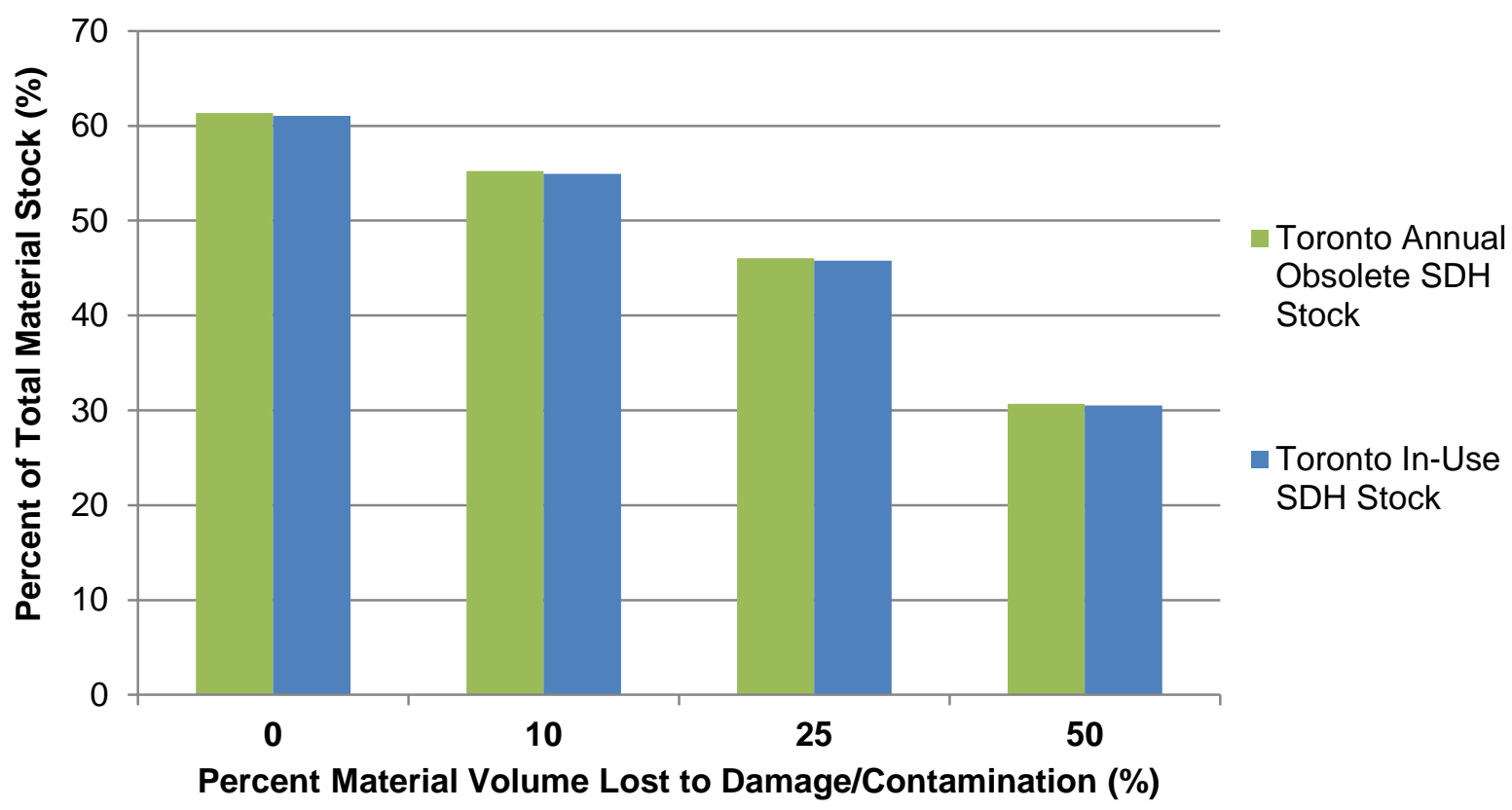

Figure 45. Percent of total material stock volume that is recyclable at the building scale, in-use SDH city scale, and annual city scale.

The results in Figure 45 indicate that the percent of recyclable material volumes in annual obsolete SDH stocks and in-use SDH stocks were found to be almost all equal. Like reusable material stocks, the highest percent of recyclable materials was found to be in the annual obsolete SDH stock (55\%) when considering a 10\% material volume loss. The difference between obsolete and in-use SDH stocks was found to be less than $1 \%$ as demonstrated in Figure 45.

The largest volume of recyclable materials was determined in Toronto's in-use SDH stock, $14,557,704 \mathrm{~m}^{3}$ when considering $10 \%$ material volume loss. Likewise, the volume of recyclable materials in Toronto's annual obsolete SDH stock was determined to be $36,062 \mathrm{~m}^{3}$ of material. However, a significant volume of the identified materials in recyclable stocks was also determined to be suitable for reuse, where the waste hierarchy demonstrates environmental preference for reuse. Considering $50 \%-90 \%$ of the material volume that is suitable for both reuse and recycling is reused, the resulting total recyclable material stock in Toronto's in-use $\mathrm{SDH}$ would be $7,316,699-10,534,812 \mathrm{~m}^{3}$. The resulting total recyclable material stock in Toronto's annual obsolete SDH would be $17,497-25,748 \mathrm{~m}^{3}$. 


\subsection{Embodied Primary Energy Consumption and $\mathrm{CO}_{2}$ Emissions}

Embodied $\mathrm{CO}_{2}$ emissions and primary energy consumption equivalents of reusable materials (assuming no loss to material volume from damage/contamination) in Toronto's in-use and annual obsolete SDH stocks are presented in Figure 46, Figure 47, Figure 48, and Figure 49. Absolute $\mathrm{CO}_{2}$ emissions and primary energy consumption results for reusable materials considering $10-50 \%$ volume loss from damage and contamination are outlined in Appendix C, Table 21 - Table 24.

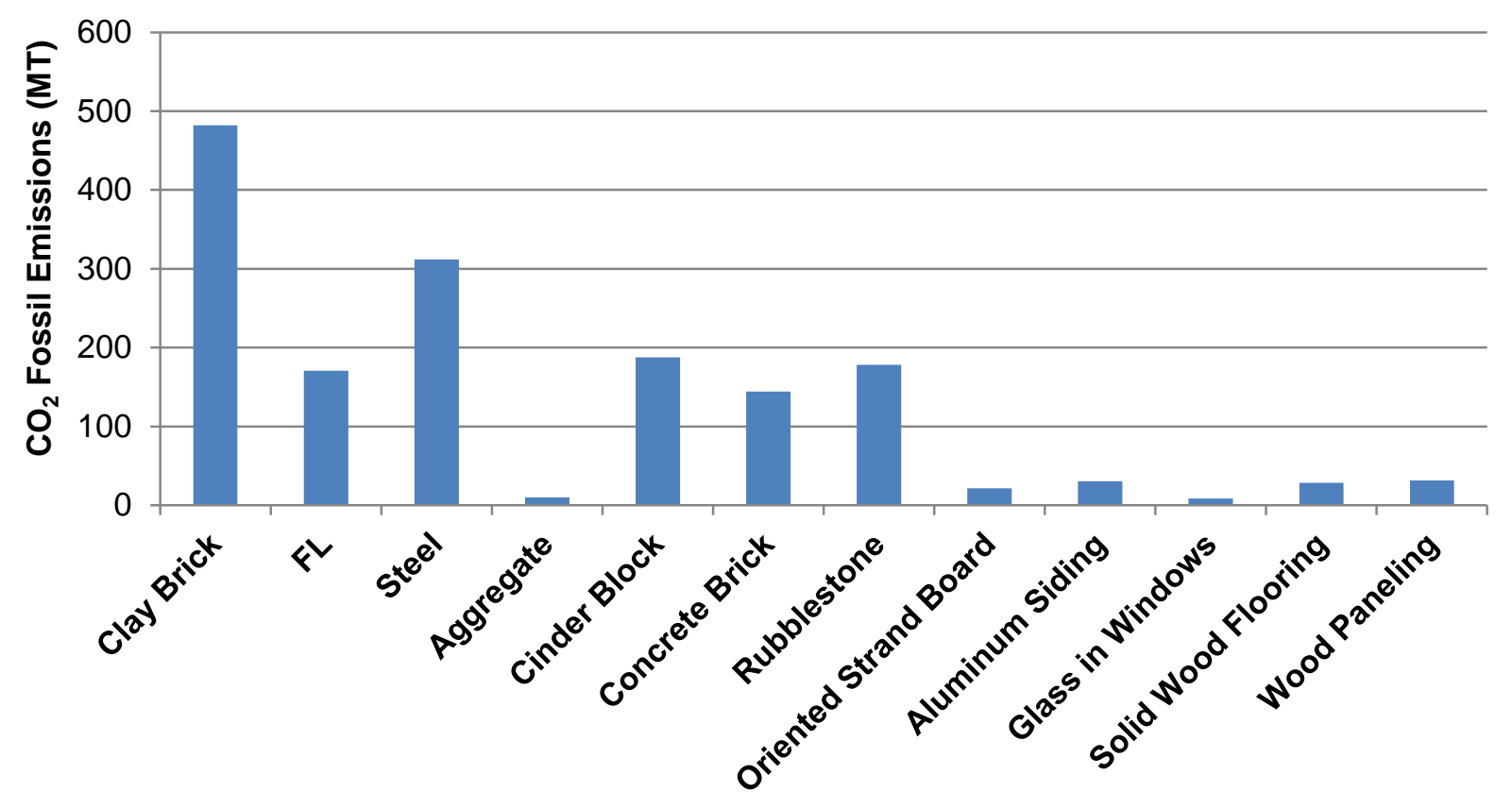

Figure 46. Embodied $\mathrm{CO}_{2}$ emissions (megatonne) equivalents of select reusable materials of Toronto's in-use SDH stock. 


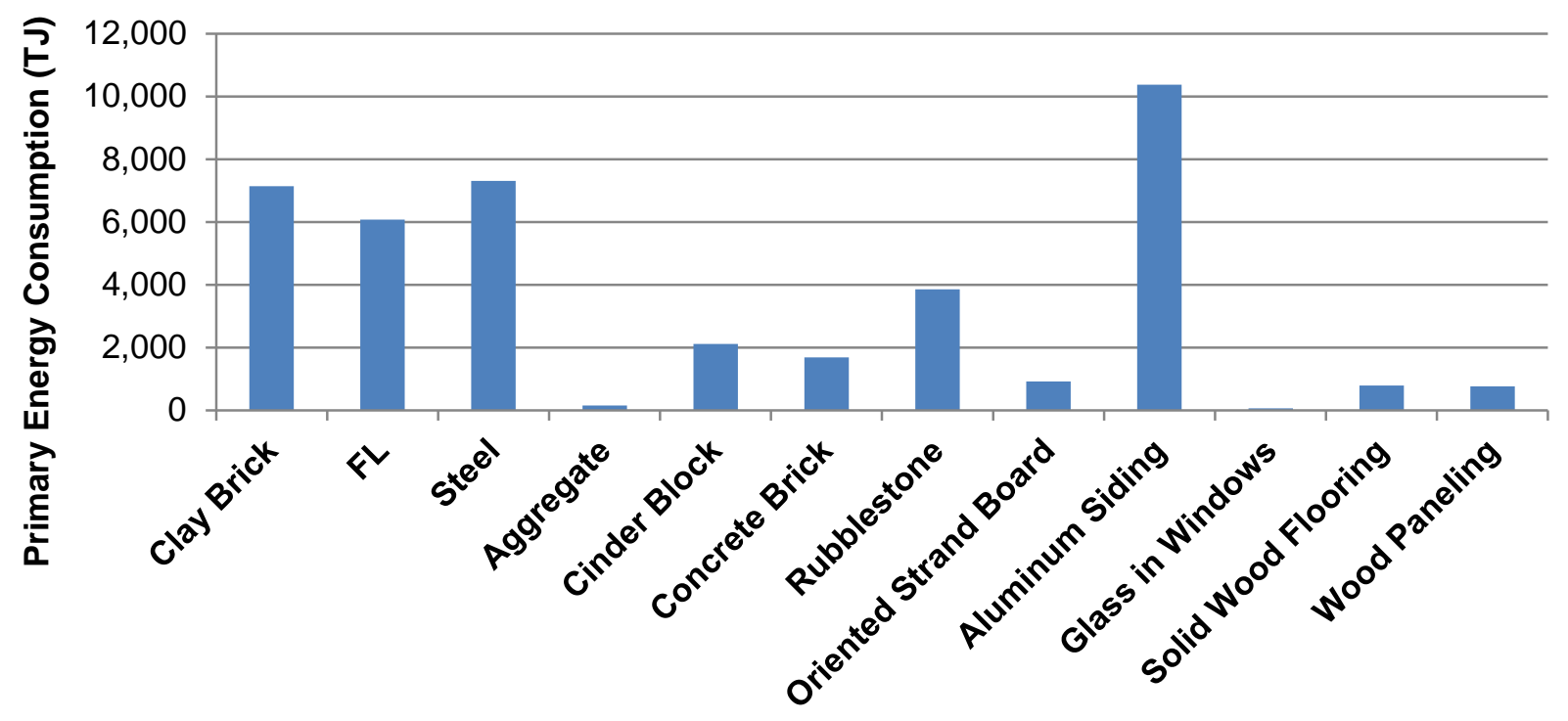

Figure 47. Embodied primary energy consumption (terajoules) equivalents of select reusable materials of Toronto's in-use SDH stock.

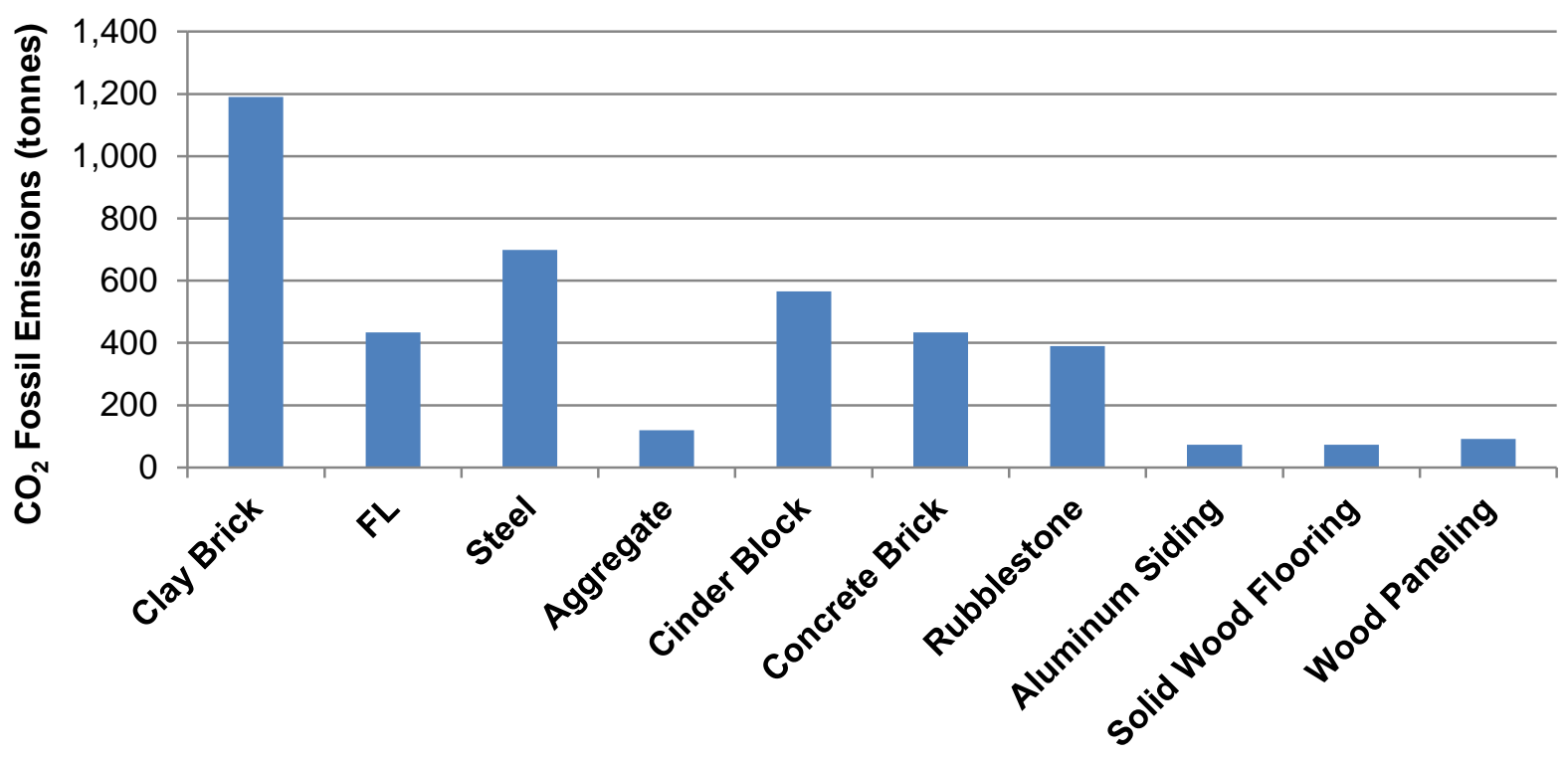

Figure 48. Embodied $\mathrm{CO}_{2}$ emissions (tonnes) equivalents of reusable materials of Toronto's annual obsolete SDH stock. 


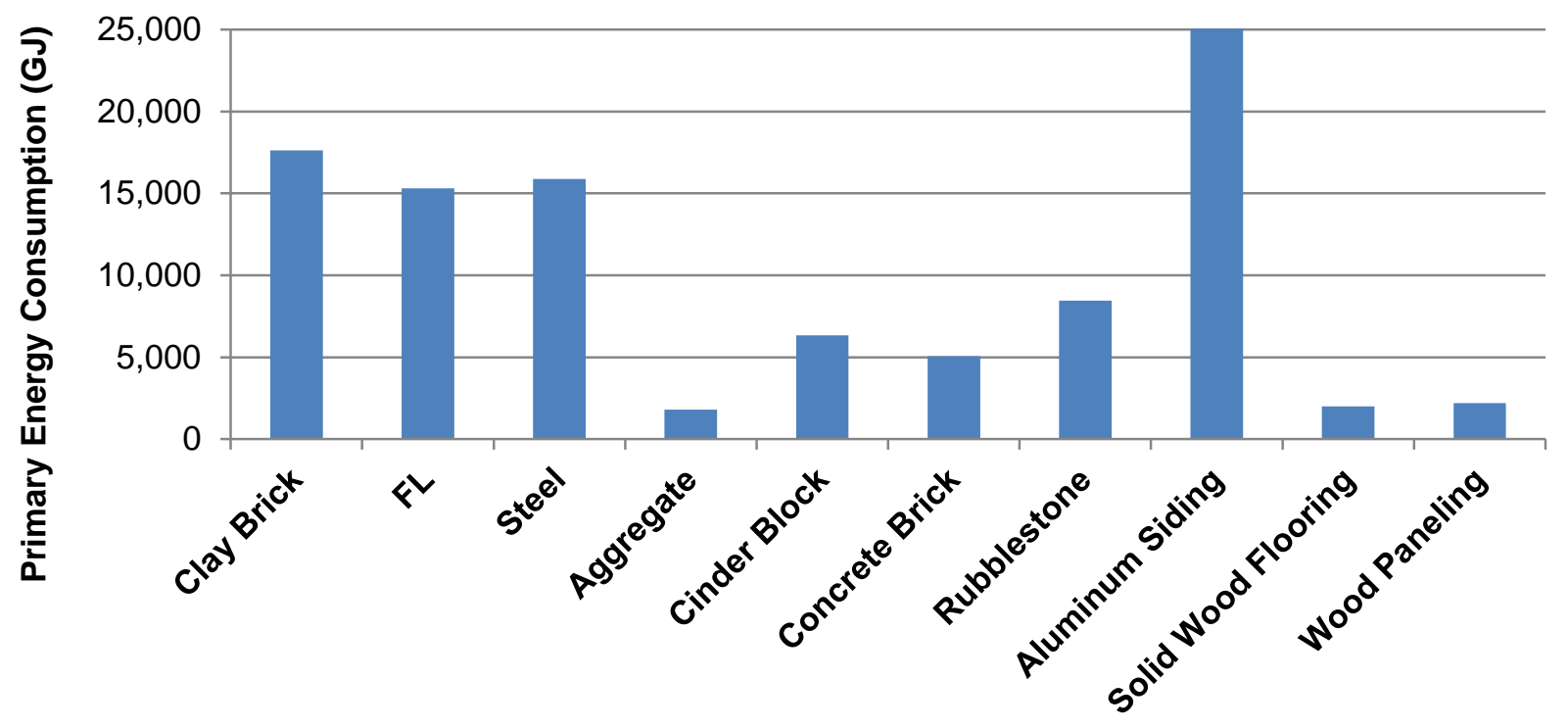

Figure 49. Embodied primary energy consumption (gigajoule) equivalents of select reusable materials of Toronto's annual obsolete SDH stock.

It was found that the reusable material stock in Toronto's in-use SDH is equivalent to 803 1,446 MT of $\mathrm{CO}_{2}$ emissions and 20,628 - 37,130 TJ of primary energy consumption based on embodied impact data for virgin materials. Annually, the reusable material stock found in Toronto's obsolete SDH is equivalent to 2,160 - 3,888 tonnes of $\mathrm{CO}_{2}$ emissions and 51,789$93,221 \mathrm{GJ}$ of primary energy consumption based on embodied impact data for virgin impact.

Figure 46 and Figure 48 demonstrate that clay bricks, steel, and cinder block comprised the three largest proportions of $\mathrm{CO}_{2}$ emissions in Toronto's in-use and annual obsolete SDH reusable material stocks. As well, Figure 47 and Figure 49 demonstrate that aluminum, clay brick and steel comprised the three largest proportions of the total primary energy consumed in Toronto's in-use SDH and annual obsolete SDH stock. Although, FL also comprises stands out as comprising a proportion of the total primary energy consumed in both SDH stocks. As such, a more in-depth discussion of embodied impacts is outlined below for the materials that comprised the largest proportions of their respective stocks.

\section{Clay Bricks}

Clay bricks were significant in both in-use and annual obsolete reusable material stocks expressed in embodied $\mathrm{CO}_{2}$ emissions and primary energy consumption, which is to be 
expected as clay bricks comprised a significant volume in the respective reusable materials stocks as well. Based on a LCA of virgin clay brick production conducted by the Athena Sustainability Materials Institute (ASMI) (1998), 98\% of the total $\mathrm{CO}_{2}$ emitted in the extraction of raw resource, transportation, and manufacturing of bricks in Canada is emitted during the kiln firing stage, about $317 \mathrm{~kg}$ per 1000 metric modular bricks.

Manufacturing activities also make up $98 \%$ of the total embodied energy consumed in virgin clay brick. However along with energy consumed by the kiln, additional processing occurring in manufacturing facilities comprises a significant proportion (42\%) of total embodied energy as well. In Ontario, kilns consume natural gas and additional processing activities consume electricity. As such, consumption of electricity is becoming intensified as manufacturing facilities become more automated. (ASMI,1998)

In Toronto, all clay brick comes from manufacturing facilities in Ontario. On average and including backhaul, trucks transport clay bricks $80 \mathrm{~km}$ from manufacturing facilities into Toronto (ASMI, 1998). Comparatively, the City of Toronto measures about $40 \mathrm{~km}$ from its most western to eastern point. As well, because the streets in Toronto are less conducive to large transportation trucks, it is likely that reuse would not greatly reduce the embodied impacts involved with transporting virgin clay brick (which are relatively very small anyway). On the other hand, reuse may have potential to reduce embodied impacts associated with clay brick manufacturing, providing significant environmental benefit. For example, if clay bricks were reclaimed for reuse annually from obsolete $\mathrm{SDH}$, they would represent an embodied energy of $10,721-19,298 \mathrm{GJ}$ and $\mathrm{CO}_{2}$ emissions of $720-1,197$ tonnes.

\section{Cinder Block}

Cinder block was determined to be the third largest contributor of $\mathrm{CO}_{2}$ emission in both in-use and annual obsolete reusable material stocks: 94 - 169 MT and 283 - 509 tonnes of $\mathrm{CO}_{2}$ emissions in the stocks, respectively. These results are not surprising as cinder block made up a significant volume in the respective reusable materials stocks as well.

An ASMI report outlining embodied impacts of virgin cinder block production could not be found. Instead, generalities were drawn from a LCA of virgin concrete brick product in 1998 by ASMI. Toronto specific data from the report indicates that $68 \%$ of $\mathrm{CO}_{2}$ emissions from all excavation, transportation, and processing activities involved in producing one cubic meter of cement bricks 
occur in the processing cement for the bricks (ASMI,1998). Cement production was found to emit just over $3 \mathrm{~kg}$ of $\mathrm{CO}_{2}$ per tonne of cement (ASMI,1998).

\section{Framing Lumber}

FL $\mathrm{CO}_{2}$ emissions results may be conservative, as they do not include biogenic carbon, the carbon lost in decomposing wood, and as FL volumes for several of the archetypes were found to be low in comparison to existing literature (personal communication, $\mathrm{NABH}$ ). Nevertheless, FL still comprised a large volume of the total materials stocks and so it is not surprising that it had significant impacts on total $\mathrm{CO}_{2}$ emission and primary energy consumption in reusable material stocks. FL was determined to be a large contributor to the total primary energy consumed in Toronto's in-use and annual obsolete SDH reusable material stocks: 3,035 - 5,463 TJ in the in-use stock and 7,659-13,785 GJ in the obsolete stock.

Based on an embodied impact study conducted by ASMI (2009), 98\% of FL's primary energy consumption occurs in its manufacturing, where, in Ontario $89 \%$, of this is from biomass feedstock sources. It is unclear in what step of the manufacturing (sawing, kiln-drying, or planning) that biomass feedstock energy is most utilized. However, with exception to biomass, it is clear that kiln-drying activities consume over half the amount of energy as sawing and planning combined.

\section{Steel}

Steel was determined to be one of the largest contributors to the total $\mathrm{CO}_{2}$ emitted and primary energy consumed in Toronto's in-use and annual obsolete SDH reusable material stocks: 156 $281 \mathrm{MT}$ of $\mathrm{CO}_{2}$ emissions and 3,658 - 6,584 TJ of primary energy consumption in the in-use stock and 350 - 629 tonnes of $\mathrm{CO}_{2}$ emissions and 7,944 - 14,299 GJ of primary energy consumption in the annual obsolete stock.

Even though the volume of steel in in-use stocks was nominal in comparison to the remaining identified materials, the high proportion of $\mathrm{CO}_{2}$ emissions and primary energy consumption from steel found in this study is to be expected because metals are generally considered to have high embodied impacts in comparison to some other common structural materials (ASMI, 2002). Based on an embodied impact report conducted by ASMI in 2002, embodied energy is consumed mostly in the forms of coal, electricity, and natural gas. However, the $\mathrm{CO}_{2}$ emissions and energy consumption differ greatly based on the steel product. 
In reality, steel typically incorporates some content of recycled material that can significantly lower embodied impacts associated with its production. For example, in North America the majority of steel manufacturing utilizes electric arc furnace (versus basic oxygen furnace) technology, which can be fed up to $90 \%$ reclaimed steel by weight. The Steel Recycling Institute (2011) reports that about $55 \%$ by weight of reclaimed steel comes from post-consumer sources such as obsolete buildings, while $35 \%$ by weight comes from off-cuts at manufacturing facilities in North America.

Even so, reuse of steel would have more pronounced environmental benefits than steel recycling. Yet the results outlined in Objective Two outline that steel is much more readily recycled because of the high financial value as scrap (Gorgolewski et al, 2006).

\footnotetext{
Aluminum

Aluminum comprised the largest proportion of embodied primary energy consumption in both inuse and annual obsolete SDH reusable material stocks: 5,188 - 9.339 TJ and 12,523 - 22,542 GJ of energy in the stocks respectively. Virgin aluminum production is considered one of the most energy intensive of all metals. In reality, about $33 \%$ of all aluminum comes from reclaimed sources; although it is not clear how much of this is from obsolete buildings (The Aluminum Association, 2013).

An ASMI study could not be sourced for aluminum. However, information regarding energy consumption could be gleaned from The Aluminum Associations website and cross-referenced to ensure its accuracy. For example, aluminum manufacturing in North America typically relies on hydroelectric power because of its large electricity requirements (The Aluminum Association, 2013). Hydroelectric power is considered by many in the construction industry as a less environmentally harmful method to generate energy than other common methods that rely on non-renewable resources. However, since there is ample demand for energy, if this energy was not directed to aluminum production, it could useful to many other sources.
} 


\section{Main Findings}

In the following chapter, the main findings of this thesis are outlined with respect to the research objectives to provide the context of how those findings relate to this thesis' research problem.

\subsection{Objective One}

The first objective of this thesis was to identify and measure the volume of materials in SDH that represent typical unit types in Toronto's single detached housing stock. This objective was achieved by developing five archetypes to represent construction styles common to different eras in Toronto.

\subsubsection{Changes in SDH Material Composition Over Time Impact Reusability/ and Recyclability of Materials}

Material inventories of the five archetypes demonstrated that construction materials in the exterior envelope and interior partitions have changed significantly over time, impacting the overall reusability and recyclability of the archetypes. Thus, these findings reinforce the importance of considering the historical diversity of Toronto's typical SDH styles and building materials when addressing the research questions of this thesis.

For example, over time SDH were found to have increasingly larger usable floor areas, which reflected in higher volumes of key reclaimable structural materials such as CIP concrete, masonry, aggregate, and FL. However, generally it was found that older archetypes (Century and Wartime) had a higher volume of reusable materials and more recent archetypes had a higher volume of recyclable materials. Furthermore, increasing requirements by building codes to reduce operating energies of buildings over the past couple of decades was reflected in increasing volumes of insulation, which is a material generally not considered reusable or recyclable.

Therefore these results highlight the importance of design and material specifics in new construction in determining the reclaimability of building materials once the building itself becomes obsolete, which aligns with the Design for Deconstruction movement. Design for Deconstruction is based on the idea of pre-emptively thinking about the end life of a building in its design and construction, considering preference for reusable materials and mechanical 
material connections that facilitate little damage to materials when recovered from SDH (US EPA, n.d.).

As well, by developing archetype specific material inventories for typical SDH, this thesis provides useful information for developing more building specific waste management plans. Wimalasena (2011) explains that waste management plans intended to increase reclamation of materials headed to landfill are more economically efficient when tailored to the specific construction style of the building and consider the building's material composition. Typically an external surveyor is brought in to determine the material composition of a building, involving additional costs (Guy and Nicholas, 2011). This thesis may provide a general understanding of typical material composition and some alterative waste management opportunities for those materials to provide an initial understanding to homeowners before they invest in a professional opinion.

\subsection{Objective Two}

The second objective of this thesis was to identify the reusability/recyclability of materials inventoried in the five archetypes and determine the opportunities/infrastructure currently available in the City of Toronto to absorb suitable materials. This objective was achieved by reviewing the literature and gleaning from it insight into knowledge, practice, and local infrastructure pertaining to reuse or recycling of the identified materials. The main findings of this objective and their significance are outlined below.

\subsubsection{Deconstruction is an Important Tool for Reclaiming Materials}

It was clear from the literature review of material reusability/recyclability that deconstruction is an important tool for facilitating maximum material reusability and recyclability. However, it is well established that the additional labour costs associated with deconstruction generally make it unattractive (Wardle, 2006). Therefore, the immediate cost benefits of reusing or recycling materials have to outweigh the additional costs of deconstruction in order for it to become more widely utilized in Toronto. Countries with high building material reclamation rates demonstrate that incentive for material reuse and recycling can be provided through a few methods, which all stem from government influence.

The first method is to increase landfill-tipping fees (Wardle, 2006). For example, Saotome (2007) compared average landfill tipping fees between Denmark and Southern Ontario, where fees in Denmark ranged from $\$ 100$ - 185 CAD per tonne and in Ontario ranged from $\$ 45$ - 70 
CAD per tonne in 2006. Likewise, Denmark reclaims about $94 \%$ by weight of its CRD wastes, while Ontario reclaims about $20 \%$ by weight for recycling at disposal sites (NRCan, 2006). The second method is to impose additional taxes on landfilling large quantities of materials (Saotome, 2007). The third method is to make deconstruction more attractive by necessitating it through regulations either by banning certain materials from landfill or by prescribing that reusable and recyclable materials must be reclaimed (MHSPE, 2001).

Despite the incentive barriers to wide spread deconstruction of $\mathrm{SDH}$, there are many examples of deconstruction initiatives thriving in American cities. The success of deconstruction organizations in the U.S.A is that they are not-for-profit. Homeowners can get significant tax exemptions because they are donating reclaimed materials to these organizations, which is similar to what is happening in Toronto with not-for-profit organizations like Habitat for Humanity. The tax exemption in the U.S.A. can be so large that the homeowners can make profit, although the payback is usually months to a year after deconstruction is finished (personal communication, Ted Rieff). As well, tax exemptions are usually only significant enough to pay back additional costs for deconstruction in the U.S.A. if the homeowner is in the $30 \%$ tax bracket, excluding the majority of citizens and, overall, widespread uptake of deconstruction (person communication, Ted Rieff).

\subsubsection{Lack of Material Specific Codes or Standards}

It was clear from the reusability/recyclability analysis that there is generally insufficient specification from building codes concerning reused or recycled building materials in new construction. Specifications are important as they make using reclaimed materials in construction more approachable for homebuilders. Wardle (2006) suggests that lack of clear information and limitations in buildings codes present significant barriers to widespread uptake of material reuse.

For example, the OBC 2012 provides no clear definitions of reused versus recycled materials, making the concepts vague for homebuilders. As well, there is limited reference to using secondary products in new SDH construction in the prescriptive pathway of the OBC 2012 (although these materials may be more readily acceptable in the alternative performance based pathway that is approved by a structural engineer). Finally, the OBC does not offer insight into the specific mechanical or physical qualities that are required by reused materials, which are especially pertinent to materials reused in structural applications. 
Other than building codes, this thesis also found a lack of material standards or standardized testing methods for reusing or recycling building materials in new construction. In the case of $\mathrm{FL}$, the literature demonstrated that existing visual grading methods used for virgin lumber are not transferable for grading reclaimed FL (Falk et al, 2008; Davis, 2012). Yet, no such standardize grading scheme exists and hinders the growth of the reused FL market (Falk, 1999).

To develop appropriate building codes and material standards, it is clear more research is needed. For example, CSA standards for deconstruction were developed based on the finding from a technical committee of academic and industry professionals as well as the public. Thus to provide regulatory agents with sufficient information to standardize material testing or quality, more academic and industry research is needed to define technical and design aspects of secondary products.

\subsubsection{Lack of Infrastructure to Absorb Reclaimed Materials}

Based on findings from the opportunities to drop-off reclaimed materials analysis in Toronto, this thesis suggests that current facilities to drop-off reclaimed materials could not sufficiently absorb the volume of reclaimable materials from obsolete SDH.

However this thesis also provides useful information, by achieving objective three, that may direct where future facilities would be most appropriately established. This thesis was able to map out the location of reclaimable materials available in obsolete SDH and found that the highest volume of reusable and recyclable materials were in SDH fitting the Wartime archetype. As well, it was found that from 2008 to 2012 specific areas in Toronto had higher concentrations of SDH cleared demolition permits. These are also the areas where new houses are being constructed in place of the demolished ones.

Thus this thesis suggests that reuse and recycling drop-off facilities should be built in or close to areas with a high concentration of SDH demolition and SDH fitting the Wartime archetype. Doing so would reduce transportation distances from obsolete SDH sites to facilities. If secondary products were resold at these facilities there would be the added benefits of reduced transportation distance to new SDH construction site. These reclaimable material 'hot spot' areas are demonstrated in Figure 50. 
Even so, infrastructure such as drop-off facilities should also take into account material composition of the stocks and is further discussed below. Also discussed below is that infrastructure development is a pertinent area where information is needed to design infrastructure specific to Toronto.

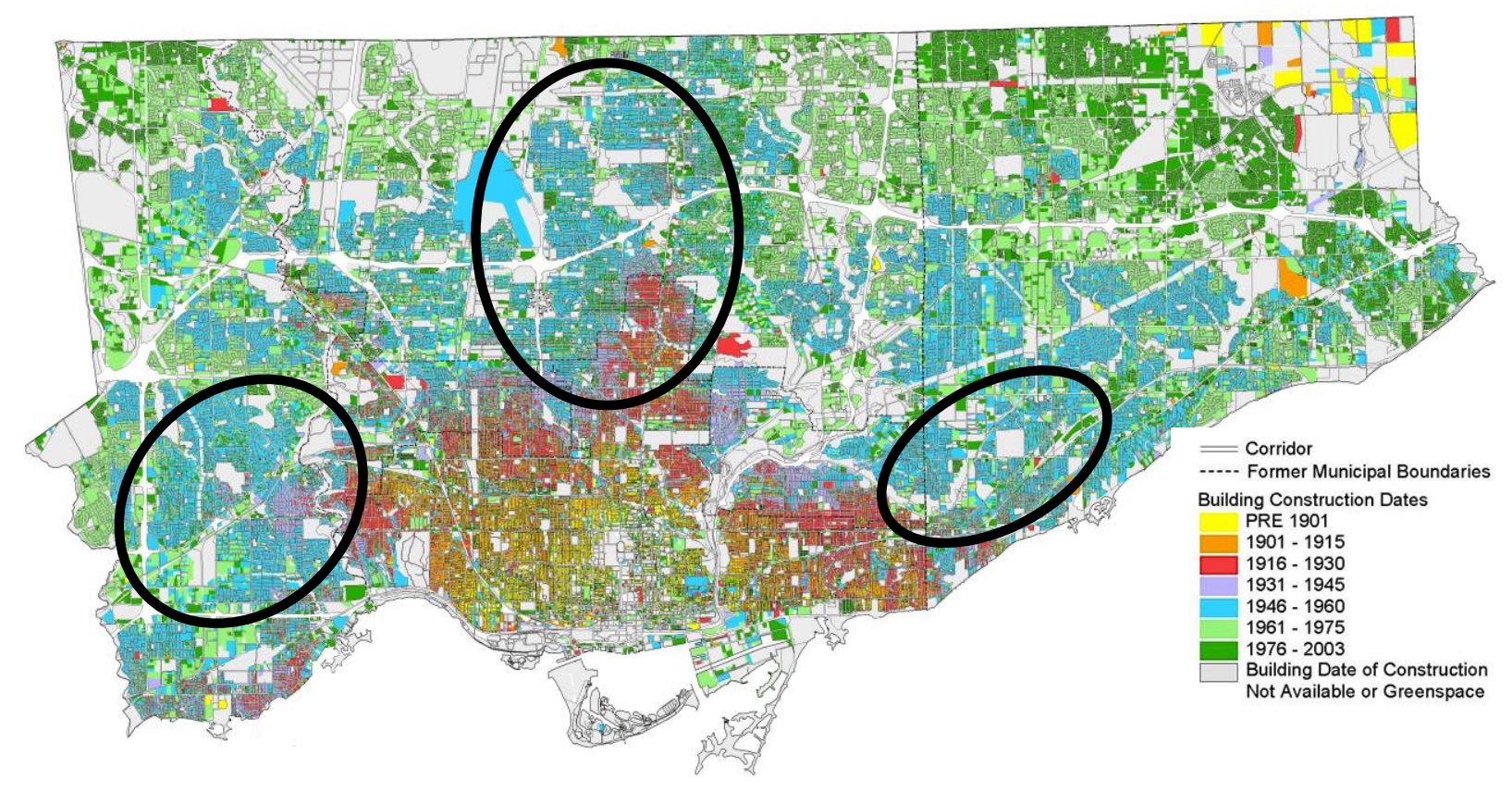

Figure 50. Hot spot areas in Toronto for developing drop-off facilities.

\subsection{Objective Three}

The third objective was to determine the environmental implications of reclaiming reusable and recyclable materials in Toronto. This objective was achieved by extrapolating material volumes to all of Toronto's in-use and annual obsolete SDH and then finding equivalent embodied carbon and energies of reusable materials.

\subsubsection{Potential to Reduce Toronto Metabolism of Building Materials}

$61-66 \%$ of the material volume in Toronto's in-use and annual obsolete SDH are suitable for reuse and recycling. Furthermore, the results of the reusability/recyclability analysis found that the materials that comprise the largest proportions of Canada's total CRD landfilled wastes all had some suitability for reuse, recycling, or both. Currently most of Toronto's obsolete SDH material is headed for landfill and highlights that the current system is insufficiently managing 
demolition waste, which is stressing dwindling supplies on void landfill space while the stocks' reusable content represents significant amounts of embodied carbon and energy.

These findings suggest that Toronto's metabolism of building materials is unnecessarily high, as a significant volume of material of total stocks could be reintroduced into Toronto's urban fabric. Reintroducing these materials in this way offers potential to create a more cyclical metabolism mimicking that of ecosystems, reducing its dependence on hinterland and global resources. As well, reintroducing these stocks through reuse would contribute to the City of Toronto's Climate Change Action Plan by conserving embodied $\mathrm{CO}_{2}$ emissions and the city's goal of conserving energy consumption (City of Toronto, 2011; City of Toronto, 2007). Although, material manufacturing outside of the city is likely not recognized by the City of Toronto emission and energy reports.

The high metabolism of Toronto's building materials may be addressed naturally overtime by necessity as a reaction to the increasing difficulties of acquiring virgin materials or landfill space to sequester them. In many ways, these issues were the precipices for many European countries to take action (Hendricks and Jenssen, 2001; Malia, 2013). However what this thesis demonstrates is that Toronto can be proactive in reducing metabolic flow through implementing city scale urban mining.

\subsubsection{Materials to Target Depend on Environmental Goals}

This thesis examined three environmental indicators, 1) implications to reducing demolition waste headed to landfill, 2) embodied $\mathrm{CO}_{2}$ emissions equivalents of the reusable material stock, and 3) embodied primary energy equivalents of the reusable material stock.

When in-use and annual obsolete stocks were examined through these three environmental indicators, this thesis demonstrated that certain materials had the largest impacts on stock composition. When examining material volume headed to landfill: FL, clay bricks, and aggregate comprised the largest volumes of reusable stocks and CIP concrete, clay bricks, and FL comprised the largest volumes of the recyclable material stocks. When examining $\mathrm{CO}_{2}$ emission equivalents: clay bricks, steel, and cinder block generated the largest emissions in reusable stocks. Finally, when examining primary energy consumption: aluminum, steel, and clay bricks consumed the largest proportions of energy in Toronto's in-use SDH stock and aluminum, clay 
bricks, and FL consumed the largest proportions of energy in Toronto's annual obsolete SDH stock.

These findings demonstrate that reclaiming these materials at the city scale would have more environmental benefit than others also identified in the SDH. Targeting these materials would be useful for developing the most effective policy and infrastructure to address environmental concern; where investment into city scale reclamation of these materials would have the largest environmental impact. However, discerning which materials to target is dependent on the environmental goals of Toronto: targeting waste, conserving carbon emissions of material production, or conserving energy consumption of material production.

Based on the environmental goals of Toronto, the special needs of the targeted materials can be considered in directing the development of policy to facilitate the reclamation, management, and reintroduction of those materials back into new construction. As well, the special needs of the targeted materials can be considered in directing the development of reuse and recycling infrastructure. For instance targeted infrastructure would consider the most appropriate technology, skills for trained professionals, and storage spaces to ensure that material reuse and recycling is maximized.

The findings of this thesis would suggest that if Toronto wanted to effectively address all three environmental indicators in the short and long term, with the most efficiency, then clay bricks would be the material to target. Clay bricks were found to be significant in stocks expressed in all three indicators. Where Toronto has reclaimed some construction waste brick and downcycled it into the Leslie spit, new systems to maximize reuse of brick in new buildings should be looked at in the future. Especially since clay brick is still widely used in SDH as a cladding material and has added historical and cultural significance within this city, which can be preserved best through reuse. 


\section{Conclusions}

The findings of this thesis provide a foundation of information that can be used to draw out a preliminary MFA for Toronto's SDH in 2012. Assuming new construction of 1073 SDH (CMHC, 2012) and 869 obsolete SDH in 2012 (City of Toronto Open Data, 2013), Figure 51 and Figure 52 outline a basic urban metabolism, considering only waste from obsolete buildings and not waste generated in construction or renovation activities. In these figures, the dashed outer circles represent the boundary of the urban unit, where raw resources and landfill fall outside of the boundary. It should be noted that both figures are not to scale, but attempt to show basic differences in stock sizes.

Figure 51 illustrates Toronto's metabolism of building materials in SDH for 2012 in the current system, based on existing statistics of material reclamation and landfilling from NRCan (2006). Although Figure 51 illustrates that $20 \%$ of demolition waste by weight is reclaimed for recycling in Toronto, in reality it is unlikely that all of this reclaimed material is reintroduced within the urban unit. Likewise, it is more unlikely that all or most of these materials are recycled into products used in new construction.

It is apparent in Figure 51 that the metabolism is predominantly linear, relying heavily on the input of virgin building materials and output of demolition waste, which is mostly landfilled. This linear metabolism is largely believed to be unsustainable because of its dependency on hinterland and global resources, which are becoming increasingly difficult to acquire. 


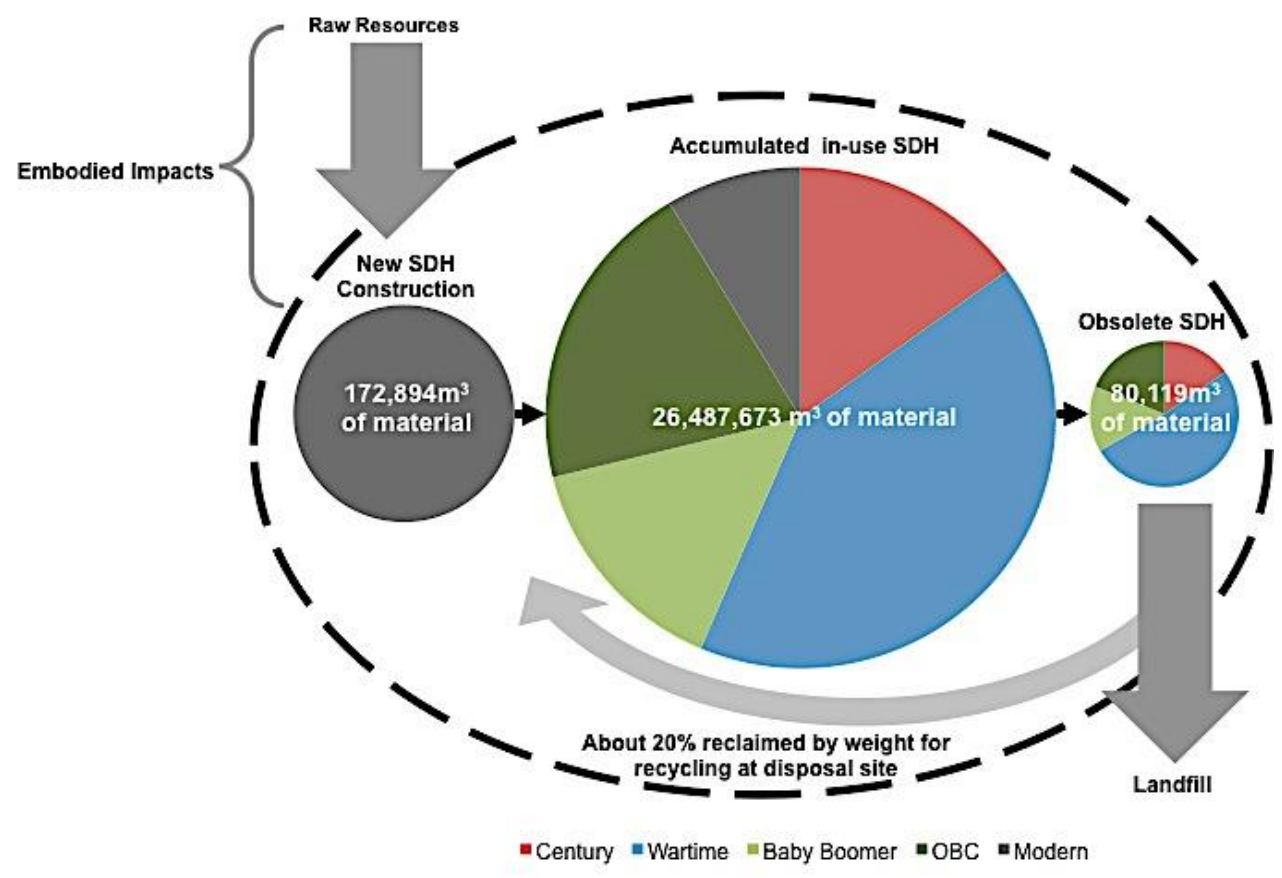

Figure 51. 2012 Toronto SDH building material flow considering only demolition waste, not to scale.

Thus, this thesis sought to answer the research questions of 1) what is an estimated inventory and flow of materials in Toronto's in-use and annual obsolete SDH stocks that is suitable for reuse and recycling, and 2) what are the environmental implications of reclaiming SDH demolition waste for reuse or recycling through three indicators: volume of demolition waste headed to landfill, embodied $\mathrm{CO}_{2}$ emissions of reusable materials, and embodied energy of reusable materials.

By answering these research questions, this thesis estimated that a significant volume of materials that could be reclaimed for reuse and recycling: $16,160,233-17,442,256 \mathrm{~m}^{3}$ of material in Toronto's in-use SDH and 40,124 - 43,364m ${ }^{3}$ of materials in Toronto's annual obsolete SDH. Based on the potential environmental benefits as expressed by the three environmental indicators, this thesis supports Toronto's needs to consider developing policy and infrastructure to increase reuse and recycling of building materials.

To demonstrate these results, Figure 52 shows the same 2012 preliminary metabolism as Figure 51 but instead highlights how metabolism changes when Toronto maximizes reclamation 
of suitable materials volumes and incorporates those materials back into the urban fabric. As well Figure 52 outlines the percent of materials in 2012's new construction, in-use, and obsolete stocks that could be reclaimed for reuse and/or recycling; where reusable and recyclable material stocks are represented in the inner, shaded circles in Figure 52. It is clear that in 2012 a greater percent of materials leaving Toronto's accumulated SDH stock through obsolete SDH were reclaimable than what was being newly constructed and added into the in-use SDH stock at the same time.

Overall Figure 52 emphasizes that by maximizing reuse and recycling, Toronto's metabolism of SDH building materials is predominately cyclical, rather than linear. The system relies less on hinterland resources for virgin building materials and landfilling and becomes more localized within the urban unit. Thus there is less pressure and dependency on external resources and overall, the system is more regenerative and behaves more like sustainable ecosystems.

Figure 52 also highlights that there are immediate environmental benefits to reintroducing materials back into urban fabric as about $61-66 \%$ of the material volume in annual obsolete stocks can be reclaimed. Prioritizing reuse as a waste management strategy was found to have significant equivalent embodied impacts as well. For example, as shown in Figure 52 reuse of materials from Toronto's annual obsolete SDH was found to be equivalent to a saving of 2,160 3,888 tonnes of $\mathrm{CO}_{2}$ emissions and 51,789 - 93,221 GJ of primary energy consumption from virgin material production, which is about the amount of primary average energy consumed in 2011 by 484 - 871 average Canadian households (Statistics Canada, 2013). 


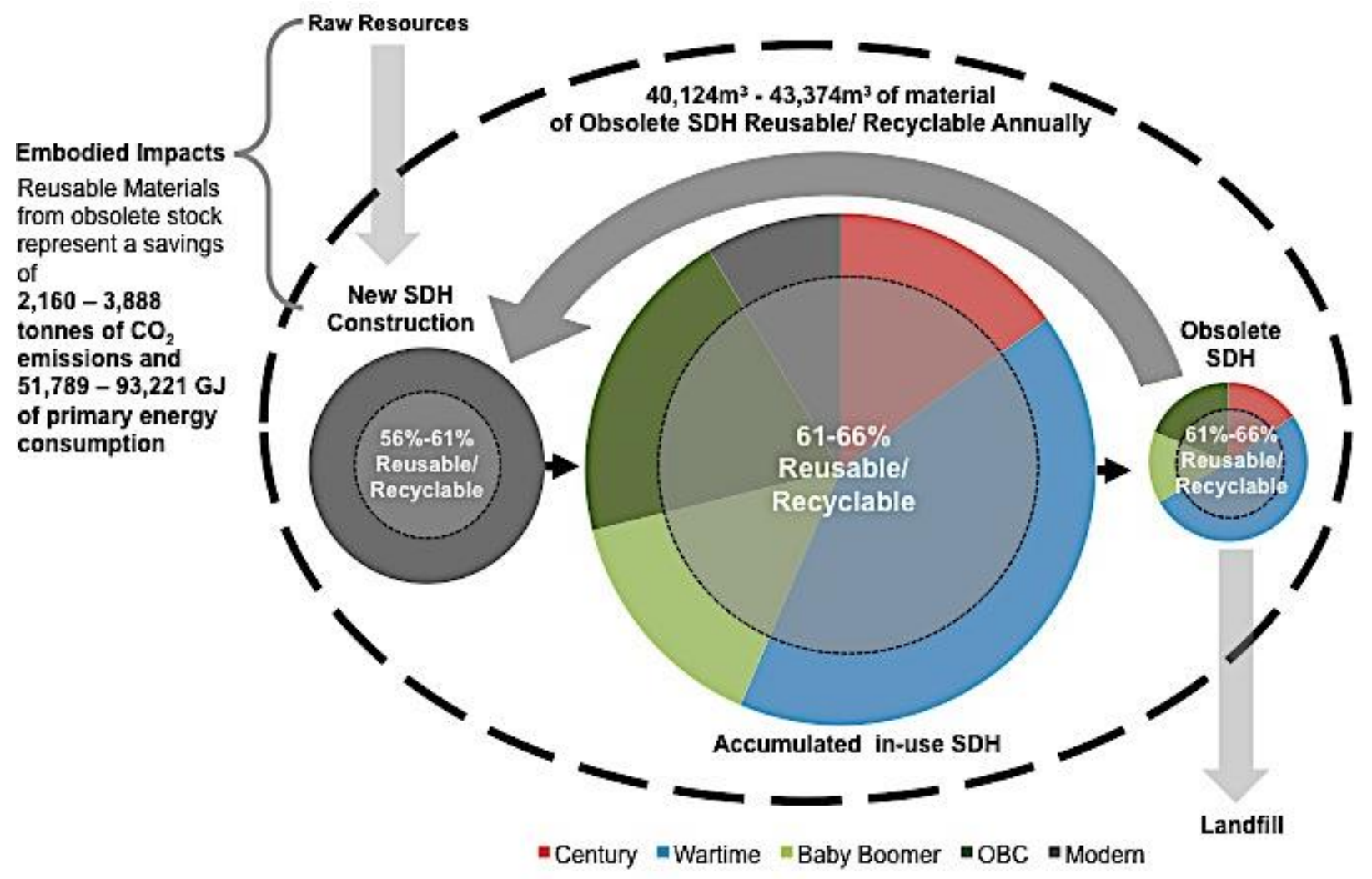

Figure 52. 2012 Toronto SDH building material flow when the maximum volume of reusable and recyclable materials are reclaimed; considering only demolition waste and not to scale.

Likewise, the thesis found that $61-66 \%$ of the material volume in the accumulated stock of $\mathrm{SDH}$ in-use in Toronto could be reclaimed for reuse and recycling, as seen in Figure 52. Prioritizing reuse as a waste management strategy, materials in Toronto's in-use SDH would be equivalent to a savings of 803 - 1,446 MT of $\mathrm{CO}_{2}$ emissions from virgin material production, which is higher than the $692 \mathrm{MT}$ of total $\mathrm{CO}_{\text {2equivalent }}$ emissions produced by Canada's major economic sectors in 2010 (Statistics Canada, 2012a). As well, reuse of materials in Toronto's inuse SDH would be equivalent to a savings of 20,628 - 37,130 TJ of primary energy consumption from virgin material production, which is about 4 - 7 times higher than the total energy consumed by Toronto in 2011 (5,140 TJ of energy). Thus, the reclaimable stock of materials in Toronto's in-use stock of SDH estimated in this thesis suggests that there are also long term potential environmental benefits to reclaiming suitable materials for reuse and recycling.

Since this thesis has established that there are significant potential environmental benefits, both in the short term (in annual obsolete SDH) and long term (in-use SDH), of reusing and/recycling 
suitable materials, the next question becomes what needs to change in order to maximize urban mining in Toronto.

The main findings of this thesis present a few suggestions that are useful in discerning how to maximize reclamation of suitable materials. For example, it is apparent that deconstruction is key in maximizing reuse and recycling and so financial incentive to promote deconstruction is important. More rigid measures could be taken to not only promote deconstruction and reclamation of materials but to mandate it through overarching regulation. For example, the City of Toronto could enforce deconstruction by making it a stipulation for obtaining demolition permits. More so than just deconstruction, stricter demolition permits could ask for a waste management plans that prioritize reuse over recycling. Developing waste management plans could be an asset as they assist in providing strategies for how materials are going to be recovered, separate (or decontaminated), and delivered to appropriate facilities.

At the same time, similar regulations at the provincial level through 102/94 and 103/94 demonstrate that regulations are not effective unless they are enforced. Partly enforcement comes down to monitoring obsolete building materials either at the building site or at disposal sites to ensure that reusable or recyclable materials are not being landfilled. Regularly monitoring wastes provides valuable information into not only the success of regulations but into Toronto's flows of building materials out of the city and therefore may be useful for future descriptive urban metabolism research and urban design by offering trends of waste management activities over time.

However information is only useful driver for change with it is disseminated to the right sources. Descriptive information about Toronto building material metabolism, such as the results found in this thesis, can be useful to decision makers who shape policy and infrastructure design. For example, this thesis found that descriptions of reclaimable material stocks and locations of annual available reclaimable resources can be applied into shaping and optimizing urban mining strategies that effectively maximize the environmental benefits of reuse and recycling. Education is also important to those directly involved in the demolition (or deconstruction) as these are the people that recover, separate, and direct waste to reuse or recycling facilities. Likewise, education is also important to those involved in design and construction, as they are the people directly involved with applying secondary products into new $\mathrm{SDH}$. As found in this thesis, current building codes offer little information on using reclaimed materials and so there is 
a need to develop an educational process to get designers, specifiers, contractors, and demolition crews up-to-date with best practices on using reclaimed materials, designing SDH to maximize reclamation of materials, and reclaiming materials for first reuse and then recycling along with education on why it is important and how it can benefit them and urban sustainability. Education of this kind could also be tied into the process of obtaining building or demolition permits, as permits are the city's most direct avenue to control the manner in which SDH are being constructed and taken down.

Lack of education (in terms of communication between reclamation experts and professional end-users and the public), enforced regulations, appropriate building codes and material standards, financial incentive, and general descriptive data on reclaimable material stocks and flows are all common barriers identified from the literature to maximizing reuse and recycling of building materials in North America (Falk, 1999; Wardle, 2001). These barriers were also highlighted in this thesis. More so, this thesis highlights that by overcome these common barriers and maximize reuse and recycling through urban mining of building materials from obsolete SDH, there are significant environmental benefits to be gained by the City of Toronto.

\subsection{Limitations of Research}

This thesis was able to answer its research questions and successfully establish an estimate of the inventory of reusable and/ recyclable materials in in-use and annual obsolete SDH stocks. Using these estimates, the implications for three environmental indicators were also established. Nevertheless this thesis had a number of limitations that need to be taken into consideration when understanding its results, including:

- Renovations or updates to SDH were not considered and therefore overall material volume estimates may be lower than reality.

- Results are outlined in volume whereas the majority of Canadian waste statistics are outlined in weight.

- Results do not present a full metabolism of the SDH in Toronto, as there are additional input and output flows of materials from construction and renovation activities.

- One-off SDH (that do not fit any archetype) are not represented and so the inventory results are not completely characteristics of every individual house style in Toronto. 
- Embodied impact results do not take into consideration the additional carbon emissions and energy consumption involved in transporting, preparing materials for reuse, and installing secondary products into buildings.

\subsection{Future Work}

This thesis is breaking new ground by bringing together material flow analysis and waste management research to develop stocks of reclaimable materials in Toronto's SDH at the city scale. As such, there are many avenues of future research to continue exploring the city scale impacts of Toronto's redevelopment or inventories of reclaimable materials in other cities. Presented here are three further avenues of research to build on the present analysis and could be useful to decision-makers in creating cyclical urban systems in Toronto with higher reclamation of suitable building materials for reuse and recycling.

\subsubsection{Developing Material Stocks for Remaining Building Types}

The results of this thesis cannot be compared to other urban metabolism studies, such as those conducted for Hong Kong and Vienna, because it does not consider all building types. Future work to inventory material stocks should include other residential buildings such as apartments, semi-detached, and row houses, and also other building typologies such as industrial, commercial, or institutional to be more directly relevant in growing the pool of information available for future Toronto metabolic analyses.

\subsubsection{Cost Optimization for Deconstruction in Toronto}

This thesis highlights that deconstruction is important in maximizing reclamation of reusable and recyclable materials. One of the main barriers to deconstruction is that it is perceived to be more expensive than demolition. This thesis does not specifically get into cost values of materials, however, there is evidence to suggest that resale and tax benefits from reusing materials can outweigh additional costs associated with labour required to deconstruct SDH.

At the same time, understanding costs associated with deconstruction, transportation, resale, and tax benefits would be important to consumers and decision makers. As well, this information could be important in highlighting the areas for increased cost efficiency. Particularly similar research could compare deconstruction and reclamation for reuse and recycling to demolition and landfilling in the context of Toronto. 


\subsubsection{Infrastructure Systems}

A thorough analysis comparing Toronto's current infrastructure and that of countries or cities with higher reclamation rates could offer beneficial insight into developing infrastructure In Toronto. Research should consider lessons learned from other countries as well as their best practices. However, focus should be placed on how this infrastructure could be adapted to Toronto by defining the factors that most influence its socio-economic and environmental effectiveness (in terms of costs, impacts on homeowners, and ability to absorb and redistribute materials with the lowest environmental impacts). 


\section{Appendix A - Examples of Construction Drawings}
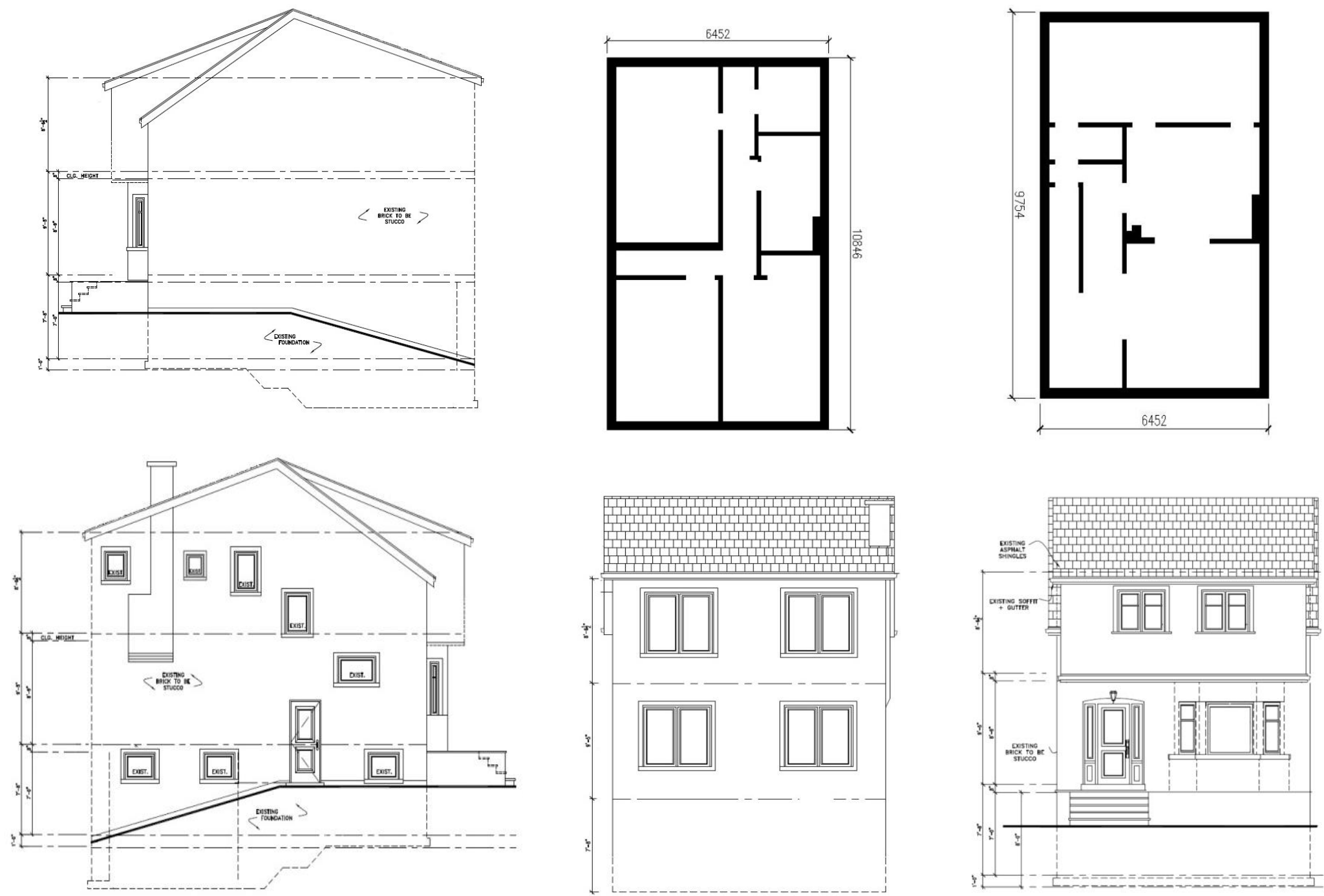

Figure 53. Century archetype elevations (original with adaptations), floor plans (from AutoCAD) (personal communication, homeowners; CMHC, 2003). 

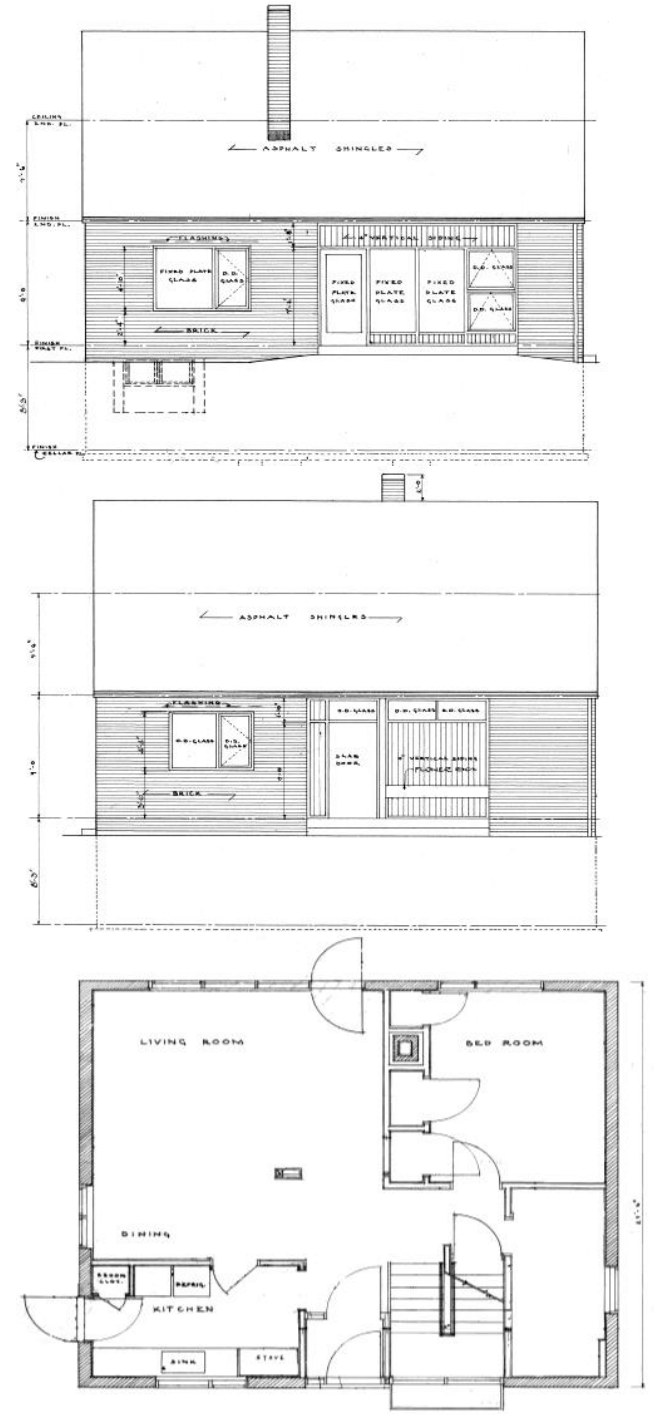
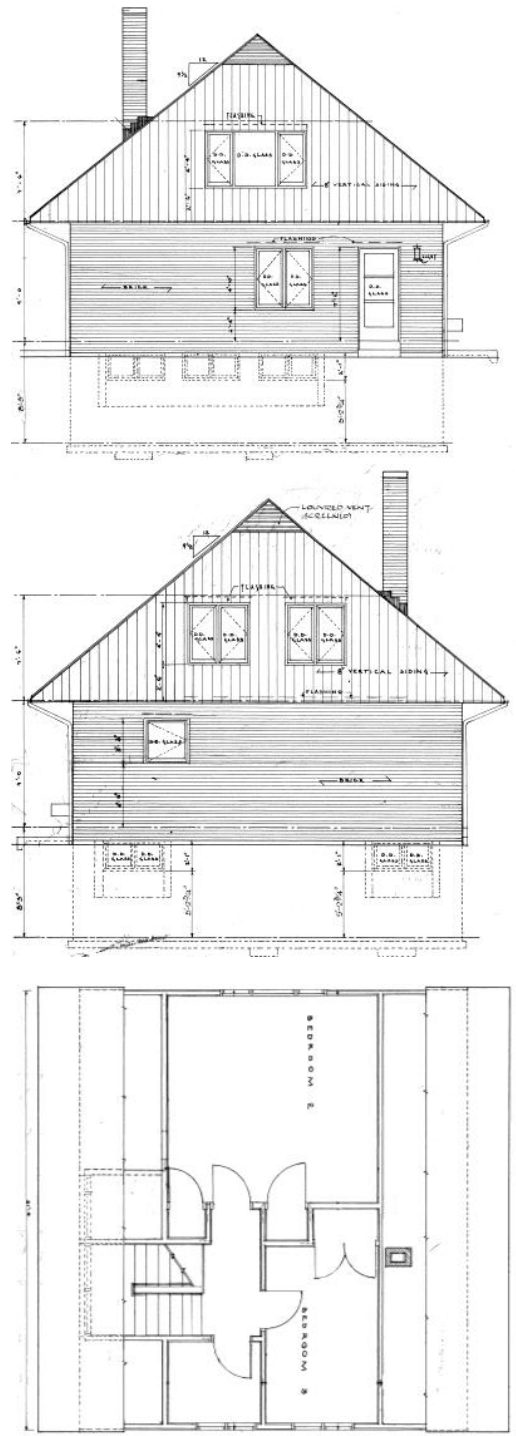

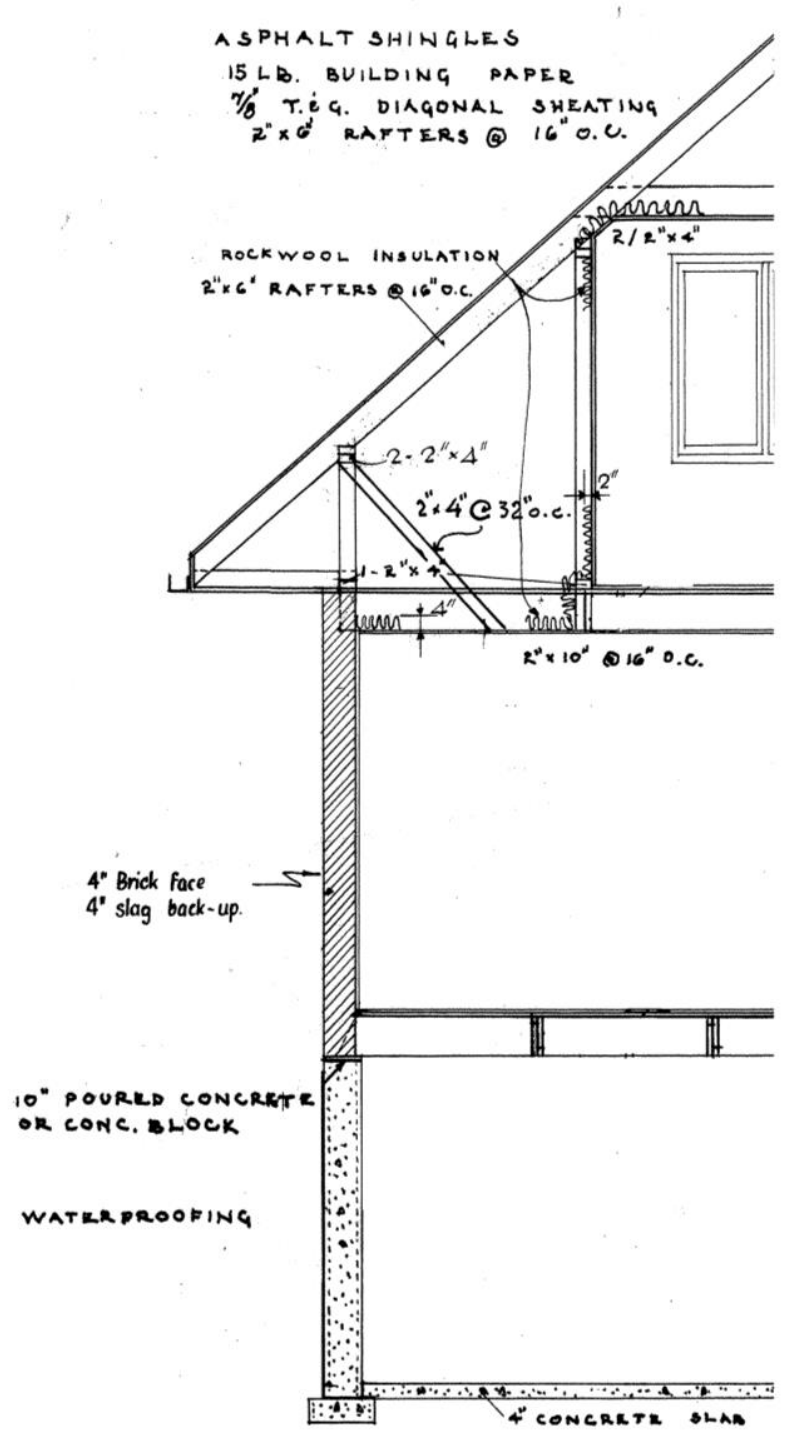

Figure 54. Wartime archetype elevations, first and second floor plans, and wall section (original drawings) (personal communication, CHMC). 

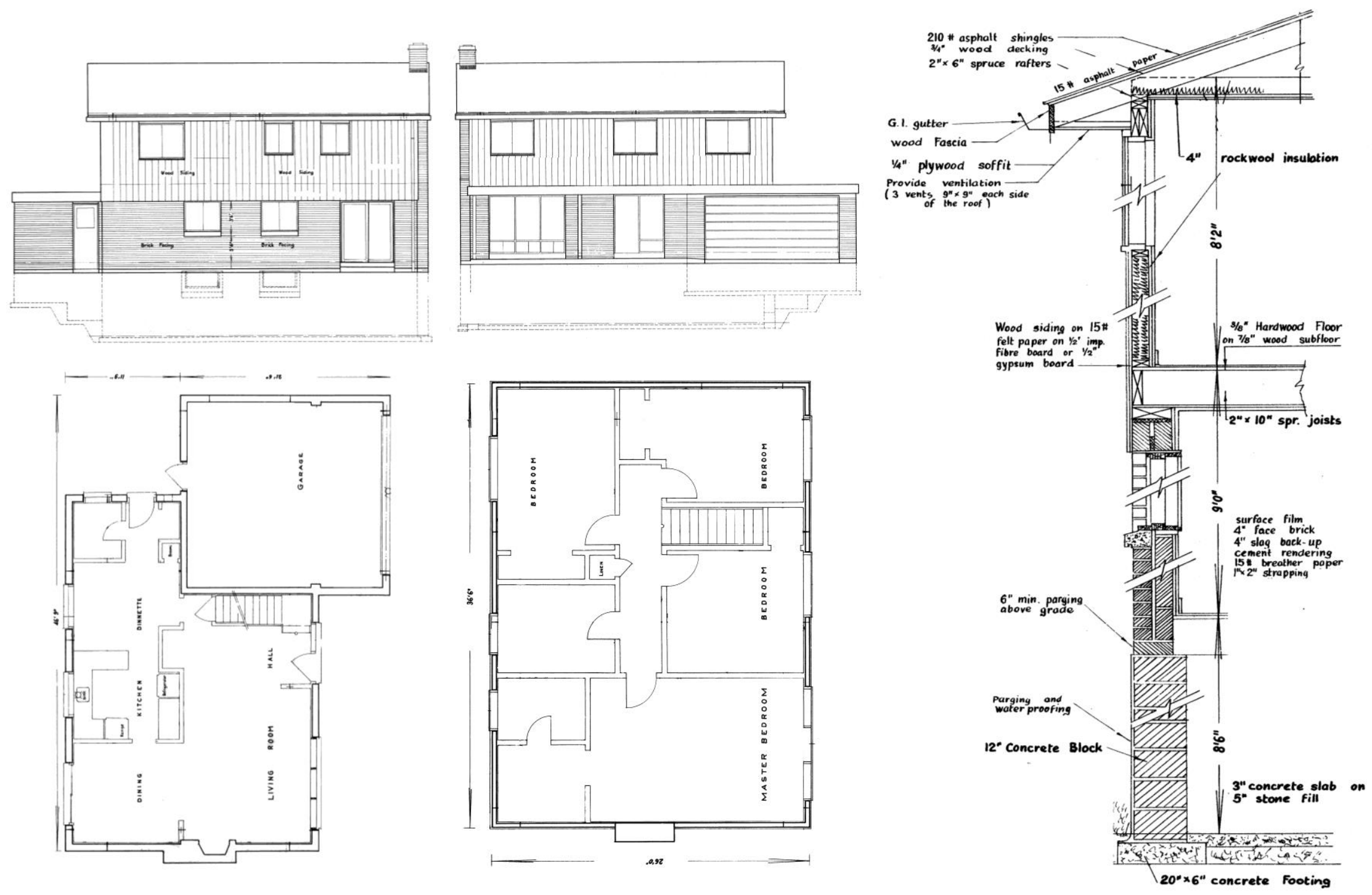

Figure 55. Baby Boomer archetype front and rear elevations, first and second floor plans, and wall section (original drawings) (personal communication, $\mathrm{CMHC}$ ). 

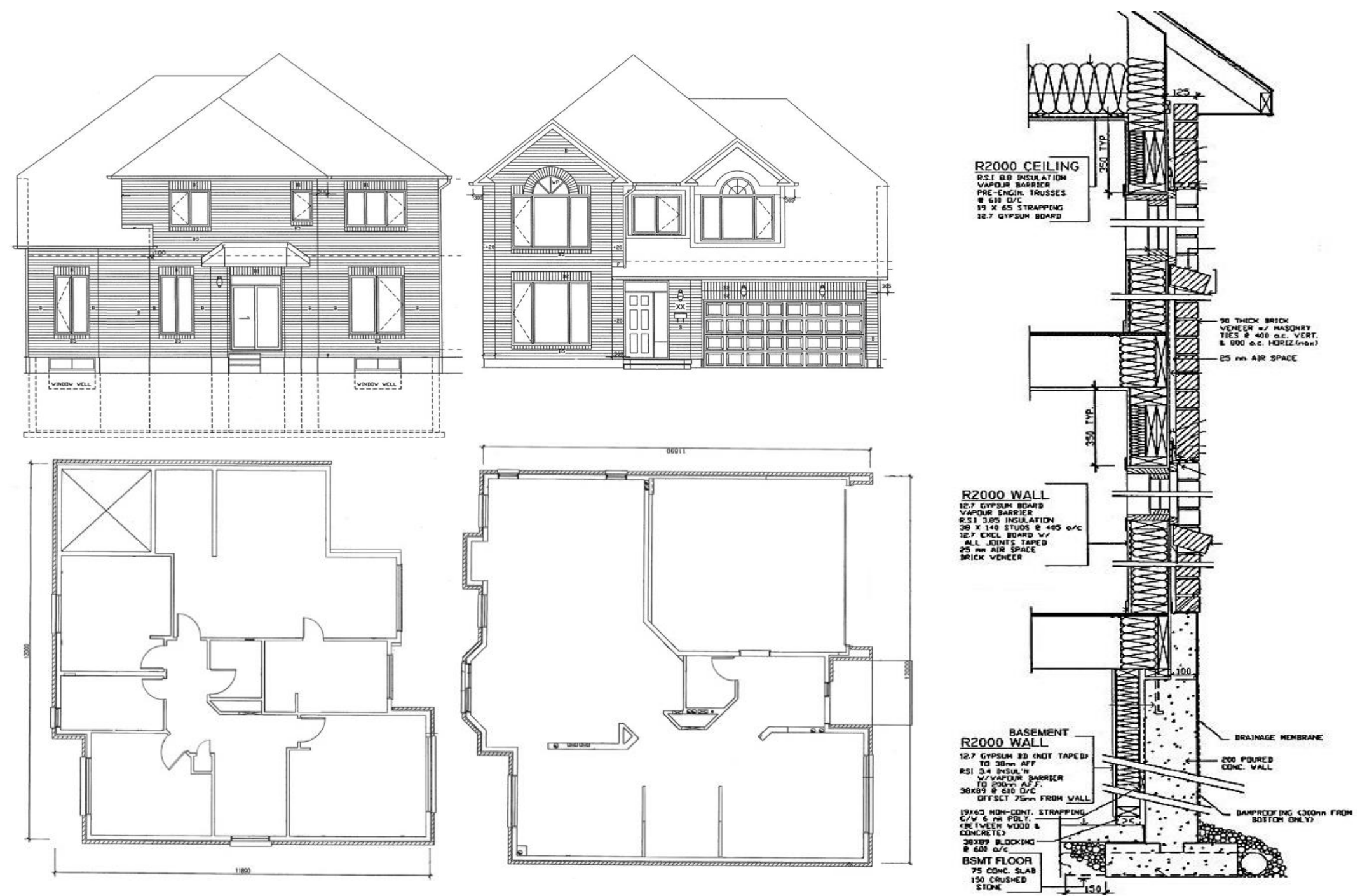

Figure 56. $\mathrm{OBC}$ and Modern archetype front and rear elevations, first and second floor plans, and wall section (original drawings) (NRCan and CMHC, 1998). 


\section{Appendix B - Assumptions for Determining Material Volumes}

Below a list of assumptions is presented with the corresponding archetype(s) that the assumption relates to. These assumptions were applied unless otherwise stated on the construction drawings.

1. Interior partitions have double studs at ends and corners. (All Relevant Archetypes)

2. Double studs beside and under windows. (All Relevant Archetypes)

3. Triple studs at corners of exterior partitions. (Wartime, Baby Boomer, OBC, Modern)

4. Wood and metal studs at $400 \mathrm{~mm}$. (All Relevant Archetypes)

5. $15 \mathrm{lb}$ Asphalt felt for roofing. (All Relevant Archetypes)

6. Waterproofing in basement is HDPE membrane. (All Relevant Archetypes)

7. Single pane of window glass and door glass same over all eras.

8. Assuming insulation is fiberglass batt with a depth equal to stud depth. (OBC, Modern)

9. Framing lumber, width less than $39 \mathrm{~mm}$ included strapping and lath.

10. Doors are not beveled.

11. No knockouts in steel studs.

12. Extrusions in cinder blocks represent $40 \%$ of its volume, based drawings of typical two hole 254mm long cinder block. (All Relevant Archetypes)

13. All masonry (clay and concrete brick and cinder blocks) and mortar is composed of $30 \%$ mortar and 70\% masonry, based on literature from Cavalline and Weggel (2013). (All Relevant Archetypes)

Tables 1-5 outline the material dimensions inputted to determine material volumes, while the remaining dimensions were measured on the construction drawings. Inputted dimensions were sourced directly from construction drawings if they matched the literature. Inputs marked with a asterisks ( ${ }^{*}$ ) were not available in the drawings and, instead, reflect consensus in the literature including sources such as the WUFI Pro 5.2 Materials Databases, Ontario Building Codes for 1990 and 2012, online renovation and do-it-yourself forums, historical outlines for materials, and the CMHC 'Renovating Distinctive Houses' series. 
Table 9. Identified materials dimensions.

\begin{tabular}{|c|c|c|c|c|}
\hline \multicolumn{5}{|c|}{ Century House } \\
\hline Primary Location & Material & Y (Width) & X (Depth) & Z (Height \\
\hline \multirow{3}{*}{$\begin{array}{l}\text { Load Bearing } \\
\text { Exterior Envelope } \\
\text { Climate Control }\end{array}$} & Brick and Mortar & Measured & 200 & Measured \\
\hline & Wood Studs & 50.8 & 101.6 & Measured \\
\hline & Insulation & Measured & Measured & $50.8^{*}$ \\
\hline \multirow{2}{*}{ Cladding } & Wood Clapboard & Measured & 18 & Measured \\
\hline & Tongue \& Groove Wood Boards & Measured & 19.05 & Measured \\
\hline \multirow{2}{*}{ Roofing } & Asphalt Shingles & Measured & 3 & Measured \\
\hline & Tongue \& Groove Wood Boards & Measured & $25.4^{*}$ & Measured \\
\hline \multirow{4}{*}{ Structural Roof } & Rafters & 50.8 & Measured & 152.4 \\
\hline & Joists & 50.8 & Measured & 152.4 \\
\hline & Collar Ties & 25.4 & Measured & 101.6 \\
\hline & Ridge & 25.4 & Measured & 152.4 \\
\hline \multirow{3}{*}{ Interior Finish } & Strapping & 76 & 25 & Measured \\
\hline & Wood Lath & Measured & 8 & Measured \\
\hline & 3 Coat Plaster & Measured & 22 & Measured \\
\hline Interior Partitions & Wood Studs & 50.8 & Measured & 101.6 \\
\hline \multirow{2}{*}{ Structural Flooring } & Joists & 50.8 & Measured & 204.2 \\
\hline & Subflooring & Measured & Measured & 25.4 \\
\hline \multirow{2}{*}{ Flooring Finish } & Hardwood & Measured & Measured & 22.2 \\
\hline & Linoleum & Measured & Measured & $6^{*}$ \\
\hline \multirow{2}{*}{ Basement Wall } & Brick and Mortar & Measured & 304.8 & Measured \\
\hline & Parging & Measured & $9.0^{*}$ & Measured \\
\hline \multirow{2}{*}{ Foundation } & Rubblestone & Measured & $457.2^{*}$ & Measured \\
\hline & Aggregate & Measured & Measured & 10 \\
\hline Windows & Glass & Measured & 6.35 & Measured \\
\hline \multirow{2}{*}{ Doors } & Exterior wood & Measured & $40.6^{*}$ & Measured \\
\hline & Interior wood & Measured & $34.9^{*}$ & Measured \\
\hline
\end{tabular}


Table 10. Identified materials dimensions.

\begin{tabular}{|c|c|c|c|c|}
\hline \multicolumn{5}{|c|}{ Wartime House } \\
\hline Primary Location & Material & Y (Width) & X (Depth) & Z (Height) \\
\hline \multirow{6}{*}{$\begin{array}{l}\text { Load Bearing } \\
\text { Exterior Envelope }\end{array}$} & Clay Brick and Mortar & Measured & 101.6 & Measured \\
\hline & Concrete Brick and Mortar & Measured & 101.6 & Measured \\
\hline & Wood Studs & 41.3 & 92.1 & Measured \\
\hline & Steel Angle (flattened) & Measured & $152.4-215.8$ & 6.3-7.9 \\
\hline & Wood Lintels & Measured & 41.3 & $142.9-244.5$ \\
\hline & Insulation & Measured & Measured & $50.8-101.6$ \\
\hline \multirow{3}{*}{ Climate Control } & Parging & Measured & $9.0^{*}$ & Measured \\
\hline & Asphalt Impregnated Paper & Measured & $0.2^{*}$ & Measured \\
\hline & Asphalt Felt & Measured & $2.0^{*}$ & Measured \\
\hline \multirow{2}{*}{ Cladding } & Wood Clapboard & Measured & 18 & Measured \\
\hline & Tongue \& Groove Wood Boards & Measured & 19.05 & Measured \\
\hline \multirow{3}{*}{ Roofing } & Asphalt Shingles & Measured & $3.0^{*}$ & Measured \\
\hline & Tongue \& Groove Wood Boards & 22.2 & Measured & Measured \\
\hline & Rafters & 41.3 & Measured & 142.9 \\
\hline & Joists & 41.3 & Measured & 244.5 \\
\hline \multirow[t]{4}{*}{ Roof Structural } & Collar Ties & 41.3 & Measured & 142.9 \\
\hline & Ridge & 15.9 & Measured & 142.9 \\
\hline & Framing & 41.3 & Measured & 92.1 \\
\hline & Strapping & 44.5 & 22.2 & Measured \\
\hline \multirow[t]{2}{*}{ Interior Finish } & Gypsum Lath & Measured & 25.4 & Measured \\
\hline & Plaster & Measured & $12.7^{*}$ & Measured \\
\hline \multirow[t]{2}{*}{ Interior Partitions } & Wood Studs & 41.3 & 92.1 & Measured \\
\hline & Joists & 41.3 & Measured & $193.7-244.5$ \\
\hline \multirow{3}{*}{ Floor Structural } & Wood Beams & $41.3-193.7$ & Measured & $244.5-295.3$ \\
\hline & Posts & 92.1 & 193.7 & Measured \\
\hline & Tongue \& Groove Subflooring & Measured & Measured & $25.4^{*}$ \\
\hline \multirow{2}{*}{ Floor Finishing } & Hardwood & Measured & Measured & $12.7^{*}$ \\
\hline & Linoleum & Measured & Measured & $6.0^{*}$ \\
\hline \multirow{3}{*}{ Basement Walls } & Concrete Blocks and Mortar & Measured & 254 & Measured \\
\hline & Waterproofing & Measured & $0.6^{*}$ & Measured \\
\hline & Pier & 406.4 & 304.8 & Measured \\
\hline \multirow{2}{*}{ Foundations } & Footings & $457.2-609.6$ & Measured & $152.4-304.8$ \\
\hline & Concrete Slab & Measured & Measured & 101.6 \\
\hline & Aggregate & Measured & Measured & 152.4 \\
\hline \multirow[t]{3}{*}{ Windows } & Glass Pane & Measured & $6.35^{\star}$ & Measured \\
\hline & Interior Wood & Measured & 34.9 & Measured \\
\hline & Glass & Measured & $19.1^{*}$ & Measured \\
\hline
\end{tabular}


Table 11. Identified materials dimensions.

\begin{tabular}{|c|c|c|c|c|}
\hline \multicolumn{5}{|c|}{ Baby Boomer } \\
\hline Primary Location & Material & Y (Width) & X (Depth) & Z (Height) \\
\hline \multirow{6}{*}{$\begin{array}{l}\text { Load Bearing } \\
\text { Exterior Envelope }\end{array}$} & Clay Brick and Mortar & Measured & 101.6 & Measured \\
\hline & Concrete Brick and Mortar & Measured & 101.6 & Measured \\
\hline & Wood Studs & 41.3 & 92.1 & Measured \\
\hline & Steel Angle (flattened) & Measured & $190.5-215.8$ & $6.3-7.9$ \\
\hline & Wood Lintels & & 92.1 & $193.7-244.5$ \\
\hline & Insulation & Measured & Measured & 101.6 \\
\hline \multirow{3}{*}{ Climate Control } & Parging & Measured & $9.0^{*}$ & Measured \\
\hline & Building Paper & Measured & $0.7^{*}$ & Measured \\
\hline & Asphalt Felt & Measured & $2.0^{*}$ & Measured \\
\hline \multirow{2}{*}{ Cladding } & Aluminum Siding & Measured & $0.56^{*}$ & Measured \\
\hline & Fibreboard & Measured & 12.7 & Measured \\
\hline \multirow{3}{*}{ Roofing } & Asphalt Shingles & Measured & $3.0^{*}$ & Measured \\
\hline & Plywood & Measured & Measured & 19.05 \\
\hline & Rafters & 41.3 & Measured & 142.9 \\
\hline \multirow{4}{*}{ Roof Structural } & Joists & 41.3 & Measured & 142.9 \\
\hline & Collar Ties & 41.3 & Measured & 92.1 \\
\hline & Ridge & 15.9 & Measured & 142.9 \\
\hline & Framing & 41.3 & Measured & 92.1 \\
\hline \multirow{2}{*}{ Interior Finish } & Strapping & 50.8 & 25.4 & Measured \\
\hline & Drywall & Measured & 12.7 & Measured \\
\hline \multirow[t]{3}{*}{ Interior Partitions } & Wood Studs & 41.3 & 92.1 & Measured \\
\hline & Joists & 41.3 & Measured & $193.7-244.5$ \\
\hline & Wood Beams & $41.3-142.9$ & Measured & $193.7-295.3$ \\
\hline \multirow[t]{2}{*}{ Floor Structural } & $\begin{array}{l}\text { Steel Wide Flange Beam } \\
\text { (cross sectional area) }\end{array}$ & Measured & Measured & 2322.5 \\
\hline & Plywood Subflooring & Measured & Measured & 22.2 \\
\hline \multirow{2}{*}{ Floor Finishing } & Hardwood & Measured & Measured & 9.52 \\
\hline & Linoleum & Measured & Measured & Measured \\
\hline \multirow{3}{*}{ Basement Walls } & CIP Concrete & Measured & 304.8 & Measured \\
\hline & Waterproofing & Measured & $0.6^{\star}$ & Measured \\
\hline & Pier & 203.2-304.8 & $203.2-304.8$ & Measured \\
\hline \multirow{3}{*}{ Foundations } & Footings & Measured & 406.4-508 & 152.4 \\
\hline & Concrete Slab & Measured & Measured & 76.2 \\
\hline & Aggregate & Measured & Measured & 127 \\
\hline \multirow[t]{2}{*}{ Windows } & Double Pane Glass & Measured & $12.7^{*}$ & Measured \\
\hline & Exterior Wood & Measured & $40.6^{*}$ & Measured \\
\hline \multirow[t]{2}{*}{ Doors } & Interior Wood & Measured & $34.9^{*}$ & Measured \\
\hline & Glass & Measured & $19.1^{*}$ & Measured \\
\hline
\end{tabular}


Table 12. Identified materials dimensions.

\begin{tabular}{|c|c|c|c|c|}
\hline \multicolumn{5}{|c|}{ OBC } \\
\hline Primary Location & Material & Y (Width) & X (Depth) & Z (Height) \\
\hline \multirow{4}{*}{$\begin{array}{l}\text { Load Bearing } \\
\text { Exterior Envelope }\end{array}$} & Wood Studs & 38 & 89 & Measured \\
\hline & Steel Angle (flattened) & Measured & $180-190$ & $6-8$ \\
\hline & Wood Lintels & Measured & 38 & 235 \\
\hline & Insulation & Measured & $89^{*}$ & Measured \\
\hline \multirow{3}{*}{ Climate Control } & Vapour Barrier & Measured & $0.15^{\star}$ & Measured \\
\hline & Kraft Paper & Measured & $0.24^{*}$ & Measured \\
\hline & Asphalt Felt & Measured & $2.0^{*}$ & Measured \\
\hline \multirow{3}{*}{ Cladding } & Brick and Mortar & Measured & 90 & Measured \\
\hline & Vinyl Siding & 8 & Measured & Measured \\
\hline & Plywood Sheathing & Measured & 12.7 & Measured \\
\hline \multirow{2}{*}{ Roofing } & Asphalt Shingles & Measured & $3.0^{*}$ & Measured \\
\hline & Plywood Sheathing & Measured & Measured & $9.5^{*}$ \\
\hline \multirow{5}{*}{$\begin{array}{l}\text { Pre-Engineered } \\
\text { Roof Truss } \\
\text { Interior Finishes } \\
\text { Interior Partitions }\end{array}$} & Cord & $38^{*}$ & Measured & $184^{*}$ \\
\hline & Web & 38 & Measured & 89 \\
\hline & Drywall & Measured & 12.7 & Measured \\
\hline & Wood Studs & 38 & 89 & Measured \\
\hline & Joists & 38 & Measured & 235 \\
\hline \multirow[t]{3}{*}{ Floor Structural } & $\begin{array}{l}\text { Steel Wide Flange Beams } \\
\text { (cross sectional area) }\end{array}$ & - & Measured & $2860-5890$ \\
\hline & Steel Columns (flattened) & 3889 & $4.76^{*}$ & Measured \\
\hline & Plywood Subflooring & Measured & Measured & $16^{*}$ \\
\hline \multirow{2}{*}{ Floor Finishes } & Carpet & Measured & Measured & $19.1^{*}$ \\
\hline & Ceramic Tile & Measured & Measured & $9.5^{*}$ \\
\hline \multirow{3}{*}{ Basement Walls } & CIP Concrete & Measured & $100-200$ & Measured \\
\hline & Drainage Membrane & Measured & $0.6^{*}$ & Measured \\
\hline & Footings & Measured & 500 & 150 \\
\hline \multirow[t]{2}{*}{ Foundations } & Concrete Slab & Measured & Measured & $75-100$ \\
\hline & Aggregate & Measured & Measured & 150 \\
\hline \multirow[t]{2}{*}{ Windows } & Double Pane Glass & Measured & $12.7^{\star}$ & Measured \\
\hline & Exterior Wood & Measured & 45 & Measured \\
\hline \multirow[t]{2}{*}{ Doors } & Interior Wood & Measured & 35 & Measured \\
\hline & Glass & Measured & $19.1^{*}$ & Measured \\
\hline
\end{tabular}


Table 13. Identified materials dimensions.

\begin{tabular}{|c|c|c|c|c|}
\hline \multicolumn{5}{|c|}{ Modern } \\
\hline Primary Location & Material & Y (Width) & X (Depth) & Z (Height) \\
\hline \multirow{4}{*}{$\begin{array}{l}\text { Load Bearing } \\
\text { Exterior Envelope }\end{array}$} & Wood Studs & 38 & 140 & Measured \\
\hline & Steel Angle (flattened) & Measured & $180-190$ & $6-8$ \\
\hline & Wood Lintels & Measured & 38 & 235 \\
\hline & Insulation & Measured & 152.4 & Measured \\
\hline \multirow{4}{*}{ Climate Control } & Vapour Barrier & Measured & $0.15^{*}$ & Measured \\
\hline & Kraft Paper & Measured & $0.24^{*}$ & Measured \\
\hline & Asphalt Felt & Measured & $2.0^{*}$ & Measured \\
\hline & Brick and Mortar & Measured & 90 & Measured \\
\hline \multirow{2}{*}{ Cladding } & Wood Paneling & 8 & Measured & Measured \\
\hline & OBS Sheathing & Measured & 12.7 & Measured \\
\hline \multirow{2}{*}{ Roofing } & Asphalt Shingles & Measured & $3.0^{*}$ & Measured \\
\hline & OBS Sheathing & Measured & Measured & $9.5^{\star}$ \\
\hline \multirow{6}{*}{$\begin{array}{l}\text { Pre-Engineered } \\
\text { Roof Truss } \\
\text { Interior Finishes } \\
\text { Interior Load } \\
\text { Bearing Partitions } \\
\text { Non Load Bearing } \\
\text { Partitions }\end{array}$} & Cord & $38^{*}$ & Measured & $184^{*}$ \\
\hline & Web & 38 & Measured & 89 \\
\hline & Drywall & Measured & 12.7 & Measured \\
\hline & Wood Studs and Plates & 38 & 140 & Measured \\
\hline & Steel Studs and Plates (flattened) & $120-122$ & $0.46^{*}$ & Measured \\
\hline & Joists & 38 & Measured & 235 \\
\hline \multirow[t]{4}{*}{ Floor Structural } & $\begin{array}{l}\text { Steel Wide Flange Beams } \\
\text { (cross sectional area) }\end{array}$ & - & Measured & $2860-5890$ \\
\hline & Steel Columns (flattened) & 3889 & $4.76^{*}$ & Measured \\
\hline & Plywood Subflooring & Measured & Measured & $16^{*}$ \\
\hline & Hardwood & Measured & Measured & $19.1^{*}$ \\
\hline \multirow[t]{2}{*}{ Floor Finishing } & Carpet & Measured & Measured & $19.1^{*}$ \\
\hline & Ceramic Tile & Measured & Measured & $9.5^{*}$ \\
\hline \multirow{3}{*}{ Basement Walls } & CIP Concrete & Measured & $100-200$ & Measured \\
\hline & Drainage Membrane & Measured & $0.6^{*}$ & Measured \\
\hline & Footings & Measured & 500 & 150 \\
\hline \multirow[t]{2}{*}{ Foundations } & Concrete Slab & Measured & Measured & $75-100$ \\
\hline & Aggregate & Measured & Measured & 150 \\
\hline \multirow[t]{2}{*}{ Windows } & Double Pane Glass & Measured & $12.7^{*}$ & Measured \\
\hline & Exterior Wood & Measured & 45 & Measured \\
\hline \multirow[t]{2}{*}{ Doors } & Interior Wood & Measured & 35 & Measured \\
\hline & Glass & Measured & $19.1^{*}$ & Measured \\
\hline
\end{tabular}




\section{Appendix C - Absolute Values for Results}

Table 14. Volumes $\left(\mathrm{m}^{3}\right)$ of materials inventoried in the five archetypes.

\begin{tabular}{|c|c|c|c|c|c|}
\hline & Century & Wartime & Baby Boomer & OBC & Modern \\
\hline FL width $>38 \mathrm{~mm}$ & 9.9 & 11.9 & 12.2 & 17.8 & 18.5 \\
\hline FL width $<38 \mathrm{~mm}$ & 3.1 & 0.2 & 0.1 & - & 0.6 \\
\hline Clay Brick and Mortar & 38.5 & 7.7 & 9.4 & 16.8 & 16.8 \\
\hline Cinder Block and Mortar & - & 9.2 & 12.5 & - & - \\
\hline Rubblestone and Mortar & 6.0 & - & - & - & - \\
\hline Concrete Brick and Mortar & - & 7.4 & 9.3 & - & - \\
\hline Aggregate & 0.6 & 11.6 & 12.5 & 18.2 & 18.2 \\
\hline CIP Concrete & - & 10.4 & 16.5 & 39.4 & 39.4 \\
\hline Steel & - & 0.1 & - & 0.4 & 0.5 \\
\hline Solid Wood Sheathing & 5.3 & 6.5 & - & - & - \\
\hline Engineered Wood Sheathing & - & - & 6.6 & 7.8 & 7.8 \\
\hline Aluminum & - & - & 0.1 & - & 0.0 \\
\hline Vinyl & - & - & - & - & 0.0 \\
\hline Asphalt Shingles & 0.2 & 0.4 & 0.3 & 0.8 & 0.8 \\
\hline Wood Paneling & 0.5 & 1.1 & - & - & - \\
\hline Glass & 0.1 & 0.1 & 0.3 & 0.3 & 0.3 \\
\hline Solid Wood Doors & 0.9 & 1.2 & 0.7 & 0.6 & 0.6 \\
\hline Drywall & - & - & 4.2 & 6.5 & 7.9 \\
\hline Gypsum Lath & - & 4.8 & - & - & - \\
\hline Plaster & 7.6 & 2.8 & - & - & - \\
\hline Linoleum & 0.1 & 0.1 & 0.2 & - & - \\
\hline Ceramic Tiles & - & - & - & 0.7 & 0.7 \\
\hline Carpet & - & - & 1.8 & 1.9 & 1.2 \\
\hline Solid Wood Flooring & 2.0 & 1.0 & - & - & 0.7 \\
\hline Roofing Felt & - & 0.3 & 0.4 & 0.8 & 0.8 \\
\hline Breathing Paper & - & - & - & - & - \\
\hline Basement Waterproofing & - & 0.1 & 0.1 & 0.1 & 0.1 \\
\hline Parging & 0.5 & 0.5 & 1.0 & - & - \\
\hline Polyethylene Vapour Barrier & - & - & - & - & - \\
\hline Insulation * Including Air Volume & 4.4 & 6.7 & 13.6 & 24.1 & 46.2 \\
\hline Total & 79.9 & 83.9 & 101.6 & 136.2 & 161.1 \\
\hline
\end{tabular}


Table 15. Volumes $\left(\mathrm{m}^{3}\right)$ of materials in Toronto's in-use SDH stock.

\begin{tabular}{|c|c|c|c|c|c|c|}
\hline & Century & Wartime & $\begin{array}{c}\text { Baby } \\
\text { Boomer }\end{array}$ & OBC & Modern & Total \\
\hline FL width > 38mm & 492,202 & $1,553,874$ & 470,139 & 700,527 & 261,968 & $3,478,710$ \\
\hline FL width $<38 \mathrm{~mm}$ & 156,153 & 21,433 & 5,536 & - & 7,892 & 191,014 \\
\hline Clay Brick and Mortar & $1,919,596$ & 999,997 & 360,167 & 658,344 & 237,065 & $4,175,168$ \\
\hline $\begin{array}{l}\text { Cinder Block and } \\
\text { Mortar }\end{array}$ & - & $1,201,406$ & 480,699 & - & - & $1,682,104$ \\
\hline $\begin{array}{l}\text { Rubblestone and } \\
\text { Mortar }\end{array}$ & 300,092 & - & - & - & - & 300,092 \\
\hline $\begin{array}{l}\text { Concrete Brick and } \\
\text { Mortar }\end{array}$ & 0 & 967,204 & 356,472 & - & - & $1,323,676$ \\
\hline Aggregate & 30,594 & $1,510,919$ & 480,016 & 715,734 & 257,730 & $2,994,993$ \\
\hline CIP Concrete & 0 & $1,361,495$ & 636,156 & $1,548,410$ & 557,571 & $4,103,632$ \\
\hline Steel & 0 & 6,617 & 1,790 & 17,405 & 6,570 & 32,382 \\
\hline $\begin{array}{l}\text { Solid Wood } \\
\text { Sheathing }\end{array}$ & 265,094 & 848,098 & - & - & - & $1,113,191$ \\
\hline $\begin{array}{l}\text { Engineered Wood } \\
\text { Sheathing }\end{array}$ & - & - & 253,213 & 306,290 & 110,293 & 669,795 \\
\hline Aluminum & - & - & 2,413 & - & - & 2,413 \\
\hline Vinyl & - & - & - & 392 & - & 392 \\
\hline Asphalt Shingles & 12,444 & 49,908 & 13,001 & 32,933 & 11,859 & 120,145 \\
\hline Wood Paneling & 24,680 & 146,878 & - & - & 141 & 171,700 \\
\hline Glass & 4,509 & 18,705 & 9,881 & 10,117 & 3,643 & 46,854 \\
\hline Solid Wood Doors & 46,315 & 152,362 & 25,037 & 23,378 & 8,418 & 255,511 \\
\hline Drywall & - & - & 160,063 & 254,458 & 111,850 & 526,371 \\
\hline Gypsum Lath & - & 630,258 & - & - & - & 630,258 \\
\hline Plaster & 378,937 & 367,994 & - & - & - & 746,931 \\
\hline Linoleum & 5,641 & 16,868 & 7,527 & - & - & 30,037 \\
\hline Ceramic Tiles & - & - & - & 27,562 & 9,925 & 37,487 \\
\hline Carpet & - & - & 70,459 & 74,035 & 16,486 & 160,981 \\
\hline Solid Wood Flooring & 97,516 & 130,687 & - & - & 10,174 & 238,377 \\
\hline Roofing Felt & - & 33,265 & 16,580 & 32,933 & 11,859 & 94,637 \\
\hline Breathing Paper & - & 1,429 & 1,907 & 1,767 & 636 & 5,740 \\
\hline $\begin{array}{l}\text { Basement } \\
\text { Waterproofing }\end{array}$ & - & 7,298 & 1,974 & 3,102 & 1,117 & 13,491 \\
\hline Parging & 26,974 & 65,349 & 36,649 & - & - & 128,973 \\
\hline $\begin{array}{l}\text { Polyethylene Vapour } \\
\text { Barrier }\end{array}$ & - & - & - & 1,105 & 637 & 1,741 \\
\hline $\begin{array}{l}\text { Insulation * Including } \\
\text { Air Volume }\end{array}$ & 216,687 & 870,789 & 523,335 & 945,572 & 654,494 & $3,210,877$ \\
\hline Total & $3,977,434$ & $10,962,836$ & $3,913,015$ & $5,354,062$ & $2,280,327$ & $26,487,673$ \\
\hline
\end{tabular}


Table 16. Volumes $\left(\mathrm{m}^{3}\right)$ of materials in Toronto's annual obsolete SDH stock.

\begin{tabular}{|c|c|c|c|c|c|}
\hline & Century & Wartime & Baby Boomer & OBC & Total \\
\hline FL width $>38 \mathrm{~mm}$ & 1,077 & 4,674 & 1,135 & 1,854 & 8,740 \\
\hline FL width $<38 \mathrm{~mm}$ & 342 & 64 & 13 & - & 420 \\
\hline Clay Brick and Mortar & 4,201 & 3,008 & 870 & 1,742 & 9,821 \\
\hline Cinder Block and Mortar & - & 3,614 & 1,161 & - & 4,774 \\
\hline Rubblestone and Mortar & 657 & - & - & - & 657 \\
\hline Concrete Brick and Mortar & 0 & 2,909 & 861 & - & 3,770 \\
\hline Aggregate & 67 & 4,545 & 1,159 & 1,894 & 7,665 \\
\hline CIP Concrete & - & 4,095 & 1,536 & 4,097 & 9,729 \\
\hline Steel & - & 20 & 4 & 46 & 70 \\
\hline Solid Wood Sheathing & 580 & 2,551 & - & - & 3,131 \\
\hline $\begin{array}{l}\text { Engineered Wood } \\
\text { Sheathing }\end{array}$ & - & - & 611 & 811 & 1,422 \\
\hline Aluminum & - & - & 6 & - & 6 \\
\hline Vinyl & - & - & - & 1 & 1 \\
\hline Asphalt Shingles & 27 & 150 & 31 & 87 & 296 \\
\hline Wood Paneling & 54 & 442 & - & - & 496 \\
\hline Glass & 10 & 56 & 24 & 27 & 117 \\
\hline Solid Wood Doors & 101 & 458 & 60 & 62 & 682 \\
\hline Drywall & - & - & 386 & 673 & 1,060 \\
\hline Gypsum Lath & - & 1,896 & - & - & 1,896 \\
\hline Plaster & 829 & 1,107 & - & - & 1,936 \\
\hline Linoleum & 12 & 51 & 18 & - & 81 \\
\hline Ceramic Tiles & - & - & - & 73 & 73 \\
\hline Carpet & - & - & 170 & 196 & 366 \\
\hline Solid Wood Flooring & 213 & 393 & - & - & 607 \\
\hline Roofing Felt & - & 100 & 40 & 87 & 227 \\
\hline Breathing Paper & - & 4 & 5 & 5 & 14 \\
\hline Basement Waterproofing & - & 22 & 5 & 8 & 35 \\
\hline Parging & 59 & 197 & 88 & - & 344 \\
\hline Polyethylene Vapour Barrier & - & - & - & 3 & 3 \\
\hline $\begin{array}{l}\text { Insulation * Including Air } \\
\text { Volume }\end{array}$ & 474 & 2,619 & 1,264 & 2,502 & 6,859 \\
\hline Total & 8,705 & 32,975 & 9,448 & 14,168 & 65,296 \\
\hline
\end{tabular}


Table 17. Volumes $\left(\mathrm{m}^{3}\right)$ of reusable materials in Toronto's in-use SDH stock.

\begin{tabular}{|c|c|c|c|c|c|c|}
\hline & Century & Wartime & $\begin{array}{c}\text { Baby } \\
\text { Boomer }\end{array}$ & OBC & Modern & Total \\
\hline FL width $>38 \mathrm{~mm}$ & 492,202 & $1,553,874$ & 470,139 & 700,527 & 261,968 & $3,478,710$ \\
\hline FL width $<38 \mathrm{~mm}$ & 156,153 & 21,433 & 5,536 & - & 7,892 & 191,014 \\
\hline Clay Brick and Mortar & $1,343,717$ & 699,998 & - & - & - & $2,043,715$ \\
\hline $\begin{array}{l}\text { Cinder Block and } \\
\text { Mortar }\end{array}$ & - & 840,984 & - & - & - & 840,984 \\
\hline $\begin{array}{l}\text { Rubblestone and } \\
\text { Mortar }\end{array}$ & 210,064 & - & - & - & - & 210,064 \\
\hline $\begin{array}{l}\text { Concrete Brick and } \\
\text { Mortar }\end{array}$ & - & 677,043 & - & - & - & 677,043 \\
\hline Aggregate & 30,594 & $1,510,919$ & 480,016 & 715,734 & 257,730 & $2,994,993$ \\
\hline CIP Concrete & - & - & - & - & - & - \\
\hline Steel & - & 6,617 & 1,790 & 17,405 & 6,570 & 32,382 \\
\hline Solid Wood Sheathing & - & - & - & - & - & - \\
\hline $\begin{array}{l}\text { Engineered Wood } \\
\text { Sheathing }\end{array}$ & - & - & - & - & 110,293 & 110,293 \\
\hline Aluminum & - & - & 2,413 & - & - & 2,413 \\
\hline Vinyl & - & - & - & - & - & - \\
\hline Asphalt Shingles & - & - & - & - & - & - \\
\hline Wood Paneling & 24,680 & 146,878 & - & - & 141 & 171,700 \\
\hline Glass & - & - & & & 3,643 & 3,643 \\
\hline Solid Wood Doors & 46,315 & 152,362 & 25,037 & 23,378 & 8,418 & 255,511 \\
\hline Drywall & - & - & - & - & - & - \\
\hline Gypsum Lath & - & - & - & - & - & - \\
\hline Plaster & - & - & - & - & - & - \\
\hline Linoleum & - & - & - & - & - & - \\
\hline Ceramic Tiles & - & - & - & - & - & - \\
\hline Carpet & - & - & - & - & - & - \\
\hline Solid Wood Flooring & 97,516 & 130,687 & - & - & 10,174 & 238,377 \\
\hline Roofing Felt & - & - & - & - & - & - \\
\hline Breathing Paper & - & - & - & - & - & - \\
\hline $\begin{array}{l}\text { Basement } \\
\text { Waterproofing }\end{array}$ & - & - & - & - & - & - \\
\hline Parging & - & - & - & - & - & - \\
\hline $\begin{array}{l}\text { Polyethylene Vapour } \\
\text { Barrier }\end{array}$ & - & - & - & - & - & - \\
\hline $\begin{array}{l}\text { Insulation * Including } \\
\text { Air Volume }\end{array}$ & - & - & - & - & - & - \\
\hline Total & $2,401,242$ & $5,740,797$ & 984,931 & $1,457,043$ & 666,829 & $11,250,842$ \\
\hline
\end{tabular}


Table 18. Volumes $\left(\mathrm{m}^{3}\right)$ of recyclable materials in Toronto's in-use SDH stock.

\begin{tabular}{|c|c|c|c|c|c|c|}
\hline & Century & Wartime & $\begin{array}{c}\text { Baby } \\
\text { Boomer }\end{array}$ & OBC & Modern & Total \\
\hline FL width $>38 \mathrm{~mm}$ & 492,202 & $1,553,874$ & 470,139 & 700,527 & 261,968 & $3,478,710$ \\
\hline FL width $<38 \mathrm{~mm}$ & 156,153 & 21,433 & 5,536 & - & 7,892 & 191,014 \\
\hline Clay Brick and Mortar & $1,343,717$ & 699,998 & 252,117 & 460,841 & 165,945 & $2,922,618$ \\
\hline $\begin{array}{l}\text { Cinder Block and } \\
\text { Mortar }\end{array}$ & - & 840,984 & 336,489 & - & - & $1,177,473$ \\
\hline $\begin{array}{l}\text { Rubblestone and } \\
\text { Mortar }\end{array}$ & - & - & - & - & - & _ \\
\hline $\begin{array}{l}\text { Concrete Brick and } \\
\text { Mortar }\end{array}$ & - & 677,043 & 249,530 & - & - & 926,573 \\
\hline Aggregate & - & - & - & - & - & - \\
\hline CIP Concrete & - & $1,361,495$ & 636,156 & $1,548,410$ & 557,571 & $4,103,632$ \\
\hline Steel & - & 6,617 & 1,790 & 17,405 & 6,570 & 32,382 \\
\hline Solid Wood Sheathing & 265,094 & 848,098 & - & - & 0 & $1,113,191$ \\
\hline $\begin{array}{l}\text { Engineered Wood } \\
\text { Sheathing }\end{array}$ & - & - & 253,213 & 306,290 & 110,293 & 669,795 \\
\hline Aluminum & - & - & 2,413 & - & - & 2,413 \\
\hline Vinyl & - & - & - & - & - & - \\
\hline Asphalt Shingles & 12,444 & 49,908 & 13,001 & 32,933 & 11,859 & 120,145 \\
\hline Wood Paneling & 24,680 & 146,878 & - & - & 141 & 171,700 \\
\hline Glass & 4,509 & 18,705 & 9,881 & 10,117 & 3,643 & 46,854 \\
\hline Solid Wood Doors & 46,315 & 152,362 & 25,037 & 23,378 & 8,418 & 255,511 \\
\hline Drywall & - & - & 160,063 & 254,458 & 111,850 & 526,371 \\
\hline Gypsum Lath & - & - & - & - & - & - \\
\hline Plaster & - & - & - & - & - & - \\
\hline Linoleum & - & - & - & - & - & - \\
\hline Ceramic Tiles & - & - & - & 27,562 & 9,925 & 37,487 \\
\hline Carpet & - & - & 70,459 & 74,035 & 16,486 & 160,981 \\
\hline Solid Wood Flooring & 97,516 & 130,687 & - & - & 10,174 & 238,377 \\
\hline Roofing Felt & - & - & - & - & - & - \\
\hline Breathing Paper & - & - & - & & & - \\
\hline $\begin{array}{l}\text { Basement } \\
\text { Waterproofing }\end{array}$ & - & - & - & - & - & - \\
\hline Parging & - & - & - & - & - & - \\
\hline $\begin{array}{l}\text { Polyethylene Vapour } \\
\text { Barrier }\end{array}$ & - & - & - & - & - & - \\
\hline $\begin{array}{l}\text { Insulation * Including } \\
\text { Air Volume }\end{array}$ & - & - & - & - & - & - \\
\hline Total & $2,442,630$ & $6,508,083$ & $2,485,824$ & $3,455,955$ & $1,282,735$ & $16,175,227$ \\
\hline
\end{tabular}


Table 19. Volumes $\left(\mathrm{m}^{3}\right)$ of reusable materials in Toronto's annual obsolete SDH stock.

\begin{tabular}{|c|c|c|c|c|c|}
\hline & Century & Wartime & Baby Boomer & OBC & Total \\
\hline FL width $>38 \mathrm{~mm}$ & 1,077 & 4,674 & 1,135 & 1,854 & 8,740 \\
\hline FL width $<38 \mathrm{~mm}$ & 342 & 64 & 13 & - & 420 \\
\hline Clay Brick and Mortar & 2,941 & 2,106 & - & - & 5,047 \\
\hline Cinder Block and Mortar & - & 2,530 & - & - & 2,530 \\
\hline Rubblestone and Mortar & 460 & - & - & - & 460 \\
\hline $\begin{array}{l}\text { Concrete Brick and } \\
\text { Mortar }\end{array}$ & - & 2,036 & & - & 2,036 \\
\hline Aggregate & 67 & 4,545 & 1,159 & 1,894 & 7,665 \\
\hline CIP Concrete & - & - & - & - & - \\
\hline Steel & - & 20 & 4 & 46 & 70 \\
\hline Solid Wood Sheathing & - & - & - & - & - \\
\hline $\begin{array}{l}\text { Engineered Wood } \\
\text { Sheathing }\end{array}$ & - & - & - & - & \\
\hline Aluminum & - & - & 6 & - & 6 \\
\hline Vinyl & - & - & - & - & - \\
\hline Asphalt Shingles & - & - & - & - & - \\
\hline Wood Paneling & 54 & 442 & - & - & 496 \\
\hline Glass & - & - & - & - & - \\
\hline Solid Wood Doors & 101 & 458 & 60 & 62 & 682 \\
\hline Drywall & - & - & - & - & - \\
\hline Gypsum Lath & - & - & - & - & - \\
\hline Plaster & - & - & - & - & - \\
\hline Linoleum & - & - & - & - & - \\
\hline Ceramic Tiles & - & - & - & - & - \\
\hline Carpet & - & - & - & - & - \\
\hline Solid Wood Flooring & 213 & 393 & - & - & 607 \\
\hline Roofing Felt & - & - & - & - & - \\
\hline Breathing Paper & - & - & - & - & - \\
\hline Basement Waterproofing & - & - & - & - & - \\
\hline Parging & - & - & - & - & - \\
\hline $\begin{array}{l}\text { Polyethylene Vapour } \\
\text { Barrier }\end{array}$ & - & - & - & - & - \\
\hline \multirow[t]{2}{*}{$\begin{array}{l}\text { Insulation * Including Air } \\
\text { Volume }\end{array}$} & - & - & - & - & - \\
\hline & - & - & - & - & - \\
\hline Total & 5,256 & 17,268 & 2,378 & 3,856 & 28,757 \\
\hline
\end{tabular}


Table 20. Volumes $\left(\mathrm{m}^{3}\right)$ of recyclable materials in Toronto's annual obsolete SDH stock.

\begin{tabular}{|c|c|c|c|c|c|}
\hline & Century & Wartime & Baby Boomer & OBC & Total \\
\hline FL width $>38 \mathrm{~mm}$ & 1,077 & 4,674 & 1,135 & 1,854 & 8,740 \\
\hline FL width $<38 \mathrm{~mm}$ & 342 & 64 & 13 & - & 420 \\
\hline Clay Brick and Mortar & 2,941 & 2,106 & 609 & 1,219 & 6,875 \\
\hline Cinder Block and Mortar & - & 2,530 & 812 & - & 3,342 \\
\hline Rubblestone and Mortar & - & - & - & - & - \\
\hline Concrete Brick and Mortar & - & 2,036 & 602 & - & 2,639 \\
\hline Aggregate & - & - & - & - & - \\
\hline CIP Concrete & - & 4,095 & 1,536 & 4,097 & 9,729 \\
\hline Steel & - & 20 & 4 & 46 & 70 \\
\hline Solid Wood Sheathing & 580 & 2,551 & - & - & 3,131 \\
\hline Engineered Wood Sheathing & - & - & 611 & 811 & 1,422 \\
\hline Aluminum & - & - & 6 & - & 6 \\
\hline Vinyl & - & - & - & - & - \\
\hline Asphalt Shingles & 27 & 150 & 31 & 87 & 296 \\
\hline Wood Paneling & 54 & 442 & - & - & 496 \\
\hline Glass & 10 & 56 & 24 & 27 & 117 \\
\hline Solid Wood Doors & 101 & 458 & 60 & 62 & 682 \\
\hline Drywall & - & - & 386 & 673 & 1,060 \\
\hline Gypsum Lath & - & - & - & - & - \\
\hline Plaster & - & - & - & - & - \\
\hline Linoleum & - & - & - & - & - \\
\hline Ceramic Tiles & - & - & - & 73 & 73 \\
\hline Carpet & - & - & 170 & 196 & 366 \\
\hline Solid Wood Flooring & 213 & 393 & - & - & 607 \\
\hline Roofing Felt & - & - & - & - & - \\
\hline Breathing Paper & - & - & - & - & - \\
\hline Basement Waterproofing & - & - & - & - & - \\
\hline Parging & - & - & - & - & - \\
\hline Polyethylene Vapour Barrier & - & - & - & - & - \\
\hline $\begin{array}{l}\text { Insulation * Including Air } \\
\text { Volume }\end{array}$ & - & - & - & - & - \\
\hline Total & 5,346 & 19,576 & 6,002 & 9,145 & 40,069 \\
\hline
\end{tabular}


Table 21. $\mathrm{CO}_{2}$ Fossil Emissions (megatonne) equivalents of reusable materials of Toronto's in-use SDH stock.

\begin{tabular}{lcccc}
\hline & \multicolumn{3}{c}{ Percent } & Volume Lost to Damage/Contamination \\
& $\mathbf{0 \%}$ & $\mathbf{1 0 \%}$ & $\mathbf{2 5 \%}$ & $\mathbf{5 0 \%}$ \\
\cline { 2 - 5 } & & & & \\
Clay Brick & 482 & 434 & 362 & 241 \\
Cinder Block & 188 & 169 & 141 & 94 \\
Concrete Brick & 144 & 130 & 108 & 72 \\
Rubblestone & 178 & 160 & 134 & 89 \\
Aggregate & 10 & 9 & 8 & 5 \\
FL & 171 & 154 & 128 & 85 \\
Solid Wood Flooring & 29 & 26 & 21 & 14 \\
Wood Paneling & 32 & 29 & 24 & 16 \\
Engineered Wood Sheathing & 22 & 19 & 16 & 11 \\
Steel & 312 & 281 & 234 & 156 \\
Aluminum Siding & 30 & 27 & 23 & 15 \\
Glass in Windows & 8.6 & 7.7 & 6.5 & 4.3 \\
& & & & 803 \\
Total & 1,607 & 1,446 & 1,205 & \\
\hline
\end{tabular}

Table 22. Primary Energy Consumption (terajoules) equivalents of reusable materials of Toronto's in-use SDH stock.

\begin{tabular}{lcccc}
\hline & \multicolumn{3}{c}{ Percent Volume Lost to Damage/Contamination } \\
& $\mathbf{0 \%}$ & $\mathbf{1 0 \%}$ & $\mathbf{2 5 \%}$ & $\mathbf{5 0 \%}$ \\
\cline { 2 - 4 } & & & & \\
Clay Brick & 7,141 & 6,426 & 5,355 & 3,570 \\
Cinder Block & 2,110 & 1,899 & 1,583 & 1,055 \\
Concrete Brick & 1,688 & 1,519 & 1,266 & 844 \\
Rubblestone & 3,859 & 3,473 & 2,894 & 1,930 \\
Aggregate & 157 & 142 & 118 & 79 \\
FL & 6,070 & 5,463 & 4,552 & 3,035 \\
Solid Wood Flooring & 791 & 712 & 593 & 395 \\
Wood Paneling & 760 & 684 & 570 & 380 \\
Engineered Wood Sheathing & 923 & 831 & 693 & 462 \\
Steel & 7,316 & 6,584 & 5,487 & 3,658 \\
Aluminum Siding & 10,376 & 9,339 & 7,782 & 5,188 \\
Glass in Windows & 64 & 57 & 48 & 32 \\
& & & & \\
Total & 41,255 & 37,130 & 30,942 & 20,628 \\
\hline
\end{tabular}


Table 23. $\mathrm{CO}_{2}$ Fossil Emissions (tonne) equivalents of reusable materials of Toronto's annual obsolete SDH stock.

\begin{tabular}{lcccc}
\hline & \multicolumn{3}{c}{ Percent Volume Lost to Damage/Contamination } \\
& $\mathbf{0} \%$ & $\mathbf{1 0 \%}$ & $\mathbf{2 5 \%}$ & $\mathbf{5 0 \%}$ \\
\cline { 2 - 5 } & & & & \\
Clay Brick & 1,191 & 1,297 & 1,081 & 720 \\
Cinder Block & 565 & 509 & 424 & 283 \\
Concrete Brick & 434 & 390 & 325 & 217 \\
Rubblestone & 390 & 351 & 293 & 195 \\
Aggregate & 119 & 107 & 89 & 60 \\
FL & 433 & 390 & 325 & 217 \\
Solid Wood Flooring & 73 & 66 & 55 & 36 \\
Wood Paneling & 92 & 82 & 69 & 46 \\
Steel & 699 & 629 & 524 & 350 \\
Aluminum Siding & 74 & 66 & 55 & 37 \\
& & & & 2,160 \\
Total & 4,069 & 3,888 & 3,240 & \\
\hline
\end{tabular}

Table 24. Primary Energy Consumption (gigajoules) equivalents of reusable materials of Toronto's annual obsolete SDH stock.

\begin{tabular}{lcccc}
\hline & \multicolumn{3}{c}{ Percent Volume Lost to Damage/Contamination } \\
& $\mathbf{0} \%$ & $\mathbf{1 0 \%}$ & $\mathbf{2 5 \%}$ & $\mathbf{5 0 \%}$ \\
\cline { 2 - 5 } & & & \\
Clay Brick & 17,632 & 19,298 & 16,081 & 10,721 \\
Cinder Block & 6,348 & 5,713 & 4,761 & 3,174 \\
Concrete Brick & 5,078 & 4,570 & 3,809 & 2,539 \\
Rubblestone & 8,447 & 7,602 & 6,335 & 4,223 \\
Aggregate & 1,806 & 1,625 & 1,354 & 903 \\
FL & 15,317 & 13,785 & 11,488 & 7,659 \\
Solid Wood Flooring & 2,012 & 1,811 & 1,509 & 1,006 \\
Wood Paneling & 2,195 & 1,975 & 1,646 & 1,097 \\
Steel & 15,887 & 14,299 & 11,916 & 7,944 \\
Aluminum Siding & 25,047 & 22,542 & 18,785 & 12,523 \\
& & & \\
Total & 99,769 & 93,221 & 51,789 \\
\hline
\end{tabular}




\section{Glossary}

Deconstruction:

Demolition waste:

Downcycled:

Embodied Impacts (or cradle-to-gate impacts):

Masonry:

Reclaim:

Recycling:

Reuse:

Solid Wood

Products:

Urban metabolism:

Urban mining: selective disassembly of building with the intentions of preserving material integrity (Falk and Guy, 2007).

building debris generated from disassembly of an obsolete building.

a recycled material with reduced quality, functionality, or recyclability because of its remanufacturing/reprocessing.

a quantities description of the resources consumption, emissions to air, water, and land, and human health implications associated with extraction of raw resources, manufacturing/processing, and transporting high quality building materials to market.

umbrella term for clay bricks, concrete bricks, and cinder blocks.

taking a material out of the waste stream to use as resource for reuse or recycling.

waste management strategy that uses reclaimed materials by remanufacturing/reprocessing into new secondary products.

waste management strategy that uses reclaimed materials or objects in their original or mostly original form.

umbrella term framing lumber, solid wood sheathing, solid wood paneling, and solid wood flooring.

"the sum total of the technical and socio-economical processes that occur in cities, resulting in growth, production of energy, and elimination of waste" (Kennedy et al, 2007).

reclaiming obsolete materials from an urban unit. 


\section{References}

Addis, B. (2006). Building with Reclaimed Components and Materials. London, United Kingdom: Earthscan.

Anityasari, M., \& Karbernick, H. (2008). A concept of reliability evaluation for reuse and remanufacturing. International Journal of Sustainable Manufacturing, 1, 3-17.

ASMI, Athena Sustainable Material Institute. (1998). Lifecycle analysis of brick and mortar products. Ottawa, ON: Venta, G.J.

ASMI, Athena Sustainable Material Institute. (2002). Cradle-to-gate life cycle inventory: Canadian and US steel production by mill type. Ottawa, ON: Markus Engineering Services.

ASMI, Athena Sustainable Material Institute. (2009). A Cradle-to-Gate Life Cycle Assessment of Canadian Softwood Lumber. Ottawa, ON.

Baccini, P., \& Brunner, P. H. (2012). Metabolism of the anthroposhpere: Analysis, evaluation, design. Cambridge, United Kingdom: The Massachusetts Institute of Technology Press.

Balson, T., \& Lowres, F. (2012). Operational and embodied carbon in new build housing: $A$ reappraisal. Knowl hill, United Kingdom: NHBC Foundation.

Bektas, F., Wang, K., Ceylan, H. (2009). Effects of crushed clay brick aggregate on mortar durability. Construction and Building Materials, 23,1909-1914.

Bergman, R. D., Falk, R. H., Salazar, J., Gu, H., Napier, T. R., Meil, J. (2013). Life-cycle energy and GHG emissions for new and recovered softwood framing lumber and hardwood flooring considering end-of-life scenarios (Research Paper FPL-RP-672). Madison, WI.

U.S. Department of Agriculture, Forest Service, Forest Products Laboratory.

Blaszak, K.M. (2010). Toward Sustainability: Prioritizing Retrofit Options for Toronto's SingleFamily Homes. Retrieved from Theses and dissertations (Paper 1271), http://digitalcommons.ryerson.ca/dissertations/1271

Braungart, M., \& McDonough, M. (2002). Cradle to Cradle: Remaking the Way We Make Things. New York, NY: North Point Press.

BRE \& WRAP, Building Research Establishment \& Waste and Resource Action Programme. (2008). Recycled gypsum in concrete construction product applications. Oxfordshire, UK: Dunster, A.M.

Bristow, D. N. \& Kennedy, C. A. (2013). Urban metabolism and the energy stored in cities implications for resilience. Journal of Industrial Ecology, 17, 656-667. 
Broto, V. C., Allen, A., \& Raprport, E. (2012). Interdisciplinary perspectives on urban metabolism. Journal of Industrial Ecology, 16, 851-861.

Brunner, P. H. (2011). Urban Mining. Journal of Industrial Ecology, 15, 339-341.

Brunner, P. H., \& Rechberger, H. (2004). Practical Handbook of Material Flow Analysis. Boca Raton, FL: Lewis Publishers.

Butler, L., West, J. S., \& Tighe, S. I. (2011). Quantification of Recycled Concrete Aggregate (RCA) Properties for Usage in Bridges and Pavements: An Ontario Case Study. Retrieved May 2013 from http://conf.tac-atc.ca/english/annualconference/tac2011/docs/p3/butler.pdf

Carpenter, A., Jambeck, J.R., Gardner, K., Weitz, K. (2012). Life Cycle Assessment of End-ofLife Management Options for Construction and Demolition Debris. Journal of Industrial Ecology, 17, 396 - 406.

Cavalline, T. L., \& Weggel, D. C. (2013). Recycled brick masonry aggregate concrete. Structural Survey, Emerald Group Publishing Limited, 31,160-180.

CCA, Canadian Construction Association. (2001). A Best Practice Guide to Solid Waste Reduction. Retrieved September 2012 from http://www.cca-acc.com/pdfs/en/membersonly/cca81.pdf

CH2M HILL Canada Itd. (2000). Report Construction, Renovation and Demolition (CRD) Waste Characterization Study. Retrieved from October 2013 from http://www.recyclecddebris.com/rCDd/Resources/Documents/CSICanada01.pdf

Chandara, C., Azizli, K. A. M., Ahmad, Z. A., Sakai, E. (2009). Use of waste gypsum to replace natural gypsum as set retarders in Portland cement. Waste Management, 29, 1675-1679.

Chen, H., Yen, T., Chen, K. (2003). Use of building rubbles as recycled aggregates. Cement and Concrete Research, 33, 125-132.

City of Ottawa. (2012). Phase 1- Discussion Paper [Graphic Illustration]. Retrieved January 2013 from http://ottawa.ca/en/city-hall/public-consultations/environment/phase-1discussion-paper

City of Toronto. (2003). [Graphical Illustration]. Construction Dates Map. Retrieved June 2012 from http://www.ryerson.ca/madar/geospatial/toronto/digital/

City of Toronto. (2007). Change is in the air: Toronto's commitment to an environmentally sustainable future. Retrieved December 2013 from http://www1.toronto.ca/staticfiles/City\%200f\%20Toronto/Environment\%20and\%20Energy/ Our\%20Goals/Files/pdf/C/backgroundfile-2428.pdf

City of Toronto. (2011). Annual energy consumption and greenhouse gas emissions report. Retrieved December 2013 from 
http://www1.toronto.ca/staticfiles/City\%200f\%20Toronto/Environment\%20and\%20Energy/ Action\%20Plans,\%20Policies\%20\&\%20Research/Files/2011\%20Annual\%20energy\%20c onsumption\%20and\%20GHG\%20emissions\%20report\%20-\%20Ci_2.pdf

City of Toronto. (2013a). Labour force survey data - industry profiles. Retrieve November 2013 from http://www1.toronto.ca/wps/portal/contentonly?vgnextoid=ef1d3c6d9c8ba310 VgnVCM10000071d60f89RCRD\&vgnextchannel=e71032d0b6d1e310VgnVCM10000071 d60f89RCRD

City of Toronto. (2013b). Toronto Archives. Retrieved on October 2013

http://www.toronto.ca/archives/current_19century.htm

City of Toronto. (2013c). Toronto Neighbourhood Profiles. Retrieved May 2013 from:

http://www.toronto.ca/demographics/neighbourhoods.htm

City of Toronto. (2013d). [Graphical Illustration].Toronto's Location Greater Toronto Area-

Regions. Retrieved September 2013 from

http://www.toronto.ca/special_events/pme/location.htm

City of Toronto. (2013e). Ward Profiles. Retrieved May 2013 from

http://www.toronto.ca/demographics/neighbourhoods.htm

City of Toronto. (2013f). [Graphical Illustration]. Citywide Zoning By-law Residential Zones.

Retrieved July 2013 from http://www.toronto.ca/zoning/pdf/city-wide_Residential_5692013.pdf

City of Toronto. (2013g). Facts about Toronto's trash. Retrieved October 2013 from http://www.toronto.ca/garbage/facts.htm\#a006

CMHC. (1985). Housing issues in the 1980's and 1990's structural adjustment in the residential construction industry. CMHC: Canada.

CMHC. (2000). Renovating distinctive homes: 1 11/2 storey post-war homes. CMHC: Canada.

CMHC. (2002). Renovating distinctive homes: one-storey houses of the 60's and 70's. CMHC: Canada.

CMHC. (2003). Renovating distinctive homes: the century home. CMHC: Canada.

CMHC. (2006). Canadian Housing Observer 2006. Retrieved October 2013 from http://www.cmhc-schl.gc.ca/odpub/pdf/65102.pdf

CMHC. (2013). Table027-0001 - Canada Mortgage and Housing Corporation, housing starts, under construction and completions in centres 10,000 and over, Canada, provinces, selected census metropolitan areas, monthly (units) [CANSIM database file]. Retrieved October 2013 from http://www5.statcan.gc.ca/cansim/pickchoisir?lang=eng\&p2=33\&id=0270001\#F1 
CMHC Toronto, Market Analysis Centre. (2001 - 2012). Housing Now Toronto. Retrieved August 2013 from http://publications.gc.ca/site/eng/search/search.html?st=1\&ssti=1\&ast=Housing+now+Tor onto\&cnop $=1$ \&cnst $=\& e=1 \& \_e=0 n \& f=1 \& \_f=o n \& \_$adoof $=0$ \& $r q . s s p=6 \& p s i=1$

CMRA, Construction Materials Recycling Association. (2013). Recycled Concrete Aggregate Ready Mix Used in Structural Applications. Retrieved September 2013 from http://www.concreterecycling.org/histories.html

CMRA, Construction Materials Recycling Association, Asphalt Shingle Recycling Project, \& US EPA Innovations Workgroup. (2007). Environmental Issues Associated With Asphalt Shingle Recycling. Gainesville, FL: Townsend, T., Powell, J., \& Xu, C.

Codoban, N., \& Kennedy, C. (2008). Metabolism of Neighbourhoods. Journal of Urban Planning and Development, 134, 21-31.

Cooper, D.R., \& Allwood, J.M. (2013). Reusing Steel and Aluminum Components at End of Product Life. Environmental Science and Technology, 46, 10334 -10340.

Cossu, R., Salieri, V., Bisinella, V. (2012). Urban Mining - A Global Cycle Approach to Resource Recovery from Solid Waste. Padavo, Italy: CISA Publisher.

CUCS, Center of Urbanism and Community Studies. (1979). The changing structure of land development industry in the Toronto area. Toronto, ON: Rudin, J. R.

Cutler, A., \& Breiman, L. (1994). Archetypal Analysis. American Statistical Association and American Society for Quality, 36, 338-347.

Davis, J. B. (2012). Suitability of Salvage Timber in Structural Design. Retrieved from DSpace@MIT, http://dspace.mit.edu/handle/1721.1/73782

Davila, C. C. (2013). Embodied energy / memory: Wood urban mining and accounting in shrinking Youngstown (OH). Paper presented at R+R 2013 Reclaim and Remake International Symposium, Washington, DC.

Dennis, R. (1989), Toronto's first apartment-house boom: an historical geography, 1900-1920 [ISSN 0316-0068]. Published by University of Toronto.

De Selincourt, K. (2012). Embodied Energy - a ticking time bomb? Published by Green Building Magazine, Green Building Press.

DOE, Department of Environment, Climate Change and Water NSW. (2010). Roof beams and timbre removal (ISBN 978-1-74232-436-4). Sydney, Australia. Published by State of NSW and the Department of Environment, Climate Change and Water. 
Dovetail Partners. (2013). The current state of wood reuse and recycling in North America and recommendations for improvements. Minneapolis, MN: Howe, J., Bratkovich, S., Bowyer, J., Frank, M., \& Fernholz, K.

Emergent Structures. (2010). Completed projects. Retrieved September 2013 from http://www.emergentstructures.org/projects-completed

Environment Canada. (2003). COMPRO \#9 Ontario's 3Rs Regulations and the Waste Diversion Act. Retrieved October 2012 from http://www.on.ec.gc.ca/epb/fpd/cpb/3009-e.html

Environment Canada \& NRCan, Natural Resources Canada. (1993). Construction and demolition waste in Canada: Quantification of waste and identification of opportunities for diversion from disposal. Ottawa, ON: SENES Consultants Itd.

European Commision. (2011). Service contract on management of construction and demolition waste - SR1. Paris, France: Bio Intelligence Service.

Falk, R. H. (1999). Wood-Framed Building Deconstruction - A Source of Lumber for Construction? Retrieved June 2012 from from http://www.fpl.fs.fed.us/documnts/pdf2002/falk02a.pdf

Falk, R. H., DeVisser, D., Standen, C., \& Stansbury, D. (1999). Effect of damage on the grade yield of recycled lumber. Forest Products Journal, 49, 71-79.

Falk, R. H., \& Green, D. (1999). Stress grading of recycled lumber and timber. Structural engineering in the 21st century: proceedings of the 1999 Structures Congress. New Orleans, L: U.S.A.

Falk, R. H., \& Guy, B. (2007). Unbuilding: Salvaging the architectural treasures of unwanted houses. Newtown, CT: The Taunton Press.

Falk, R.H., Maul, D.G., Cramer, S. M.; Evans, \& J., Herian, V. (2008). Engineering properties of Douglas-fir lumber reclaimed from deconstructed buildings (Research Paper FPL-RP650). Madison, WI. U.S. Department of Agriculture, Forest Service, Forest Products Laboratory.

FCSHWM, Florida Center for Solid and Hazardous Waste Management. (2000). Implementing Deconstruction in Florida: Materials Reuse Issues, Disassembly Techniques, Economics and Policy. Gainesville, FL: Kilbert, C.J. \& Languell, J.L.

FPL, Forest Products Laboratory. (1964). History of Lumber Yard Sizes Standards. Madison, WI. U.S. Department of Agriculture, Forest Service, Forest Products Laboratory.

Friends of the Spit. (2013). About the spit. Retrieved September 2013 from http://www.friendsofthespit.ca/ 
Gao, W., Ariyama, T., Ojima, T., Meier, A. (2001). Energy impacts of recycling disassembly material in residential buildings. Energy and Buildings, 33, 553-562.

Gorgolewski, M. (2008). Designing with reused building components: some challenges. Building Research \& Information, 36, 175-188.

Gorgolewski, M., Straka, V., Edmonds, J., \& Sergio, C. (2006). Facilitating greater reuse and recycling of structural steel in the construction and demolition process. Retrieved July 2013 from http://www.reuse-steel.org/files/General/Executive\%20summary.pdf

Greenspec. (2012). Reclaimed Materials. Retrieved on December 2012 from http://www.greenspec.co.uk/reclaimed-materials.php

Hawken, P., Lovins, E., \&Lovins, H. (1999). Natural capitalism: Creating the next industrial revolution. Snowmass, CO: Rocky Mountain Institute.

Guy, B., and Gibeau, E. (2003). A Guide to Deconstruction. Retrieved January 2012 from http://www.deconstructioninstitute.com/files/learn_center/45762865_guidebook.pdf

Guy, B., \& Nicholas, D. (2011). Temporal process in research, green building and material reuse. Presented at Considering Research: Reflecting upon current themes in Architectural Research. Detroit, MI.

Hein, T. (2011). Recycling Masters. Avenues, 2, 10-13. Retrieved September 2013 from http://mediaedge.imirus.com/Mpowered/book/vavenues12/i2/p1

Hendricks, C.F., \& Janssen, G. M. T. (2001). Reuse of construction and demolition waste in the Netherlands for road construction. Heron, 46, 109-117.

Hendricks, C., Obernosterer, R., Muller, D., Kytzia, S., Baccini, P., \& Brunner, P.H. (2000). Material Flow analysis: a tool to support environmental policy decision making. Case studies on the city of Vienna and the Swiss lowlands. Local Environment, 5, 311-328.

ICLEI, International Council for Local Environmental Initiatives. (1996). The local agenda 21 planning guide. Toronto, ON: International Council for Local Environmental Initiatives \& Interiordir. (No Date). [Graphic Illustration]. Saltbox Section Aa O. Retrieved October 2013 from http://www.interiordir.com/home-interior/saltbox-section-aa-o.html

Islam, R. U. L. (2011). Performance Evaluation of Recycled Asphalt Shingles (RAS) in Hot Mix Asphalt (HMA): An Ontario Perspective. Retrieved from University of Waterloo Electronic Theses and Dissertations, http://hdl.handle.net/10012/5834

ISWA, ISWA WG-Recycling \& Waste Minimisation. (2011). Waste Prevention, Waste Minimization and Resource Management - ISWA Key Issue Paper. ISWA: Goorhuis, M., \& Bartl, A. 
Janowiak, J. J., Falk, R. H., Beakler, B. W., Lampo, R. G., \& Napier, T.R. (2005). Remilling of salvaged wood siding coated with lead-based paint: part 2. Wood product yield. Forest Products Journal, 55, 81-86.

Janowiak, J. J., Falk, R. H., \& Kimmel, J. D. (2007). Feasibility of producing value-added wood products from reclaimed hemlock lumber (Research Paper FPL-RP-645). Masison, WI. U.S. Department of Agriculture, Forest Service, Forest Products Laboratory.

Kay, T., \& Essex, J. (No Date). Pushing reuse: Toward a low-carbon construction industry. London, United Kingdom: Bioregional.

Kennedy, C., \& Hoornweg, D. (2012). Mainstreaming Urban Metabolism. Journal of Industrial Ecology, 16, 780-782.

Kennedy, C., Cuddihy, J., \& Engel-Yan, J. (2007). The changing metabolism of cities. Journal of Industrial Ecology, 11, 43-59.

Kennedy, C., Pinceti, S., \& Bunje, P. (2011). The study of urban metabolism and its application to urban planning and design. Environmental Pollution, 159, 1965-1973.

Kernan, P. (2002). Old to new: Design guide salvaged building materials for new construction. Retrieved September 2012 from http://www.metrovancouver.org/about/publications/Publications/oldtonewdesignguidesalv mat08-1.pdf.

Khalad, F. M., \& DeVenny, A. S. (2004). Recycling of Demolished Masonry Rubble as Coarse Aggregate in Concrete: Review. Journal of Materials in Civil Engineering,16, 331-340.

Kim, J. K., \& Missios, P. (2007). Does size really matter? Landfill scale impacts on property value. Applied Economics Letters, 14, 719-723.

Krook, J., \& Baas, L. (2013). Getting serious about mining the technosphere: a review of recent landfill mining and urban mining research. Journal of Cleaner production, 55, 1-9.

International Development Research Centre.

Lethman, S. (2012). Resource Recovery and Material Flow in the City. Journal of Green Building, 6, 88-105.

Malia, M., Brito, J. D., Pinheiro, M. D., \& Miguel, B. (2013). Construction and demolition waste indicators. Waste Management and Research,13, 241-255.

MHSPE, Ministry of Housing, Spatial Planning and the Environment. (2001). Fact-sheets on waste in the Netherlands: Construction and demolition waste. Retrieved October 2013 from http://minvrom.nl 
MNR, Ministry of Natural Resources of Ontario. (2009). State of the Aggregate Resource in Ontario Study (SAROS) - Paper 4 (ISBN 978-1-4435-3797-1). Published by Queen's Printer for Ontario: LVM Jegel.

NAHB and BoA, National Association of Home Builders and Bank of America. (2007). Study of Life Expectancy of Home Components. Retrieved September 2013 from http://www.nahb.org/fileUpload_details.aspx?contentID=99359

Napier, T., Falk, R. H., Guy, B., \& Drodz, S. (2005). Regulatory and Policy Issues for Reuse and Remanufacture of Wood Materials Coated with Lead-Based Paint (Research Paper FPL-GTR164). Madison, WI. U.S. Department of Agriculture, Forest Service, Forest Products Laboratory.

New West Gypsum Recycling Inc. (2013). Recycling Process. Retrieved September 2013 from http://www.nwgypsum.com/index.php?option=com_content\&task=view\&id=58\&ltemid=67

Norby, A. S., Berge, B., Hakonsen, F., \& Hestnes, A. G. (2009). Criteria for salvagability: the reuse of bricks. Building Research \& Information, 37, 55-67.

NRCan \& CMHC, National Research Council of Canada, \& Canadian Mortgage and Housing Corporation. (1998). CCHT twin research houses.

NRCan, Natural Resources Canada \& Government of Canada. (2006). An Analysis of Resource Recovery Opportunities in Canada and the Projection of Greenhouse Gas Emission Implications. Published by Natural Resources Canada: Sinclair, R.

O'Brien, E. (2006). Life Cycle Analysis of the Deconstruction of World War II Army Barracks at Ft. McCellan in Anniston, Alabama. Retrieved from University of Florida Theses and Dissertations Collection, http://ufdc.ufl.edu/ufetd/results/?t=deconstruction

Odum, E. P. (1997). Ecology: A bridge between science and society. Sunderland, MA: Sinauer Associates.

Olson, B. D. (2011). Residential building material reuse in sustainable construction. Retrieved from Washington State University Electronic Dissertations and Theses - Civil and Environmental Engineering, http://hdl.handle.net/2376/3479

Onishi, K., Fujino, T., Kondo, Y., Ikami, H., \& Asaeda, T. (2012). Applicability of recycled gypsum composite mortar as raw material for foundation work of single family houses. Journal of Asian Architecture and Building Engineering, 119-124.

Province of Ontario. (2012). Ontario Building Code 2012. Queen's Printer for Ontario.

Province of Ontario. (2013). Curbing Sprawl. Retrieved October 2013 from https://www.placestogrow.ca/index.php?option=com_content\&task=view\&id=281\&ltemid= 84 
PWGSC, Public Work and Government Services Canada. (2000). The environmentally responsible construction and renovation handbook. Retrieved January 2013 from http://www.tpsgc-pwgsc.gc.ca/biens-property/gd-env-cnstrctn/index-eng.html

RCO, Recycling Council of Ontario. (2006). Let's climb another molehill: An examination of construction, renovation, and demolition (CRD) waste diversion in Canada and associated greenhouse gas emission impacts. Retrieved October 2013 from http://www.nrcan.gc.ca/sites/www.nrcan.gc.ca.minerals-metals/files/pdf/mms-smm/busiindu/rad-rad/pdf/f-molehill-r-eng.pdf

Rhys, J. (2011). Cumulative Carbon Emissions and Climate Change: Has the economics of climate change lost contact with physics? Oxford, UK: The Oxford Institute for Energy Studies.

Sahely, H. R., Dudding, S., \& Kennedy, C. A. (2003). Estimating the urban metabolism of Canadian cities: Greater Toronto Are case study. Canadian Journal of Civil Engineering, 30, 468-483.

Saotome, T. (2007). Development of construction and demolition waste recycling in Ontario. Retrieved September 3, 2012 from http://msep.mcmaster.ca/epp/publications/Development_of_C\&D_recycling_in_Ontario.pf

Sianchuk, R. A., Ackom, E. K., MaFarlane, P. N. (2012). Determining stocks and flows of structural wood products in single family homes in the United States between 1950 and 2010. Forest Products Journal, 62, 90-101.

Shehata, M. H., Christidis, C., Mikhaiel, W., Rogers, C., \& Lachemi, S. (2010). Reactivity of reclaimed concrete aggregate produced from concrete affected by alkali-silica reaction. Cement and Concrete Research, 40, 575-582.

Smith, J. T. (2009). Recycled Concrete Aggregate - A Viable Aggregate Source For Concrete Pavements. Retrieved from University of Waterloo Electronic Theses and Dissertations, http://hdl.handle.net/10012/4900

Statistics Canada. (2004). Waste management industry survey: Business and government sectors 2002. Retrieved October 2013 from www.statcan.ca.

Statistics Canada. (2010). Waste management industry survey: Business and government sectors 2010. Retrieved October 2013 from www.statcan.ca.

Statistics Canada. (2012a). Canada's GHG emissions. Retrieved December 2013 from http://www.ec.gc.ca/ges-ghg/default.asp?lang=En\&n=022BADB5-1 
Statistics Canada. (2012b). Structural type of dwelling [Data Table]. Retrieved October 2013 from http://www12.statcan.gc.ca/census-recensement/2011/ref/dict/dwellinglogements013-eng.cfm

Statistics Canada. (2013). Households and the Environment: Energy Use [Data Table]. Retrieved December 2013 from http://www.statcan.gc.ca/pub/11-526-s/11-526-s2013002eng.htm

Steel Recycling Institute. (2011). Steel Recycling Institute. Retrieved May 2012 from http://www.recycle-steel.org/en/Sustainability/CO2\%20Reduction.aspx

Teodorescu, I. (2012). Building small houses in postwar Canada: architect, homeowners, and bureaucratic ideals 1947-1974. Retrieve from Open Access Thesis and Dissertations, http://digitool.library.mcgill.ca/thesisfile114277.pdf

The Aluminum Association. (2013). Recycling Aluminum Products. Retrieved May 2013 from http://www.aluminum.org/Content_bk100511/ContentGroups/Aluminum_Now_Magazine1/ July_August_2007/Recycled_Aluminum_Products.htm

Thormark, C. (2006). The effect of material choice on the total energy need and recycling potential of a building. Building and Environment, 41, 1019-1026.

Tomalty, R. (1997). The compact metropolis: growth management and intensification in Vancouver, Toronto, and Montreal. ICURR Press: Toronto, ON.

UNDE \& SAPD, United Nations Department of Economic \& Social Affairs Population Division. (2013). World urbanization prospects, the 2011 revision. Retrieved October 2013 from http://esa.un.org/unup/

US Army Corps of Engineers. (2004). Reuse of concrete materials from building demolition (Public Works Technical Bulletin 200-1-27). Washington, DC.

U.S. Census Bureau. (2012). Characteristics of New Housing. Retrieved September 2013 from http://www.census.gov/construction/chars/completed.html

US EPA, United States Environmental Protection Agency. (2008). Technical Memorandum Brownfields Sustainability Pilot Allen-Morrison Site, Lynchburg, Virginia. Retrieved September 2012 from http://www.epa.gov/brownfields/sustain_plts/factsheets/allenmorrison.pdf

US EPA. (no date). Design for Deconstruction. Retrieved January 2014 from http://www.epa.gov/region09/greenbuilding/pdfs/DesignForDeconstrManual.pdf

Verbeeck, G., \& Hens, H. (2007). Life Cycle Optimization of Extremely Low Energy Dwellings. Journal of Building Physics, 31, 143-175. 
Wardle, K. 2001. Factors Influencing the Expansion of the Used Building Material Sector in Southern British Columbia. Retrieved from ProQuest, UMI Dissertations Publishing.

Warren-Rhodes, K., \& Koenig, A. (2001). Escalating trends in the urban metabolism of Hong Kong: 1971-1997. Ambio, 30, 429-438.

WDCDSC, Waste Diversion in the Construction and Demolition Sector in Calgary. (2011) The City of Calgary: Construction and Demolition Waste Diversion (UE2011-12). Published by The City of Calgary.

WHMD, Waste and Hazardous Materials Division, Michigan Department of Environmental Quality. (2007). Drywall Recycling. Lansing: MI.

Winistorfer, P., Chen, Z., Lippke, B., \& Stevens, N. (2005). Energy consumption and greenhouse gas emissions related to the use, maintenance, and disposal of a residential structure. Wood and Fiber Science, 37, 128 - 139.

Wolman, A. (1965). The metabolism of cities. Scientific American, 213,179-190.

Worldwatch Institute. (2007). State of the world: Our urban future. Washington, DC: W.W. Norton \& Company, Inc.

Yang, J., Ddamba, S., Ul-Islam, R., Safiuddin, Md., Tighe, S. (2013). Investigation on Use of Recycled Asphalt in Ontario Hot Mix Asphalt: A Canadian Case Study. Canadian Journal of Civil Engineering, CJCE-2013-002.

Yang, J., Qiang, D., \& Bao, Y. (2011). Concrete with recycled concrete aggregate and crush clay bricks. Construction and Building Materials, 25, 1935-1945.

Yeheyis, M., Hewage, K., Alam, M. S., Eskicioglu, C., \& Sadiq, R. (2013). An overview of construction and demolition waste management in Canada: a lifecycle analysis approach to sustainability. Clean Technology and Environmental Policy, 15, 81-91 